\title{
TÓPICOS EM CIÊNCIAS DA SAÚDE
}

VOLUME VIII
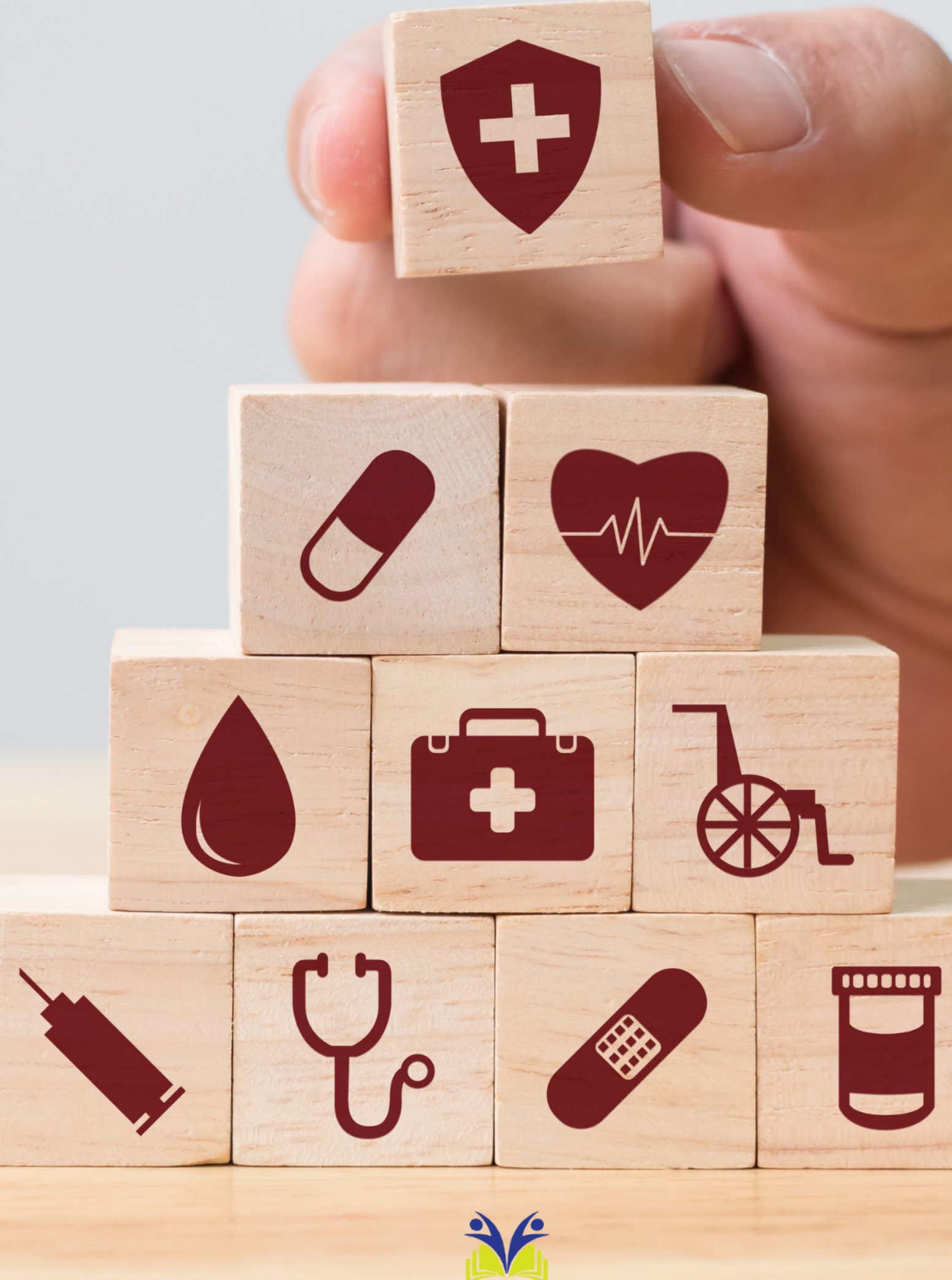
Frederico Celestino Barbosa

Tópicos em ciências da saúde

$8^{\mathrm{a}} \mathrm{ed}$.

Piracanjuba-GO

Editora Conhecimento Livre

Piracanjuba-GO 
$8^{\mathrm{a}}$ ed.

\title{
Dados Internacionais de Catalogação na Publicação (CIP)
}

\author{
Barbosa, Frederico Celestino \\ B238T Tópicos em ciências da saúde \\ / Frederico Celestino Barbosa. - Piracanjuba-GO
}

Editora Conhecimento Livre, 2021

$$
233 \text { f.: il }
$$

DOI: $10.37423 / 2021$.edcl 383

ISBN: 978-65-5367-027-3

Modo de acesso: World Wide Web

Incluir Bibliografia

1. equipe-multidisciplinar 2. prevenção 3. tratamento 4. cuidados I. Barbosa, Frederico Celestino II.

Título

CDU: 613

https://doi.org/10.37423/2021.edc1383

O conteúdo dos artigos e sua correção ortográfica são de responsabilidade exclusiva dos seus respectivos autores. 


\title{
EDITORA CONHECIMENTO LIVRE
}

\section{Corpo Editorial}

\author{
Dr. João Luís Ribeiro Ulhôa \\ Dra. Eyde Cristianne Saraiva-Bonatto \\ MSc. Frederico Celestino Barbosa \\ MSc. Carlos Eduardo de Oliveira Gontijo \\ MSc. Plínio Ferreira Pires
}




\section{SUMÁRIO}

CAPÍTULO 1

O DESENHO-HISTÓRIA EM ARTETERAPIA NO PROCESSO DE REABILITAÇÃO DE

DEPENDENTES DE DROGAS PSICOATIVAS

Ana Cláudia Afonso Valladares Torres

Marcos Vinicius Santos da Câmara

DOI 10.37423/211205082

CAPÍTULO 2

AVALIAÇÃO COMPUTACIONAL DE PARÂMETROS RADIOBIOLÓGICOS PARA UM CASO DE GLIOBLASTOMA MULTIFORME

Letícia Fröhlich

Mairon Marques do Santos

Mirko Salomón Alva Sánchez

Viviane Rodrigues Botelho

Thatiane Alves Pianoschi Alva

DOI 10.37423/211205085

CAPÍTULO 3

41

AVALIAÇÃO DE REAÇÕES ADVERSAS IMEDIATAS À INFUSÃO DE QUIMIOTERÁPICOS EM PACIENTES AMBULATORIAIS: UMA REVISÃO DE LITERATURA

Camila Maciel de Carvalho

Luciana Lucena Aranha de Macêdo

Patrícia Maria Simões de Albuquerque

DOI 10.37423/211205086

CAPÍTULO 4 65 A CONFIGURAÇÃO JURÍDICO-CONSTITUCIONAL DOS SERVIÇOS PÚBLICOS DE SAÚDE NO COMBATE ÀS INIQUIDADES SOCIAIS: UMA ABORDAGEM À LUZ DA FILOSOFIA DA SAÚDE.

Ricardo Bezerra de Oliveira

Layza Bezerra Maciel Pereira

Rosa Maria Ferreiro Pinto

Flávio Pereira de Oliveira

DOI 10.37423/211205087

CAPÍTULO 5

BUSCA DO SENTIDO DE VIDA: A EXPERIÊNCIA DE UMA MÃE DE CRIANÇA COM CÂNCER Ana Paula da Silva

Karina Mauro Dib

Noely Cibeli dos Santos

DOI 10.37423/211205104 
ASSOCIAÇÃO DA ADIPOSIDADE VISCERAL COM O PERFIL GLICÍDICODE JOVENS

ADULTOS COM EXCESSO DE PESO

Paula Oliveira Dazini

Letícia Ferreira Delgado

Flávio Augusto Teixeira Ronzani

Carla Márcia Moreira Lanna

Ana Paula Carlos Cândido

DOI 10.37423/211205108

CAPÍTULO 7

CONSUMO ALIMENTAR E SUA RELAÇÃO COM PARÂMETROS CLÍNICOS E NUTRICIONAIS DE INDIVÍDUOS OBESOS PORTADORES DE DOENÇA HEPÁTICA GORDUROSA NÃO ALCOÓLICA

Maria Raquel Oliveira

Maira Schuchter Ferreira

Letícia Ferreira Delgado

Paula Oliveira Dazini

Flávio Augusto Teixeira Ronzani

Carla Márcia Moreira Lanna

Sheila Cristina Potente Dutra Luquetti

DOI 10.37423/211205111

CAPÍTULO 8

ATENDIMENTO FISIOTERAPÊUTICO EM PACIENTE LESADO MEDULAR: RELATO DE EXPERIÊNCIA

Talita Helrigle Andrade

Matheus Silva de Oliveira

Fabiana Santos Franco

DOI 10.37423/211205120

CAPÍTULO 9

REDES DE ATENÇÃO À SAÚDE, PANORAMA E DESAFIOS NA PERSPECTIVA DE GESTORES, PROFISSIONAIS E USUÁRIOS

Audrilara Arruda Rodrigues Campos

Maria Conceição De Oliveira

Lilia Aparecida Kanan

DOI 10.37423/211205121 
HISTÓRICO DA FORMAÇÃO DO NUTRICIONISTA, COM ÊNFASE NA NUTRIÇÃO SOCIAL:

UMA REVISÃO NARRATIVA

Cristina Garcia Lopes Alves

Monique Louise Cassimiro Inácio

Eliane Garcia Rezende

Michel Cardoso De Angelis Pereira

Luís Fernando Farah de Tófoli

DOI 10.37423/211205124

\section{CAPÍTULO 11}

ATIVIDADE ANTIOXIDANTE, COMPOSIÇÃO CENTESIMAL E MINERAL DE COGUMELOS

PLEUROTUS OSTREATUS

Neilier Rodrigues da Silva Junior

Maria Goreti de Almeida Oliveira

DOI 10.37423/211205125

CAPÍTULO 12

O VISAGISMO E A SUA APLICABILIDADE NA ODONTOLOGIA

Camila Ferreira de Souza

DOI 10.37423/211205133

CAPÍTULO 13

PERFIL EPIDEMIOLÓGICO DOS PACIENTES INTERNADOS COM HANSENÍASE EM UM HOSPITAL DE REFERÊNCIAS DE DOENÇAS INFECCIOSAS DE FORTALEZA-CE DE 2009 A 2019

William Arruda Tavares

Geraldo de Azevedo Souza

Humberto Maciel Gondim Gonçalves Filho

Severino Ferreira Alexandre

DOI 10.37423/211205137 
ANTIBIOFILM ACTIVITY OF GLYCOLIC PLANT EXTRACTS ON KLEBSIELLA

PNEUMONIAECLINICAL ISOLATES

Patrícia Michelle Nagai de Lima

Lucas de Paula Ramos

Thaís Cristine Pereira

Marcela dos Santos Oliveira

Maria Angélica de Sá Assis

Suelen Simões Amaral

Leandro Wagner Figueira

Carlos Eduardo Rocha Santos

João Manoel Theotônio dos Santos

Luciane Dias de Oliveira

DOI 10.37423/211205139

CAPÍTULO 15

A EFETIVIDADE DAS PAUSAS PASSIVAS E ATIVAS NO AMBIENTE DE TRABALHO PARA O CONTROLE DAS QUEIXAS MUSCULOESQUELÉTICAS: UMA REVISÃO INTEGRATIVA

Francisca Maria Aleudinelia Monte Cunha

DOI 10.37423/211205144

CAPÍTULO 16

O TRANSTORNO DE PERSONALIDADE NARCISISTA E AS RELAÇÕES AFETIVAS: UMA CONTRIBUIÇÃO DA PSICANÁLISE

Aline Arruda da Fonseca

Erilane Érica Leôncio

Thatyanna Karla de Britto Poggi Lins

DOI 10.37423/211205176 


\section{Capítulo 1}

doi) $10.37423 / 211205082$

O DESENHO-HISTÓRIA EM ARTETERAPIA NO PROCESSO DE REABILITAÇÃO DE DEPENDENTES DE DROGAS PSICOATIVAS 


\section{Resumo}

Introdução: A complexidade em torno do tratamento e da reabilitação psicossocial de dependentes de drogas indica a necessidade de considerar a eficácia de ferramentas criativas e inovadoras, como o uso do desenho-história em Arteterapia voltada para aqueles que dificilmente verbalizam suas emoções e sentimentos espontaneamente. Objetivo: Este estudo objetivou avaliar o uso de desenhoshistórias em Arteterapia na perspectiva terapêutica para dependentes de drogas, usuários de um serviço de Saúde Mental. Método: Trata-se de uma pesquisa mista realizada com 108 dependentes de drogas, por meio de questionário e um desenho-história temático da "Ponte da vida" em Arteterapia. Para análise dos dados, utilizou-se a análise quantitativa e agregaram-se as frequências das variáveis numéricas e também a técnica da análise de conteúdo temática. Resultados: A partir da análise, agruparam-se os resultados em cinco categorias, o desenho da ponte como: (a) projeção da sua própria expressão emocional relacionada à dependência de drogas; (b) manifestação da ambivalência perante a vida; (c) conscientização da significação simbólica de travessia ou passagem; (d) mediadora da preparação para a solução dos problemas ou de aspectos saudáveis para o futuro e (e) não relacionada com o sofrimento psíquico decorrente da dependência de drogas. Conclusão: 0 uso de desenhos-histórias em Arteterapia na perspectiva terapêutica para dependentes de drogas foi eficaz, para que os participantes expusessem verbalmente suas emoções e sentimentos.

Palavras-chave: Transtornos relacionados ao uso de substâncias. Saúde mental. Terapia pela Arte. Enfermagem psiquiátrica. 


\section{INTRODUÇÃO}

No Brasil, com a Reforma Psiquiátrica, iniciou-se um novo ciclo de cuidados em saúde mental, com a oferta de serviços substitutivos de atenção psicossocial como novo protagonista de cuidado integral de base territorial e humanizado, em detrimento ao modelo hospitalocêntrico hegemônico (BRASIL, 2015; MACEDO et al., 2017). Assim, emergiu uma rede de cuidados compartilhados denominada Rede de Atenção Psicossocial (RAPS) instituída pelo decreto n.o 7.508/2011, que definiu os Centros de Atenção Psicossocial (CAPS) como o principal instrumento de implementação da Política Nacional de Saúde Mental (BRASIL, 2011).

Os CAPS são uma estratégia de transformação da assistência de cuidados em saúde mental regida pela alegria, pelo acolhimento, pela atenção, pela escuta e pela socialização do sujeito em um modelo aberto e transdisciplinar (BRASIL, 2015). Os cuidados têm uma aproximação com o território e buscam a produção de sentido que potencializa a transformação da vida (SNPD, 2017c). As oficinas terapêuticas são importantes instrumentos de reabilitação do CAPS, que são espaços que propiciam aos usuários meios de buscar suas potencialidades, valorizar os aspectos saudáveis da vida e permitir a expressão da subjetividade, por exemplo, por meio das artes criativas (Farias et al., 2016).

A expressão artística e as práticas lúdicas têm sido desenvolvidas com pessoas em sofrimento mental com a finalidade da expressão das singularidades dos sujeitos, valorização de habilidades e potenciais criativos, do rompimento com a medicalização e controle da vida (ASSUNÇÃO et al., 2018). Ademais, a Arteterapia tem sido aplicada aos dependentes de drogas psicoativas, de modo a favorecer a expressão verbal e a não verbal de alcoolistas, a contribuir para o autoconhecimento, a autorreflexão no processo terapêutico e para a transformação pessoal e comportamental (VALLADARES-TORRES; COSTA, 2018; VALLADARES-TORRES; LAGO, 2018b).

O desenho-história é uma ferramenta de projeção temática e gráfica, que pode ser usado no contexto da Arteterapia, por estimular o diálogo e a compreensão da subjetividade latente do sujeito (TRINCA, 2013). É possível compreender o momento de vida que os participantes, dependentes de drogas estão vivenciando no momento da confeç̧ão das produções artísticas (VALLADARES-TORRES, 2018a; 208b; VALLADARES-TORRES; LAGO, 2018a). Igualmente, por meio de atividades lúdicas, criativas e simbólicas, faz-se refletir o processo de reabilitação dos toxicômanos e a externalização de conteúdos subjetivos e inconscientes dos usuários (VALLADARES-TORRES; CALLAI, 2018; VALLADARES-TORRES; TORRES, 2018; VALLADARES-TORRES et al. 2018). 
Outro estudo que abordou um desenho temático em Arteterapia denominado "Metáfora da chuva" e desenvolvido junto a dependentes de drogas, aplicado por Angelim e Valladares-Torres (2019) esclareceu sobre o processo de adoecimento dos participantes e foi uma estratégia em saúde mental de auxílio na elaboração do plano de cuidados aos usuários de um CAPS-ad (álcool e outras drogas).

As drogas fazem parte do cotidiano humano há milhares de anos, nos contextos mais diversos, nos primórdios da civilização são encontrados relatos do uso de drogas em celebrações, festivas, em contexto religioso/espiritual/cultural (SNPD, 2017c). Segundo os autores, são diversos os fatores que levam um indivíduo a consumir drogas, o que torna quase impossível apontar apenas um aspecto como predominante para o uso dessa substância.

Diante da complexidade em torno do tratamento e da reabilitação psicossocial de dependentes de drogas, indica-se a necessidade de considerar a eficácia de ferramentas criativas e inovadoras. A presente pesquisa tem, portanto, como pergunta principal: Será que o uso do desenho-história da "Ponte da vida" em Arteterapia será eficaz para dependentes de drogas, um público que frequentemente tem dificilmente de verbalizar suas emoções e sentimentos?

\section{OBJETIVOS}

Tem-se como objetivos avaliar o uso de desenho-história em Arteterapia na perspectiva terapêutica para dependentes de drogas, usuárias de um serviço de Saúde Mental e conhecer o perfil desses participantes.

\section{PERCURSO METODOLÓGICO}

\section{TIPO DE ESTUDO}

Estudo descritivo, exploratório e com abordagem mista, que uniu os números e cálculos matemáticos da pesquisa quantitativa para traçar o perfil dos participantes com o caráter subjetivo da pesquisa qualitativa, para analisar as verbalizações dos desenhos-histórias da "Ponte da vida". Objetivou-se, também, explorar e aprofundar os resultados encontrados por meio do estudo descritivo e exploratório (MINAYO, 2007).

\section{PARTICIPANTES DA PESQUISA}

Obteve-se a adesão de uma amostra de 108 usuários do CAPS-ad III e utilizou-se como critérios de inclusão: ser dependente de drogas psicoativas, de ambos os sexos, apresentar idade igual ou superior 
a dezoito anos e com registro de admissão no CAPS-ad de período ilimitado. Excluíram-se os que apresentassem dificuldade física e/ou mental de compreender e/ou desenvolver o desenho e/ou responder os instrumentos da pesquisa. Ressalta-se que os participantes foram escolhidos de forma aleatória e integraram-se de maneira anônima e voluntária à investigação, após serem informados dos objetivos e da forma de participação, sendo sempre respeitados os procedimentos éticos vigentes.

\section{LOCAL DO ESTUDO}

A pesquisa foi realizada em um Centro de Atenção Psicossocial voltado para dependentes de álcool e de outras drogas III (CAPS-ad III) do Distrito Federal, que dispõe de oficinas terapêuticas, atendimentos grupais, individuais e familiares/comunidade com uma equipe transdisciplinar em saúde mental. No CAPS-ad existem os regimes de tratamento intensivo (hospital-dia), semi-intensivo e não intensivo, assim o acolhimento integral - internação e para os usuários são oferecidos atendimento com projetos terapêuticos individualizados. O CAPS-ad III é destinado a municípios com a população acima de 200.000 habitantes e funciona em período integral diariamente (SNPD, 2017a).

\section{COLETA DOS DADOS}

A coleta de dados ocorreu mediante um encontro único e individual de Arteterapia com duração de, aproximadamente, duas horas cada. Os encontros foram realizados em sala disponibilizada pela instituição, durante o período de março a novembro de 2019.

Inicialmente, para desenvolver o levantamento dos participantes, foram realizadas entrevistas com eles e busca ativa nos prontuários. O questionário sociodemográfico, clínico e psiquiátrico continha os dados, a saber: idade, sexo, data de nascimento, tipo de dependência de drogas e tempo de acompanhamento no serviço (CAPS-ad).

Em seguida, solicitou-se a confecção de um desenho temático "Ponte da vida" e, para a coleta dos dados, foram disponibilizados materiais gráficos (canetinhas hidrocores, giz de cera, lápis de cor, lápis preto e borracha) e papel sulfite branco A4.

E, finalmente, foi realizada uma entrevista sobre o desenho elaborado por meio das questões: título do desenho da "Ponte da vida", de que tipo de material era confeccionada a ponte (madeira, metal, concreto, pedra e outros), características da ponte (triste e/ou feliz; perigosa e/ou segura; geradora de medo/ansiedade e/ou era amigável; frágil e/ou forte; tamanho grande, pequena e/ou média; altura alta, baixa e/ou mediana; pobre e/ou rica; bonita e/ou feia; resistente e/ou flexível e por quê?), faça 
uma história sobre o desenho produzido ou em que essa ponte o fazia você lembrar ou pensar, o que essa ponte tinha a ver com ele/a, qual o sentido da ponte vida dele/a, de onde a ponte veio e para onde ela vai levá-lo/a, o que está fazendo na ponte e qual a responsabilidade dele/a daqui para frente?

A intervenção de Arteterapia foi coordenada por uma arteterapeuta e por acadêmicos de Enfermagem, pesquisadores, que contribuíram durante a intervenção, ora no acompanhamento da confecção dos desenhos "Ponte da vida" e do inquérito sobre eles, ora na busca ativa pelos dados sociodemográfico, clínico e psiquiátrico dos participantes.

\section{PROCEDIMENTOS DE ANÁLISE DOS DADOS}

Utilizou-se a análise quantitativa e agregaram-se as frequências e porcentagens das variáveis numéricas dos dados sociodemográficos, clínicos e psiquiátricos, que foram expostas em forma de Tabela.

Em relação aos dados sobre os desenhos-história, aplicou-se a técnica da análise de conteúdo temática proposta por Bardin (2011); após a leitura flutuante das histórias, foram categorizadas, descritas e interpretadas as informações obtidas pelas unidades temáticas. Também foram agregadas as frequências e porcentagens das variáveis numéricas em cada unidade temática. Optou-se por realizar análises simbólicas dos desenhos em outro estudo, posteriormente.

\section{PROCEDIMENTOS ÉTICOS}

O presente estudo faz parte do projeto denominado "A Arteterapia como dispositivo terapêutico nas toxicomanias", que foi aprovado pelo Comitê de Ética em Pesquisa da Fundação de Ensino e Pesquisa em Ciências da Saúde, sob o CAAE no 44625915400005553. Todos os participantes assinaram o Termo de Consentimento Livre e Esclarecido.

Para garantir o anonimato, os participantes foram identificados pela letra " $\mathrm{P}$ ", sendo diferenciados pelo número posterior à letra, de forma sequencial, que foi adotado para identificação ao longo do artigo. Os participantes foram classificados de forma crescente pelo tempo de acompanhamento no serviço, isto é, quanto menor o número sequencial, menor o tempo de acompanhamento do participante no CAPS-ad. 


\section{RESULTADOS E DISCUSSÃO}

\section{CARACTERÍSTICAS DA AMOSTRA}

Neste estudo, 108 participantes com idades entre 18 a 77 anos, com média de idade de 42,8 anos, $80,6 \%$ do sexo masculino realizaram o desenho-história sobre o tema "Ponte da vida" e responderam o questionário da pesquisa sobre os dados sociodemográficos, clínicos e psquiquiátricos. A Tabela 1 apresenta as variáveis sociodemográficas, clínicas e psiquiátricas dos participantes da pesquisa.

Tabela 1. Características sociodemográficas, clínicas e psiquiátricas dos participantes da pesquisa. Brasília, Distrito Federal, Brasil, 2019. ( $\mathrm{N}=108)$

\begin{tabular}{lll}
\hline Variáveis & \multicolumn{2}{c}{ Total Porcentagem } \\
\hline Sexo & (n) & \\
\hline Masculino & 87 & $80,6 \%$ \\
\hline Feminino & 21 & $19,4 \%$ \\
\hline Idade & & \\
\hline $18-35$ & 33 & $30,6 \%$ \\
\hline $36-49$ & 37 & $34,3 \%$ \\
\hline 50 ou mais & 38 & $35,1 \%$ \\
\hline Droga de Dependência & & \\
\hline Álcool & 62 & $57,4 \%$ \\
\hline Crack/Cocaína & 06 & $5,6 \%$ \\
\hline Cannabis & 04 & $3,7 \%$ \\
\hline Múltiplas Drogas & 36 & $33,3 \%$ \\
\hline Tempo de acompanhamento no & \\
serviço (CAPS-ad) & & \\
\hline De 0 a 1m & 32 & $29,6 \%$ \\
\hline De 2 m a $<1$ ano & 30 & $27,8 \%$ \\
\hline De 1 a 2 anos & 19 & $17,6 \%$ \\
\hline >2 anos & 27 & $25,0 \%$ \\
\hline
\end{tabular}

Fonte: Dados da pesquisa (2021)

No que tange à situação clínica e psiquiátrica, o grupo foi composto por dependentes de álcool (57,4\%) e prevaleceram participantes que tinham o tempo de acompanhamento no CAPS-ad menor do que um ano $(57,4 \%)$.

É um problema de saúde publica o consumo de substâncias psicoativas e o uso dependente de álcool, por causa de sua prevalência elevada e dos seus danos socioeconômicos e pessoais (Silva et al., 2010; Oliveira et al., 2017). Uma avaliação nacional realizada pelo II Levantamento Nacional de Álcool e Drogas (INCTPPAD, 2014) mostra que, entre as substâncias psicoativas ilícitas mais consumidas pelo brasileiro adulto, no ano de 2012 , foi a maconha, que predominou em cerca de $2,5 \%$, seguida pela cocaína com $1,7 \%$ e estimulantes com $1,1 \%$. Já em relação ao consumo de álcool, a prevalência de 
dependentes foi de, aproximadamente, 10,48\% em homens e 3,63\% em mulheres. A maior incidência de homens entre o grupo de dependentes de drogas é um dado que corrobora os encontrados na presente pesquisa.

Em relação à idade prevalente de adultos-jovens, alguns estudos realizados no Brasil se assemelham à prevalência encontrada nesta pesquisa (Oliveira et al., 2017). Segundo os autores, ainda que o uso do álcool tenha seu início na adolescência, ou mesmo na infância, é somente na fase adulta que o impacto negativo na vida da pessoa dependente de drogas se revela, o que faz com que a busca por assistência se instale nesse período.

O tratamento no acolhimento integral do CAPS-ad é de até quinze dias e nas terapias é de, aproximadamente, dois anos. O fato de ter um número maior de participantes com até um ano no CAPS-ad se justifica pelo tempo limite de tratamento no CAPS-ad e os que estão no acolhimento integral e em regime intensivo no hospital-dia foram os mais disponíveis, em termo de tempo, para desenvolver a pesquisa.

\section{CATEGORIAS DOS DESENHOS-HISTÓRIAS COM O USO DAS SUBSTÂNCIAS}

A partir da análise dos dados, foi possível identificar cinco categorias do desenho-história da "Ponte da vida" assim nomeadas: (a) projeção da sua própria expressão emocional relacionada à dependência de drogas; (b) manifestação da ambivalência perante a vida; (c) conscientização da significação simbólica de travessia ou passagem; (d) mediadora da preparação para a solução dos problemas ou de aspectos saudáveis para o futuro e (e) não relacionada com o sofrimento psíquico decorrente da dependência de drogas.

\section{(a) 0 desenho da ponte como projeção da sua própria expressão emocional relacionada à dependência de drogas}

Desde a Antiguidade, as artes expressivas têm sido usadas pelo homem como métodos de cura e veículos de comunicação, pois o desenho representa a projeção pessoal e a relação direta da manifestação do momento atual de vida do seu autor dependente de drogas (Valladares-Torres, 2017). Atualmente, as artes se tornaram uma das ferramentas clínicas para promover a saúde e o bem-estar psicológico dos indivíduos (Darewych, Bowers, 2018). 
Nos relatos sobre o desenho projetivo "Ponte da vida", constatou-se que 40 autores (37\%) conseguiram verbalizar a conexão do desenho com sua vida pessoal relacionada à dependência de drogas. São apresentados alguns relatos a seguir.

A ponte representa minha vida pessoal, ainda não consegui concluir meios objetivos, assim como a ponte. Estou procurando meios para terminar a ponte e cuidar mais de mim (P8).

A ponte é a trajetória da minha vida, estou querendo perder o medo e conseguir passar por ela para me levar para um caminho bom (P23).

A ponte é a minha vida, ela é triste, perigosa, frágil, pobre, feia, medrosa e ansiosa, assim como eu. A ponte e eu estamos vivendo sem sentido, apenas vegetando (P45).

Tanto a ponte, como eu, somos fortes, corajosos e grandes. A ponte representa a alegria e a superação da dependência (P52).

Foram complementados pelos relatos:

A ponte tem tudo haver comigo. Quando eu estava no período mais difícil da minha vida, meus filhos falaram para eu passar pela ponte. Pois por meio de escolhas corretas, eu iria conseguir atravessar a ponte e superar o alcoolismo (P88).

A ponte representa minha luta contra o álcool - o caminho para me livrar do álcool e as rachaduras são as minhas recaídas (P96). A ponte representa o meu tratamento (P105).

O desenho facilita a expressão de sentimentos, a elaboração verbal de dependentes de drogas sobre seu momento de vida. Além do que, o desenho é uma ferramenta lúdica, que permite ao participante elaborar seu conteúdo expressivo por meio do distanciamento reflexivo (Valladares-Torres, 2017).

A expressão pelo desenho da ponte também foi utilizada positivamente pelos autores Darewych e Bowers (2018), voltados para participantes de diferentes nacionalidades (Austrália, Canadá e Ucrânia). Os autores concluíram que o desenho da ponte estimulou criativamente a imaginação dos participantes, pois eles refletiram sobre seus objetivos de vida, obtiveram insights sobre suas forças suas emoções, determinaram suas fontes de significado da vida e exploraram seus aspectos espirituais.

Outro estudo que corroborou com os achados desta pesquisa e foi desenvolvido com mulheres dependentes de drogas internadas em uma Comunidade Terapêutica com o uso projetivo de desenhos, agora, de "caminhos" em vez de "ponte". Constatou que os desenhos auxiliaram as participantes a compreender melhor o caminho da recuperação, representaram uma metáfora para a 
capacidade de mudança, além de terem oferecido insights sobre o uso de substâncias e seu estado psicológico (Hanes, 2017).

\section{(b) O desenho da ponte como manifestação da ambivalência perante a vida}

A ambivalência de sentimentos, de condutas e de comportamentos é um tema comum, quando o dependente de drogas se encontra no Estágio 2 de mudança, a Contemplação, definido por Prochaska, DiClemente e Norcross (1992).

Nos relados sobre o desenho projetivo "Ponte da vida", constatou-se que 22 respostas (20,4\%) trouxeram o tema ambivalência perante a vida. Algumas verbalizações dos participantes foram apresentadas a seguir.

A ponte é triste, frágil, pobre e gera medo e ansiedade, mas também segura, resistente, grande e bonita. A ponte lembra o passado/presente com as coisas boas e a perda de tudo e vai para o futuro atingir sua vitória (P35).

A ponte é um misto de sentimentos, de um lado pressão e arrependimento, do outro, liberdade (P37).

A ponte é meio triste e meio feliz, às vezes ela é perigosa e às vezes segura, às vezes é forte e às vezes é frágil. Tenho momentos bons e ruins, difíceis e alegres. Tenho dúvidas e incertezas, o que me levam a ter medo e a ficar desesperado, ansioso e inseguro em relação ao futuro. Por isso, preciso descobrir quando $e$ como vai ser esse novo caminho (P90).

A ponte remete a dualidade da vida: do abuso ao não abuso do álcool. Posso crescer na vida e voltar a ser o que era antes. No momento a ponte é perigosa, medrosa, ansiosa, frágil, pobre e feia, mas também é feliz e flexível (P93).

Os relatos expõem aspectos negativos e positivos que se sobrepõem na vida dos participantes em relação à sua dependência de drogas. No Estágio 2 de Contemplação (Prochaska; DiClemente; Norcross, 1992), a pessoa tem pouca percepção da relação causa-consequência dos problemas decorrentes do uso abusivo de substâncias psicoativas. Os autores acrescentam, ainda, que é nesse Estágio que a pessoa tem consciência da sua doença e da necessidade de tratamento, entretanto percebe a dificuldade de mudança no estilo de vida para encontrar uma solução satisfatória dos seus problemas e melhorar sua qualidade de vida.

Alguns relatos dessa categoria seguem ancorados nas esferas de dualidade psicoafetiva e revelaram sentimentos de tristeza, de ansiedade, de insegurança, de medo, de fragilidade e de sofrimento relacionados com a dependência de drogas. No grupo de dependentes de drogas tem sido diagnosticado mais comumente os Transtornos de Ansiedade e de Depressão (Lucchese et al., 2017), o que justifica em parte a presença desses sentimentos de forma recorrente. 
Complementam Silva, Oliveira e Graça (2018) que a dependência de drogas se desenvolve com mais frequência em pessoas que têm depressão, bem como o consumo intenso de drogas pode desencadear sintomas psicóticos, estresse e vulnerabilidade social. Outro estudo acrescenta que a associação de maior risco de autoextermínio nos grupos com histórico de consumo de substâncias psicoativas e sugere uma avaliação de transtornos psíquicos associados à dependência de drogas (Danieli et al., 2017).

\title{
(c) O desenho da ponte como conscientização da significação simbólica de travessia ou passagem
}

A ponte representa uma passagem entre duas dimensões distintas, que podem ser: entre a terra e o céu, entre a vida e a morte e entre a contingência até a imortalidade. Pode simbolizar, ainda, uma difícil travessia ou uma provação a ser suplantada de diversas dimensões espirituais: moral, ritual e religiosa (CHEVALIER; GHEERBRANT, 2017). Nas verbalizações dos desenhos-histórias se observam semelhanças temáticas direcionadas à representação simbólica da "Ponte da vida" como uma travessia ou passagem, expressos em 47 trabalhos (43,5\%). A seguir foram apresentados alguns exemplos:

A ponte é o processo de transformação que estou vivendo, isto é, as etapas que estou passando na minha vida neste momento. De um processo sombrio vai para um lugar de paz (P31).

A ponte vai me levar de um ambiente cheio de maldade, corrupção e medo para um lugar perto da natureza, com tranquilidade e paz (P50).

A ponte é uma transição da depressão, problemas oculares e motores, situação precária e te ter ficado sem dinheiro até para comer, em direção a uma vida melhor organizada, composta de alegria e convívio social com os amigos (P65)

\begin{abstract}
A ponte é a passagem do uso do álcool até a sobriedade. Não é qualquer pessoa que consegue atravessar a ponte, pois muitos não conseguem passar. No início, eu vivi com árvores e matos secos, depois que encontrei o CAPS-ad e atravessar a ponte apareceram árvores e flores frescas e coloridas (P102).
\end{abstract}

A dependência de drogas traz o afastamento do convívio familiar, muitos indivíduos perdem o emprego, desestruturam a vida social, enfrentam preconceitos internos e externos, sendo necessários, no tratamento, uma organização e um suporte emocional (Silva; Oliveira; Graça, 2018). A ideia de passagem de sentimentos de tristeza para alegria e paz, também, foi registrada por alguns participantes, decorrentes ao processo de adoecimento pelas drogas. 
A ponte representa a mudança, me trouxe de um lugar escuro e vai me levar para um lugar feliz, me transportando para outra vida (P24).

A ponte vai trazer mudança e crescimento para mim. Vim de um passado triste e vou para um lugar melhor (P85).

A ponte vai do Norte: da tristeza, perigo, medo para o Sul: fortaleza, beleza e resistência (P91).

A ponte é a travessia, a mudança do passado, da tristeza, da perda da esposa para a felicidade e a vontade de viver. De uma floresta confusa, oculta para uma vida plena de liberdade (P106).

Aspectos que reforçam a dualidade apresentada na categoria do desenho da "Ponte da vida" como manifestação da ambivalência sobre a vida. O medo da recaída na travessia também foram verbalizados por alguns participantes.

Vou atravessar do lado ruim: tristeza, irresponsabilidades, más condutas e rebeldias, em direção a um lado bom: felicidades, oportunidades, busca por mais segurança na vida. E vou batalhar para meu pneu não furar, isto é, lutar para as coisas ruins não aparecerem para atrapalhar a minha travessia (P17).

Vou atravessar a ponte sem cair, ela começa em uma escada subindo e termina em uma escada para descer, numa descida arriscada (P20).

Estou em cima da ponte olhando para baixo e pensando o que vou fazer: continuar caminhando na ponte ou cair dela - suicídio. A ponte leva do vazio existencial e da escuridão para a continuidade da vida (P28).

As recaídas são esperadas, quando a pessoa tenta mudar seu padrão de comportamento e estilo de vida, mas volta ao uso da substância e para Estágios de mudanças anteriores. O usuário, quando identifica suas situações de risco, pode treinar estratégias de enfrentamento, recuperar sua autoeficácia e evitar recaídas (SNPD, 2017a).

(d) O desenho da ponte como mediadora da preparação para a solução dos problemas ou de aspectos saudáveis para o futuro.

As verbalizações dos desenhos-história fizeram surgir projeções objetivas e metas para o futuro. Mesmo diante das vulnerabilidades e das adversidades desencadeadas pela dependência de drogas, cada indivíduo com seu grau de resiliência pode encontrar saídas satisfatórias para seus problemas. Foram encontradas 98 respostas $(90,7 \%)$ nesta categoria, em que são apresentados alguns exemplos, separados pelas temáticas apresentadas.

A busca por se manter no tratamento foi um item bastante citado nos desenhos-história. 
Vou chegar até o final da ponte, isto é, seguirei meu tratamento assiduamente até o fim (P2). Quero continuar meu tratamento no CAPS-ad, conseguir manter meu foco e alcançar meus objetivos e ter boa saúde e uma vida saudável (P34). Quero continuar no tratamento e seguir em frente (P103). Não ser covarde, seguir o tratamento e participar dos grupos (P107).

Outro item também citado foi o desejo de mudança no estilo de vida.

Quero mudar minhas atitudes (P17). Quero mudar meu trajeto de vida (P23). Vou me fortalecer cada vez mais e mudar meus hábitos de vida (P24). Estou procurando sempre melhorar e renovar as relações com as pessoas (P26). Tenho que dar um passo de cada vez e pensar muito bem antes de cada decisão (P95). Quero melhorar minha mentalidade para seguir em frente (P106).

A continuidade no tratamento, bem como a mudança no estilo de vida são aspectos importantes para que o tratamento seja efetivo. É papel do CAPS-ad construir e gerenciar, junto com os usuários e seus familiares um projeto terapêutico individualizado e oferecer lhes cuidados humanizados com a inserção psicossocial. Além disso, precisa identificar as demandas e necessidades dos seus usuários para que a equipe transdisciplinar possa direcionar os cuidados de maneira singular e objetivo (SNPD, 2017b). O desejo em recompor a estrutura e dinâmica familiar foi listado nas verbalizações dos desenhos.

Quero estar mais presente dos meus filhos (P17). Estou procurando sempre melhorar as relações com a minha família (P26). Eu desejo cuidar do meu filho menor e ter mais tempo para a família (P65). Desejo ter responsabilidade sobre minha família (P73).

Na dependência de drogas, sobressai a obsessão pela substância psicoativa em detrimento da estabilidade familiar, o que gera conflitos e abandono familiar, mesmo que tenham filhos (Danieli et al., 2017) - dados que estão em consonância com o presente estudo. Adquirir um trabalho e a volta aos estudos foram desejos apresentados entre o grupo de participantes.

Vou me regenerar e conseguir um emprego (P10). Vou melhorar e buscar produtividade na vida (P12). Vou voltar a trabalhar (P13). Quero conseguir arranjar um emprego (P34).

Vou fazer minha travessia do Brasil para o Canadá, para poder estudar e aperfeiçoar na minha profissão (P5). Vou terminar meus estudos (P6). Vou cursar a faculdade de Tecnologia da Informação (P22). Eu vou continuar estudando para aprender a escrever (P67).

Dados do Ministério da Saúde apontam que existe uma relação entre o abandono do ambiente escolar com uma dificuldade no aprendizado, possivelmente, causada pelo consumo de substâncias psicoativas que vêm ocorrendo cada vez de forma mais precoce (Mascarenhas et al., 2014). Observou-se em pesquisa realizada no sul do Brasil sobre perfil sociodemográfico de pessoas atendidas em CAPS-ad, que poucos $(13,6 \%)$ conseguiram concluir o Ensino Médio e apenas 18,1\% concluíram o Ensino Superior. Aspectos que se refletem nas 
dificuldades de inserção da pessoa no mercado de trabalho, baixa renda e maior vulnerabilidade social (Danieli et al., 2017; Oliveira et al., 2017).

A dependência de drogas é considerada um problema grave de Saúde Mental e social, com efeitos potencialmente devastadores sobre as expectativas profissionais e sobre a sociedade, igualmente, sobre a saúde física e emocional do usuário e sobre as relações familiares, o que demanda ações de intervenções públicas (ZANINI; Sotili, 2019). Os aspectos almejados e também registrados foram os de estar em abstinência das drogas e a prevenção de recaídas.

Vou afastar-me de quem bebe, parar de beber (P32). Quero ficar limpasem as drogas (P34). Vou seguir em frente e resistir ao desejo de beber (P42). Quero manter em abstinência do álcool (P64). Não quero voltar a beber (P73).

Quero lutar para não ter recaídas (P49). Quero passar para uma vida fazendo o melhor, sem tropeçar (P62). Vou continuar a ter força de vontade e não voltar a beber (P71). Não quero cair da ponte, espero que ela seja sempre segura (P80). Quero parar de usar cigarro e álcool (P82). Quero passar pela ponte sem medo de cair (P87). Não posso deixar a ponte cair (P96). Não quero que a ponte caia, preciso fazer uma sondagem na ferragem da ponte (P108).

Estima-se, de acordo com a população mundial de 2013, que 27 milhões de pessoas tinham algum transtorno decorrente do uso ou de dependência de drogas. Conhecer o perfil sociodemográfico juntamente com as demandas dos dependentes de drogas é um fator fundamental para a melhoria da assistência, prevenção de recaída e tratamentos (Esper, 2013).

\section{(e) $\mathrm{O}$ desenho da ponte não relacionada com o sofrimento psíquico decorrente da dependência de}

\section{drogas}

O Estágio 1 de mudança - Pré-contemplação - elaborado por Prochaska, DiClemente e Norcross (1992) pressupõe os usuários que não percebem a possibilidade de mudança em suas vidas, pois não consideram que a dependência de drogas Ihes traga alguma malefício. Nos relados sobre o desenho projetivo da ponte, constatou-se que 22 respostas $(20,4 \%)$ trouxeram a Pré-contemplação como tema. Algumas verbalizações dos participantes são apresentadas a seguir.

A ponte não tem nada haver com minha história de vida. Na imagem, estou somente na prainha, observando a ponte (P10).

A ponte não tem nada haver com minha vida de drogas, só representa minha travessia para reencontrar a família e ver os pais na Bahia (P36). 
A ponte não tem nada haver comigo, não tem sentido algum. É apenas a ponte $J K(\mathrm{P} 49)$.

A ponte não tem muita haver comigo, só faz recordar da beleza e grandiosidade dela (P66).

Os usuários não conseguiram relacionar a "Ponte da vida" com sua dependência de drogas e, em nenhum momento, relataram problemas de saúde, sociais e familiares e o desejo de mudança, aspectos que corroboram com o Estágio 1 de Pré-contemplação. Além da desconexão com o momento e as necessidades de vida atual, os usuários se colocaram em uma atitude de passividade perante a vida e/ou trouxeram um significado de ponte real no sentido literal e não simbólico.

Um artigo de revisão sistemática de literatura que identificou e avaliou criticamente estudos sobre a eficácia das intervenções Arteterapias criativas na dependência de drogas e constatou um efeito positivo para a musicoterapia em prol do aumento do estado de contemplação $(0,9)$, da prontidão do tratamento $(0,76)$, da motivação $(0,54)$ e do menor desejo $(-0,54)$ mesmo em curto prazo (Megranahan; LYNSKEY, 2018). O que mostra que as Arteterapias criativas podem alterar positivamente o Estágio 1 de Pré-contemplação para o Estágio 2 de Contemplação de Prochaska, DiClemente e Norcross (1992).

Camicia et al. (2018), ao utilizarem a técnica de Arteterapia "desenhe uma ponte" e o inventário familiar de necessidades com familiares de pacientes que sofreram Acidente Vascular Cerebral (AVC), concluíram que essa técnica melhorou a comunicação, o apoio e a educação efetiva com o grupo de familiares cuidadores de pacientes com AVC e que deve ser mais amplamente empregada.

O desenho como uma ferramenta criativa facilita a expressão de sentimentos e emoções, especialmente para aqueles adultos que tem dificuldades de comunicação (Chica Díaz, 2017). Complementam Saavedra et al. (2018), que as práticas criativas podem melhorar significativamente as inclusões sociais e o bem-estar em pessoas com doença mental grave. Participar de oficinas criativas ajuda os participantes a elaborarem significados pessoais e promover a recuperação.

\section{LIMITAÇÕES DO ESTUDO}

Mesmo que este estudo tenha abordado um grupo grande de dependentes de drogas, nota-se a necessidade de outras pesquisas que possam aprofundar qualitativamente os dados encontrados, para que se entrelacem com mais profundidade o perfil e a história de vida dos sujeitos com os desenhos-histórias. Além disso, a composição da amostra se concentrou em apenas um único serviço de saúde mental. 


\section{CONTRIBUIÇÕES PARA A PRÁTICA}

Os achados desta pesquisa indicam a necessidade de se ampliar o escopo dos cuidados em Saúde Mental com a inclusão de atividades assistenciais criativas e inovadoras. O desenho projetivo "Ponte da vida" é uma ferramenta de autoconhecimento para a prática em saúde mental junto a dependentes de drogas, em uma forma mais elaborada e distanciada das emoções, capaz de trazer a reflexão sobre o processo de adoecimento do seu autor dependente de drogas. Pelo desenho da "Ponte da vida", é possível que os participantes consigam acessar os conteúdos do inconsciente para poder integrá-los à consciência de forma mais lúdica, do que a verbalização do seu problema de forma tradicional nas terapias.

\section{CONSIDERAÇÕES FINAIS}

O uso de desenhos-histórias em Arteterapia na perspectiva terapêutica para dependentes de drogas foi eficaz para que os participantes expusessem verbalmente suas emoções e sentimentos, pois o mundo simbólico pode auxiliar no processo de conhecimento de si mesmo e do outro, compreender em qual estágio se encontra o autor e qual a solução que ele encontra para enfrentar a vida, as dificuldades. Foi assim que os desenhos-história se fizeram entender, além de acompanhar a dinâmica da estrutura psíquica do sujeito, de maneira conectada com o passado, com o presente e com o futuro, como exposto pelas unidades temáticas da ponte como mediadora da preparação para a solução dos problemas ou de aspectos saudáveis para o futuro e da sua relação com a projeção atual à expressão emocional.

Portanto, pelos desenhos-histórias, foi possível comunicar sentimentos, emoções, opiniões e experiências dos seus autores por meio das unidades temáticas como a ponte da vida como projeção da sua própria expressão emocional relacionada à dependência de drogas, das manifestações da ambivalência perante a vida e da conscientização da significação simbólica de travessia ou passagem. Mesmo que o desenho da "ponte da vida" não tenha sido relacionado com o sofrimento psíquico decorrente da dependência de drogas de seu autor, essa categoria simbolizou o seu mundo psíquico atual, isto é, a não consciência da doença e da sua necessidade de tratamento.

O recurso à imaginação, ao simbolismo e às metáforas enriquece o processo terapêutico e é por isso que o desenho da "Ponte da vida" pode ser utilizado para dependentes de drogas de forma contínua nos serviços de saúde mental. Sugere-se, ainda, a continuidade de investigações futuras com ações de artes criativas para facilitar a expressão emocional de dependentes de drogas e facilitar os cuidados 
em saúde mental. Recomenda-se, ainda, que o estudo seja replicado em outros territórios e com outras realidades para possibilitar a generalização desses achados.

\section{AGRADECIMENTOS}

Os autores agradecem o apoio da gestão e dos profissionais do CAPS-ad III, assim como a colaboração dos usuários da instituição e dos auxiliares de pesquisa na coleta de dados, em particular dos alunos de enfermagem da disciplina de Saúde Mental da FCE/UnB - ano de 2019. 


\section{REFERÊNCIAS}

ANGELIM, S. M. A. V.; VALLADARES-TORRES, A. C. A. O desenho 'metáfora da chuva' como instrumento de comunicação terapêutica da problemática drogadição. Rev Científica Arteterapia Cores da Vida. v.26, n.1, p.48-57, Jan./Jun. 2019. Disponível em: www.abcaarteterapia.com

ASSUNÇÃO, L. M. et al. A vida como obra de arte: práticas lúdicas e de expressão artística com usuários de hospital psiquiátrico. Cadernos Brasileiros de Saúde Mental. v.10, n.27, p.114-27, 2018.

BARDIN, L. Análise de conteúdo. Lisboa, Portugal: Edições 70 - Brasil: edição revista e ampliada; 2011.

BRASIL. Ministério da Saúde. Portaria n. 3.088, de 23 de dezembro de 2011. Institui a Rede de Atenção Psicossocial para pessoas com sofrimento ou transtorno mental e com necessidades decorrentes do uso de álcool, crack e outras drogas, no âmbito do Sistema Único de Saúde. Brasília, 2011. Disponível em: http://bvsms.saude.gov.br/bvs/saudelegis/gm/2011/prt3088_23_12_2011_rep.html

BRASIL. Ministério da Saúde. Coordenação Geral de Saúde Mental. Saúde mental em dados 12, 2015. 48p. Disponível em:

http://www.mhinnovation.net/sites/default/files/downloads/innovation/reports/Report_12-edicaodo-Saude-Mental-em-Dados.pdf

CAMICIA, M. et al. Determining the needs of family caregivers of stroke patients during inpatient rehabilitation using interview, art, and survey. Rehabilitation Nursing Journal. v.0, n.0, p. 0-0, Jan. 2018. In press.

CHEVALIER, J.; GHEERBRANT, A. Dicionário de símbolos: mitos, sonhos, costumes, gestos, formas, figuras, cores, números. 27. ed. Rio de Janeiro: José Olympio, 2017.

CHICA DÍAZ, E. El dibujo como una herramienta para expresar sentimientos y emociones en la tercera edad. Universidad de Granada. Departamento de Dibujo. Máster Oficial Universitario en Dibujo: Creación, Producción y Difusión. Nov. 2017. 129p. Disponible en: http://hdl.handle.net/10481/48012

DANIELI, R. V. et al. Perfil sociodemográfico e comorbidades psiquiátricas em dependentes químicos acompanhados em comunidades terapêuticas. J Bras Psiquiatr. v.66, n.3, p.139-49, 2017.

DAREWYCH, O. H.; BOWERS, N. R. Positive arts interventions: creative clinical tools promoting psychological well-being. Journal International Journal of Art Therapy. v.23, n.2, p.62-9, 2018.

ESPER, L. H. et al. Mulheres em tratamento ambulatorial por abuso de álcool: características sociodemográficas e clínicas. Rev Gaúcha Enferm. v.34, n.2, p.93-101, 2013.

FARIAS, I. D. et al. Therapeutic workshops as expressions of subjectivity. SMAD, Rev. Eletrônica Saúde Mental Álcool Drog. v.12, n.3, p.147-53, 2016. Available from: http://pepsic.bvsalud.org/pdf/smad/v12n3/03.pdf

HANES, M. Road to recovery: road drawings in a gender-specific residential substance use treatment center. Journal of the American Art Therapy Association. v.34, n.4, p.201-8, Nov. 2017. 
INCTPPAD - Instituto Nacional de Ciência e Tecnologia para Políticas Públicas de Álcool e outras Drogas. II Levantamento Nacional de Álcool e Drogas (LENAD). São Paulo; 2014.

LUCCHESE, R. et al. Transtorno mental comum entre indivíduos que abusam de álcool e drogas: estudo transversal. Texto Contexto Enferm. v.26, n.1, p.e4480015, 2017.

MACEDO, J. P. et al. A regionalização da saúde mental e os novos desafios da Reforma Psiquiátrica brasileira. Saúde e Sociedade. v.26, n.1, p.155-70, 2017.

MASCARENHAS, M. A. et al. Characterization of users of psychoactive substances at the clinic for addictive disorder with emphasis on chemical dependence. Rev Baiana Saúde Pública. v.38, n.4, p.83753, 2014. Available from: http://files.bvs.br/upload/S/0100-0233/2014/v38n4/a4912.pdf

MEGRANAHAN, K.; LYNSKEY, M. T. Do creative arts therapies reduce substance misuse? A systematic review. The Arts in Psychotherapy. v.57, p.50-58, 2018.

MINAYO, M. C. S. O desafio do conhecimento. 10. ed. São Paulo: HUCITEC, 2007.

OLIVEIRA, V. C. et al. Sociodemographic and clinical profile of people assisted in a CAPS ad in the South of Brazil. Rev Baiana Enfer. v.31, n.1, p.e16350, 2017. Available from: https://portalseer.ufba.br/index.php/enfermagem/article/view/16350/14060

PROCHASKA, J. A.; DICLEMENTE, C. C.; NORCROSS, J. C. In search of how people change: applications to addictive behaviour. Am Psychol. v.47, n.9, p.1102-14, Sep. 1992.

SAAVEDRA, J. et al. Recovery and creative practices in people with severe mental illness: evaluating well-being and social inclusion. Disabil Rehabil. V.40, n.8, p.905-11, Apr. 2018. Available from: https://www.ncbi.nlm.nih.gov/pubmed/28637124

SILVA, D. A. S.; OLIVEIRA, N. R.; GRAÇA, M. S. A relação entre transtornos mentais e o uso de substâncias psicoativas. Rev Ciência (In) Cena. v.1, n.6, p.38-50, 2018.

SILVA, L. H. P. et al. Perfil dos dependentes químicos atendidos em uma unidade de reabilitação de um hospital psiquiátrico. Esc Anna Nery. v.14, n.3, p.585-90, 2010.

SNPD - Secretaria Nacional de Políticas sobre drogas. Intervenção breve. 11. ed. Brasília: SUPERA, 2017a. Módulo 4.

SNPD - Secretaria Nacional de Políticas sobre drogas. Modalidades de tratamento e encaminhamento. 11. ed. Brasília: SUPERA, 2017b. Módulo 6.

SNPD - Secretaria Nacional de Políticas sobre drogas. O uso de substâncias psicoativas no Brasil. 11. ed. Brasília: SUPERA, 2017c. Módulo 1.

TRINCA, W. Procedimentos de desenhos-estórias: formas derivadas, desenvolvimentos e expansões. São Paulo: Vetor, 2013.

VALLADARES-TORRES, A. C. A. A Arteterapia como dispositivo terapêutico no acolhimento integral das toxicomanias. Rev Artt AATESP. v.8, n.1, p.38-56, 2017. Disponível em: http://aatesp.com.br/resources/files/downloads/28_08_2018_01_30_44_revista_v8_n2_2017.pdf 
VALLADARES-TORRES, A. C. A. Arteterapias criativas com mulher dependente de múltiplas drogas um estudo de caso. Rev Científica Arteterapia Cores da Vida. v.25, n.1, p.26-37, Jan./Jun. 2018a. Disponível em: http://www.abcaarteterapia.com

VALLADARES-TORRES, A. C. A. Mulheres dependentes de drogas - desenho projetivo da figura humana e sua relação com os sintomas de ansiedade e depressão. Rev Científica Arteterapia Cores da Vida. v.25, n.1, p.38-48, Jan./Jun. 2018b. Disponível em: http://www.abcaarteterapia.com

VALLADARES-TORRES, A. C. A.; CALLAI, V. S. A exploração de desenho/colagem projetivo da árvore: uma visão dos usuários do serviço. Rev Científica Arteterapia Cores da Vida. v.25, n.2, p.28-37, Jul./Dez. 2018. Disponível em: http://www.abcaarteterapia.com

VALLADARES-TORRES, A. C. A.; COSTA, M. V. G. Máscaras em Arteterapia com usuários do Centro de Atenção Psicossocial - álcool e outras drogas. Rev Científica Arteterapia Cores da Vida. v.25, n.2, p.316, Jul./Dez. 2018. Disponível em: http://www.abcaarteterapia.com

VALLADARES-TORRES, A. C. A.; LAGO, D. M. S. K. Imaginário de dependentes de drogas sobre desenho projetivo/colagem da árvore em Arteterapia - estudos de caso. Rev Científica Arteterapia Cores da Vida. v.25, n.2, p.38-52, Jul./Dez. 2018a. Disponível em: http://www.abcaarteterapia.com

VALLADARES-TORRES, A. C. A.; LAGO, D. M. S. K. O uso da máscara e a tipologia de Jung em Arteterapia com alcoolistas - estudos de caso. Rev Científica Arteterapia Cores da Vida. v.25, n.2, p.17-27, Jul./Dez. 2018b. Disponível em: http://www.abcaarteterapia.com

VALLADARES-TORRES, A. C. A.; TORRES, K. N. Efeitos das Arteterapias criativas com dependentes de drogas: uso da arte, da música e da dança/movimentos corporais. Rev Científica Arteterapia Cores da Vida. v.25, n.1, p.13-25, Jan./Jun. 2018. Disponível em: http://www.abcaarteterapia.com

VALLADARES-TORRES, A. C. A. et al. Programa de Arteterapias criativas com usuários do Centro de Atenção Psicossocial-álcool e outras drogas. Rev Científica Arteterapia Cores da Vida. v.25, n.1, p.3-12, Jan./Jun. 2018. Disponível em: http://www.abcaarteterapia.com

ZANINI, R. S.; SOTILI, M. Uso de drogas, repercussões e intervenções neuropsicológica. Cadernos Brasileiros de Saúde Mental. v.11, n.28, p.94-116, 2019. 


\section{Capítulo 2}

doi) $10.37423 / 211205085$

AVALIAÇÃO COMPUTACIONAL DE PARÂMETROS RADIOBIOLÓGICOS PARA UM CASO DE GLIOBLASTOMA MULTIFORME

\section{Letícia Fröhlich}

Mairon Marques do Santos

Mirko Salomón Alva Sánchez

Viviane Rodrigues Botelho

Thatiane Alves Pianoschi Alva
Universidade Federal de Ciências da Saúde de Porto Alegre

Instituto Federal Goiânio

Universidade Federal de Ciências da Saúde de Porto Alegre

Universidade/Federal de Ciências da Saúde de Porto Alegre

Universidade Federal de Eiências da Saúde de Porto Alegre, 
Resumo: O glioblastoma multiforme (GBM) é considerado o câncer mais agressivo do Sistema Nervoso Central; o tratamento mais comum para essa neoplasia é a radioterapia. A avaliação do planejamento radioterápico é realizada através de curvas de histograma dose - volume (DVH), que analisa a dose depositada no volume de interesse sem considerar os parâmetros biológicos dos tecidos. Portanto, propuseram-se modelos matemáticos que descrevessem a fração de sobrevivência celular incluindo critérios biológicos; esses modelos são utilizados para calcular a probabilidade de controle tumoral (TCP), que quantifica a qualidade e eficácia do tratamento baseada em fatores de radiossensibilidade celular. Assim, utilizou-se o modelo linear quadrático (MLQ), que contabiliza os eventos letais gerados pela radiação ionizante. $O$ objetivo deste trabalho é avaliar computacionalmente a TCP a partir do MLQ com e sem repopulação celular para um caso clínico de GBM. Com as equações de TCP, analisou-se as distribuições de dose, TCP e DVH, comparando os resultados obtidos através da simulação e sistema de planejamento. Observou-se que a TCP sem repopulação superestima o valor da probabilidade do controle tumoral, enquanto a TCP com repopulação reflete o aumento de células que pode ocorrer durante o tratamento, reduzindo o controle das células tumorais. Ademais, avaliou-se a TCP-volume para analisar o controle tumoral no volume de tratamento e conclui-se que a análise do DVH sem critérios biológicos pode subestimar o sucesso do tratamento. Assim, percebe-se a importância da implementação da TCP nos protocolos de planejamento clínico, devido a inserção dos parâmetros radiobiológicos.

Palavras-chave: Radioterapia, TCP, simulação Monte Carlo, glioblastoma multiforme. 


\section{INTRODUÇÃO}

O glioblastoma multiforme (GBM) é o tipo mais comum e agressivo tumor cerebral, sendo o quinto tipo de carcinoma mais comum do mundo. Este tipo de neoplasia é mais frequente em homens, geralmente de 50 a 60 anos de idade e tem como fator de risco o tabagismo e consumo de álcool [1]. Para que ocorra um prolongamento da expectativa de vida de pacientes acometidos por GBM, o diagnóstico precoce da doença e o rápido início do tratamento são indispensáveis. Agosti et al. [2] afirma que para a ocorrência de um tratamento eficaz para um caso de GBM são necessárias, na maioria dos casos, a utilização de três técnicas de tratamento: cirurgia para a diminuição do tumor, ressecamento do tecido tumoral restante com radioterapia e quimioterapia caso ainda reste algum resquício da neoplasia. Ressaltando que a radioterapia é o tratamento mais indicado e o mais eficiente após a cirurgia pelo seu alto índice de precisão na região tumoral [2].

No tratamento radioterápico, o controle de dose é imprescindível para a preservação dos tecidos sadios adjacentes ao volume tumoral; a sobredose em tais tecidos pode ocasionar efeitos colaterais indesejados, como o desenvolvimento de câncer secundário em função da radioindução proveniente dos feixes de radiação, assim como a não erradicação total do tecido neoplásico poderá ocasionar em um tumor recidivo [3].

A avaliação do planejamento radioterápico pode ser realizada por meio de curvas de histogramas dose - volume (DVH), com o qual se pode analisar se a dose depositada no volume de interesse está de acordo com a dose prescrita, assim como, se a dose depositada nos órgãos de risco adjacentes está em conformidade com os valores de restrição. Entretanto, essa avaliação não leva em consideração parâmetros biológicos do tecido, apenas a dose depositada em um determinado volume [3].

Existem modelos matemáticos que descrevem a fração de sobrevivência celular inserindo critérios biológicos, os quais são utilizados para o cálculo da curva de sobrevivência celular em função da dose depositada no tecido; tal modelo é conhecido como a probabilidade de controle tumoral (TCP, do inglês Tumor Control Probability), ou seja, é a capacidade que a dose inserida no tecido biológico tem de reduzir o número de células tumorais encontradas na região. Assim, a TCP quantifica a qualidade e eficácia do tratamento baseada em fatores de radiossensibilidade celular e ela pode ser obtida por diferentes modelos matemáticos, como: Binomial, Poissoniano, de Zaider-Minerbo, de Dawson-Hillen e pelo modelo linear quadrático com e sem repopulação celular [4]. 
Alevei et [5] afirmou que valores baixos da TCP estão relacionados ao aumento do volume tumoral em decorrência do aumento do número de células clonogênicas, mostrando a influência da repopulação celular no modelo. Já Nuraini e Widita [6] afirmam que se o feixe de radiação incidindo na região tumoral não for letal, há a possibilidade das células se regenerarem e assim, ocorrer a proliferação celular do volume tumoral. Dessa forma, evidencia-se a importância da análise do controle tumoral no planejamento radioterápico. A fração de sobrevivência celular considera a relação entre a deposição de dose incidida no tecido tumoral e o efeito biológico que acarreta essa dose. Todavia, a análise da homogeneidade da distribuição de dose deveria levar em consideração não apenas a dose depositada no tecido biológico, mas também deveria ser verificado o controle tumoral da região neoplásica para um tratamento mais efetivo $[5,6]$.

Uma ferramenta que pode ser utilizada para simular a dose depositada em meios biológicos e, dessa forma, analisar as curvas de sobrevivência celular, são as simulações computacionais utilizando o método Monte Carlo. Existem diversos códigos de simulação que utilizam este método, como por exemplo, o código PENELOPE (PENetration and Energy Loss of Positron and Electrons), que será utilizado na realização deste trabalho $[7,8,9,10]$.

Dessa forma, o objetivo deste artigo é avaliar a probabilidade de controle tumoral a partir do modelo linear quadrático (MLQ) sem e com repopulação celular para um caso clínico de glioblastoma multiforme, obtida a partir de distribuições de dose de simulações computacionais e planejamento clinico.

\section{MATERIAIS E MÉTODOS}

\subsection{PROBABILIDADE DE CONTROLE TUMORAL}

A TCP pode ser descrita através de modelos matemáticos que relacionam o número de células iniciais e a fração de sobrevivência das células tumorais, como mostra a equação (1):

$$
T C P=e^{-N_{0} \cdot S f}
$$

em que $N_{0}$ é o número inicial de células e $S_{f}$ é a fração de sobrevivência celular. $A$ fração de sobrevivência celular é uma relação que considera o número total de células antes e depois da irradiação no tecidual. Em particular, este trabalho considera a fração de sobrevivência baseada no MLQ $[4,10,11]$. 


\subsubsection{MODELO LINEAR QUADRATICO}

O modelo linear quadrático (MLQ) é utilizado para quantificar a fração de sobrevivência celular no tecido tumoral baseado em parâmetros de radiossensibilidade [9], conforme a equação (2) :

$$
S_{f}=e^{-\propto D-\beta D^{2}}
$$

sendo $\alpha$ diretamente relacionado à quebra simples da fita de DNA e proporcional a dose $(\alpha D)$. 0 parâmetro $\beta$ relaciona-se com a quebra dupla da fita de DNA, sendo proporcional ao quadrado da dose $\left(\beta D^{2}\right)$ e, portanto, de maior letalidade celular [3].

Dessa forma, como a TCP é descrita em função de $S_{f}$, substituindo-se a equação (2) em (1), obtemos a equação (3) :

$$
T C P=e^{-N_{0} \cdot e^{-\propto D-\beta D^{2}}}
$$

Para modelos mais realisticos, considera-se a repopulação celular que contabiliza o crescimento tumoral durante o tratamento radioterápico. Assim, adiciona-se à equação (2) os termos de: taxa efetiva de repopulação tumoral $(\lambda)$ e o tempo total de exposição $\left(\mathrm{t}^{\prime}\right)$, o qual é calculado a partir da subtração do tempo total de tratamento (t) pelo tempo que as células permanecem sem se reproduzir após a sua irradiação $\left(t_{k}\right)$, como se pode observar na equação (4)[10]:

$$
t^{\prime}=t-t_{k}
$$

Dessa forma, chega-se a uma nova equação para a fração de sobrevivência celular, dada por pela equação (5) :

$$
S_{f}=e^{-\alpha D-\beta D^{2}}+\lambda t^{\prime}
$$

em que $\lambda=\frac{\ln 2}{t_{d}}$, em que $t_{d}$ é o tempo de duplicação celular.

Assim, a TCP com repopulação considera os parâmetros de tempo de tratamento, de repopulação e de duplicação, além de outros fatores como dose por fração e número de frações, conforme equação (6):

$$
T C P=e^{-N_{0} \cdot e^{\left[-n d(\alpha+\beta d)+\frac{\ln 2}{t_{d}}\left(t-t_{k}\right)\right]}}
$$

em que d é a dose por fração e $n$ o número de frações. 
Para determinação da TCP foram considerados os parâmetros para glioblastoma multiforme que são apresentados na Tabela 1.

Tabela 1. Valores dos parâmetros utilizados para o cálculo da TCP

\begin{tabular}{ccc}
\hline Parâmetros & Valor utilizado & Referência \\
\hline$\alpha$ & $0,36 \mathrm{~Gy}^{-1}$ & Alevei $(2020)^{5}$ \\
$\beta$ & $0,042 \mathrm{~Gy}^{-2}$ & Alevei $(2020)^{5}$ \\
$\mathrm{t}$ & $35 \mathrm{dias}$ & Qi, X.S et al $(2012)^{13}$ \\
$\mathrm{t}_{\mathrm{k}}$ & 28 dias & Bloch $(2012)^{10}$ \\
$\mathrm{t}_{\mathrm{d}}$ & 4,8 dias & Wilson $(2016)^{14}$ \\
$\mathrm{~N}_{0}$ & $10^{9}$ células & Bloch $(2012)^{10}$ \\
$\mathrm{~d}$ & $2 \mathrm{~Gy}$ & Marra $(2016)^{12}$ \\
$\mathrm{n}$ & 25 frações & Marra $(2016)^{12}$ \\
$\mathrm{D}$ & $50 \mathrm{~Gy}$ & Marra $(2016)^{12}$ \\
\hline
\end{tabular}

Fonte: $O$ autor (2021).

\subsection{VALIDAÇÃO E CONDIÇÕES DE SIMULAÇÃO CLINICA}

Para validação do feixe de irradiação de $6 \mathrm{MV}$, simulou-se um cubo de $30 \mathrm{~cm}$ de aresta, preenchido com água, com um campo quadrado de $10 \mathrm{~cm}$. Utilizou-se o código PENELOPE [8], versão 2008. Determinou-se as curvas de porcentagem de dose em profundidade, PDP, e o perfil de dose comparando-as com as obtidas experimentalmente com o equipamento LINAC Varian 2100 do serviço de Radioterapia do Hospital Santa Rita do Complexo Santa Casa de Misericórdia de Porto Alegre.

Foi realizado um planejamento clínico utilizando o sistema de planejamento (TPS) Eclipse, versão 13.1, em um objeto simulador de cabeça e pescoço composto de polimetilmetacrilato (PMMA) com 9,2 cm de raio e $20 \mathrm{~cm}$ de altura. A distância fonte e superfície foi de $100 \mathrm{~cm}$, um feixe de fótons de $6 \mathrm{MV}, 8$ campos quadrados de $4 \mathrm{~cm}$ que geram um arco na circunferência na cabeça. Nas mesmas condições clínicas foi realizada a simulação do objeto simulador de cabeça e pescoço. Considerou-se um número de partículas primárias de $2 \times 10^{9}$ e resolução espacial de $0,25 \mathrm{~cm}$.

Para analisar os dados obtidos foi implementado um código Matlab ${ }^{\circledR}$ por meio do qual analisou-se as distribuições de dose e TCP. Em seguida, para verificar se a dose depositada no volume de interesse está de acordo com a dose prescrita, determinou-se o histograma dose-volume (DVH). E da mesma forma, determinou-se o histograma TCP-Volume.

\section{RESULTADOS E DISCUSSÕES}




\subsection{VALIDAÇÃO DO FEIXE DE SIMULAÇÃO}

Para a validação do feixe de radiação, foram determinadas as curvas de PDP e perfil de dose, ambas comparadas com dados clínicos, apresentadas nas Figuras 1 e 2, respectivamente.

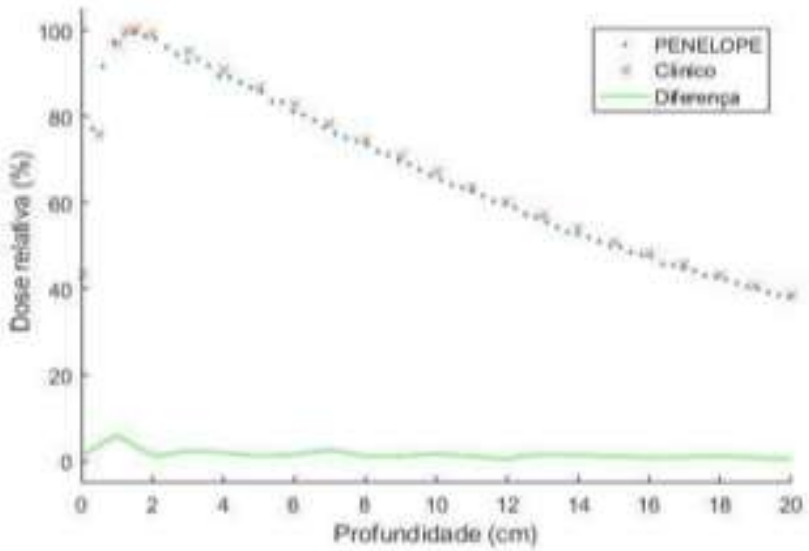

Figura 1: Curva de PDP para um feixe de $6 \mathrm{MV}$ em um campo de $10 \mathrm{~cm} \times 10 \mathrm{~cm}$

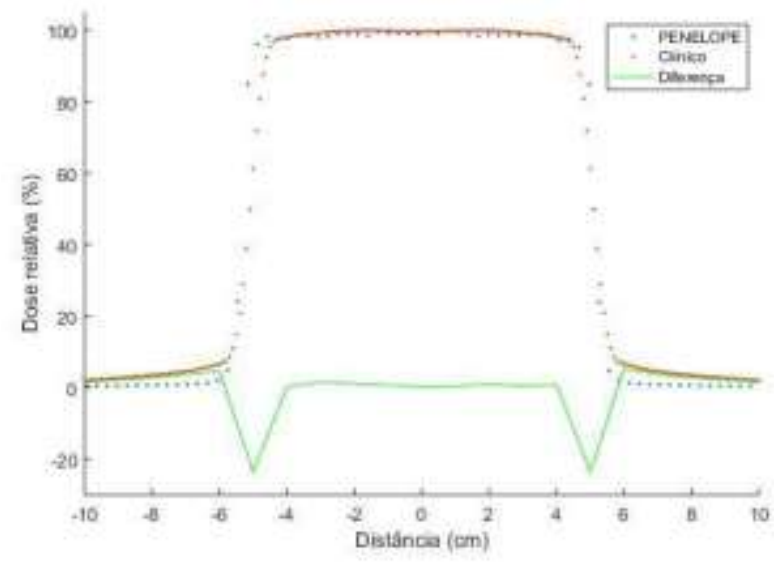

Figura 2: Curva de perfil de dose para um feixe de $6 \mathrm{MV}$ em um campo de $10 \mathrm{~cm} \times 10 \mathrm{~cm}$ na profundidade de máxima dose.

Para a curva de PDP (Figura 1), as diferenças encontradas entre dados simulados e os dados clínicos foram menores que $2,5 \%$, em todas as profundidades, com exceção da profundidade de $1 \mathrm{~cm}$, em que a diferença foi de 5,9\%. Tal diferença ocorre porque, na região anterior a profundidade de build up, na qual a curva apresenta um alto gradiente de dose, de tal forma que uma pequena variação de posição pode levar a uma grande variação de dose depositada. Para as curvas de perfil de dose (Figura 2), as diferenças entre os dados simulados e dados clínicos foram de 1,6\%, com exceção da região da borda de campo. Salienta-se que estas diferenças nas regiões de alto gradiente podem ser reduzidas aumentando-se o número de pontos experimentais nessa região.

\subsection{ANALISE DA TCP}

A Figura 3 mostra a distribuição dose para um tratamento clínico realizado com 8 campos de incidência, em forma de arco, podendo-se observar o gradiente de dose com alta deposição de dose central na região tumoral, assim como redução de dose nos tecidos adjacentes. 

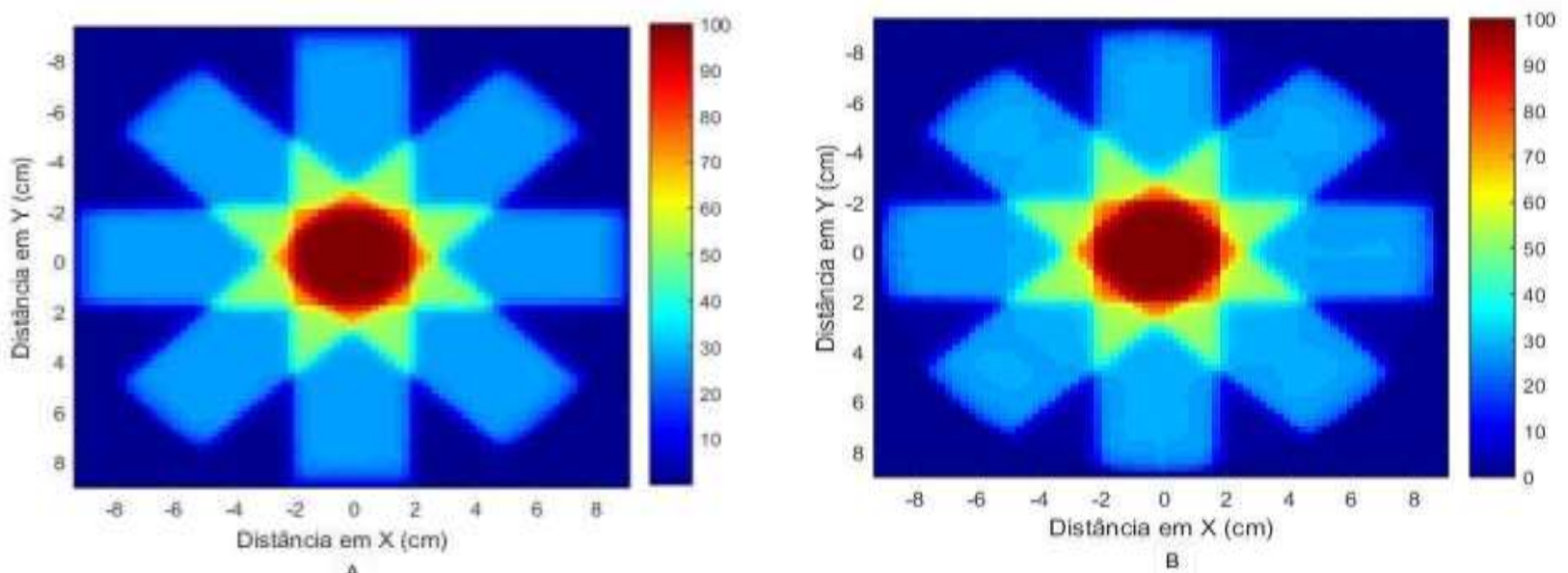

B

Figura 3: Distribuição de dose da simulação e planejamento clínico, para 8 campos de radiação em um feixe de 6 MV. (A) Simulação - PENELOPE; (B) TPS.

Para comparar as duas distribuições de dose, foi determinado o perfil de dose na linha central, como apresentado na Figura 4:

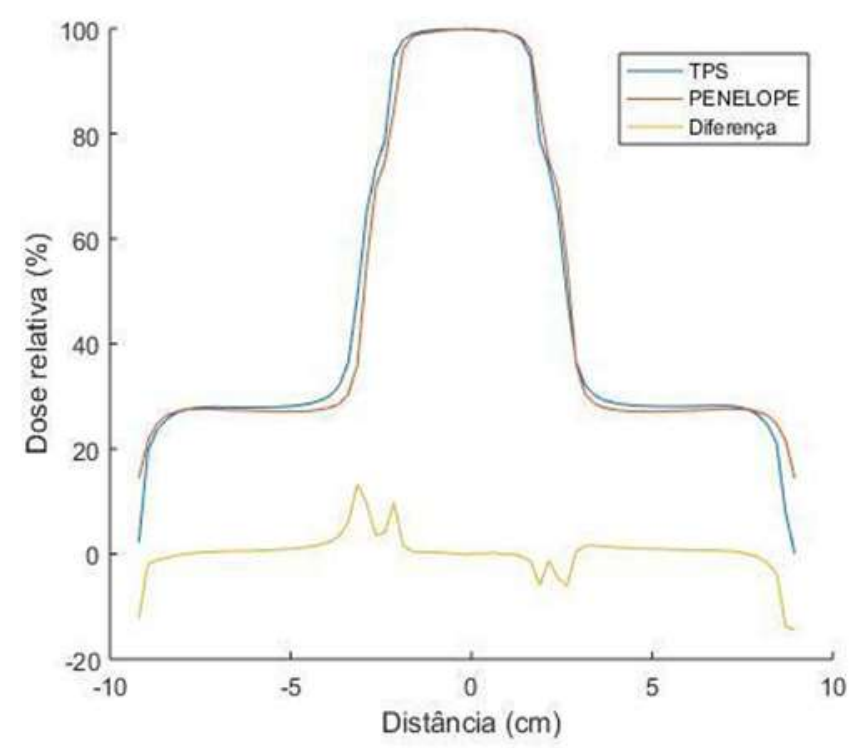

Figura 4: Perfil de dose dos dados simulados e dos dados de TPS, para 8 campos de radiação em um feixe de $6 \mathrm{MV}$.

Da mesma forma, a diferença entre as curvas de perfil de dose obtida com dados simulados e dados de TPS mostram uma diferença menor que 1\% na região central, que corresponde ao PTV (do inglês, Planning Target Volume) é o volume de planejamento do alvo. As maiores diferenças, em torno de $13 \%$, foram encontradas fora da região de interesse. 
A Figura 5 apresenta a TCP sem repopulação com dados da simulação e dados de TPS, obtida utilizadando a equação (3) e os dados de distribuição de dose na região central, onde a cobertura do planejamento atingiu $95 \%$ da dose máxima relativa. A região em vermelho que é considerada o controle tumoral máximo é mais extensa que a região de dose máxima visualizada na Figura 3. Isso se deve a relação exponencial da TCP com a dose.

Considerando a repopulação celular, equação (6), percebe-se uma redução da região de alto controle tumoral que pode ser observado na Figura 6 quando comparado com a Figura 5. Isso deve-se ao fato que o fator de repopulação celular reforça a sobrevivência celular.

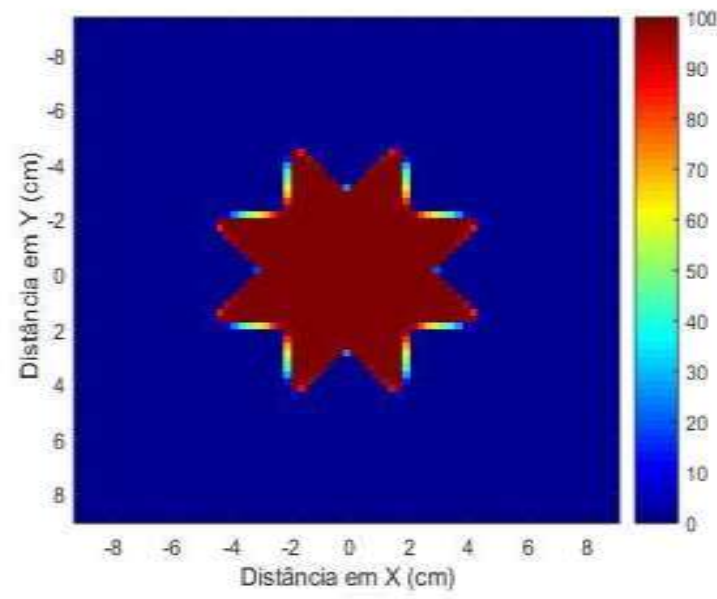

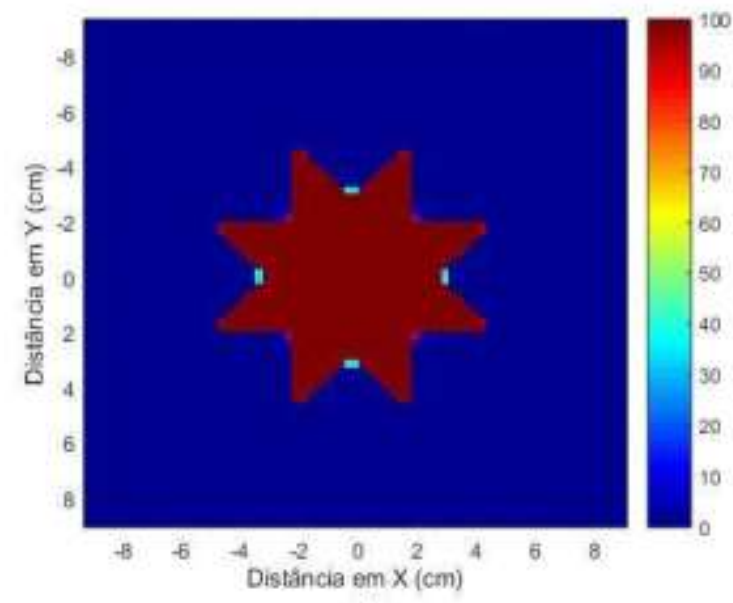

B

Figura 5: TCP sem repopulação. (A) Simulação - PENELOPE. (B) TPS.

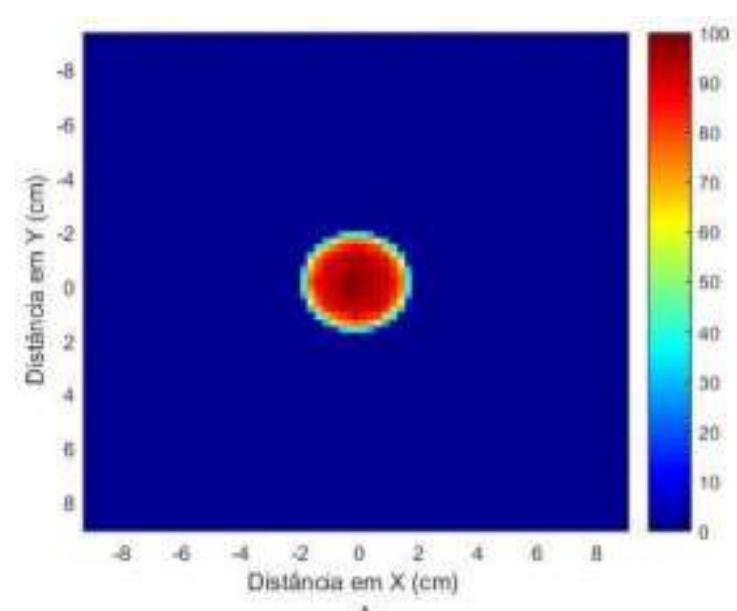

A

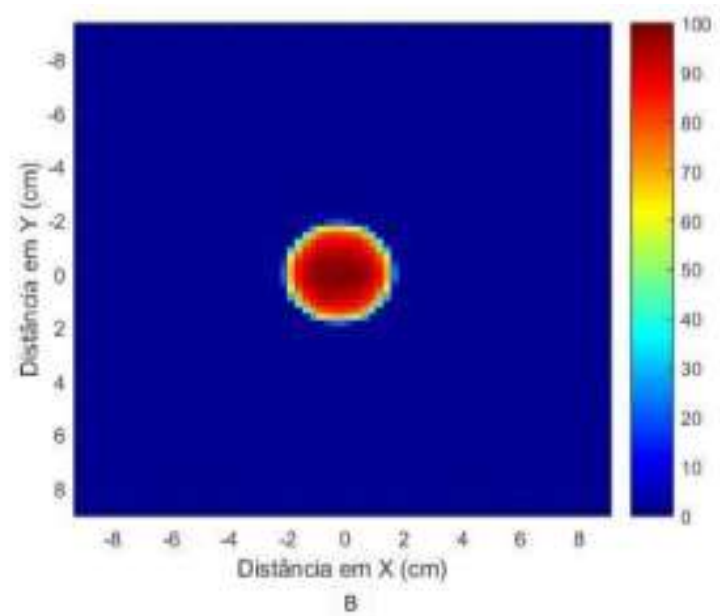

Figura 6: TCP com repopulação. (A) Simulação - PENELOPE. (B) TPS.

Para a comparação entre a simulação e TPS, foram determinadas as curvas de perfil de TCP, com e sem repopulação, e as curvas de perfil de dose, e o resultado é apresentado na Figura 7. 


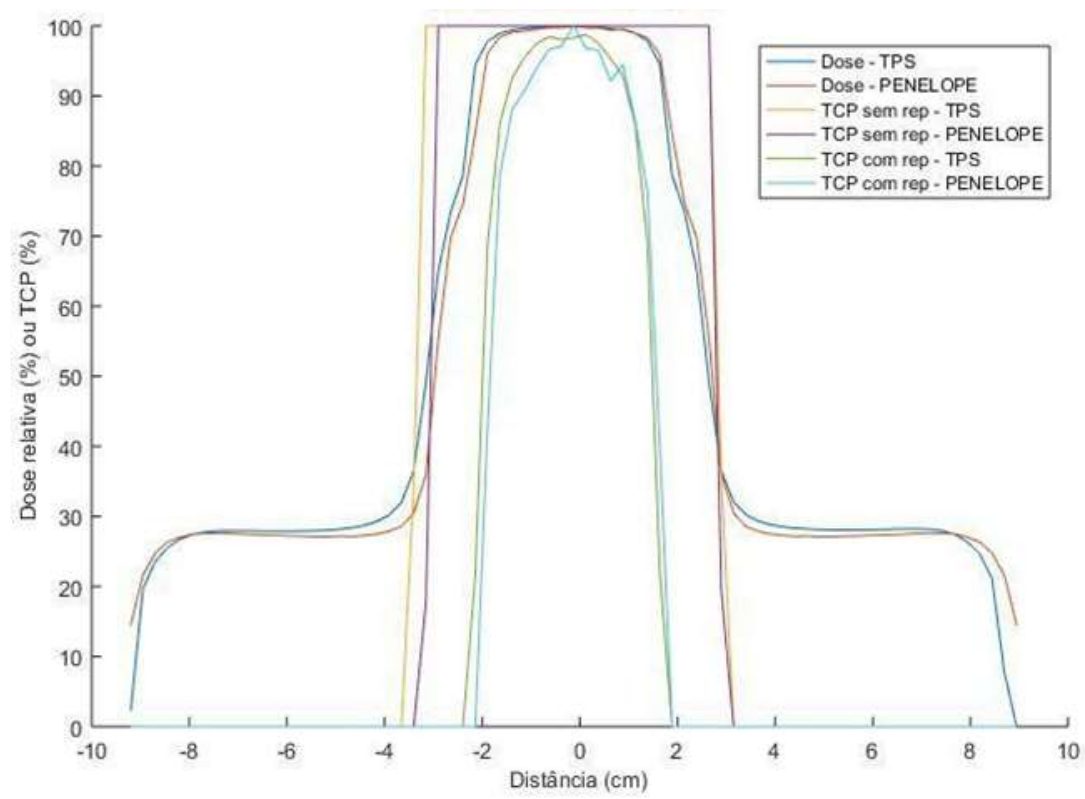

Figura 7: Curva comparativa de perfil da simulação do caso clínico de 8 campos para PENELOPE e TPS. Para a legenda do eixo vertical, considera-se dose relativa (\%) as curvas de Dose - TPS e Dose PENELOPE e TCP (\%) para as curvas de TCP com e sem repopulação para o TPS e PENELOPE.

Analisando a Figura 7, observa-se que a TCP sem repopulação superestima o valor da probabilidade de controle tumoral, pois estende grande parte das regiões, ainda que com baixa deposição de dose, para valores de probabilidade de 100\%. Frometa-Castillo et al. [15] afirma que não há a possibilidade de encontrar um valor de TCP igual a $100 \%$, pois, ao passo que o número de frações aumenta, a probabilidade de se encontrar células neoplásicas em atividade diminui, todavia, não chega a um valor nulo.

Entretanto, para o modelo com repopulação, os valores da TCP ficam abaixo da curva de dose relativa, inclusive na região de tratamento, mostrando que, mesmo para altas doses, o controle tumoral é reduzido. Consequentemente, a TCP sugere uma redução na eficácia do tratamento dada a permanência de células clonogênicas ou recidivas.

\subsection{HISTOGRAMA DOSE-VOLUME (DVH) E TCP-VOLUME}

A Figura 8 representa as curvas de DVH e as curvas de TCP-volume, com e sem repopulação, da simulação e TPS. 


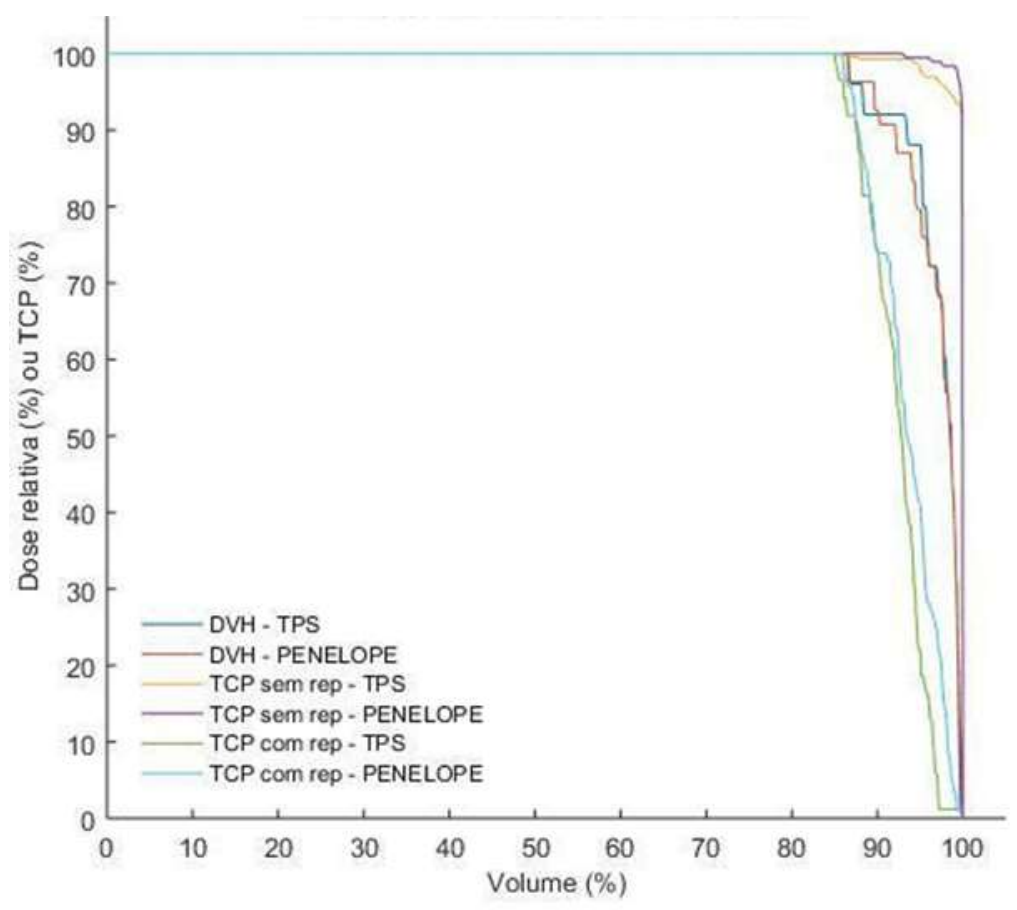

Figura 8: Curva de DVH e Curva de TCP-Volume.

Calculou-se a área abaixo das curvas de DVH e TCP-Volume e dividiu-se pela área abaixo da curva de uma curva de DVH ideal. Os resultados destes cálculos são observados na Tabela 2. Pode-se perceber que a porcentagem encontrada para a TCP com repopulação está abaixo da porcentagem para o DVH, o que ressalta que uma variação de dose, mesmo que dentro dos limites permitidos pelos protocolos clínicos, leva a uma variação significativa no controle tumoral. Já o volume da TCP sem repopulação se aproximou do DVH ideal.

Tabela 2: Análise qualitativa de DVH e TCP - Volume.

\begin{tabular}{llll}
\hline & DVH (\%) & $\begin{array}{l}\text { TCP sem repopulação } \\
(\boldsymbol{\%})\end{array}$ & $\begin{array}{l}\text { TCP com } \\
\text { repopulação (\%) }\end{array}$ \\
\hline PENELOPE & 97,18 & 99,72 & 92,27 \\
TPS & 97,06 & 99,91 & 93,29 \\
\hline
\end{tabular}

Fonte: O autor (2021).

Todavia, na prática, a probabilidade de controle tumoral não é analisada na clínica, considerando-se apenas o percentual de dose depositada no volume tumoral, e não o efeito biológico que a dose incidida causa.

De acordo com a literatura os parâmetros radiobiológicos podem variar. Para o número inicial de células encontra-se valores entre $10^{6}$ e $10^{9}$ [10]. O tempo de tratamento também pode ser alterado, 
ou seja, clínicas e hospitais podem seguir protocolos que incluam o tratamento nos finais de semana, como afirma Santos e Neves [17]. Da mesma maneira, pode-se considerar modificações de dose diária e o número de sessões por dia. Assim, a modelagem depende da alteração desses parâmetros.

\section{CONCLUSÕES}

Neste trabalho, analisaram-se as curvas de TCP, considerando modelos com e sem repopulação, comparando os perfis de dose e DVH da simulação e planejamento clínico. Os resultados mostram que a repopulação subestima a probabilidade de controle tumoral, o que sugere maiores deposições de dose para erradicação do tumor. Assim, espera-se que a curva de TCP, que inclui parâmetros radiobiológicos de repopulação celular auxilie na verificação dos planejamentos clínicos com uma análise que leve em conta não apenas a variação de dose, como o DVH, mas também a biologia celular através da fração de sobrevivência. Essa análise pode ser estendida a outros modelos matemáticos que incluem outros parâmetros de radiossensibilidade, dose, número de frações, número inicial de células e tempo de tratamento a fim de se obterem modelos mais realistas para serem aplicados na prática clínica.

\section{AGRADECIMENTOS}

Agradecemos ao Hospital Santa Rita do Complexo Hospitalar Santa Casa de Misericórdia de Porto Alegre pela colaboração e fornecimento dos dados clínicos e dados de planejamento clínico. 


\section{REFERÊNCIAS}

[1] CONSTANTINOS, A.; DIMITRIOS, T.T. Glioblastoma multiforme: Pathogenesis and treatment. Elsevier, v. 152, p. 63-82, 2015.

[2] AGOSTI, A.; CATTANEO, C.; GIVERSO, C.; AMBROSI, D.; CIARLETTA, P. A computational framework for the personalized clinical treatment of glioblastoma multiforme. Zaam, v. 98, p. 2307-2327, 2018.

[3] SALVAJOLI, J. V.; SOUHAMI, L.; FARIA, S.L. Radioterapia em Oncologia, 2ª ed. São Paulo: Atheneu, 2013.

[4] SANTOS, M. M. Probabilidade de Controle Tumoral: Modelos e Estatísticas [dissertação]. Ribeirão Preto (SP): Universidade de São Paulo; 2014.

[5] ALEVEI, V.C.; STEWART, R. D.; KIM, M.; MEYER, J.; RENGAN, R.. Volume effects in the TCP for hypoxic and oxygenated tumors. AAPM, v. 47, p. 4626-4633, 2020.

[6] NURAINI, R.; WIDITA, R. Tumor control probability (TCP) and normal tissue complication probability (NTCP) with consideration of cell biological effect. IOP Conf. Series: Journal of Physics: Conf. Series $1245 ; 2019$.

[7] SEMPAU, J; SANCHEZ-REYES, A; SALVAT, F; OULAD BEN TAHAR, H; B. JIANG, S; M. FERNANDEZVAREA, J. Monte Carlo simulation of eléctron beams from an accelerator head using PENELOPE. Physics in Medicine and Biology, v. 46, p. 1163-1186, 2001.

[8] SALVAT, F. ; VAREA, J. ; SEMPAU, J. PENELOPE-2014: A code System for Monte Carlo Simulation of Electron and Photon Transport. Universitat de Barcelona; Barcelona, 2011.

[9] SÁNCHEZ, M.S.A.. Verificação 3D da distribuição da dose em radiocirurgia estereotáxica através de simulação Monte Carlo e dosimetria por ressonância magnética nuclear [doutorado]. Ribeirão Preto (SP): Universidade de São Paulo; 2012.

[10] BLOCH, J.C.. Avaliação de técnicas radioterápicas conformacionais utilizando critérios físicos e biológicos [dissertação]. Ribeirão Preto (SP): Universidade de São Paulo; 2012.

[11] DAWSON, A.; HILLEN,T.. Derivation of the tumor control probability (TCP) from a cell cycle model. Computacional and mathematical methods in medicine, v. 7, p. 121-141, 2006.

[12]MARRA, J.S.. Sobrevida após radioterapia para gliomas de alto grau [dissertação]. Ribeirão Preto (SP): Universidade de São Paulo;2016.

[13] X. SHARON Q.; QIUHUI, Y., STEVE, P.; LEE, X.; ALLEN, L.; DIAN, W.. An estimation of radiobiological parameters for head-and-neck câncer cells and the clinical implications. MDPI, v. 4, p. 566-580, 2012.

[14] WILSON, G.D.; THIBODEAU, B.J,; FORTIER, L.E.; PRUETZ, B.L.; GALOFORO, S.; MARPLES, B.; BASCHNAGEL, A.M.; AKERVALL, J.; HUANG, J.. Cancer stem cell signaling during repopulation in head and neck cancer. Stem cells international, v. 2016, p. 10, 2016.

[15] TERMAN, F-C.; PYAKURVAL, A.; PISEAUX-AILLON, R.. Simulator of radioation biological effects in tumor in order to determinate the tumor control probability. Elsevier, v. 16, 2019. 
[16] ICRU Report 60, Bethesda: ICRU, 1998. 24p.

[17] FRÖLICH, L.; SÁNCHEZ, M.S.A.; PIANOSCHI, T.A.. Análise da variação de células iniciais no modelo linear quadrático sem repopulação para determinação da TCP utilizando simulação Monte Carlo PENELOPE. Congresso Brasileiro de Radioterapia. On-line. 2020.

[18] SANTOS, M.M.; NEVES, UPC.. ROC analysis in radiotherapy: A TCP model-based teste. Scientific Research, v. 3, p. 186-193, 2013. 


\section{Capítulo 3}

doi) $10.37423 / 211205086$

\section{AVALIAÇÃO DE REAÇÕES ADVERSAS IMEDIATAS À INFUSÃO DE QUIMIOTERÁPICOS EM PACIENTES AMBULATORIAIS: UMA REVISÃO DE LITERATURA}


Resumo: O câncer é um dos mais proeminentes problemas de saúde pública mundial e se caracteriza pelo crescimento descontrolado de células. O tratamento que se destaca para essa condição é a quimioterapia antineoplásica, que é administrada principalmente pela via oral e intravenosa, sendo a última, realizada em âmbito hospitalar e ambulatorial. Os antineoplásicos agem indiscriminadamente em células cancerosas e normais, produzindo reações adversas, que podem ser imediatas ou tardias e estão relacionadas com o aumento de morbimortalidade. As reações adversas imediatas são comumente associadas à infusão de antineoplásicos e a sua ocorrência, no ambulatório, é relevante, visto a dificuldade de monitorá-la. Estudos de notificação dessas reações promovem uma maior compreensão dos problemas apresentados pelos pacientes oncológicos, estabelecendo o significado da reação e contribuindo para intervenção e acompanhamento adequado. Dessa forma, o presente trabalho teve como objetivo identificar e analisar as evidências técnico-científicas acerca de reações adversas imediatas à infusão (RAll) de quimioterápicos em pacientes ambulatoriais. Foi feita uma revisão não sistemática de literatura sobre a avaliação de RAll, em pacientes ambulatoriais, nos últimos dez anos. A incidência global de RAll variou entre 1,9\% e 8,9\%. Os estudos revisados apresentaram um total de 1222 pacientes com RAll, com uma maior prevalência no sexo feminino $(65,3 \%)$ em relação ao sexo masculino (34,7\%) e com a média da idade variando entre 54,6 e 65 anos. Além do sexo e da idade, fatores de risco como a presença de comorbidades e alergias prévias, assim como a falta de pré-medicação, contribuíram para o aumento e/ou agravamento de RAll de quimioterápicos. As reações adversas mais relatadas foram dispneia ou falta de ar; rubor; hipotensão; prurido e eritema, configurando-se como reações de hipersensibilidade. A severidade das reações adversas foi avaliada pelos Critérios Comuns de Terminologia para Eventos Adversos, na maioria dos estudos, e se classificaram principalmente em grau 1 e 2, com sua soma variando entre 42,5\% e 90\%. Essas reações foram associadas principalmente aos taxanos, agentes de platina e anticorpos monoclonais, condizendo com a literatura. A infusão da droga foi interrompida com aparecimento da reação em 92,3\% dos estudos revisados e medicamentos sintomáticos foram utilizados em 76,8\%, sendo a hospitalização $(23,1 \%)$ conduta para casos mais graves. A incidência de RAll é heterogênea e varia essencialmente de acordo com fatores sociodemográficos, clínicos e farmacológicos, sendo necessário o monitoramento e notificações dessas reações, buscando segurança e melhor qualidade de vida para o paciente.

Palavras-chave: Câncer; Agentes antineoplásicos; Reação à infusão; Ambulatorial. 


\section{INTRODUÇÃO}

O câncer se caracteriza por um crescimento acelerado e descontrolado de células, resultando na formação de tumores, que se desenvolvem em qualquer região do corpo. Tal condição engloba um conjunto de doenças que têm em comum o desenvolvimento de células indiferenciadas, capazes de invadir tecidos e órgãos, podendo se propagar, além do local de origem, para outras partes do corpo, gerando a metástase (OMS, 2020; INCA, 2020).

As principais formas de tratamento do câncer são a cirurgia, a radioterapia e a quimioterapia e elas podem ser utilizadas de forma isolada ou associada. A escolha varia quanto às características e suscetibilidade dos tumores a cada terapêutica, além de individualidades do paciente. Na maioria dos casos, o tratamento consiste na combinação das diferentes técnicas (BRANDÃO et al., 2010; BRASIL, 2017; WHO, 2018).

A quimioterapia é uma forma tratamento sistêmico e consiste na utilização de agentes antineoplásicos com o objetivo de eliminar as células tumorais do organismo (ANDRADE, 2007). O tratamento quimioterápico é promissor contra o câncer e pode ser empregado com finalidade curativa ou paliativa, de forma isolada ou combinada, dependendo do tipo de tumor, extensão da doença e condições físicas do paciente (BONASSA; GATO, 2012; BRASIL, 2017).

Os antineoplásicos são fármacos anticrescimento, que atuam em nível celular, interferindo, de alguma forma, nos processos de crescimento e divisão das células (INCA, 2008). Contudo, eles ainda apresentam baixa especificidade para as células neoplásicas, atacando as células de rápida proliferação, sejam elas cancerosas ou normais, produzindo efeitos indesejáveis ou reações adversas (INCA, 2013; ALMEIDA et al., 2005). As células do sistema hematopoiético, folículos capilares, mucosa do trato gastrointestinal e pele apresentam uma taxa de divisão até mesmo maior do que as células tumorais, e por isso, são alvos dos antineoplásicos, explicando os efeitos adversos mais comuns ao tratamento, como náuseas, vômitos, diarreia, alopecia e maior suscetibilidade a infecções (SCHEIM, 2005; SILVA; COMARELLA, 2013).

De acordo com o tempo de aparecimento, em relação à infusão da droga, as reações podem ser classificadas em imediatas, precoces, retardadas e tardias, surgindo dentro de poucas horas, dias, meses e anos, respectivamente (RIUL; AGUILLAR, 1999). As reações imediatas são aquelas que ocorrem durante ou poucas horas após a administração do medicamento e podem ser graves e potencialmente fatais, sendo importante o conhecimento das manifestações que ocorrem durante ou 
logo após a administração do quimioterápico e, em caso de aparecimento, a infusão da droga deve ser cessada imediatamente (SILVA et al., 2015).

A administração de antineoplásicos acontece por diferentes vias, sendo a oral e a intravenosa, as mais comumente utilizadas. A terapia intravenosa é aplicada em ciclos, que consiste na administração de um ou mais medicamentos, em intervalos de tempo regulares, podendo ser feito com o paciente hospitalizado ou em nível ambulatorial (BRASIL, 2019).

As reações adversas imediatas são potencialmente associadas à infusão de agentes antineoplásicos e podem variar com o tipo de agente administrado, a duração, a frequência de infusão e a exposição prévia (ROSELLÓ et al., 2017). A maioria das reações imediatas é do tipo reação de hipersensibilidade, caracterizadas por urticária, angioedema, rinoconjuntivite, broncoespasmo e anafilaxia, tipicamente imunomediada por imunoglobulina E (GIAVINA-BIANCHI; PATIL; BANERJI, 2017). A ocorrência dessas reações é particularmente relevante, em nível ambulatorial, onde a administração da droga e observação subsequente do paciente são limitadas a um curto período de tempo (FERRARI et al., 2014).

O baixo índice terapêutico dos quimioterápicos requer uma avaliação das reações adversas decorridas desse tipo de tratamento, sendo papel da farmacovigilância o reconhecimento das reações adversas imediatas à infusão dos quimioterápicos, suas gravidades e alternativas para controle e prevenção (ANVISA, 2011). Além disso, as notificações são importantes, pois possibilitam a avaliação da causalidade e relevância da reação, sendo a subnotificação um grave problema, pois impossibilita o conhecimento do perfil clínico dos pacientes, retarda a adoção de alternativas para controle e a adoção de medidas preventivas (BONASSA; GATO, 2012).

À vista disso, realizar uma revisão de literatura para caracterizar a ocorrência e intensidade de reações adversas imediatas ao uso da quimioterapia intravenosa, em âmbito ambulatorial, é de grande importância para prática clínica, fornecendo subsídios para prestação de assistência, prevenção de complicações do tratamento e busca por novas terapias, para fins de segurança e melhor qualidade de vida do paciente. 


\section{OBJETIVOS}

\section{OBJETIVO GERAL}

Identificar as evidências científicas descritas na literatura sobre as reações adversas imediatas à infusão de quimioterápicos em pacientes ambulatoriais.

\section{OBJETIVOS ESPECÍFICOS}

- Verificar a incidência de reações adversas imediatas à infusão (RAll) de quimioterápicos;

- Analisar o perfil sociodemográfico e clínico dos pacientes acometidos com RAll;

- Descrever sinais e sintomas apresentados pelos pacientes;

- Analisar a severidade das RAll de quimioterápicos;

- Caracterizar as drogas antineoplásicas relacionadas às RAll;

- Avaliar as condutas adotadas após aparecimento das reações.

\section{MATERIAIS E MÉTODOS}

Trata-se de uma revisão bibliográfica sobre a incidência de reações adversas imediatas à infusão de quimioterápicos em pacientes ambulatoriais através de uma busca eletrônica nas bases de dados: PubMed, Google Scholar e Scopus durante os últimos 10 anos (2011 a 2021). As palavras-chave utilizadas foram: reação à infusão/ infusion reaction, agentes antineoplásicos/ antineoplastic agents e ambulatorial/ outpatient.

Após a pesquisa, nos bancos de dados, foram incluídos estudos que relatavam a avaliação de reações à infusão de antineoplásicos, de forma imediata e em ambiente ambulatorial; nos idiomas inglês e português e que estivessem disponíveis na íntegra. Foram excluídos estudos que apresentavam reações adversas tardias; uso de antineoplásicos orais; reações em pacientes internos e estudos de dessensibilização, além de relato de caso; revisão sistemática e ensaios clínicos de fases iniciais.

Foram obtidos 1079 estudos, no total, e após a exclusão dos duplicados, em mais de uma base de dados, e leitura dos títulos e resumos, 36 estudos foram pré-selecionados e analisados na íntegra. Posteriormente, 13 estudos foram selecionados por melhor atenderem aos critérios de inclusão deste trabalho. 


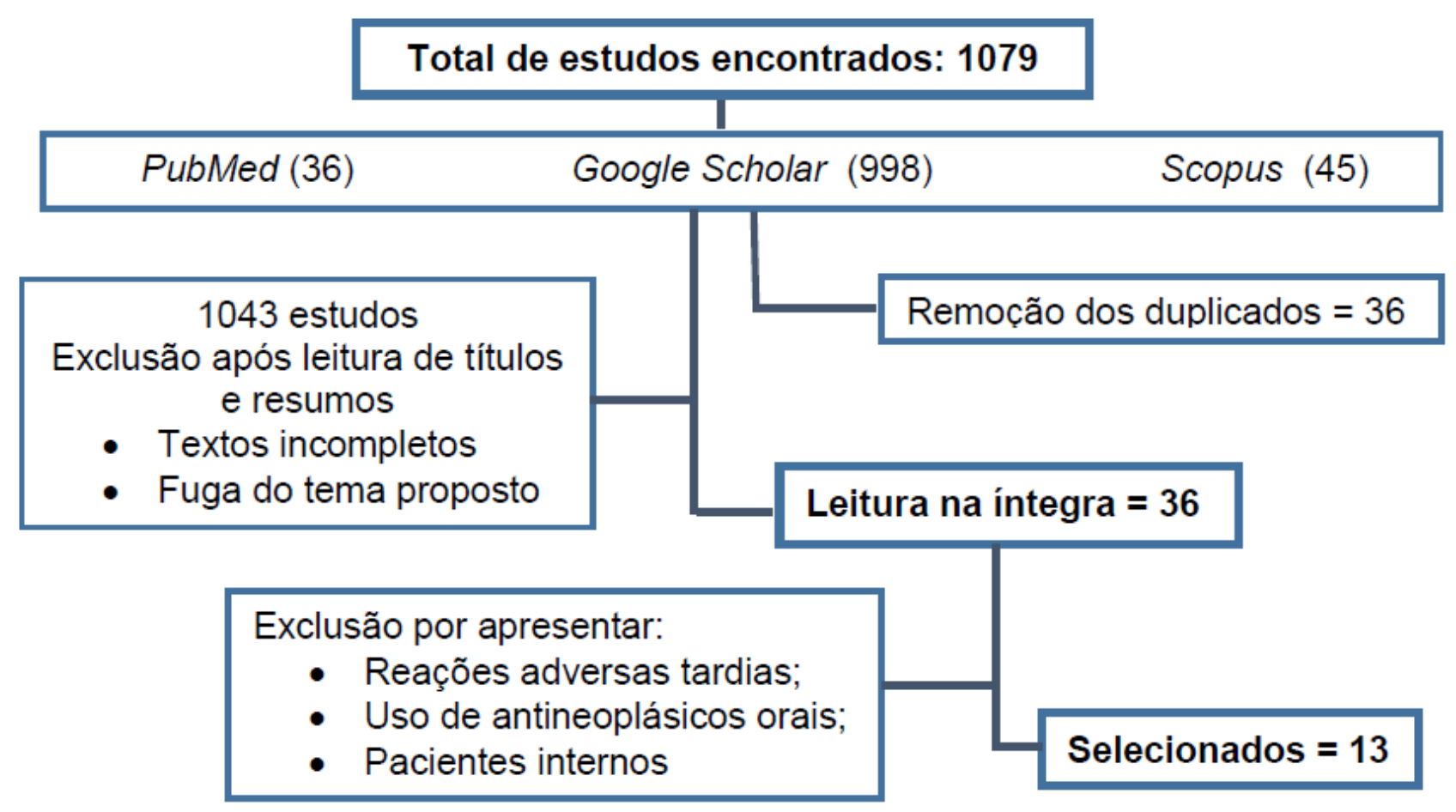

Figura 1. Fluxograma da busca e seleção dos estudos

\section{RESULTADOS}

A busca bibliográfica resultou em 1079 estudos, dos quais, após exclusão dos duplicados e leitura dos títulos e resumos, 36 foram analisados na íntegra, desses, foram selecionados 13 , seguindo os critérios de inclusão/exclusão propostos.

Os estudos selecionados são originários de diferentes países do mundo, com o predomínio de estudos americanos. A incidência global de reações adversas imediatas à infusão de quimioterápicos variou entre $1,9 \%$ e $8,9 \%$. Vale a pena ressaltar que alguns estudos não especificaram o total de pacientes envolvidos, o que impossibilitou o cálculo da incidência (Tabela 1). 
Tabela 1. Informações epidemiológicas apresentadas nos estudos revisados (*)

\begin{tabular}{|c|c|c|c|}
\hline REFERÊNCIAS & PAÍs & $\begin{array}{l}\text { TOTAL DE } \\
\text { PACIENTES } \\
\text { ESTUDO (N) }\end{array}$ & $\begin{array}{c}\text { INCIDÉNCIA } \\
\text { DE RAII } \\
(\%) \\
\end{array}$ \\
\hline DeMoor et al. (2011) & EUA & 4000 & 4 \\
\hline Tamiya et al. (2011) & Japão & 255 & 1,9 \\
\hline Hopps et al. (2012) & EUA & NE & _ \\
\hline Keating et al. (2013) & EUA & NE & - \\
\hline Muallaoglu et al. (2013) & Turquia & 2213 & 6,2 \\
\hline Wong et al. (2014) & EUA & NE & - \\
\hline Ferrari et al. (2014) & Itália & NE & _ \\
\hline Parel et al. (2014) & França & 191 & 8,9 \\
\hline Banerji et al. (2014) & EUA & NE & - \\
\hline Levin et al. (2016) & EUA & NE & _ \\
\hline Sun e Li (2019) & China & 860 & 8,9 \\
\hline Freitas (2020) & Brasil & NE & _ \\
\hline arbosa-Lima et al. (2020) & Brasil & 249 & 2,4 \\
\hline
\end{tabular}

(*) NOTA: Somente artigos publicados a partir de 2011.

NE - Não especificado.

No total, 1222 pacientes ambulatoriais apresentaram reações adversas imediatas à infusão de quimioterápicos. Desse total de pacientes com RAll, 986 tiveram o sexo especificado, sendo 644 do sexo feminino e 342 do sexo masculino, com uma maior prevalência nas mulheres (65,3\%). A média da idade dos pacientes com RAll variou entre 54,6 e 65 anos, apresentando um intervalo de aproximadamente dez anos entre os estudos (Tabela 2). 
Tabela 2. Informações sobre o sexo e a idade dos pacientes ambulatoriais com RAll de quimioterápicos $(*)$

\begin{tabular}{|c|c|c|c|c|c|c|}
\hline \multirow{3}{*}{ REFERÊNCIAS } & \multirow{3}{*}{$\begin{array}{l}\text { TOTAL DE } \\
\text { PACIENTES } \\
\text { COM RAII } \\
\text { (N) }\end{array}$} & \multicolumn{4}{|c|}{ SEXO DOS PACIENTES C/ RAII } & \multirow{3}{*}{$\begin{array}{l}\text { MÉDIA } \\
\text { DA } \\
\text { IDADE } \\
\text { (ANOS) }\end{array}$} \\
\hline & & \multicolumn{2}{|c|}{ FEMININO } & \multicolumn{2}{|c|}{ MASCULINO } & \\
\hline & & $\mathbf{N}$ & $\%$ & $\mathbf{N}$ & $\%$ & \\
\hline $\begin{array}{c}\text { DeMoor et al. } \\
\text { (2011) }\end{array}$ & 160 & $\mathrm{NE}$ & $\mathrm{NE}$ & $\mathrm{NE}$ & $\mathrm{NE}$ & 55 \\
\hline $\begin{array}{c}\text { Tamiya et al. } \\
\text { (2011) }\end{array}$ & 5 & 2 & 40 & 3 & 60 & 65 \\
\hline $\begin{array}{l}\text { Hopps et al. } \\
\text { (2012) }\end{array}$ & 153 & 80 & 52,3 & 73 & 47,7 & 57 \\
\hline $\begin{array}{l}\text { Keating et al. } \\
\text { (2013) }\end{array}$ & 125 & 43 & 44 & 82 & 66 & 58 \\
\hline $\begin{array}{l}\text { Muallaoglu et al. } \\
\qquad(2013)\end{array}$ & 138 & 94 & 68,1 & 44 & 31,9 & 56 \\
\hline $\begin{array}{l}\text { Wong et al. } \\
\text { (2014) }\end{array}$ & 48 & 30 & 62 & 18 & 38 & 58 \\
\hline $\begin{array}{c}\text { Ferrari et al. } \\
(2014)\end{array}$ & 240 & 196 & 82 & 44 & 18 & 58 \\
\hline $\begin{array}{l}\text { Parel et al. } \\
\text { (2014) }\end{array}$ & 17 & 16 & 94 & 1 & 6 & 56,2 \\
\hline $\begin{array}{c}\text { Banerji et al. } \\
\text { (2014) }\end{array}$ & 152 & 134 & 88,2 & 18 & 11,8 & 55 \\
\hline $\begin{array}{l}\text { Levin et al. } \\
\text { (2016) }\end{array}$ & 67 & 31 & 46 & 36 & 54 & 58 \\
\hline $\begin{array}{l}\text { Sun e Li } \\
(2019)\end{array}$ & 76 & NE & NE & NE & NE & 56,9 \\
\hline $\begin{array}{l}\text { Freitas } \\
(2020)\end{array}$ & 35 & 14 & 40 & 21 & 60 & 54,6 \\
\hline $\begin{array}{l}\text { Barbosa-Lima et } \\
\text { al. }(2020)\end{array}$ & 6 & 4 & 66,7 & 2 & 33,3 & 54,8 \\
\hline TOTAL ${ }^{(* *)}$ & 1222 & 644 & 65,3 & 342 & 34,7 & - \\
\hline
\end{tabular}

$\left.{ }^{*}\right)$ NOTA: NE - Não especificado.

$\left({ }^{* *}\right)$ : O total apresentado para o número de pacientes do sexo feminino e masculino não inclui os estudos DeMoor e cols. (2011) e Sun e Li (2019), já que não estão especificados nos mesmos.

A correlação entre a presença de comorbidades e o risco de desenvolver RAll foi discutida em 5 estudos. As mais relatadas foram: hipertensão arterial sistêmica (HAS), que variou entre 52\% e 21,25\%; diabetes mellitus (DM), entre $10 \%$ e $4,2 \%$ e cardiopatias, entre 5,7\% e $3 \%$. 
O consumo do tabaco e o álcool foram analisados em 2 estudos. Para Freitas (2020), dos pacientes que desenvolveram RAll, 65,7\% eram tabagistas e 54,3\%, etilistas e para Hopps e cols. (2012), os fumantes ativos tiveram uma incidência aumentada de RAll de $23,6 \%$ quando comparados a não fumantes ou ex-fumantes.

Em 7 estudos, foi avaliada a correlação entre o histórico de alergias prévias e a ocorrência de RAll. No estudo de DeMoor e cols (2011), não houve correlação. Para Barneji e cols. (2014), Levin e cols. (2016) e Freitas (2020), 50\%, 30\% e 11,4\% dos pacientes com RAll, respectivamente, tinham histórico de alergias prévias. Keating e cols. (2013), verificaram maior risco de RAll em pacientes com alergia a sulfa e Ferrari e cols. (2014) observaram que os pacientes com alergias anteriores a antineoplásicos têm um risco aumentado para desenvolver RAll grave.

As reações adversas imediatas mais comuns à infusão de quimioterápicos, entre os estudos revisados, foram do tipo reação de hipersensibilidade e se caracterizaram por: dispneia $(53,8 \%)$; rubor $(53,8 \%)$; eritema (38,5\%); hipotensão (38,5\%); prurido (38,5\%\%); dor, aperto e pressão no peito (30,8\%) e urticária $(30,8 \%)$, como demonstrado na Tabela 3. Houve mortes devido à RAll de quimioterápicos, em dois estudos, com baixa prevalência (1\%) em ambos.

Tabela 3. Ocorrência das principais RAll de quimioterápicos apresentada nos estudos revisados

\begin{tabular}{ccc}
\hline PRINCIPAIS RAII & \multicolumn{2}{c}{$\begin{array}{c}\text { ESTUDOS REVISADOS } \\
\text { (N) }\end{array}$} \\
\hline Dispneia & 7 & 53,8 \\
Rubor & 7 & 53,8 \\
Eritema & 5 & 38,5 \\
Hipotensão & 5 & 38,5 \\
Prurido & 5 & 38,5 \\
Dor, aperto e pressão no peito & 4 & 30,8 \\
Urticária & 4 & 30,8 \\
\hline
\end{tabular}

De acordo com a Tabela 4, dez dos treze estudos classificaram a severidade de suas reações através do instrumento Critérios Comuns de Terminologia para Eventos Adversos. O grau de severidade se apresentou entre 1 e 5, com uma maior prevalência dos graus 1 e 2, ou seja, reações leves e 
moderadas, que somados, variou entre $42,5 \%$ e $90 \%$. A soma dos graus 3 e 4 variou entre $10 \%$ e $57,5 \%$. Dois estudos apresentaram reações de grau 5, com prevalência de 1\% em ambos.

Tamiya e cols. (2011), embora tenham classificado suas reações através do CTCAE, não especificaram a quantificação dos graus. Os estudos de Wong e cols. (2014) e Barbosa-Lima e cols. (2020) não avaliaram a severidade das reações notificadas e o estudo de Banerji e cols. (2014) utilizou a Classificação de Brown para classificar a severidade das RAll encontradas (Tabela 4).

Tabela 4. Grau de severidade das RAll de quimioterápicos apresentado nos estudos revisados (*)

\begin{tabular}{|c|c|c|c|}
\hline \multirow[b]{2}{*}{ REFERÊNCIAS } & \multicolumn{3}{|c|}{ GRAU DE SEVERIDADE (\%) } \\
\hline & $1+2$ & $3+4$ & 5 \\
\hline DeMoor et al. (2011) & 73 & 26 & 1 \\
\hline Tamiya et al. (2011) & NE & NE & NE \\
\hline Hopps et al. (2012) & 87,6 & 12,4 & 0 \\
\hline Keating et al. (2013) & 42,5 & 57,5 & 0 \\
\hline Muallaoglu et al. (2013) & 89,2 & 10,8 & 0 \\
\hline Wong et al. (2014) & - & - & - \\
\hline Ferrari et al. (2014) & 90 & 10 & 0 \\
\hline Parel et al. (2014) & 82,3 & 17,6 & 0 \\
\hline Banerji et al. (2014) & $\mathrm{CB}$ & $\mathrm{CB}$ & $\mathrm{CB}$ \\
\hline Levin et al. (2016) & 88 & 12 & 0 \\
\hline Sun e Li (2019) & 78,9 & 19,8 & 1,3 \\
\hline Freitas (2020) & 85,7 & 14,3 & 0 \\
\hline Barbosa-Lima et al. (2020) & - & - & - \\
\hline
\end{tabular}

(*) NOTA: “-“ Grau de severidade não avaliado no estudo. CB: Classificação de Brown. NE: Não especificado. 
Os resultados de severidade das RAll de acordo com a Classificação de Brown, no estudo de Banerji e cols. (2014), são mostrados na Figura 3, com uma maior prevalência de reações moderadas (67\%).

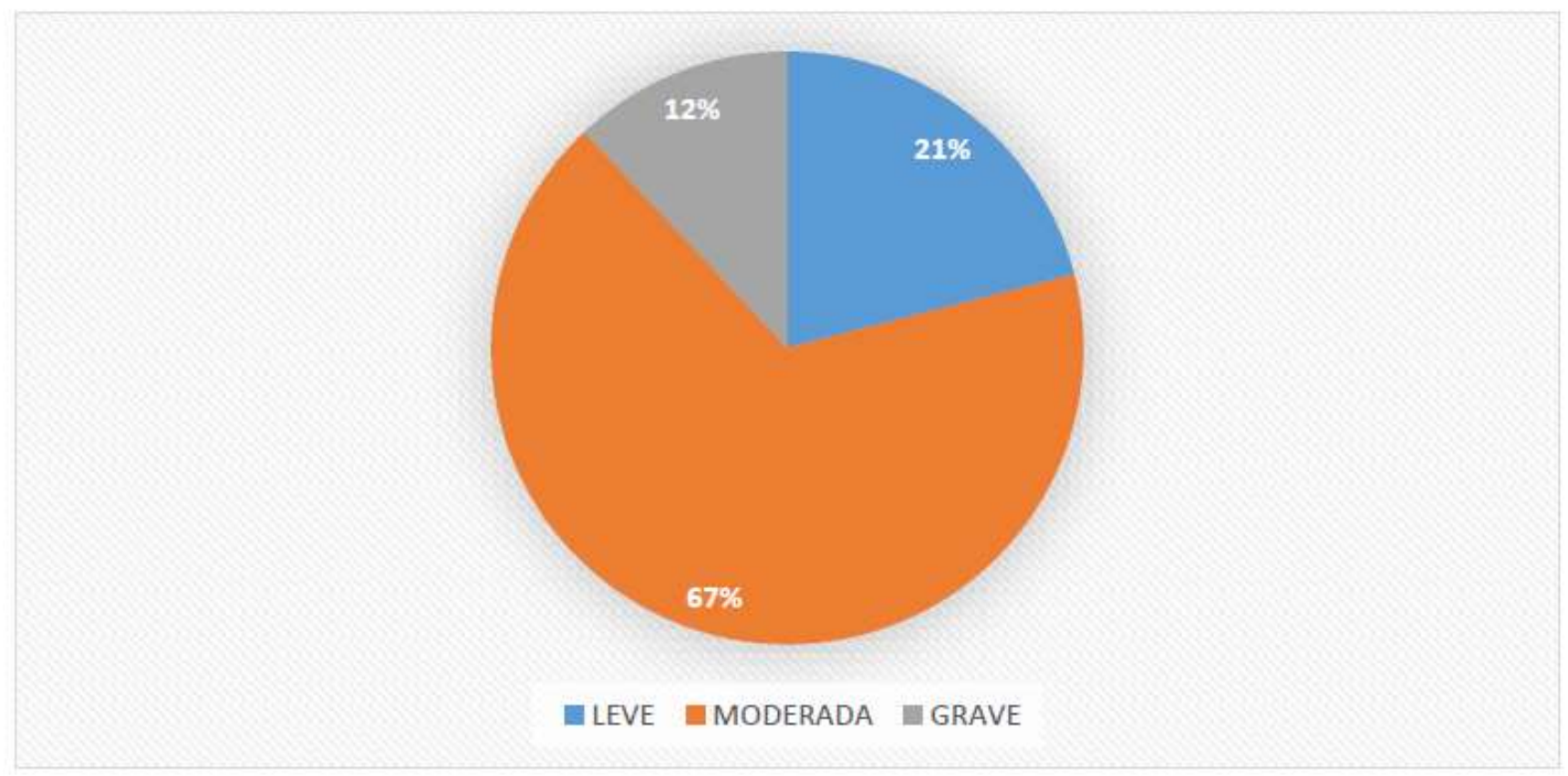

Figura 2. Grau de severidade de RAll de quimioterápicos pela Classificação de Brown

As drogas relacionadas à maior incidência de RAll, nos estudos revisados, variaram entre taxanos (paclitaxel e docetaxel); agentes de platinas (carboplatina, cisplatina e oxaliplatina) e anticorpos monoclonais (rituximabe, cetuximabe), principalmente. Para os estudos que analisaram diferentes classes de quimioterápicos, o rituximabe apresentou maior prevalência para Demoor e cols. (2011) (37,5\%) e Barbosa-Lima e cols. (2020) (33,3\%); docetaxel (27,6\%) para Muallaoglu e cols (2013); paclitaxel $(36,25 \%)$ para Ferrari e cols. (2014) e oxaliplatina $(28,6 \%)$ para Freitas (2020), de acordo com a Tabela 5.

Tamiya e cols. (2011) avaliaram a incidência de RAll para dois antineoplásicos pertencentes a uma mesma classe, carboplatina (80\%) e cisplatina (20\%); Barneji e cols. (2014) estimaram para dois antineoplásicos de classes diferentes, paclitaxel $(70,4 \%)$ e carboplatina $(29,6 \%)$ e Parel e cols. (2014) avaliaram para oxaliplatina sozinha e em diferentes combinações, entretanto, não quantificou os resultados. Cinco estudos avaliaram RAll atribuídas a apenas um tipo de antineoplásico:

cetuximabe; rituximabe; carboplatina; oxaliplatina, dessa forma, $100 \%$ da incidência de RAll foi atribuída a essa droga (Tabela 5). 
Tabela 5. Principais drogas relacionadas

\section{TAXANOS (\%) AGENTES DE PLATINA ANTICORPOS \\ (\%) \\ (\%)} REFERÊNCIAS

\begin{tabular}{|c|c|c|c|c|c|c|c|}
\hline & 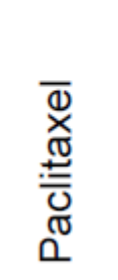 & 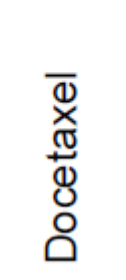 & 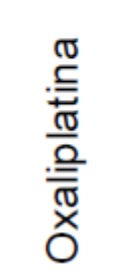 & 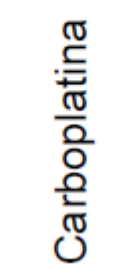 & 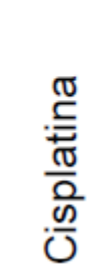 & 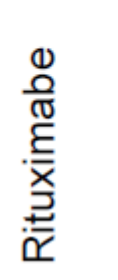 & 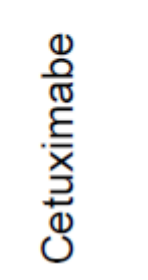 \\
\hline $\begin{array}{c}\text { DeMoor et al. } \\
(2011)\end{array}$ & 14,4 & 1,9 & 4,4 & 10 & - & 37,5 & 0,6 \\
\hline $\begin{array}{c}\text { Tamiya et al. } \\
\text { (2011) }\end{array}$ & - & - & - & 80 & 20 & - & - \\
\hline $\begin{array}{l}\text { Hopps et al. } \\
\text { (2012) }\end{array}$ & - & - & - & - & - & - & $100^{(* *)}$ \\
\hline $\begin{array}{c}\text { Keating et al. } \\
(2013)\end{array}$ & - & - & - & - & - & - & 100 \\
\hline $\begin{array}{l}\text { Muallaoglu et al. } \\
\qquad(2013)\end{array}$ & 9,7 & 27,6 & 16,1 & 11,1 & 2,1 & 18 & - \\
\hline $\begin{array}{c}\text { Wong et al. } \\
(2014)\end{array}$ & - & - & 100 & - & - & - & - \\
\hline $\begin{array}{l}\text { Ferrari et al. } \\
\qquad(2014)\end{array}$ & 36,2 & 4,6 & 23,3 & 6,7 & 1,2 & 9,6 & 0,4 \\
\hline $\begin{array}{l}\text { Parel et al. } \\
\text { (2014) }\end{array}$ & - & - & $\mathrm{NE}$ & - & - & - & - \\
\hline $\begin{array}{c}\text { Banerji et al. } \\
\text { (2014) }\end{array}$ & 70,4 & - & - & 29,6 & - & - & - \\
\hline $\begin{array}{l}\text { Levin et al. } \\
\quad(2016)\end{array}$ & - & - & - & - & - & 100 & - \\
\hline $\begin{array}{l}\text { Sun e Li } \\
(2019)\end{array}$ & - & - & - & 100 & - & - & - \\
\hline $\begin{array}{l}\text { Freitas } \\
(2020)\end{array}$ & 20 & 22,9 & 28,6 & - & - & - & - \\
\hline $\begin{array}{l}\text { Barbosa-Lima et } \\
\text { al. }(2020)\end{array}$ & 16,7 & - & - & 8,3 & 8,3 & 33,3 & - \\
\hline
\end{tabular}

A administração de pré-medicação, antes da infusão dos antineoplásicos, foi relatada em 5 estudos, sendo os corticosteroides, antieméticos e anti-histamínicos administrados em todos eles. Parel e cols. (2014) e Muallaoglu e cols. (2013) relataram que a administração de pré-medicação levou a uma 
menor incidência de RAll. Keating e cols. (2013) afirmaram que o pré-tratamento foi associado com risco menor de apresentar reação de grau 3 ou 4. Para Ferrari e cols. (2014) e Hopps e cols. (2012), a incidência de RAll foi semelhante entre os pacientes não pré-tratados e pré-tratados.

Os tipos de câncer mais presentes, nos estudos, foram o de pulmão $(53,8 \%)$; ovário $(46,2 \%)$; mama (38,5\%); colorretal, gástrico e linfoma (30,8\%), assim como demonstrado na Tabela 6. Dois estudos focaram em câncer específicos, em um deles, os pacientes apresentavam câncer de ovário e no outro, câncer torácico (80\% de pulmão). Um dos estudos não especificou os tipos de câncer que acometeram os pacientes.

Tabela 6. Frequência dos principais tipos de câncer nos estudos revisados

\begin{tabular}{ccc}
\hline TIPOS DE CÂNCER & \multicolumn{2}{c}{$\begin{array}{c}\text { ESTUDOS REVISADOS } \\
(\mathbf{N})\end{array}$} \\
\hline Pulmão & 7 & 53,8 \\
Ovário & 6 & 46,2 \\
Mama & 5 & 38,5 \\
Colorretal & 4 & 30,8 \\
Gástrico & 4 & 30,8 \\
Linfoma & 4 & 30,8 \\
\hline
\end{tabular}

As condutas mais adotadas, nos estudos revisados, após o aparecimento de RAll de quimioterápico, foram: interrupção imediata da infusão (92,3\%) e a utilização de medicamentos sintomáticos (76,9\%) como anti-histamínicos H1 e H2 e corticosteroides. A oxigenoterapia (38,5\%) e administração de fluidos intravenosos $(30,8 \%)$ também foram relatadas em alguns estudos. Assim como, as condutas de suspensão dos ciclos de quimioterapia $(38,5 \%)$ ou reintrodução da quimioterapia

$(38,5 \%)$ e hospitalização $(23,1 \%)$. As condutas de suspensão do ciclo quimioterápico e hospitalização foram mais utilizadas em casos graves (geralmente reações de grau 3 e 4) e a reintrodução da quimioterapia foi conduta, em geral, para pacientes com reações de grau 1 e 2 . A realização de testes cutâneos $(23,1 \%)$ de hipersensibilidade imediata para estratificação de risco e dessensibilização $(23,1 \%)$ à droga foram condutas conseguintes descritas em certos estudos (Tabela 7). 
Tabela 7. Frequência das condutas adotadas após o aparecimento de RAll de quimioterápicos nos estudos revisados

\begin{tabular}{ccc}
\hline CONDUTAS & \multicolumn{2}{c}{ ESTUDOS REVISADOS } \\
(N) & (\%) \\
\hline Interrupção imediata da infusão & 12 & 92,3 \\
Medicamentos sintomáticos & 10 & 76,9 \\
Oxigenoterapia & 5 & 38,5 \\
Suspensão da quimioterapia & 5 & 38,5 \\
Reintrodução da quimioterapia & 5 & 38,5 \\
Fluidos intravenosos & 4 & 30,8 \\
Hospitalização & 3 & 23,1 \\
Teste cutâneo & 3 & 23,1 \\
Dessensibilização & 3 & 23,1 \\
\hline
\end{tabular}

\section{DISCUSSÃO}

A incidência de RAll de quimioterápicos variou entre os diferentes países dos estudos revisados. A heterogeneidade dessa incidência pode estar relacionada a diferentes características das populações estudadas, classe de antineoplásico, uso de pré-medicação, histórico de alergias e, dessa forma, não reflete a realidade dessas regiões. Alguns estudos fornecem a incidência de RAll por número de infusão e, outros, por número de pacientes, havendo uma falta de padronização e dificuldade para obtenção e interpretação desse dado. No presente trabalho, a incidência foi estimada pelo número de pacientes.

Os estudos de Parel e cols. (2014) e Sun e Li (2019) apresentaram a incidência mais alta (8,9\%) dentre os demais estudos. Ambos analisaram as RAll de agentes de platina, sendo a oxaliplatina analisada no de Parel e cols. (2014) e a carboplatina no de Sun e Li (2019). Apesar de ser a incidência mais alta, dentre os estudos revisados, ainda é uma incidência baixa quando comparada a outros estudos de agentes dessa mesma classe, como os de Okayama e cols. (2015) e Shao e cols. (2010) que apresentaram incidência de 17,2\% e 12,7\%, respectivamente, para oxaliplatina. Geralmente, a 
incidência de qualquer grau de reação a composto de platina é relatada como sendo de 12 a $25 \%$ (SIU; CHAN; AU, 2006; KIM et al., 2009; POLYZOS et al., 2009).

Quanto aos dados sociodemográficos, foi observada uma maior prevalência para o sexo feminino (65,3\%), o que é semelhante aos estudos de Aghamohammadie e cols. (2019) (60\%) e Koliyakodu e cols. (2021) (61,6\%). O risco aumentado relacionado ao gênero pode ser devido a diferenças em fatores farmacocinéticos, imunológicos e hormonais (ROUT et al., 2017). As mulheres geralmente têm massa corporal inferior, redução da depuração hepática e metabolização de drogas em taxas diferentes em comparação com os homens (BRESSLER; BAHL, 2003). Elas também apresentam maior probabilidade de desenvolver alergias a medicamentos (WAHEED; HILL; DHAWAN, 2016). Dentre os estudos, apenas o de Sun e Li (2019) não especificou o sexo dos pacientes envolvidos, enquanto para o de DeMoor et al. (2011), não foi possível quantificar, já que sociodemograficamente, englobava dados de pacientes com RAll de antineoplásicos e outras classes de medicamentos.

A média da idade dos pacientes com RAll mostrou uma variação entre 54,6 e 65 anos nos estudos revisados. A incidência de reações adversas aumenta com o aumento da idade, o que pode estar relacionado à diminuição da capacidade de metabolização e funções excretórias, levando ao acúmulo da droga no corpo e aumentando o risco de reações adversas e à imunossenescência, associada ao enfraquecimento do sistema imunológico (ROUT et al., 2017; ALVES; BUENO, 2019). Além disso, o câncer é mais comum à medida que envelhecemos, devido a mutações genéticas e a sua lenta progressão em alguns casos (AGHAMOHAMMADI et al., 2019).

Essa média da idade, entre os estudos revisados, foi menor e praticamente igual para os dois estudos brasileiros encontrados, Freitas e cols. (2020) e Barbosa-Lima e cols. (2020), apresentando 54,6 e 54,8 anos, respectivamente e, em contrapartida, foi maior no estudo japonês de Tamyia e cols. (2011), com 65 anos. Esses dados podem estar relacionados ao Índice de Desenvolvimento Humano (IDH) dos países, visto que o IDH do Japão é superior ao dos outros países dos estudos e o IDH do Brasil é o menor, com exceção da China (RELATÓRIO DE DESENVOLVIMENTO HUMANO, 2020).

A correlação entre a presença de comorbidades e o consumo de agentes agravantes (álcool e tabaco) e a incidência de RAll foi analisada em alguns estudos. As comorbidades mais relatadas foram HAS, DM e cardiopatias, sendo HAS a mais comum. As doenças cardiovasculares fazem parte dos fatores de risco para o desenvolvimento de reações de hipersensibilidade imunomediadas, tipo de reação com maior predominância nos estudos revisados (SIMONS et al., 2011). Pacientes que utilizavam álcool 
e/ou eram tabagistas mostraram uma incidência aumentada de RAll, o que pode estar relacionado à característica cancerígena dessas substâncias, que contribuem para o desenvolvimento de diversos tipos de câncer (INCA 2021 a/b).

Alergias prévias apresentaram-se como fator de risco para o aumento da incidência e/ou gravidade das RAll de quimioterápicos em alguns dos estudos revisados. A literatura mostra que pacientes com histórico de alergias têm maiores chances de desenvolver reações a medicamentos (GOMES; DEMOLY, 2005).

As reações adversas mais relatadas, nos estudos, foram relacionadas ao sistema respiratório, cardiovascular e pele e incluíram: dispneia ou falta de ar; dor, aperto e pressão no peito; hipotensão; rubor; prurido; eritema e urticária. Estando de acordo com a literatura, pois embora as reações adversas decorrentes de antineoplásicos possam afetar qualquer sistema orgânico do corpo, os sinais e sintomas mais comuns são rubor, prurido, urticária, alterações de pressão arterial e frequência cardíaca, dispneia, tontura, náusea, vômitos, broncoespasmo, angioedema e choque anafilático (SILVA et al., 2015; ROSELLÓ et al., 2017 e CASTELLS et al., 2008).

Essas reações são imprevisíveis e se enquadram no tipo reação de hipersensibilidade imediata, que ocorre em até 1 hora de infusão, podendo ser mediada por IgE (reações alérgicas) ou não imunomediadas (ROSELLÓ et al., 2017). Cerca de 15\% de todas as RAM são do tipo reação de hipersensibilidade e a maioria dos agentes antineoplásicos é passível de causar esse tipo de reação, apresentando um risco ainda maior quando a administração é feita por via parenteral (VOGEL, 2010, ZETKA, 2012; DEMOLY et al., 2014).

A severidade das reações adversas, na maioria dos estudos, foi classificada de acordo com os Critérios Comuns de Terminologia para Eventos Adversos, variando do grau 1, com sintomas leves como prurido e urticária, ao grau 5, maior grau de severidade, incluindo o óbito (ANVISA, 2011; NCI, 2017). Os graus 1 e 2 apresentaram uma maior prevalência nos estudos revisados, com a soma variando entre 42,5\% e 90\%. Roselló e cols (2017) corroboram esse resultado ao afirmar que a maioria das reações à infusão de antineoplásicos apresenta grau leve, enquanto que, as severas, são menos frequentes. $E$, estudos como o de Lenz (2007) e Bertolazzi e cols. (2015), relataram reações leves a moderadas em mais de $90 \%$ dos casos de RAll.

As drogas relacionadas à maior incidência de RAll, presentes nos estudos revisados que avaliaram diferentes medicamentos, foram das classes dos taxanos (paclitaxel e docetaxel); agentes de platinas 
(carboplatina, cisplatina e oxaliplatina) e anticorpos monoclonais (rituximabe, cetuximabe). Foram encontrados estudos que avaliaram RAll para apenas um tipo de droga, incluindo rituximabe, cetuximabe, oxaliplatina e carboplatina. De acordo com Zetka (2012), todas as terapias anticancerígenas, sejam elas quimioterápicos, anticorpos monoclonais ou novos agentes, têm potencial de causar reação relacionada à infusão. Dessa forma, pacientes que recebem ciclos repetidos desses quimioterápicos são propensos a desenvolver reações à infusão, sendo os sais de platina, os taxanos, as asparaginases e os anticorpos monoclonais, os principais (DEMOLY et al, 2014; CASTELLS; MATULONIS, 2015; ROSELLÓ et al., 2017).

A exposição aos compostos de platina leva ao desenvolvimento de reações de hipersensibilidade imunomediadas e a chance de desenvolver a hipersensibilidade aumenta com o número de exposição ao agente, incluindo um período de sensibilização. A incidência de uma RHS para carboplatina é de cerca de $12 \%$; oxaliplatina causa RHS variando entre $0,5 \%$ e $25 \%$ e cisplatina, apresenta menor incidência, de 1\% a 5\% (ROSELLÓ et al., 2017; ROGERS et al., 2019).

As reações aos taxanos não são mediadas por IgE e ocorrem, provavelmente, devido a uma liberação direta de mediadores de mastócitos. As RHS para o paclitaxel ocorrem em até $30 \%$ dos pacientes, entretanto, esse número baixa para $4 \%$ com o uso de pré-medicação. Assim, todos os pacientes devem ser tratados com corticosteroides e anti-histamínicos antes da administração de taxanos (CASTELLS et al., 2012; ROSELLÓ et al., 2017).

Os anticorpos monoclonais têm um potencial para causar reações não alérgicas, resultantes da liberação de citocinas logo após a infusão e ocorrem, geralmente, na primeira dose. A incidência da reação varia de $77 \%$ com rituximabe a $15 \%$ com cetuximabe e diminui com cada curso subsequente de terapia (ROSELLÓ et al., 2017; BARBER, 2019).

Os 5 estudos que relataram o uso de pré-medicação, incluindo corticosteroides, antieméticos e antihistamínicos, tiveram resultados favoráveis, com uma diminuição na incidência e/ou gravidade de RAll nos pacientes pré-tratados, quando comparado com pacientes não tratados. Entretanto, nos estudos de Ferrari e cols (2014) e Hopps e cols (2012), a incidência de RAll foi semelhante nos pacientes com e sem pré-medicação. De acordo com Castells e cols. (2012), o uso de anti-histamínicos e corticosteroides, como pré-medicação, reduz a taxa de reações e sua gravidade, mas não impede o reaparecimento de uma reação de hipersensibilidade em casos de reexposição à droga. 
Os tipos de câncer mais descritos nos estudos foram os de pulmão, mama, colorretal, ovário, gástrico e linfomas e estão relacionados aos tipos de câncer mais incidentes tanto em países desenvolvidos, quanto em desenvolvimento, visto que há estudos revisados de ambos. Nos países desenvolvidos, o câncer se relaciona ao processo de urbanização e desenvolvimento, prevalecendo o de pulmão, próstata, mama feminina, cólon e reto. Enquanto que, nos países em desenvolvimento, ainda é alta a taxa de câncer associado a infecções, como de colo de útero, estômago, esôfago e fígado (FERLAY et al, 2014). Entretanto, os principais tipos de câncer, nos países em desenvolvimento, estão passando por transição, com o aumento da incidência de câncer relacionado ao processo de urbanização e melhor desenvolvimento socioeconômico (BRAY et al., 2018).

A interrupção imediata da infusão da quimioterapia após o aparecimento da RAll e a utilização de medicamentos sintomáticos como anti-histamínicos $\mathrm{H} 1$ e $\mathrm{H} 2$ e corticosteroides foram as primeiras condutas relatadas na maioria dos estudos. A oxigenoterapia e administração de fluidos intravenosos também foram práticas citadas em alguns estudos. Bonassa e Santana (2005) corroboram essas condutas ao esclarecerem que, uma vez identificados os sinais ou sintomas de uma reação, a quimioterapia deverá ser imediatamente interrompida e o acesso venoso mantido com soroterapia. Assim como, para tratamento das reações leves, há um consenso para a administração de antihistamínicos $\mathrm{H} 1$ e $\mathrm{H} 2$ combinados e uso de corticosteroides de acordo com a prescrição médica e protocolos existentes na instituição (SILVA et al., 2015; ROSELLÓ et al., 2017).

A suspensão dos ciclos e hospitalização foram condutas para os casos mais graves, geralmente, reações de grau 3 e 4 . E, a retomada da infusão deu-se principalmente em casos que apresentaram apenas reações de grau 1 e 2. De acordo com Bonassa e Santana (2005), quando as reações são controladas rapidamente, não contra-indicam a readministração da droga após a remissão completa do quadro. O retorno imediato ao tratamento, especialmente no mesmo dia e com a mesma medicação, é importante principalmente para centros de tratamento ambulatorial e seus pacientes (OLSON et al.,1998). Reações à infusão de alto grau (a partir de 3) podem ser prolongadas e não responder rapidamente aos medicamentos sintomáticos, exigindo interrupção, modificação ou descontinuação imediata do tratamento, resultando em eventos hospitalares para cuidados de suporte ao paciente (VIALE, 2009).

A realização de testes cutâneos de hipersensibilidade imediata para estratificação de risco e dessensibilização ao antineoplásico foram condutas conseguintes descritas em certos estudos. Os testes cutâneos permitem determinar o risco de reações de hipersensibilidade e indicar protocolos de 
dessensibilização (OTANI et al., 2017). Enquanto a dessensibilização é uma alternativa para evitar reações de hipersensibilidade, através do uso de pré-medicações e doses mais baixas do quimioterápico, estimulando a tolerância do organismo até a dose terapêutica necessária (BABAIE et al., 2019).

\section{CONCLUSÃO}

A análise da incidência de reações adversas imediatas à infusão de quimioterápicos foi limitada, visto que ela só foi estimada em alguns dos estudos revisados, devido à insuficiência de dados e à falta de padronização para determiná-la. Entretanto, ainda é possível afirmar que a incidência global de RAll de quimioterápicos é heterogênea, sendo mais próxima em estudos relacionados a uma mesma classe de antineoplásico. Fatores sociodemográficos, clínicos e farmacológicos influenciam na incidência de RAll, que é maior em mulheres e pessoas com idade mais avançada. A presença de comorbidades e alergias prévias e o uso de agentes agravantes também podem estar relacionados a uma maior incidência de RAll. No tratamento do câncer, as reações adversas podem se desenvolver com a infusão de quase todos os tipos de agentes antineoplásicos e os taxanos, agentes de platina e anticorpos monoclonais são as classes mais relacionadas. O uso de pré-medicação, com corticosteroides e antihistamínicos, antes da infusão dessas drogas está associado a uma menor incidência de RAll. As reações adversas mais presentes, nos estudos, foram as reações de hipersensibilidade e estavam relacionadas principalmente ao sistema respiratório, cardiovascular e pele. Essas reações, em sua maioria, apresentaram-se de leves a moderadas, sendo possível continuar o tratamento, com o mesmo antineoplásico, após a estabilização do quadro do paciente. Existem poucos estudos de incidência, avaliação ou notificação de RAll, principalmente em ambiente ambulatorial, dificultando a adoção de medidas preventivas e manejo, que garantem a segurança e melhor qualidade de vida do paciente. 


\section{REFERÊNCIAS}

AGHAMOHAMMADIE, H. SHRESTHA, S.; KAVOUSI, A.; MILTON, B. Assessment of Prescribing Pattern of Chemotherapy Drugs and Monitoring Of Adverse Drug Reaction in Cancer Patients. International Journal of Pharmaceutical Science Invention, v.8, n.1, p. 42-51, 2019.

ALMEIDA, V. L.; LEITÃO, A.; REINA, L. C.; MONTANARI, C. A.; DONNICI, C. L.; LOPES, M. T. Câncer e agentes antineoplásicos ciclo-celular específicos e ciclo-celular não específicos que interagem com o DNA: uma introdução. Química Nova, v. 28, n. 1, p. 118-129, 2005.

ALVES, A. S. e BUENO, V. Imunosenescência: participação de linfócitos $T$ e células mieloides supressoras nas alterações da resposta imune relacionadas ao envelhecimento. Einstein Journal, v.17, n. 2. 2019.

ANDRADE, M. Administração de quimioterápicos: uma proposta de protocolo de enfermagem. Revista Brasileira de Enfermagem, v. 60, n. 3, p. 331- 335, 2007.

ANVISA. Agência Nacional de Vigilância Sanitária. Sociedade Brasileira de Farmacêuticos em Oncologia. Guia para Notificações de Reações Adversas em Oncologia. 2. ed. São Paulo, 2011.

BABAIE, D.; SHAMSIAN, B. S.; MOMTAZMANESH, N.; GODARZIPOUR, H.; AMIMONI, M.; BASHARDOUST, B. et al. Rapid Desensitization for Hypersensitivity Reactions to Chemotherapeutic Drugs. A Case Series. Iran Journal Pharmaceutical Research, v.18, n. 3, p. 1047-1051. 2019.

BARBER, F. D. Adverse Events of Oncologic Immunotherapy and Their Management. Asia-Pacific Journal Oncology Nursing, v. 6, n. 3, p. 212-226, 2019.

BARBOSA-LIMA, R.; KAMEO, S. Y.; VASSILIEVITCH, A. C.; FONSECA, T. V.; SILVA, G. M.; SAWADA, N. O. Perfil clínico de pacientes oncológicos e reações de hipersensibilidade aos agentes antineoplásicos sistêmicos. Revista Enfermagem Contemporânea, v. 9, n. 2, p. 185-191, 2020.

BANERJI, A.; LAX, T.; GUYER, A.; HURWITZ, S.; CAMARGO, C. A.; LONG, A. A. Management of hypersensitivity reactions to carboplatin and paclitaxel in an outpatient oncology infusion center: a 5year review. The Journal of Allergy and Clinical Immunology: In Practice, v. 2, n. 4, p. 428-433, 2014.

BERTOLAZZI, L. G.; LANZA, M. V.; BITENCOURT, E. C.; CANILLE, R. M.; PEREIRA, L. P.; OLIVEIRA, K. A. et al. Incidência e caracterização de reações adversas imediatas à infusão de quimioterápicos em hospital sentinela. Archives of Health Sciences, v. 22, n. 3. 2015.

BONASSA, E. M.; SANTANA, T. B. Enfermagem em Terapêutica Oncológica. 3. ed. Atheneu. São Paulo, 2005.

BONASSA, E. M.; GATO, M. I. Terapêutica oncológica para enfermeiros e farmacêuticos. 4. ed. Atheneu. São Paulo, 2012.

BRANDÃO, H.; DAVID, J. P.; COUTO, R. D. NASCIMENTO, J. A. P; DAVID, J. M. Química e farmacologia de quimioterápicos antineoplásicos derivados de plantas. Química Nova, v. 33, n. 6, p. 1359-1369, 2010. BRASIL. Ministério da Saúde. ABC do Câncer - Abordagens Básicas para o Controle do Câncer. 3. ed. Rio de Janeiro, 2017. 
BRASIL. Ministério da Saúde. Manual de Bases Técnicas em Oncologia. Sistema de Informação Ambulatorial do SUS - SIA/SUS. 25. ed. Brasília, 2019.

BRAY F.; FERLAY, J.; SOERJOMATARAM, I.; SIEGEL, R.L.; TORRE, L. A.; JEMAL, A. Global cancer statistics 2018: GLOBOCAN estimates of incidence and mortality worldwide for 36 cancers in 185 countries. CA: A Cancer Journal for Clinicians, v. 68, n. 6, p. 394-424, 2018.

BRESSLER, R e BAHL, J. J. Principles of drug therapy for the elderly patient: In Mayo clinic proceedings. Elsevier, v.78, n.12, p.1564-1577. 2003.

CASTEllS, M. C.; TENNANT, N. M.; SLOANE, D. E.; HSU, F. I., BARRETT, N. A., HONG, D. I. Hypersensitivity reactions to chemotherapy: outcomes and safety of rapid desensitization in 413 cases. Journal of Allergy and Clinical Immunology, v. 122, p. 574-580, 2008.

CASTELLS, M.; DEL CARMEN SANCHO-SERRA, M.; SIMARRO, M. Hypersensitivity to antineoplastic agents: mechanisms and treatment with rapid desensitization. Cancer Immunology, Immunotherapy, v. 61, n. 9, p. 1575-1584, 2012.

CASTELLS, M.; MATULONIS. Infusion reactions to systemic chemotherapy. Waltham, 2015.

DEMOLY, P.; ADKINSON, N. F.; BROCKOW, K.; CASTELLS, M.; CHIRIAC, A. M. GREENBERGER, P. A.; et al. International Consensus on drug allergy. Allergy. v. 69, n. 4, p. 420-437, 2014. DEMOOR, P. A.; MATUSOV, Y.; KELLY, C.; KOLAN, S.; BARNACHEA, L.; BAZHENOVA, L. A. A retrospective review of the frequency and nature of acute hypersensitivity reactions at a medium-sized infusion center: comparison to reported values and inconsistencies found in literature. Journal of Cancer, v. 2, p. 153, 2011.

FERLAY, J. SOERJOMATARAM, I.; DIKSHIT R.; ESER S.; MATHERS, C.; REBELO, M. et al. Cancer incidence and mortality worldwide: sources, methods and major patterns in GLOBOCAN 2012. International Journal of Cancer, v. 136, n. 5, p. 359-386, 2015.

FERRARI, L. A.; FANETTI, G.; ROSSI, F. G.; BRAMBILLA, M. C.; RE, B.; BUZZONI, R. Are antineoplastic drug acute hypersensitive reactions a submerged or an emergent problem? Experience of the Medical Day Hospital of the Fondazione IRCCS Istituto Nazionale Tumori. Tumori Journal, v. 100, n. 1, p. 9-14, 2014.

FREITAS, M. S. H. S. Evidências clínicas de reações de hipersensibilidade em pacientes com câncer submetidos à quimioterapia antineoplásica: contribuições para a prática de enfermagem. 2020. 136 p. Dissertação (Mestrado em Ciências do Cuidado em Saúde). Universidade Federal Fluminense. Rio de Janeiro, 2020.

GIAVINA-BIANCHI, P.; PATIL, S. U.; BANERJI, A. Immediate Hypersensitivity Reaction to Chemotherapeutic Agents. The Journal of Allergy and Clinical Immunollogy: In Practice, v. 5, n. 3, p. 593-599, 2017.

GOMES, E. R.; DEMOLY, P. Epidemiology of hypersensitivity drug reactions. Current Opinion in Allergy Clinical Immunology, v.5, n.4, p. 309-16, 2005.

HOPPS, S.; MEDINA, P.; PANT, S, WEBB, R.; MOORMAN, M.; BORDERS, E. Cetuximab hypersensitivity infusion reactions: Incidence and risk factors. Journal of Oncology Pharmacy Practice, v. 19, n. 3, p. 222-227, 2013. 
INCA. Instituto Nacional do Câncer. Bases do Tratamento do Câncer. 3ạ ed. Rio de Janeiro. 2013. Disponível em: http://bvsms.saude.gov.br/bvs/publicacoes/inca/acoes_cap6.pdf. Acesso em: 15 set. 2021.

INCA. Instituto Nacional do Câncer. ABC do câncer: abordagens básicas para o controle do câncer. 2020. Disponível em: https://www.inca.gov.br/publicacoes/ livros/abc-do-cancer-abordagensbasicas-para-o-controle-do-cancer. Acesso: 30 set. 2021.

INCA. Tabagismo. 2021a. Disponível em: https://www.inca.gov.br/tabagismo. Acesso em: 30 out. 2021.

INCA. Bebidas alcoólicas. 2021b. Disponível em: https://www.inca.gov.br/causas-eprevencao/prevencao-e-fatores-de risco/bebidas-alcoolicas. Acesso em: 30 out. 2021.

KEATING, K. WALKO, C.; STEPHESON, B.; O'NEIL, B. H.; WEISS, J. Incidence of cetuximab-related infusion reactions in oncology patients treated at the University of North Carolina Cancer Hospital. Journal of Oncology Pharmacy Practice, v. 20, n. 6, p. 409-416, 2014.

KIM, B. H.; BRADLEY, T.; TAI, J.; BUDMAN, D. R. Hypersensitivity to oxaliplatin: an investigation of incidence and risk factors, and literature review. Oncology, v. 76, n. 4, p. 231-238, 2009.

KOLIYAKODU, P. S. A Prospective Observational Study on Evaluation of Chemotherapy Induced Adverse Drug Reactions in Cancer Patients in a Tertiary Care Hospital. Indian Journal of Pharmacy Practice, v. 14, n. 1. 2021.

LENZ, H. J. Management and preparedness for infusion and hypersensitivity reactions. The Oncologist, v.12, p. 601-609. 2007.

LEVIN, A. S.; OTANI, I. M.; LAX, T.; HOCHBERG, E.; BANERJI, A. Reactions to rituximab in an outpatient infusion center: a 5-year review. The Journal of Allergy and Clinical Immunology: In Practice, v. 5, n. 1, p. 107-113, 2017.

MUALLAOGLU, S.; DISEL, U.; MERTSOYLU, H.; BESEN, A.; KARADENIZ, C.; SUMBUL, A. T. et al. Acute infusion reactions to chemotherapeutic drugs: a single institute experience. J BUON, v. 18, n. 1, p. 261267, 2013.

$\mathrm{NCl}$. National Institute Cancer. Commom Terminology Criteria for Adverse Events (CTCAE) version 5.0. 2017. Disponível em: http://ctep.cancer.gov/ protocoldevelopment/electronic. Acesso: 20 out. 2021.

OKAYAMA, T.; ISHIKAWA, T.; SUGATANI, K.; YOSHIDA, N.; KOKURA, S.; TSUKAMOTO, S. et al. Hypersensitivity reactions to oxaliplatin: identifying the risk factors and judging the efficacy of a desensitization protocol. Clinical therapeutics, v. 37, n. 6, p. 1259-1269, 2015.

OMS. Organização Mundial de Saúde. Folha Informativa - Câncer. 2020. Disponível em: https://www.paho.org/pt/topicos/cancer. Acesso em: 3 de out. 2021.

OLSON, J. K., SOOSKY, J. I.; ANDERSON, B.; BULLER, R. E. Taxol hypersensitivity: rapid retreatment is safe and cost effective. Gynecol Oncology, v.68, p. 25-28. 1998. 
OTANI, I. M.; WONG, J.; BANERJI, A. Platinum Chemotherapy Hypersensitivity: Prevalence and Management. Immunology Allergy Clinical North American, v. 37, n. 4, p. 663-677. 2017.

PAREL, M.; RANCHON F.; NOSBAUM A.; YOU B.; VANTARD N.; SCHWIERTZ V. et al. Hypersensitivity to oxaliplatin: clinical features and risk factors. BMC Pharmacology and Toxicology, v. 15, n. 1, p. 1-6, 2014.

POLYZOS, A.; TSAVARIS, N.; GOGAS, H.; SOUGLAKOS, J.; VAMBAKAS, L.; VARDAKAS, N. et al. Clinical features of hypersensitivity reactions to oxaliplatin: a 10-year experience. Oncology, v. 76, n. 1, p. 3641, 2009.

RELATORIO DE DESEMVOLVIENTO HUMANO 2020. A próxima fronteira: O desenvolvimento humano e o Antropoceno. 2020. Disponível em:

http://hdr. undp.org/sites/default/files/hdr_2020_overview_portuguese.pdf. Acesso em: 8 set. 2021.

RIUL, S.; AGUILLAR, O. M. Quimioterapia Antineoplásica: Revisão da Literatura. REME Rev. Min. Enferm, v. 3, n. 1/2, p. $60-7,1999$.

ROSELLÓ, S.; BLASCO, I.; GARCIA FABREGAT, L.; CERVANTES, A. JORDAN, K. Management of infusion reactions to systemic anticancer therapy: ESMO Clinical Practice Guidelines. Annals of Oncology, v.28. 2017.

ROUT, A.; PANDA, R. K.; MISHYRA, P.; PARIDA, P.; MOHANTY, S. Pharmacovigilance in cancer chemotherapy in regional cancer center of Eastern

India: Prospective observational study. International Journal of Basic and Clinical Pharmacology, v.6, n.8, p.1910- 1916. 2017.

SCHEIM, C. F. Efeitos colaterais da quimioterapia em pacientes oncológicos hospitalizados. Disc. Scientia, v. 7, n. 1, p. 101-107, 2006.

SHAO, Y. Y.; HU, F. C.; LIANG, J. T.; CHIU, W. T.; CHENG, A. L.; YANG, C. H. Characteristics and risk factors of oxaliplatin-related hypersensitivity reactions. Journal of the Formosan Medical Association, v. 109, n. 5, p. 362-368, 2010.

SILVA, F. C. M.; COMARELLA, L. Efeitos adversos associados à quimioterapia antineoplásica: levantamento realizado com pacientes de um hospital do estado do Paraná. Revista Uniandrade, v. 14, n. 3, p. 263-277, 2013.

SILVA, P.; HECK, A. P.; SILVA, B. T.; AZAMBUJA, A. A. O manejo das reações agudas em quimioterapia. Acta méd, v. 36, n. 6. Porto Alegre, 2015.

SIMONS, F. E.; ARDUSSO, L. R.; BILÓ, M. B.; EL-GAMAL, Y. M.; LEDFORD, D. K.; RIG, J. et al. World allergy organization guidelines for the assessment and management of anaphylaxis. World Allergy Organization Journal, v. 4, n. 2, p. 13-37, 2011.

SIU, S. W. K.; CHAN, R. T. T.; AU, G. K. H. Hypersensitivity reactions to oxaliplatin: experience in a single institute. Annals of oncology, v. 17, n. 2, p. 259-261, 2006. 
SUN, T.; LI, L. A cohort study of hypersensitivity reaction in patients with epithelial ovarian cancer treated with carboplatin. International Journal of Gynecologic Cancer, v. 29, n. 3, 2019.

TAMIYA, M.; KUHARA, H.; HIRASHIMA, T.; KONDO, Y.; SANTO, M. MORISHITA, N. et al. Hypersensitivity reactions associated with platinum-containing antineoplastic agents for thoracic malignancies. Anticancer research, v. 31, n. 12, p. 4525-4528, 2011.

WAHEED, A.; HILL, T.; DHAWAN, N. Drug Allergy. Prim Care, v. 43, n. 3, pág. 393-400, 2016.

WHO. World Health Organization. Cancer: Diagnosis and treatment. 2018. Disponível em: http://www.who.int/cancer/treatment/en/. Acesso em: 15 set. 2021.

WONG, J. T. LING, M.; PATIL, S.; BARNEJI, A. LONG, A. Oxaliplatin hypersensitivity: evaluation, implications of skin testing, and desensitization. The Journal of Allergy and Clinical Immunology: In Practice, v. 2, n. 1, p. 40-45, 2014.

VIALE, P. H. Management of hypersensitivity reactions: a nursing perspective. Oncology, 2009.

VOGEL, W. H. Infusion reactions: Diagnosis, assessment and management. Clinical Journal of Oncology Nursing, v.14, n.2, p. 10-21. 2010. ZETKA, E. S. The essentials of chemotherapy-induced infusion reactions. Clinical Journal of Oncology Nursing, v. 16, n.5, p.527-529. 2012. 


\title{
Capítulo 4
}

doi) $10.37423 / 211205087$

\begin{abstract}
A CONFIGURAÇÃO JURÍDICO-CONSTITUCIONAL DOS SERVIÇOS PÚBLICOS DE SAÚDE NO COMBATE ÀS INIQUIDADES SOCIAIS: UMA ABORDAGEM À LUZ DA FILOSOFIA DA SAÚDE.
\end{abstract}

Ricardo Bezerra de Oliveira

\section{Layza Bezerra Maciel Pereira}

Rosa Maria Ferreiro Pinto

Flávio Pereira de Oliveira
INSTITUTO FEDERAL DE EDUCAÇÃO,

CIÊNCIA E TECNOLOGIA DO MARANHÃO -

IFMA

UNIVERSIDADE SANTA CECIILIA UNISANTA

UNIVERSIDADE SANTA CECIILIA UNISANTA

UNIVERSIDADE FEDERAL DE PELOTAS UFPel 
Resumo: A Filosofia da Saúde é o ramo do saber que nos ajuda a problematizar acerca dos principais conflitos e desafios que o Sistema Público e Privado de Saúde perpassa, seja no seu acesso, investimento ou formatação, através de ponderações críticas, profundas e metodológicas que nos ajudam a mergulhar num mar de contradições, de violações e avanços que esse sistema de garantia de direitos poderá encontrar e ofertar a seus usuários. Como conhecer e pensar a Saúde num mundo que prioriza - cada vez mais - a lucratividade em detrimento dos direitos individuais e coletivos dos usuários desses serviços? Que ideologias dominantes e opressoras impregnam os sistemas de saúde? O Filósofo da Saúde é levado a encarar o Direito à Saúde não apenas em seu viés técnico, reducionista, frio e raso, mas a adentrar no tempo, espaço, realidade e poder das reflexões críticas, de uma visão holística e totalitária do Direito. Sob a abordagem metodológica do materialismo histórico dialético, onde o fator econômico (reserva do possível e limitações orçamentárias) e social da saúde (exercício pleno deste direito) enfrentam-se numa ponderação de valores. Para isso, faremos uma revisão bibliográfica acerca da temática, numa pesquisa do tipo descritivo-explicativa e dialógica dos principais autores deste fenômeno jurídico-social. Uma gestão ética que diminui as despesas, maximiza os resultados e amplia a rede de atendimento para uma saúde plena é um mandamento constitucional de otimização que todos os gestores públicos devem incluir nas suas agendas de poder para promover a cidadania, democracia sanitária, prevenção e o restabelecimento da saúde.

Palavras-chave: Direito. Saúde. Gestão. Iniquidades Sociais. Filosofia. 


\section{INTRODUÇÃO}

A Filosofia da Saúde é o ramo do saber que nos ajuda a problematizar acerca dos principais conflitos e desafios que o Sistema Público e Privado de Saúde perpassa seja no seu acesso, investimento ou formatação, através de ponderações críticas, profundas e metodológicas que nos ajudam a mergulhar num mar de contradições, de violações e avanços que esse sistema de garantia de direitos poderá encontrar e ofertar a seus usuários.

Descobrir e questionar as verdades, os saberes, as estatísticas e os paradigmas que permeiam a área médica é uma tarefa árdua, sistemática e complexo por envolver - de forma crítica, humanizada e prática - um movimento sinérgico entre várias áreas do conhecimento - seja o Direito, Medicina ou a Sociologia - que nos levará a um mundo de idéas, sentidos e eixos que tentam explicar as demandas, as iniquidades (MATA e COSTA, 2020), as conquistas e regulamentações que permeiam o mundo da Saúde, na tentativa de se melhorar e promover, cada vez mais, direitos fundamentais relacionados à saúde.

Como conhecer e pensar a Saúde num mundo que prioriza - cada vez mais - a lucratividade em detrimento dos direitos individuais e coletivos dos usuários desses serviços? Que ideologias dominantes e opressoras impregnam os sistemas de saúde? O investimento (progressivo e contínuo) em tecnologia e ciência e novos poderá - através da saúde - reduzir as iniquidades sociais de um país? O Direito da Saúde, de fato, está amparado e leva em consideração - na sua aplicação - questões históricas, culturais, políticas e econômicos? Qual a racionalidade que há na utilização de princípios relacionados à área da saúde (reserva do possível e retrocesso social)? Quais os modelos e paradigmas que perpassam os serviços médicos?

Ao se debruçar sobre todas essas questões, o Filosofo da Saúde é levado a encarar o Direito à Saúde não apenas em seu viés técnico, reducionista, frio e raso, mas a adentrar no tempo, espaço, realidade e poder das reflexões críticas, de uma visão holística e totalitária do Direito (LARA et al., 2021).

Por meio de provocações e questionamentos sobre uma determinada realidade social, a Filosofia da Saúde levanta - por meio de seus operadores - a seguinte questão: Quais os avanços, retrocessos e superações que os sistemas e serviços públicos de saúde perpassam em nossa história constitucional? Que medidas de Justiça na saúde, o Direito e as políticas públicas se propõe a corrigir? 


\section{METODOLOGIA}

O método de abordagem de nossa pesquisa, será o método histórico-dialético onde o fator econômico e de ideologia dominantes e as questões relacionadas às violações e ameaças aos direitos advindos da saúde, que formam o sistema constitucional da garantia de direitos, se enfrentam numa ponderação de valores. Faremos, portanto, uma revisão bibliográfica da temática geradora envolvendo igualdade, promoção de direitos, cidadania e inovação no acesso à saúde para a redução das desigualdades sociais, utilizando-se documentos eletrônicos, estudos doutrinários e portarias, o que caracteriza nossa pesquisa do tipo documental.

Com relação ao método procedimental de coleta de dados que irá subsidiar as informações de nossa pesquisa, iremos recorrer a referenciais teóricos, realizando-se, assim, uma verdadeira revisão bibliográfica em virtude de grandes alterações legislativas e jurisprudenciais que o Direito Constitucional e o Direito da Tecnologia têm passado na conquista democrática dos direitos de igualdade e cidadania sanitária.

Nossa pesquisa é de cunho descritivo-explicativa porque analisamos, observamos, registramos e classificamos os fatos sociais e as políticas de saúde, enquanto conquista tecnológica para a redução das iniquidades sociais. O método procedimental de análise desses dados será o desenho de investigação qualitativa.

\section{RESULTADOS E DISCUSSÕES}

\subsection{FILOSOFIA, DIREITO E SAÚDE: CONFLITOS, LIMITES E DESAFIOS.}

Para se analisar com profundidade, coerência e precisão o panorama jurídico-legal dos serviços públicos de saúde, faz-se necessário, antes de tudo, problematizar, de forma crítica e integral, os problemas, desafios e conquistas do sistema público de saúde brasileiro que atingem milhares de usuários destes serviços, no que tange a sua efetivação enquanto direito (subjetivo, fundamental e humano) e conquista social (que se construiu nos movimentos sociais de base e de luta), na sua garantia de acesso igualitário, sobretudo às populações vulneráveis (idosos, mulheres, negros e portadores de necessidades especiais) ao seu financiamento (custeio, investimento e alocação de recursos em áreas de saúde e tecnologia, por exemplo) e evolução tecnológica (atendimento médico e de consultas via videoconferências, home cares). 
A Filosofia - enquanto ciência que nos fornece substratos para uma meditação crítica do fenômeno social, cultural e político de todos os fatos e tensões que permeiam as relações sociais - nos faz percorrer por um caminho, extenso e infinito, de reflexão (análise aprofundada dos conflitos de interesses), enfrentamento e julgamento das verdades, das teorias e das correntes que abarcam as temáticas, práticas e ações relacionadas a saúde e sus efetivação enquanto direito social indisponível e humano. Investir em Saúde, promover o avanço tecnológico e a democratização de seu acesso, são decisões políticas, são priorizações que o gestor público pode ou não adotar em suas plataformas de governo. Cada ação em saúde, cada elaboração de planos e projetos em saúde, demanda uma escolha, uma priorização, um entendimento e engajamento social sobre cumprir ou não, efetivamente, as determinações constitucionais no que diz respeito a progressiva e eficiente promoção dos direitos sociais.

A não promoção do direito à saúde poderá gerar inúmeras judicializações, como manifestação clara do ativismo judicial (ARAÚJO, LOPES e JUNQUEIRA, 2021).

O Poder Público, em toda nossa história constitucional, conseguiu compreender o âmago jurídicoaxiológico de se concretizar os direitos de segunda dimensão (trabalho, previdência, saúde e meio ambiente)? Sobre reflexão e Direito, ponderamos que:

Hoje, somos capazes de refletir sobre os problemas que envolvem escolhas políticas por meio dos vários instrumentos de articulação dos princípios constitucionais. Com isso, o discurso dogmático incorporou uma série de argumentos políticos, inclusive a própria lógica de ponderação, que sempre organizou o discurso político e que era rejeitada pelo discurso jurídico de aplicação (COSTA, 2017, p. 58).

Nesse sentido, a grande tarefa do filósofo da saúde, que se debruça sobre os problemas e contradições do sistema público de saúde e de seus respectivos serviços oferecidos é, sobretudo, mergulhar nas profundezas do conhecimento técnico-científico do que se entende por Saúde, é renovar o saber e as concepções sobre saúde ( que não mais está adstrita apenas à cura ou ao tratamento de pessoas doentes, mas numa saúde preventiva e integral), meio ambiente (questões epidemiológicas e de responsabilidade civil por danos) e acesso igualitário (judicializações, ações afirmativas e omissões do Poder Público em legislar, agir e investir em melhores serviços de saúde), é ter, em suas mãos, uma poderosa ferramental ideológica de contestação das estruturas, dos sistemas de poder e das relações institucionais que se perfazem no mundo da saúde, de sua promoção e prevenção. Nesse sentido: 
A Organização Mundial de Saúde (OMS) define saúde não apenas como a ausência de doença, mas como a situação de perfeito bem-estar físico, mental e social. Essa definição, até avançada para a época em que foi realizada, é, no momento, irreal, ultrapassada e unilateral (SEGRE, 1997, p.539).

Desta forma pergunta-se: os brasileiros, em todas as regiões do país, têm tido atendimento personalizado e de qualidade, como determina o texto constitucional e a política nacional de saúde? Existe, de fato, atendimento médico e ambulatorial para quem dele precisar? A temática de concessão de medicamentos gratuitos tem sido pauta de reivindicação pelos movimentos populares? Para André Martins (2004):

A relação entre Filosofia e Saúde está no interior da própria filosofia. Em toda a história da filosofia, esta foi vista como medicina da alma. A medicina cuidaria do corpo, enquanto a filosofia cuidaria da alma; algo como hoje se concebe usualmente a relação entre medicina e psicanálise (MARTINS, 2004, p. 950).

A Filosofia da Saúde, também, nos leva a compreender e questionar os protocolos éticos e médicos vigentes no Brasil e no mundo, a atualização e eficácia dos procedimentos cirúrgicos em face dos movimentos tecnológicos mundiais, sua precificação pelo setor privado e os conflitos advindos dos convênios, ações e serviços médicos, assim como a responsabilidade civil dos profissionais da saúde e suas respectivas excludentes pelos atos e omissões praticadas aos pacientes.

Independentemente da delimitação que se forneça ao campo de estudo da bioética, é mister que esta seja reconhecida, por um lado, como disciplina afim à filosofia possuindo, assim, uma metodologia própria, consistente em utilizar uma série de "ferramentas" conceituais, como o rigor terminológico em relação aos termos e princípios empregados, a textura lógica do discurso e a sua força argumentativa herança da tradição analítica; e, por outro lado, como uma possível reconfiguração multi e interdisciplinar de temas e problemas que implicariam a cooperação de disciplinas não estritamente filosóficas. (SIQUEIRA-BATISTA e SCHRAMM, 2004, p.1).

Existe um caminho metodológico para se pesquisar acerca dos limites e desafios da Bioética e dos direitos relacionados à vida, a sua proteção e preservação que o filosofo da saúde precisará percorrer a fim de questionar as estruturas sociais e as finalidades e funções dos serviços médicos. Os protocolos médicos, os discursos e a história de vida do paciente são instrumentais férteis que devem ser levados em consideração para que uma análise profunda e sistêmica seja feito pelo intérprete e pelo operador do direito.

Os profissionais da saúde no Brasil tem tido o cuidado de preservar a imagem, a honra e a integridade moral de seus pacientes? O direito à informação médica tem sido um paradigma a ser observado pelos médicos nas intervenções cirúrgicas de risco? Os dilemas éticos, as indenizações por danos morais e materiais em virtude de erros médicos e de danos estéticos tem servido de palco para grandes dilemas 
e intervenções judiciais na área do Direito Médico, sendo mais um conflito e desafio de enfrentamento para a Filosofia da Saúde.

\subsection{A GESTÃO EFICIENTE DOS SERVIÇOS PÚBLICOS DE SAÚdE PARA A REDUÇÃO DAS DESIGUALDADES SOCIAIS}

A eficiência é um princípio constitucional e administrativo que determina que todos os gestores e administradores públicos realizem os serviços públicos, maximizando-se os resultados com o mínimo de dispêndio possível, evitando-se assim despesas desnecessárias, inviáveis e improdutivas para o bom andamento dos serviços públicos em saúde (CARVALHEIRO, 1999).

Um grande problema enfrentando é justamente a falta de otimização e de planejamento dos trabalhos e serviços prestados pelos profissionais da saúde, pelos gestores e conveniados que, muitas vezes, são ofertados com descaso e descomprometimento social. Aliado a isso, encontramos, no panorama brasileiro, um grave problema que são os desvios dos recursos públicos em saúde aliado ao custeio indevido e ilegal de gastos pessoais dos governantes utilizando-se recursos da saúde, afrontando-se diversos princípios como os da probidade, honestidade e ética na administração pública, mitigando vidas em razão da omissão e falta de recursos para compra de leitos, medicamentos, instrumentais cirúrgicos e outros aparelhos essenciais para um bom atendimento médico e ambulatorial.

Nesse sentido, a transparência da gestão dos serviços públicos de saúde, aliado a um forte e moderno aparato tecnológico (sistemas integrados de acesso e controle de dados médico-hospitalares), poderão ser fortes instrumentos de combate às diversas iniquidades sociais na área da saúde. Com relação, ainda, às iniquidades sociais, podemos afirmar que:

No caso do Brasil o fardo é duplo, pois além de apresentar graves iniquidades na distribuição da riqueza há grandes setores de sua população vivendo em condições de pobreza que não lhes permite ter acesso a mínimas condições e bens essenciais à saúde. Para ser coerente com essa nova maneira de entender a pobreza, as estratégias para combatê-la devem incluir tanto a geração oportunidades econômicas como medidas que favoreçam a construção de redes de apoio e o aumento das capacidades desses grupos para melhor conhecer os problemas locais e globais, para estreitar suas relações com outros grupos, para fortalecer sua organização e participação em ações coletivas, para constituir-se enfim em atores sociais e ativos participantes das decisões da vida social ( BUSS e FILHO, 2006, p. 3).

Pedro Lenza (2017) e Flávia Bahia (2017), nos ensinam que as políticas públicas de afirmação também assumem um caráter pedagógico no sentido de que nos ensinam a afastar o sentimento de discriminação que vigorou durante muitos anos no Brasil, minimizando-se as diferenças e disparidades 
econômicas e sociais, entre as pessoas, na busca pela plena igualdade, como medida de dignidade, medidas estas, que se mostram necessárias quando o Poder Público se omite na oferta e na modernização dos procedimentos em saúde.

Ações judiciais têm condenado o Poder Público a custear tratamentos médicos no exterior sob a justificativa de que os Gestores Públicos não têm investido em tecnologia de serviços complexos e avançados em saúde. A Defensoria Pública tem legitimidade para promover os direitos da saúde em suas múltiplas dimensões (LAMY e OLIVEIRA, 2018).

A pandemia da COVID-19 evidenciou, de certa forma, as desigualdades sociais e regionais no acesso a leitos, medicamentos de alta complexidade, vacinas, tratamentos e escancarou os grandes desafios da atenção primária à saúde (PRADO, 2021) diante das políticas de saúde que, muitas vezes, não alcançavam as pessoas em situação de vulnerabilidade social.

\section{CONCLUSÃO}

De fato, a Ciência e a Tecnologia têm o papel de tornar a vida das pessoas mais confortável, com maior qualidade e com menos prejuízos possíveis para a saúde, vida e integridade física - seja através de novas equipamentos, redes e procedimentos - entretanto, as consequências, conflitos e desafios da aplicação da tecnologia na área da saúde e seus dilemas médicos, ambientais e éticos, são objeto de estudo da Filosofia da Saúde, enquanto ciência social, dinâmica e crítica que busca estudar a Saúde de forma integral, humana e ética, contrariando sistemas vigentes, quebrando protocolos e paradigmas a favor da vida e da dignidade da pessoa humana, construindo novas valores e novas caminhos de interpretação num movimento de renovação do conhecimento sobre as ações, serviços e políticas de saúde que tem por objetivo primordial a promoção, prevenção e restabelecimento da saúde, enquanto direito fundamental e humano.

Uma gestão ética que diminui as despesas, maximiza os resultados e amplia a rede de atendimento para uma saúde plena (com a construção de hospitais e centros de alta complexidade, com forte aparato de segurança da informação e com materiais clínicos disponíveis) é um mandamento constitucional de otimização que todos os gestores públicos devem incluir nas suas agendas de poder para promover a cidadania (participação efetiva e ativa da população no combate, controle e punição das corrupções), democracia sanitária (inserção dos usuários nas decisões dos rumos da saúde no Brasil, prevenção e o restabelecimento da saúde para as populações da cidade e do campo (em respeito ao princípio da igualdade no atendimento da saúde). 
Assim, para que a Ciência e Tecnologia na área da saúde, sejam fortificadas e implementadas, faz-se necessário que as mesmas estejam alinhadas a um sistema rígido, estável, simplificado e claro de regras jurídicas que viabilizem uma atuação sustentável, ética e eficiente de todos os pesquisadores para a melhoria dos serviços de saúde, para o progresso da nação e redução das desigualdades sociais e regionais, conforme os preceitos máximos de nossa Carta Magna de 1988. 


\section{REFERÊNCIAS}

ARAÚJO, Cynthia Pereira DE; LÓPES, Éder Maurício Pezzi; JUNQUEIRA, Regina Santos. Judicialização da saúde: saúde pública e outras questões. Editora Dialética, 2021.

BRASIL. Constituição (1988). Constituição da República Federativa do Brasil. Brasília: Senado, 1988.

BAHIA, Flávia. Direito constitucional: descomplicando o direito constitucional. 3. ed. Recife: Armador, 2017.

BUSS, Paulo M.; PELLEGRINI FILHO, Alberto. Iniqüidades em saúde no Brasil, nossa mais grave doença: comentários sobre o documento de referência e os trabalhos da Comissão Nacional sobre Determinantes Sociais da Saúde. Cadernos de Saúde Pública, v. 22, p. 2005-2008, 2006.

CARVALHEIRO, José R. Os desafios para a saúde. Estudos avançados, v. 13, p. 7-20, 1999.

COSTA, Alexandre Araújo. Curso de filosofia do Direito. Disponível em:

<https://www.passeidireto.com/arquivo/4654249/curso-de-filosofia-do-direito-alexandre-araujocosta> . Acesso em 02 de dez. de 2021.

LAMY, Marcelo; DE OLIVEIRA, Flávio Antonio. Legitimidade da Defensoria Pública para promover Ação Civil Pública por improbidade administrativa decorrente da omissão de políticas de saúde. Revista Eletrônica do Curso de Direito da UFSM, v. 13, n. 1, p. 340-369, 2018.

LARA, Mariana et al. Direito à saúde e judicialização no acesso a tratamentos de média e alta complexidade pelo Sistema Único de Saúde (SUS). Research, Society and Development, v. 10, n. 3, p. e16010313091-e16010313091, 2021.

LENZA, Pedro. Direito constitucional esquematizado. 21. ed. São Paulo: Saraiva, 2017.

MARTINS, André. Filosofia e saúde: métodos genealógico e filosófico-conceitual. Cadernos de Saúde Pública, v. 20, p. 950-958, 2004.

MATA, Matheus de Sousa; COSTA, Íris do Céu Clara. Composição do Índice de Iniquidade em Saúde a partir das desigualdades na mortalidade e nas condições socioeconômicas em uma capital brasileira. Ciência \& Saúde Coletiva, v. 25, p. 1629-1640, 2020.

SEGRE, Marco. O conceito de saúde. Disponível em: < http://www.scielo.br/pdf/rsp/v31n5/2334.pdf> . Acesso em 01 de mar. de 2019.

SIQUEIRA-BATISTA, Rodrigo; SCHRAMM, Fermin Roland. A filosofia de Platão e o debate bioético sobre o fim da vida: interseções no campo da Saúde Pública. Cadernos de Saúde Pública, v. 20, p. 855-865, 2004. 


\section{Capítulo 5}

doi $10.37423 / 211205104$

\section{BUSCA DO SENTIDO DE VIDA: A EXPERIÊNCIA DE UMA MÃE DE CRIANÇA COM CÂNCER}


Resumo: Este estudo teve como objetivo conhecer a experiência da mãe que possui um filho com câncer e como ela encontra um sentido para viver. Foi realizada uma pesquisa qualitativa, tendo como método a história oral. Como resultado, a espiritualidade, apareceu como algo importante para mãe dar sentido para a sua vida e transcender a doença inesperada do filho. Este estudo melhorou a nossa própria percepção sobre importância de significarmos as nossas vidas, repensar e significar melhor a enfermagem que pretendemos fazer.

Palavras- chave: Enfermagem Oncológica, Pediatria, Espiritualidade. 


\section{INTRODUÇÃO}

O câncer infantil é uma das doenças crônicas que mais cresce no País. Apesar do desenvolvimento e avanço tecnológico e científico, ainda existem problemas de difícil abordagem como o impacto que esta doença representa sobre o sofrimento da família vivenciando ter uma criança com câncer.

Toda doença grave, como o câncer, confronta a criança que a possui e a sua família com a possibilidade de morte eminente, desencadeando profundas transformações em suas vidas ${ }^{1}$.

É destinada às mães a manutenção da saúde do seu filho doente, assumindo ela mesma a condição de provedora destes cuidados e por estarem empenhadas a esta assistência, canalizam suas energias para aquele filho, às custas do outros papéis, assumindo uma postura de exigência consigo mesma ${ }^{2}$.

Os pais de crianças com câncer sentem um profundo abalo emocional, tratando-se sem dúvida de uma terrível experiência para o ser humano ${ }^{3}$. Se não levarmos em consideração a família do paciente, não poderemos ajudá-lo com eficiência pois seus membros experimentam diferentes estágios de adaptação ${ }^{4}$.

Assim podemos dizer, que o profissional de enfermagem que pretende lidar com as respostas humanas deve estar preparado para assistir os indivíduos e suas famílias não somente no enfrentamento da doença e sofrimento, mas também em sua busca pelo seu significado da experiência por estes vivenciadas 5 .

Diante disso, sendo o câncer uma doença de grande impacto familiar e que leva a um grande sofrimento, temos como objetivos:

- Conhecer a história de vida da mãe com criança com câncer.

- Identificar os fatores que trazem um sentido para sobreviver à situação atual.

- Fortalecer a nossa construção pessoal no desenvolvimento das habilidades.

\section{METODOLOGIA}

Dada a natureza dos objetivos utilizou-se a metodologia qualitativa de pesquisa, tendo como norte teórico a logoterapia de Victor Frankl.

A pesquisa foi realizada em uma Casa de Apoio da cidade de São Paulo que recebem mães e crianças com câncer moradoras de outros estados e que estão na cidade para realização do tratamento. Foi 
realizada a entrevista com uma mãe de criança com câncer que estava passando por esta experiência há um ano e seis meses.

O referencial metodológico escolhido foi a História Oral de Vida, pois esta abordagem permitiu uma melhor compreensão da experiência da mãe em toda a sua complexidade e especificidade. A base da existência da História Oral de Vida foi o depoimento gravado, transformando o relato oral em texto escrito seguindo as etapas de transcrição, textualização e transcriação.

As três fases são:

- Transcrição: é a passagem rigorosa da entrevista da fita para o papel incluindo as perguntas do entrevistador;

- Textualização: etapa no qual as perguntas são adicionadas às respostas, passando a ser todo o texto do domínio exclusivo do colaborador, assumindo, como personagem único, a primeira pessoa. A narrativa recebe uma pequena reorganização para se tornar mais clara. Escolhe-se então o tom vital, que é uma frase a ser colocada na introdução da História de Vida, por representar uma síntese moral da narrativa;

- Transcriação: é a etapa no qual se atua no depoimento de maneira mais ampla, invertendo-se a ordem dos parágrafos, retirando ou acrescentando se palavras e frases. Há a interferência do autor no texto, que será refeito várias vezes devendo obedecer a acertos combinados com o colaborador. ${ }^{6}$

Após a realização dos passos metodológicos, a mesma foi analisada tendo como norte teórico a logoterapia de Victor Frankl.

\section{DISCUSSÃO DOS RESULTADOS}

De acordo com a metodologia da História Oral de Vida da mãe deste estudo, o tom vital emergente foi: "Vou a igreja busco a palavra e aí vem as promessas de Deus e isso me dá força para enfrentar essa doença." Segue abaixo a síntese da História Oral de Vida:

Fátima nasceu na zona rural em Minas Gerais, tem 37 anos, é casada e tem dois filhos. Veio de uma família opressora, onde não teve oportunidades para estudar, pois seu pai não a deixava sair sozinha sem a companhia de seus irmãos: “(...) estudei até a 4ํo série, eu queria estudar em Lagoa dos Patos, e meu pai não deixou (...).". 
Relata que ainda solteira que começou a freqüentar a Igreja Evangélica da Congregação Cristã do Brasil e foi batizada. Com ajuda dos irmãos da igreja teve a oportunidade de ir morar em outra cidade, com o consentimento de sua família.

Através de uma irmã da Igreja conheceu seu marido com quem logo se casou e teve dois filhos, o Matheus que está com 8 anos e Josué com 3 anos. Fez laqueadura por reconhecer que não tem mais paciência para cuidar de criança: “(...) com o Mateus tive paciência, mas com o Josué não, ele sempre foi uma criança chorona (...)". Com o filho mais velho não teve problemas, mas com o Josué sim, pois era uma criança agitada e agressiva e com um comportamento difícil. Relata ter um marido muito bom e um casamento ótimo.

A doença de Josué foi descoberta quando ele tinha um ano e três meses, seu tio percebeu uma mancha branca em um dos olhos e só foi procurar ajuda quando as manchas aumentaram.

Quando soube da doença de Josué, relatou ter ficado muito nervosa e angustiada, com o agravante de morar na zona rural e teria que se deslocar para outros lugares. Foram realizados vários exames até constatar que era um problema sério e que o tratamento seria em São Paulo. Os irmãos da igreja e a vereadora da cidade ajudaram com a passagem.

Ao chegar em São Paulo sentiu-se nervosa: "(...) foi muito difícil enfrentar essa situação, me mandaram para uma cidade que eu nem conhecia (...)". Relatou que sentiu vontade de ir embora ao ver a paisagem de inúmeros prédios e percebeu-se com medo pelas histórias ruins que ouvia sobre São Paulo.

Além da dificuldade de ter que realizar o tratamento do seu filho em uma cidade como São Paulo, ainda havia um grande problema pela frente que era encontrar moradia e adaptar-se. Ficou primeiramente hospedada na casa de uma irmã, e depois foi morar em uma Casa de Apoio no Morumbi. Nesta primeira não se adaptou por causa do comportamento do Josué: "(...) ele não me deixava fazer nada, puxava os cabelos de uma menina pequena e o portão da casa ficava aberto e um dia foi pego lá fora (...)". Sentiu-se constrangida e mudou-se para a Casa de Apoio que reside atualmente. Coloca que ainda hoje tem dificuldade de relacionar-se com as mães que vivem ali e Josué com as crianças: “(...) já relevei muitas coisas, mas não é igual estar em nossa própria casa (...)". Aprendeu a enfrentar melhor a situação acreditando que mudar de casa nem sempre seria a solução e podendo sim encontrar problemas piores. 
Nos dias em que saia cedo para levar Josué ao hospital para realizar o tratamento, sentia-se com medo de andar sozinha devido as histórias de violência que ouvia da cidade. Relata que quando chegava no hospital ficava nervosa ao ver muitas pessoas doentes. No início acreditava que Josué era a única criança que poderia ter esta doença, pois nunca tinha ouvido falar em câncer e quimioterapia, entretanto quando chegou ao hospital percebeu crianças em pior estado: “(...) vi crianças com o mesmo problema que ele, até pior, magrinhas e que não comem nada (...)".

É evangélica desde 1992 e a única pessoa da família que ainda não é batizada é a sua mãe, pois segundo as suas crenças existe a hora de Deus e não a nossa: "(...) quando tem um batismo a convido e ela vai, mas sei que é pelo chamado de Deus, se for uma alma que pertence a Deus, Deus a chama, pois está escrito (...)". Na sua concepção as pessoas são onipotentes, materializadas e só procuram Deus em momentos difíceis: “(...) quem não vai por bem vai pela dor, as vezes está tudo bem com a pessoa e ela não se lembra de Deus somente quando esta em situação difícil (...) ás vezes pensam que somos tudo, mas não somos nada sem Deus, ele é o dono de todas as coisas (...)". Aponta Deus como ser superior: "(...)Deus é dono de todas as coisas se ele quiser acabar com tudo num piscar de olhos ele acaba (...)".

Sempre que vai a igreja, busca a palavra que é revelada por Deus através do ancião, ora e pede a Deus para libertar o seu filho. Afirma acreditar plenamente nesta libertação, pois cumpre a vontade de Deus: “(...) falou através da palavra que se eu for uma filha obediente e fiel, vai fazer uma obra em minha vida vai libertar meu filho, então vejo as mãos de Deus trabalhar em minha vida (...)".

Demonstra reconhecer as fraquezas humanas ao revelar que algumas vezes sente-se fragilizada, abandonada e sem forças devido as dificuldades de se relacionar com as pessoas nas casas de apoio por conta do comportamento de Josué, por estar longe da família e muito preocupada com o filho mais velho e a demora do tratamento. Porém sente que Deus renova sua força através de sua oração: "(...) por maior que sejam as nossas fraquezas e que nos sentimos abandonadas, ele vem na hora certa e nos fortalece (...)".

Apesar de todas as dificuldades não evidencia riscos de angustiar-se espiritualmente, pois acredita que as coisas acontecem de acordo com a vontade de Deus: “(...) meu filho vai ser liberto desse problema se for a vontade de Deus, pois ás vezes queremos uma coisa e Deus quer outra (...)". 
Evidencia em seus discursos que aos domingos vai a igreja pedir força para Deus: “(...) temos que ir a igreja buscar Deus, eu vou a igreja busco a palavra e aí vem ás promessas de Deus e isso me dá força para enfrentar essa doença, mas temos que bater a porta (...)".

Demonstra esperança e o fortalecimento das crenças no estado clínico de Josué ao declarar que vivencia os milagres de Deus, pois ele não sofreu muito os efeitos colaterais do tratamento: “(...) creio que Deus vai libertá-lo como já o libertou, faz quimioterapia desde o ano passado e o cabelo nunca caiu para ficar careca, nunca ficou magro, existem crianças que dá dó ficam magras demais (...)".

Em meio a tristeza e angustias foi capaz de ouvir desabafos de outras mães onde aparentavam estarem em extremo desespero a ponto de desejarem a morte do seu próprio filho e também a sua por não agüentarem mais vivenciar tanto sofrimento, e neste momento divide a sua experiência e lhes fortalece falando de Deus: "(...) não desejo a minha morte e nem do meu filho, quando você fala o diabo ouve, ele é sujo, e se Deus não tiver misericórdia vai acontecer e vai ficar o filho doente sofrendo e sem mãe, confia em Deus que ele vai te abençoar (...)".

Declara constantemente que busca forças para enfrentar a doença na palavra de Deus. Enfatiza que não tem do que reclamar quanto ao apoio da igreja e demonstra estar muito satisfeita pois os irmãos da igreja a ajudam, oram por ela e por Josué: “(...) Deus mostra a eles e eles me ajudam no que podem, me visitam, me apoiam e não tenho nada a falar só de bem e graças a Deus tenho visto a mão de Deus trabalhar em minha vida (...)".

Coloca que é muito difícil aceitar a sua situação longe da família: "(...) ás vezes demoro para dormir e fico pensando em todos até tarde, estou com vontade de ir embora, eu não gosto desse lugar (...)". Ás vezes conversa com seu marido por telefone e infelizmente não consegue falar com seu outro filho pois mora na fazenda com sua irmã. Demonstra preocupação pois seu outro filho quer ir morar com o pai: “(...) com o meu marido não é igual, ele tem que trabalhar e o Matheus estudar (...)".

Ela demonstra esperança de que Josué não vai ter que realizar outra cirurgia, pois que ir embora logo para casa, entretanto: “(...) quando penso que estou quase indo, a médica vem e diz que não poderei ir mais... tenho fé que Deus vai fazer essa obra (...) .aquele que busca e tem fé Deus ajuda (...)".

Diante do exposto podemos dizer que a metodologia da história oral de vida permitiu a coleta de dados, mas também uma oportunidade de entender com todos os sentidos, a vida de alguém e a busca de seu sentido de vida. Neste presente estudo, através do referencial teórico de Viktor Frankl, evidenciaremos os aspectos que sugerem a busca do sentido de vida: 
A história de vida de F.M. nos revelou que a busca pelo sentido de vida iniciou-se ainda na juventude, quando expressava o seu desejo pela continuação dos estudos. No decorrer da sua história através de eventos como: adesão a uma religião, casamento e maternidade, foram significando e dando sentido a sua vida.

A busca pelo sentido de vida é a motivação primária de uma pessoa ${ }^{7}$. O sentido do homem não é aprendido, memorizado ou objeto de consciência, ele existe por si próprio, é da própria natureza inata do ser humano, no entanto o sentido é tão real como a vida, ele deve ser encontrado pelo homem ${ }^{8}$. Não é a procura de um, mas a procura do sentido, não se trata de inventar um sentido, ele já existe ${ }^{9}$. A procura do sentido se manifesta em direção a alguém ou algo que se encontra fora da pessoa que o busca, por meio da transcendência, do ir além de si em busca de algo, de valores e da consciência última ${ }^{9}$.

O primeiro grande acontecimento que marcou a sua vida foi a adesão a uma religião. Através da rede social da igreja trouxe-lhe a oportunidade de sair da zona rural, conhecer pessoas diferentes, trabalhar e encontrar o amor, quando casou-se e constituiu uma família. De acordo com a Logoterapia, podemos descobrir o sentido de vida a três diferentes formas: 1 . Criando um trabalho ou praticando um ato; 2. Experimentando algo ou encontrando alguém; 3. Pela atitude que tomamos em relação ao sofrimento inevitável 7 .

Quando descobriu que seu filho estava com câncer, a dinâmica da família foi modificada com sua saída de casa, deixando o filho mais velho com uma irmã e ficando longe do marido: “(...) em janeiro do ano passado quando já estava com um ano e seis meses o meu irmão estava brincando com Josué quando percebeu uma mancha branca no seu olho, alertou-me mas não dei muita tenção achei que poderia ser normal, o tempo foi passando e outras manchas foram surgindo, e minha irmã pediu que eu o levasse no médico em Lagoa dos Patos, ela achava que poderia ser algo sério. Quando passamos na consulta, o médico falou que era uma catarata e pediu para que eu fosse para Coração de Jesus fazer um ultra-som. Após fazer o exame o médico chamou-me e disse que não era uma catarata como o outro médico estava achando, o problema era muito sério e não me disse mais nada, encaminhou-me para Montes Claros onde realizei outros exames e depois fui encaminhada para São Paulo (...)"

Este momento foi marcado por uma missão intransferível da responsabilidade de buscar um tratamento para Josué. Neste instante seu sentido se modifica tratando-se agora de ir em busca da cura. O ser humano é capaz de suportar os mais intensos sofrimentos quando tem um sentido para 
sua vida, uma tarefa cobrando realização, uma missão intransferível": "(...) Cheguei em São Paulo de noite e fiquei na casa de uma irmã, quando acordei só via prédios, fiquei muito nervosa, minha vontade era de ir embora, só faltei enlouquecer, pena que não posso ir, pois tenho que tratar do meu filho (...)".

O sofrimento por causas inevitáveis, constitui um dos mais profundos sentido da existência humana, quando a pessoa sofre por fatalidade que não pode impedir, ele terá a oportunidade de avaliar, se aceitar esse sofrimento, o mais nobre sentido, que é encontrar um significado no sofrimento 7 .

Quando F.M. chegou em São Paulo, se deparou com um novo problema, que foi a procura por uma moradia e a adaptação a mesma. Devido ao comportamento difícil do filho, criou-se um ambiente de brigas com as crianças e com a mães. Na casa de apoio onde encontra-se atualmente decidiu enfrentar a situação, pois escolher outro local nem sempre seria a solução para os seus problemas: “(...) é difícil ficar todos juntos aqui na casa de apoio, pois tem mãe que não deixa chegar perto de outra criança, muitas vezes a criança não fez nada e a pessoa não gosta (...)"

Quando aceitou ficar na casa de apoio, passou a aceitar as dificuldades de morar em comunidade e trabalhar as adversidades diárias, neste momento ela dá sentido ao seu sofrimento que é de continuar ali apesar de tudo: “(...) já relevei muitas coisas, mas não é igual a estar em nossa própria casa, de repente eu vou para outro lugar e tento fugir de uma atribulação e encontro outra maior (...) enfrentei muitas coisas, não fui para outra casa, pois o Josué já tinha acostumado com todos (...)".

A vida conserva o seu sentido potencial apesar de seus aspectos trágicos, em quaisquer circunstâncias mesmo nas mais miseráveis, dessa maneira pressupõe-se a capacidade do ser humano de transformar criativamente os aspectos da vida em algo construtivo e para que isso aconteça é importante que extraia o melhor de cada situação sendo otimista diante da tragédia 5 .

A pessoa pode permanecer otimista apesar da "tríade trágica" dos aspectos da existência humana que se caracterizam por: $1 . d o r ; 2$. culpa; 3 . Morte ${ }^{7}$. 0 importante é tirar o melhora da situação.

Demonstrou otimismo ao ver que o filho não emagreceu e não perdeu o cabelo, pois quando foi ao hospital ficou assustada ao se deparar com crianças com o mesmo diagnóstico, fazendo o mesmo tratamento. O que fortalece as suas crenças é perceber que a promessa de Deus está se cumprindo. É um otimismo diante da tragédia e tendo em vista o potencial humano que permite: 1 . Transformar o sofrimento numa conquista e numa realização humana; 2. Extrair da culpa a oportunidade de mudar a si mesmo para melhor; 3. Fazer da transitoriedade da vida um incentivo para realizar ações responsáveis ${ }^{7}$. 
Entre as coisas que parece tirar o sentido da vida humana estão não apenas o sofrimento, mas também a morte. O homem é o único a ter conhecimento da morte, da finitude de sua existência corporal e da transitoriedade da vida, este fato faz com que a pessoa humana seja um ser preocupado e responsável por sua transitoriedade, buscando um sentido para vida9: “(...) eu já vi duas mães desejarem a morte para seus filhos, ela falou assim: porque Deus não põe essa doença nos ladrões de que vivem roubando e matando? Falei para ela não falar isso e para confiar em Deus e que ele sabe o que faz. Outra mãe também falou que ela preferia morrer ao ver seu filho nesta situação e disse a ela que não desejo a minha morte e nem do meu filho, pois peço a Deus força e que ele o liberte. Falei para ela: se você confia em Deus porque fica falando essas coisas? Quando você fala o diabo ouve e fica cutucando, ele é sujo e se Deus não tiver misericórdia pode acontecer, e seu filho ficará doente sofrendo e sem sua mãe; confia em Deus que ele vai te abençoar e que terá forças para vencer, eu estou passando pelo mesmo problema (...)".

Nos campos de concentração, Victor Frankl observou que se o prisioneiro tinha esperança de sair para completar uma missão inacabada, apesar da intensidade da dor, aparecia uma força inexplicável que tornava o sofrimento mais leve, o prisioneiro fazia tudo quanto fosse possível para não morrer, porque sua vida teria de continuar? ${ }^{7}$.

Existiam dias em que F.M. parece estar perdendo o sentido, pois é acometida de uma tremenda angústia e desespero e então sai andando para espairecer a cabeça para não "fazer besteira consigo mesma". Nesses dias é tomada pela saudade da família e a preocupação com o filho mais velho, as dificuldades de se relacionar devido o comportamento de Josué e a demora no tratamento do filho.

Porém F.M. ora e "esfria a cabeça" e retoma a luta pelo seu objetivo inicial que é a tão sonhada cura do filho, tal retomada está norteada pelo seu sentido de vida, encontrado ainda na sua juventude através da religião e fortalecido no sofrimento da doença do filho.

F.M. aceita o desafio de sofrer com bravura, ao retomar o seu objetivo inicial. Ao aceitar esse desafio a vida recebe um sentido até o seu derradeiro instante, mantendo este sentido literalmente até o fim, em outras palavras é um sentido incondicional por incluir até o sentido potencial do sofrimento inevitável?

A história de vida de vida de F.M. é permeada pelo sentido de vida que encontra na religião, desde o início e até os dias atuais, os quais são marcados pelo sofrimento de ter um filho com câncer, estar em 
uma cidade como São Paulo tão temida pela sua violência, dificuldades de encontrar moradia e adaptar-se, separação do seu marido e filho e dificuldades financeiras.

Religião é consciência que o homem tem de sua dimensão sobre-humana, e nesta dimensão ele apoia a fé básica no sentido último da vida7: “(...) ás vezes todos estão dormindo e eu me levanto de duas a três vezes para ir ao banheiro e neste momento oro e peço a Deus para me dar força, muita força temos de pedir ajuda a Deus, temos que bater na porta, pois sei que é muito difícil, nunca pensamos que poderemos passar por uma situação dessas da qual estou passando, mas Deus tem me dado força e eu vou vencer em nome do senhor de Jesus. Meu filho vai ser liberto desse problema, se for a vontade de Deus, pois as vezes queremos uma coisa e Deus quer outra (...)".

A pessoa ao aderir uma crença religiosa pode ser uma forma de viver a sua espiritualidade, mas também é possível viver a espiritualidade sem ter religião ${ }^{10}$. As religiões representam as respostas que a humanidade tem procurado dar a tais questões, através de um conjunto de práticas e crenças ${ }^{11}$.

O homem é dirigido por uma dimensão espiritual, que o leva a buscar o sentido e a realizar seus valores, valores que já estão no mundo e se distribuem essencialmente nas áreas do trabalho ou da criatividade, do amor ou das vivências e do sofrimento ou de uma atitude face aos condicionamentos do mundo 8 .

A espiritualidade faz parte de todo ser que se questiona diante do simples fato de sua existência, diz respeito a sua relação com os valores que o transcendem, seja qual for o nome que lhes atribua, constituindo a própria essência do ser humano ${ }^{10}$.

Quando começou o tratamento em nenhum momento sentiu-se culpada e nem culpou Deus pelo motivo da doença. Ela teve dificuldade de aceitar a doença, apenas pensando no sofrimento do filho. Em nenhum momento questionou a Deus por acreditar que tanto a cura como as doenças são pertinentes das obras divina e coloca Deus um ser supremo e expressivo na sua vida.

O ser humano tem uma religiosidade inconsciente, mas pulsante no íntimo de cada pessoa, e percebe que na angústia intensa aparece uma fé, uma esperança no futuro que faz brotar o sentido de vida, a crença em Deus, que parecia estar oculta9: “(...) lidar com a doença dele é difícil, mas eu convivo porque sou mãe e tenho que lutar, mas estou levando a vida com fé em Deus (...)."

Diante de tantas dificuldades F.M. acredita que a sua força para lutar e enfrentar esta doença vem de Deus. Aos domingos vai a Igreja, buscar a palavra de Deus que é revelada através de um ancião e 
pede a Deus para libertar o seu filho e na promessa, ouve a revelação de que se for uma filha obediente e fiel vai libertar o seu filho e desta forma vê as mas de Deus trabalhar na sua vida: "(...) Temos que ir a igreja buscar Deus, eu vou a igreja busco a palavra e aí vem a promessa de Deus e isso me dá força para enfrentar essa doença (...)".

“(...) Tenho fé que Deus vai fazer essa obra...aquele que busca e tem fé Deus ajuda(...)”.

“(...) Creio que Deus vai libertá-lo como já o libertou, faz quimioterapia desde o ano passado e o cabelo nunca caqui para ficar careca, nunca ficou magro, existem crianças que dá dor ficam magras demais (...)".

"(...) Quando Josué melhorar gostaria que ele estudasse (...)".

" (...) Quando fui para Coração de Jesus, meu esposo estava fazendo a nossa casa, não havia terminado, estava no ponto de colocar telha na madeira, por dentro estava rebocado e por fora não, então ele mudou fazem seis meses e eu nunca morei lá, mas tenho fé em Deus que não vai demorar muito para ir embora (...)."

"(...) Quando penso que estou quase indo, a médica vem e diz que não poderei ir mais... tenho fé que Deus vais fazer essa obra... aquele que busca e tem fé Deus ajuda."

Cada pessoa tem uma instância que a doença jamais conseguirá atingir, a espiritualidade imaculada, o Deus vivo na intimidade da pessoa humana, o ponto de partida da fé que temos em cada pessoa?

F.M. parece estar encontrando sentido até mesmo no sofrimento, sentido este que impulsionou a busca do tratamento do câncer. Deu um passo a mais, aceitando o sofrimento de ter um filho com câncer e as dificuldades encontradas no decorrer do tratamento em São Paulo, aceitando os limites da fadiga, da incerteza da cura do filho e da distância da família.

\section{CONSIDERAÇÕES FINAIS}

A história Oral de vida como metodologia possibilitou a percepção do quanto é importante olharmos a história de vida das pessoas.

A luz do referencial teórico de Viktor Frankl instrumentalizou-nos para que pudéssemos melhor compreender a vivência de uma mãe que enfrenta o câncer do seu filho e a identificar os elementos que dão sentido na vida, para assim poder fortalecê-los. Também possibilitou melhorar o nosso 
discurso para que possamos conduzir e enfrentar melhor as adversidades decorrentes do processo da doença.

A espiritualidade apareceu como algo importante para que a mãe estudada pudesse dar sentido em sua vida e transcender a doença inesperada do filho, remetendo-nos a necessidade de compreendermos melhor a dimensão espiritual do ser humano.

A proposta aqui é a de compreendermos melhor o sentido de vida para que possamos prestar uma assistência de enfermagem a criança e sua família a partir do que é necessidade apontada por eles e não apenas norteada por normas e rotinas.

Este estudo melhorou a nossa própria percepção de quando e de que forma acessamos os elementos que dão sentido de vida, de uma família com criança com câncer, fato este que nos faz repensar a nossa própria vida e significar melhor a enfermagem da qual pretendemos fazer. 


\section{REFERÊNCIAS}

1. Valle ERM. Vivências da família da criança com câncer. In: Carvalho MMMJ. Introdução à Psciconcologia. Campinas: Editorial Psy; 1994.

2. Bezerra LFR, Fraga MNO. Acompanhar um Filho Hospitalizado: Compreendendo a vivência da mãe. Revista Brasileira de Enfermagem 1996; 49 (4):611-24.

3. Simonton SM. A família e a Cura. O Método Simonton para famílias que enfrentam uma doença. São Paulo: Summus; 1984.

4. Lunardi V L. Percepções e condutas dos profissionais de enfermagem frente ao processo de morrer e morte. Texto e Contexto de Enfermagem 2001; 10 (3): 60-81.

5. Jesus GJ. Encontrando sentido no sofrimento: a vivência da família da criança com câncer. [dissertação] São Paulo (SP): Escola de Enfermagem da Universidade de São Paulo; 2001.

6. Lima AFC. O significado da hemodiálise para o paciente renal crônico: a busca por uma melhor qualidade de vida. [dissertação] São Paulo (SP): Escola de Enfermagem da Universidade de São Paulo; 2000.

7. Frankl VE. A Busca de Sentido. Um psicólogo no campo de concentração. Rio Grande do Sul: Sinodal; 2003.

8. Rodrigues R. Fundamentos da Logoterapia. Na Clínica Psiquiátrica e Psicoterapêutica. Petrópolis: Vozes; 1991.

9. Gomes JCV. Logoterapia. A Psicoterapia Existencial Humanista de Viktor Emil Frankl. São Paulo: Loyola; 1992.

10. Hennezel, MH, Leloup J. A Arte de Morrer. Tradições religiosas e espiritualidade humanista diante da morte na atualidade. 2o ed. Petrópolis: Vozes; 1999.

11. Smeltzer CS, Bare B. Brunner \& Suddarth Tratado de Enfermagem Médico-Cirúrgica. 9o ed. Rio de Janeiro: Guanabara Koogan; 2002. 


\section{Capítulo 6}

doi) $10.37423 / 211205108$

\section{ASSOCIAÇÃO DA ADIPOSIDADE VISCERAL COM O PERFIL GLICÍDICODE JOVENS ADULTOS COM EXCESSO DE PESO}




\section{INTRODUÇÃO:}

O excesso da adiposidade abdominal em conjunto com o baixo grau de inflamação do tecido adiposo crônico promove alterações como, hipertrofe disfunções no perfil secretório dos adipócitos e parece contribuir com alteração no metabolismo dos carboidratos, ocasionando alterações metabólicas como por exemplo a resistência à insulina. Objetivo: avaliar e associar a adiposidade visceral com o perfil glicídico de jovens adultos com excesso de peso.

\section{MÉTODOS:}

Estudo transversal, realizado com indivíduos de 16 a 29 anos de ambos os sexos, atendidos em um ambulatório de obesidade e hipertensão da cidade de Juiz de Fora - MG. Foi avaliado peso, altura, índice de massa corporal, espessura do tecido adiposo visceral através da ultrassonografia e parâmetros bioquímicos como glicemia em jejum, insulina e hemoglobina glicada. A correlação foi testada com o coeficiente de correlação de Pearson. Todas as análises foram realizadas no software SPSS, versão 20.0 A significância adotada foi de $p<0,05$.

\section{RESULTADOS:}

A amostra composta por 105 indivíduos, com idade média de 22,9 \$3,02 e IMC médio de 38,72 \pm 6,01. Em relação ao perfil glicídico, 11,2\% e 21,2\% apresentaram a glicemia em jejum e a hemoglobina glicada acima da normalidade, respectivamente. De acordo com o HOMA-IR, 40\% apresentaram resistência à insulina e 80,4\% obesidade abdominal visceral (espessura da adiposidade visceral $>7 \mathrm{~cm}$ ). Através da análise estatística, evidenciou-se uma associação da adiposidade visceral com a insulina $(p=0,012)$ e HOMA-IR $(p=0,014)$. Não houve associação com a glicemia em jejum $(p=0,357)$ e a hemoglobina glicada $(0,634)$.

\section{CONCLUSÃO:}

Esses dados corroboram o papel etiopatogênico da gordura visceral no desenvolvimento de distúrbios da glicose e no processo de desregulação metabólica, através da resistência à insulina. Assim, a análise e avaliação da gordura abdominal visceral em indivíduos obesos possibilita identificação de pacientes com maior risco de desenvolver diabetes tipo 2 e outras doenças crônicas não transmissíveis que também podem estar relacionadas. 


\section{Capítulo 7}

doi) $10.37423 / 211205111$

CONSUMO ALIMENTAR E SUA RELAÇÃO COM PARÂMETROS CLÍNICOS E NUTRICIONAIS DE INDIVÍDUOS OBESOS PORTADORES DE DOENÇA HEPÁTICA GORDUROSA NÃO ALCOÓLICA

Maria Raquel Oliveira

Maira Schuchter Ferreira

Letícia Ferreira Delgado

Paula Oliveira Dazini

Flávio Augusto Teixeira Ronzani

Carla Márcia Moreira Lanna

Sheila Cristina Potente Dutra Luquetti
Universidade Federal de Juiz de Fora

Universidade Federal de Juiz de Fora

Universidade Federal de Juiz de Fora

Universidade/Federal de Juiz de Fora

Universidade Federal de Juiz de Fora

Universidade Federal de Juiz de Fora

Universidade Federal de Juiz de Fora 
INTRODUÇÃO: A doença hepática gordurosa não alcoólica (DHGNA) é caracterizada pelo acúmulo de triglicerídeos no fígado, quando não tratada pode progredir e gerar maior dano hepático. Pode estar relacionada à obesidade central, resistência à insulina, hipertensão arterial sistêmica e síndrome metabólica, entre seus determinantes ambientais a dieta pode ser um fator passível à modificações. OBJETIVO: Avaliar o consumo alimentar segundo o grau de processamento dos alimentos e sua relação com parâmetros sociodemográficos, clínicos e nutricionais de indivíduos adultos obesos portadores de (DHGNA). METODOLOGIA: Estudo transversal, dados obtidos de amostra não probabilística, coletados em primeira consulta ambulatorial dos pacientes. O diagnóstico de (DHGNA)foi realizado por ultrassom, e foram coletados dados sociodemográficos, antropométricos, de consumo alimentar, além de parâmetros clínicos. Dados estatísticos foram analisados no SPSS ${ }^{\circledR}$. RESULTADOS E DISCUSSÃO: Foram selecionados entre 102 pacientes, 26 portadores de DHGNA (graus II e III),idade média de $23,3 \pm 2,8$ anos, sendo 53,8\% mulheres e $46,2 \%$ homens, $73,1 \%$ apresentaram obesidade grau III (100\% apresentando obesidade central), 70,8\% com resistência à insulina, 19,2\% com hipertensão arterial sistêmica e 42,9\% com síndrome metabólica. Sobre o consumo alimentar observaram-se valores médios para consumo calórico total e por percentuais provenientes dos macronutrientes. Os alimentos in natura ou minimamente processados e os produtos ultraprocessados contribuíram significativamente para ingestão calórica. Os homens apresentaram resultados superiores para consumo calórico e de ultraprocessados, glicemia e para prevalência de síndrome metabólica em relação as mulheres. Os participantes categorizados com maior consumo de ultraprocessados consumiram mais calorias e menos proteínas em relação ao grupo de menor consumo. Entretanto, não houve diferença estatística para os demais parâmetros avaliados entre os grupos de maior e menor consumo de acordo com o grau de processamento. CONCLUSÃO: O padrão alimentar apresentado sugere risco para desenvolvimento de obesidade e (DHGNA), principalmente devido as inadequações relacionadas ao consumo de produtos alimentícios ultraprocessados.

Palavras-chave: obesidade, doença hepática, manejo nutricional, resistência â insulina. 


\section{INTRODUÇÃO}

A obesidade pode ser definida como um acúmulo excessivo de gordura corporal, uma condição crônica multifatorial, mas condicionada principalmente pelos perfis alimentar e de atividade física do indivíduo. No Brasil o excesso de peso e a obesidade já atingiram 56,9\% e 20,8\% da população de adultos, respectivamente ${ }^{(1)}$. Sendo assim, deve ser tratada como um problema de saúde pública grave e que demanda muitos recursos, estima-se que $2 \%$ a $8 \%$ dos gastos em tratamentos de saúde em vários países são destinados aos indivíduos com esse quadro ${ }^{(2)}$, levando em conta que o indivíduo obeso estará mais propenso a desenvolver outras doenças como por exemplo hipertensão, dislipidemia, diabetes mellitus tipo 2, osteoartrite, alguns tipos de câncer e doença hepática gordurosa não alcóolica (DHGNA)(3).

Com o ganho de peso, observamos um acúmulo de triglicerídeos intracelulares nos adipócitos, mas, com o passar do tempo e agravamento da obesidade, os triglicérides passam a acumular também em outros tecidos, principalmente o tecido hepático, gerando a esteatose hepática, e configurando a DHGNA. A patogênese da mesma envolve o acúmulo de gordura nos hepatócitos, aumentando o estresse oxidativo levando à inflamação, que é considerada fator importante para que haja a progressão para EHNA e fibrose ${ }^{(4)}$.

A DHGNA quando não tratada precoce e adequadamente pode progredir para um acúmulo de lipídeos macrovesiculares nos hepatócitos (denominado esteatose) , ou ainda em casos mais severos para um quadro de esteato-hepatite não alcoólica (EHNA; esteatose na presença de infiltrado inflamatório possivelmente com alguma fibrose), fibrose total, cirrose e até mesmo carcinoma hepatocelular $(4,5,6)$. Estima-se que 20 a 30\% da população mundial seja portadora de DHGNA, sendo esta doença hepática mais comum nos países ocidentais afetando aproximadamente 17 a $46 \%$ dos adultos que já apresentam outros sintomas de Síndrome Metabólica e aproximadamente 7\% de indivíduos com peso normal ${ }^{(7)}$.

Uma combinação de fatores ambientais e fatores genéticos determinam o risco individual de desenvolvimento e progressão de DHGNA, com um papel claro para a nutrição como um fator de risco ambiental modificável.

Nesse contexto da nutrição e alimentação, Fan e $\mathrm{Cao}^{(8)}$ citam que para o tratamento dessa doença é necessário um conjunto de fatores, entre eles a redução de calorias da dieta, através da menor ingestão de alimentos fontes de gordura saturada e colesterol e de alimentos ricos em açúcar como 
por exemplo refrigerantes ${ }^{(9)}$. Por outro lado também orientam quanto a melhora na qualidade das proteínas ingeridas, estimulo ao consumo de fontes de ácidos graxos monoinsaturados (MUFAS), probióticos e ômega-3 por ser capaz de estimular proteínas nucleares e terem como efeito a redução do processo inflamatório no organismo ${ }^{(10)}$.

Sendo a dieta um importante componente para a prevenção e tratamento da obesidade, e consequentemente, das doenças que podem surgir com a mesma, como a DHGNA, se faz necessário um enfoque na alimentação da população com intuito de melhorar os hábitos alimentares, estimulando o consumo de alimentos in natura ou minimamente processados e orientando quanto a diminuição de consumo de alimentos ultraprocessados.

Dessa foram o objetivo desse estudo é avaliar o consumo alimentar segundo o grau de processamento dos alimentos e sua relação com parâmetros sociodemográficos, clínicos e nutricionais de indivíduos adultos obesos portadores de DHGNA.

\section{METODOLOGIA}

\subsection{DELINEAMENTOS DO ESTUDO, POPULAÇÃO E CRITÉRIOS DE ELEGIBILIDADE}

Trata-se de um estudo transversal, onde se avaliou dados de uma amostra não probabilística, proveniente de um estudo maior intitulado "Associação dos fatores de risco com as complicações cardiometabólicas observadas em obesos jovens ". Este estudo foi aprovado pelo Comitê de Ética em Pesquisa da Universidade Federal de Juiz de Fora, CAAE: 80290617.7.0000.5147.

Desta forma, foram acompanhados inicialmente 102 indivíduos obesos (Índice de Massa Corporal IMC $\geq 30 \mathrm{~kg} / \mathrm{m} 2)^{(11)}$, com idade entre 16 e 30 anos, de ambos os sexos. A partir dessa amostra, foram selecionados para fins de análise, os indivíduos que no exame de ultrassonografia, apresentaram diagnóstico de DHGNA nos graus moderado a grave (grau II e grau III), totalizando, assim, 26 indivíduos adultos jovens.

Os dados de primeira consulta dos indivíduos selecionados e que aceitaram participar do estudo através da assinaram o Termo de Consentimento Livre e Esclarecido (TCLE), foram coletados no Ambulatório de Obesidade e Hipertensão do NIEPEN - Núcleo Interdisciplinar de Estudos, Pesquisas e Tratamento em Nefrologia da Universidade Federal de Juiz de Fora - Minas Gerais.

Foram considerados elegíveis os pacientes com DHGNA, maiores de 18 anos de idade, de ambos os sexos, baixo consumo de álcool, e disponível para medições antropométricas e para responder ao 
questionário de consumo alimentar. Os critérios de inelegibilidade incluíram os pacientes com obesidade e hipertensão secundárias, portadores de outras doenças hepáticas (hepatites, doença de Wilson, hemocromatose, carcinoma hepatocelular etc), os que faziam uso de medicações hepatotóxicas, glicocorticoides e outros hormônios, os que possuíam alguma amputação ou cadeirantes, os que já haviam sido submetidos a intervenções cirúrgicas como bariátrica ou lipoaspiração.

\subsection{DIAGNÓSTICO DA ESTEATOSE HEPÁTICA NÃO ALCÓOLICA}

O diagnóstico da DHGNA foi realizado a partir dos exames de ultrassom. Todos foram realizados pelo mesmo médico radiologista, que não possuía acesso aos dados clínicos dos pacientes. Os resultados foram avaliados de forma quantitativa e por percentuais, pois não existem valores de referência para essa medida. Os exames ultrassonográficos do abdome foram realizados com equipamento com transdutor convexo de 3,5 MHz, respeitando-se o seguinte protocolo:

a) Ganho total: ajustado de modo que o conteúdo líquido da vesícula biliar e o sangue no interior da veia cava inferior se apresentassem anecogênicos. Curva de ganho calibrada na posição neutra;

b) Posicionamento do paciente: decúbito dorsal horizontal;

c) Varredura do transdutor realizada no hipocôndrio direito nos eixos longitudinal, transversal e oblíquo.

Dessa forma foram avaliados: dimensões do fígado e ecotextura do parênquima, permitindo a classificação da esteatose hepática em graus (1, 2 ou 3) baseado na classificação utilizada por Saadeh et al. ${ }^{(12)}$. Determinou-se o aspecto ultrassonográfico da esteatose pelo aumento difuso da ecogenicidade hepática, que pode ser notada comparando-se a ecogenicidade do fígado com a do córtex renal ou do baço.

\subsection{PROCEDIMENTOS E COLETA DOS DADOS}

Os dados utilizados neste estudo foram coletados no ambulatório por meio de consultas previamente agendadas. O período de coleta dos dados foi de agosto de 2017 a julho de 2018, sendo as seguintes informações obtidas através de questionários elaborados pelos pesquisadores:

- Parâmetros sociodemográficos e de estilo de vida: foram coletadas dados de sexo, idade e consumo de álcool. Em relação ao consumo de álcool, avaliaram-se a frequência de consumo e a habitual quantidade consumida em cada ocasião. Uma ingestão diária de menos de $20 \mathrm{~g}$ de álcool (mulheres) 
e $30 \mathrm{~g}$ (homens) foi adotado como um ponto de corte para inclusão no estudo, de acordo com a American Gastroenterological Association ${ }^{(13)}$.

- Parâmetros nutricionais: foram avaliados dados antropométricos e de consumo alimentar. As medidas antropométricas foram realizadas segundo as orientações da Organização Mundial de Saúde (OMS) para adultos ${ }^{(11)}$. O Peso corporal foi aferido em balança digital da marca Welmy modelo $\mathrm{W}$ 200/5. Os indivíduos foram pesados em pé, descalços e com roupas leves. A estatura foi obtida por meio do estadiômetro de campo (Alturaexata), com escala em centímetros e precisão em milímetros. Os participantes ficaram de costas para o marcador, com os pés unidos, em posição ereta, olhando para frente. O esquadro móvel foi movido até o encosto da cabeça do indivíduo e a leitura foi realizada no milímetro mais próximo. Os dados de peso e estatura foram usados para calcular o Índice de Massa Corporal (IMC), que constitui a relação entre o peso $(\mathrm{kg})$ e a altura ao quadrado em metros $\left(\mathrm{m}^{2}\right)$, sendo este utilizado para classificar o estado nutricional dos participantes ${ }^{(14)}$. Também foi aferida a medida da circunferência da cintura (CC), que foi obtida medindo o ponto médio entre a margem inferior da crista ilíaca e a face externa da última costela, com fita métrica flexível e inelástica, disposta no plano horizontal, estando os participantes na posição ortostática, em expiração, descalços e com os pés ligeiramente separados. Foram considerados como ponte de corte para circunferência da cintura aumentada $\geq 88 \mathrm{~cm}$ para as mulheres e $\geq 102 \mathrm{~cm}$ para os homens ${ }^{(15)}$.

A avaliação de consumo alimentar foi realizada por meio de um recordatório alimentar de vinte e quatro horas (R24h). No R24h os participantes citaram os itens e as quantidades das porções ingeridas no dia anterior a coleta dos dados, sendo este um dia típico (quinta-feira). Para auxiliar os participantes na estimativa das porções, usou-se o álbum fotográfico elaborado por Monteiro et al.(16). A análise da ingestão total de energia e macronutrientes (carboidratos, proteínas e lipídeos) foram realizadas utilizando-se o Programa DietWin Plus. No caso dos alimentos que não estava descrito no software, foi utilizado os dados do rótulo; e para preparações foi feito o desmembramento dos ingredientes a partir de receitas padrão.

Foi avaliado também o consumo alimentar segundo o grau de processamento industrial dos alimentos, conforme metodologia já descrita em outros estudos ${ }^{(17,18)}$. Os itens de consumo alimentar foram divididos em 4 grupos, conforme descritos a seguir. O primeiro grupo são os alimentos in natura ou minimamente processados, onde foi incluído os itens arroz e outros cereais, feijão e outras leguminosas, carnes de boi, de porco e de aves, frutas, leite, raízes e tubérculos, café e chás, peixes e outros frutos do mar, verduras e legumes, ovos, castanhas e outras sementes. O segundo grupo são 
os alimentos processados, ou seja, produtos prontos para o consumo fabricados a partir da adição de sal, açúcar ou óleo, estando incluído neste grupo o pão francês, queijos, conservas de verduras e legumes e carnes secas ou salgadas. O terceiro grupo foi destinado aos ultraprocessados, produtos alimentícios prontos para consumo que são produzidos predominante ou unicamente a partir de ingredientes industriais, que em geral possuem conservantes, aditivos quimícos, vitaminas e minerais sintéticos, sendo considerado neste grupo os bolos, tortas e biscoitos doces, fast food, refrigerantes, refrescos, bebidas lácteas, pães de forma, de hambúrguer, de hot dog e similares, guloseimas, bolachas salgadas e salgadinhos tipo chips, embutidos e pratos prontos ou semi-prontos. O quarto e último grupo se refere aos ingredientes culinários que são substâncias extraídas de alimentos incluindo açúcar de mesa, óleo vegetal (e margarina), farinha de mandioca, de trigo (e outras farinhas), macarrão, gordura animal (manteiga, banha e nata), amidos, açúcares, adoçantes e leite de coco.

Como ainda não há ponto de corte para avaliar o consumo alimentar sob a ótica do grau de processamento dos alimentos, utilizou-se neste estudo o valor mediano de consumo calórico de produtos alimentícios ultraprocessados $(541,62 \mathrm{kcal})$ e de alimentos in natura ou minimamente processados (644,59 Kcal) como ponto de corte para determinar os grupos de maior consumo, ou seja, os que apresentavam consumo acima do valor mediano; ou menor consumo, ou seja, os que consumem abaixo do valor mediano.

- Parâmetros clínicos: foram coletados do prontuário a história clínica, comorbidades presentes, uso de medicamentos e dados bioquímicos (triglicerídeos e HDL séricos, glicemia de jejum, insulinemia e hemoglobina glicada). Além disso, foi aferida a pressão arterial diastólica e sistólica com os participantes deitados em maca, sendo a medida obtida por meio de esfigmomanômetro (marca), classificando o nível de HAS de acordo com a VII Diretriz Brasileira de Hipertensão(19).

Foi avaliada também a presença de resistência à insulina (RI) através do Índice Homeostasis Model Assessment (HOMA-IR), que foi calculado a partir da fórmula: HOMA-IR = insulinemia de jejum(mU/L) $\mathrm{x}$ glicemia de jejum(mmol/L)/22,5. Foi considerado como ponto de corte para a presença de RI, valor de HOMA-IR maior ou igual a 3,16 (20).

A presença de sindrome metabólica (SM) foi determinada pelos critérios da International Diabetes Federation ${ }^{(21)}$, que considerao diagnóstico de SM através da presença de circunferência abdominal $>90 \mathrm{~cm}$ para homens e $>80 \mathrm{~cm}$ para as mulheres associa a presença de dois ou mais fatores, tais fatores são triglicerídeos $\geq 150 \mathrm{mg} / \mathrm{dL}, \mathrm{HDL}-\mathrm{c}<40 \mathrm{mg} / \mathrm{dL}$ para homens e $<50 \mathrm{mg} / \mathrm{dL}$ para mulheres, pressão arterial $\geq 130 \times 85 \mathrm{mmHg}$ e glicemia de jejum $\geq 100 \mathrm{mg} / \mathrm{dL}^{(21)}$. 


\subsection{ANÁLISE ESTATÍSTICA}

A análise dos dados foi realizada utilizando o software SPSS ${ }^{\circledR}$ (Statistical Package for the Social Sciences), versão 20.0; SPSS Inc. ${ }^{\circledR}$, Chicago, IL, EUA. Os resultados foram expressos como percentual, média \pm desvio padrão ou mediana e valores mínimo e máximo, conforme o tipo e a simetria da variável a ser descrita. Após análise da normalidade dos dados pelo teste Shapiro-Wilk, as diferenças nos parâmetros clínicos e nutricionais entre gêneros (feminino e masculino) e entre os grupos de maior e menor consumo de produtos alimentícios ultraprocessados, e de maior e menor consumo de alimentos in natura foram avaliadas pelo teste $t$ de Student no caso das variáveis com distribuição normal (idade, IMC, CC, PHD, PHS e todas variáveis de consumo alimentar), e pelo teste de MannWhitney no caso das varáveis que não apresentaram distribuição normal (Insulinemia, Hb glicada e HOMA-IR). Variáveis categóricas foram comparadas pelo teste do Qui-Quadrado. Em todas as análises foi considerado o nível de significância de 0,05.

\section{RESULTADOS}

A partir dos dados coletados foram selecionados 26 indivíduos com DHGNA (graus II ou III) de uma amostra maior de 102 participantes obesos. A Tabela 1 apresenta o perfil sociodemográfico, nutricional e clínico dos indivíduos avaliados. Pode ser observado que a amostra apresentou número de indivíduos próximo entre os sexos, sendo $14(53,8 \%)$ do sexo feminino e 12 (46,2\%) do sexo masculino. A média de idade dos participantes foi de $23,27 \pm 2,79$, o que caracteriza a amostra como sendo de um grupo de adultos jovens.

Com relação ao estado nutricional, evidenciam-se médias de IMC $\left(43,43 \pm 5,65 \mathrm{Kg} / \mathrm{m}^{2}\right)$ e CC $(133,1 \pm$ 14,23 ) elevados, sendo a maior parte $(73,1 \%)$ dos indivíduos avaliados classificados com obesidade grau III, e todos apresentando obesidade central de acordo com a medida da CC. Esses dados configuram o perfil de elevado risco cardiometabólico, sendo evidenciada a presença de DHGNA grau Il em $96,2 \%$, RI em 70,8\% de indivíduos, HAS em 19,2\% e SM em 42,9\% dos participantes (Tabela 1). 
Tabela 1 - Caracterização sociodemográfica, nutricional e clínica dos participantes.

\begin{tabular}{|c|c|c|}
\hline Variáveis & $N=26$ & Média \pm DP ou \% \\
\hline \multicolumn{3}{|l|}{ Sexo (\%) } \\
\hline Feminino & 14 & 53,8 \\
\hline Masculino & 12 & 46,2 \\
\hline Idade & 26 & $23,27 \pm 2,79$ \\
\hline $\operatorname{IMC}\left(\mathrm{Kg} / \mathrm{m}^{2}\right)^{1}$ & 26 & $43,43 \pm 5,65$ \\
\hline Circunferência da Cintura (CC) & 26 & $133,1 \pm 14,23$ \\
\hline \multicolumn{3}{|l|}{ Classificação Obesidade $(\%)^{2}$} \\
\hline Grau I & 1 & 3,8 \\
\hline Grau II & 6 & 23,1 \\
\hline Grau III & 19 & 73,1 \\
\hline \multicolumn{3}{|l|}{ Obesidade Central $^{3}$} \\
\hline Não & 0 & 0 \\
\hline Sim & 26 & 100 \\
\hline
\end{tabular}

Classificação da Esteatose Hepática

(\%)

\begin{tabular}{lcc} 
Grau II & 25 & 96,2 \\
Grau III & 1 & 3,8 \\
\hline
\end{tabular}

Hipertensão Arterial Sistêmica (HAS)

(\%)

$\begin{array}{lll}\text { Não } & 21 & 80,8\end{array}$

$\begin{array}{llr}\operatorname{Sim} & 5 & 19,2\end{array}$

Resistência a Insulina (RI) (\%) ${ }^{4}$

$\begin{array}{llr}\text { Não } & 7 & 29,2\end{array}$

$\begin{array}{lll}\text { Sim } & 17 & 70,8\end{array}$

Síndrome Metabólica (SM) (\%)

Não

$12 \quad 57,1$

Sim

9

42,9

DP: desvio padrão; 1 Índice de massa corporal; 2Classificação segundo o IMC; 3Obesidade central: quando a medida da $C C \geq 88 \mathrm{~cm}$ em mulheres e $\geq 102 \mathrm{~cm}$ em homens;4HOMA-IR significando resistência à insulina quando $\geq 3,16$. 
Avaliando o perfil de consumo alimentar dos participantes do estudo, encontramos valores médios para consumo calórico total de $1925,6 \pm 957,4 \mathrm{kcal}$, para carboidrato $45,7 \pm 11,1 \%$, para proteína $17,6 \pm 6,4 \%$ e para lipídeo $37,0 \pm 8,6 \%$.

Quando considerada a contribuição calórica dos alimentos segundo o grau de processamento industrial, pode ser observado na Figura 1, que os alimentos in natura ou minimamente processados $(41,97 \pm 20,6 \%)$ e os produtos ultraprocessados $(34,31 \pm 19,7 \%)$ são os que mais contribuem, tanto considerando o total de indivíduos avaliados, como os indivíduos de ambos os sexos.

Figura 1 - Percentual de contribuição calórica dos alimentos segundo o grau de processamento considerando o total de indivíduos avaliados e o sexos (feminino e masculino).

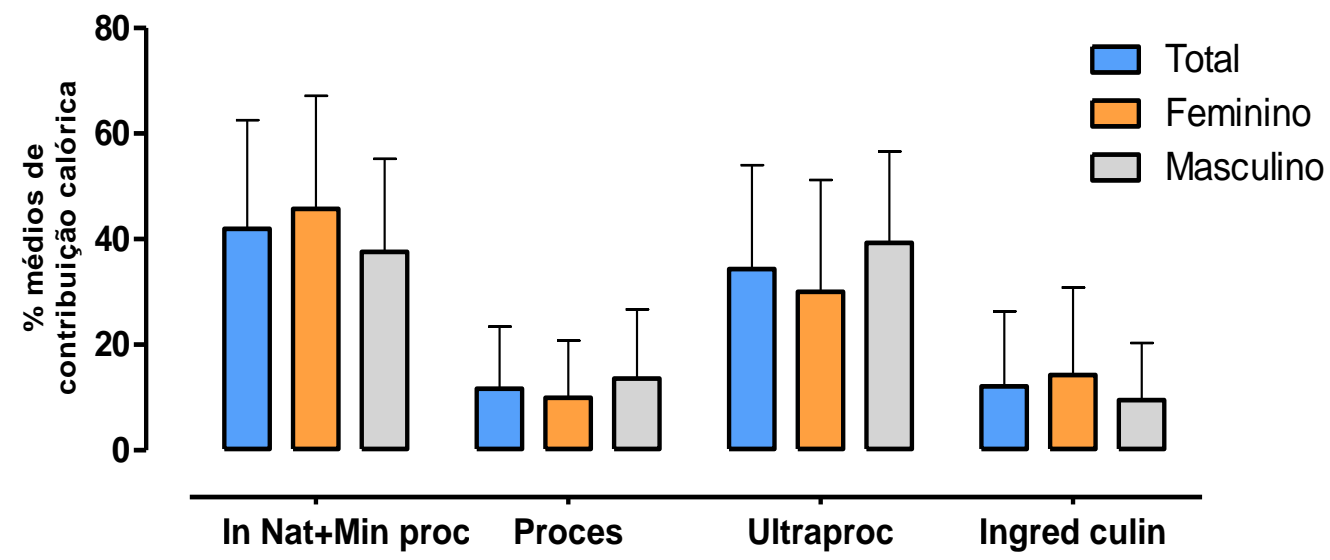

A Tabela 2 apresenta o comparativo entre os sexos, podendo ser observado que não há diferença estatística para a maioria das variáveis avaliadas, com exceção para os valores médios de glicemia (F:

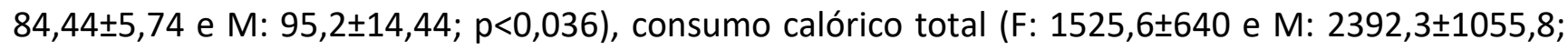
p<0,026) e consumo calórico proveniente dos produtos alimentícios ultraprocessados ( $F: 471,1 \pm 357,8$ e $M: 999,7 \pm 740,8 ; p<0,017$ ), que foram maiores entre os homens (Tabela 2). Observou-se também que a presença de SM foi maior entre os homens $(63,6 \% ; p<0,044)$. Não houve diferença entre os sexos para o grau de obesidade e de esteatose hepática, presença de obesidade central, HAS e RI. 
Tabela 2 - Comparação entre parâmetros sociodemográficos, clínicos e nutricionais segundo o gênero.

\begin{tabular}{lccc}
\hline Variáveis & $\begin{array}{c}\text { Sexo Feminino } \\
(\mathrm{n}=14)\end{array}$ & $\begin{array}{c}\text { Sexo Masculino } \\
(\mathrm{n}: 12)\end{array}$ & $\begin{array}{c}\text { p- } \\
\text { valor* }\end{array}$ \\
\hline Idade & $23,1 \pm 2,6$ & $23,4 \pm 3,1$ & 0,809 \\
\hline IMC & $42,6 \pm 4,6$ & $44,3 \pm 6,7$ & 0,460 \\
\hline CC & $129,7 \pm 12,0$ & $137,0 \pm 16,1$ & 0,201 \\
\hline PAS (mmHg) & $137,7 \pm 10,7$ & $142,4 \pm 13,3$ & 0,389 \\
\hline PAD (mmHg) & $87,0 \pm 10,2$ & $93,6 \pm 10,7$ & 0,163 \\
\hline Insulina (UI/ml) & $15,2(9,2-29-2)$ & $18,5(8,5-54,1)$ & 0,212 \\
\hline Glicemia (mg/dL) & $84,4 \pm 5,7$ & $95,2 \pm 14,4$ & 0,036 \\
\hline Hb Glicada (\%) & $5,6(5,0-9,1)$ & $5,3(4,7-6,5)$ & 0,177 \\
\hline HOMA -IR & $4,1(1,8-5,7)$ & $4,3(2,3-11)$ & 0,157 \\
\hline Caloria Total (Kcal) & $1525,6 \pm 640,0$ & $2392,3 \pm 1055,8$ & 0,017 \\
\hline Carboidratos (\%) & $48,1 \pm 13,1$ & $42,9 \pm 7,8$ & 0,246 \\
\hline Lipídeos (\%) & $34,2 \pm 9,4$ & $39,6 \pm 6,8$ & 0,115 \\
\hline Proteínas (\%) & $17,7 \pm 7,1$ & $17,5 \pm 5,8$ & 0,925 \\
\hline In natura ou & $45,7 \pm 21,4$ & $37,6 \pm 19,6$ & 0,324 \\
minimamente Processados (\%) & & & \\
\hline Processados (\%) & $10 \pm 10,8$ & $13,6 \pm 13,1$ & 0,442 \\
\hline Ultraprocessados (\%) & $30 \pm 21,2$ & $39,3 \pm 17,3$ & 0,241 \\
\hline Ingredientes Culinários (\%) & $14,3 \pm 16,6$ & $9,5 \pm 10,8$ & 0,405 \\
\hline Caloria do In natura ou & $708,7 \pm 375,0$ & $818,0 \pm 471,0$ & 0,514 \\
Minimamente Processados (kcal) & & & \\
\hline Caloria dos Ultraprocessado (Kcal) & $471,1 \pm 357,8$ & $999,7 \pm 740,8$ & 0,026 \\
\hline & & & \\
\hline
\end{tabular}

Variáveis apresentadas como média DDP ou mediana e mínimo e máximo (em parêntese). IMC: Índice de Massa Corporal. CC: cincunferência da cintura. PAS: pressão arterial sistólica. PAD: pressão arterial diastólica. Hb glicada: hemoglobina glicada. HOMA-IR: Índice Homeostasis Model Assessment. * Teste $t$ de Student ou Mann-Whitney.Diferença estatística quando $p<0,05$

Para fins de análise, categorizamos o consumo de ultraprocessados e in natura/minimamente processados, como maior e menor consumo segundo o valor mediano. Foi observado que metade $(n=13)$ dos participantes apresentou maior consumo de produtos alimentícios ultraprocessados, sendo evidenciado que estes ingerem mais calorias $(2310,37 \pm 1010,74 ; p<0,035)$ e menos proteína $(15,01 \pm 3,42 ; p<0,034)$ que os participantes do grupo de menor consumo de ultraprocessado. Para os demais parâmetros avaliados (idade, IMC, CC e parâmetros clínicos) não houve diferença estatisticamente significativa entre os grupos de maior e menor consumo de ultraprocessados (Tabela 3). 
Tabela 3 - Comparação dos parâmetros clínicos e nutricionais entre os grupos de maior e menor consumo de produtos alimentícios ultraprocessados.

\begin{tabular}{lccc}
\hline Variáveis & $\begin{array}{c}\text { Menor Consumo } \\
\text { ULTRA* } \\
(\mathrm{n}=13)\end{array}$ & $\begin{array}{c}\text { Maior Consumo } \\
\text { ULTRA* } \\
(\mathrm{n}=13)\end{array}$ & $\begin{array}{c}\text { p- } \\
\text { valor** }\end{array}$ \\
\hline Idade & $22,3 \pm 2,3$ & $24,2 \pm 3,0$ & 0,079 \\
\hline IMC & $42,5 \pm 5,5$ & $44,3 \pm 5,9$ & 0,421 \\
\hline CC & $134,4 \pm 14,3$ & $131,83 \pm 14,6$ & 0,654 \\
\hline PAS (mmHg) & $139,2 \pm 9,3$ & $141,2 \pm 15,0$ & 0,712 \\
\hline PAD (mmHg) & $89,1 \pm 13,0$ & $92,0 \pm 8,0$ & 0,549 \\
\hline Glicemia (mg/dL) & $88,2 \pm 6,5$ & $90,3 \pm 15,5$ & 0,694 \\
\hline Insulina (UI/ml) & $16,0(9,3-23,2)$ & $19,5(8,5-54,1)$ & 0,684 \\
\hline Hb Glicada (\%) & $5,3(4,8-9,1)$ & $5,5(4,7-6,5)$ & 0,971 \\
\hline HOMA - IR & $3,5(1,8-5,7)$ & $4,3(1,8-11,0)$ & 0,977 \\
\hline Caloria Total (Kcal) & $1540,9 \pm 726,5$ & $2310,4 \pm 1010,7$ & 0,035 \\
\hline Carboidratos $(\%)$ & $45,3 \pm 14,5$ & $46,0 \pm 6,6$ & 0,877 \\
\hline Lipídeos $(\%)$ & $34,4 \pm 9,8$ & $38,9 \pm 6,8$ & 0,186 \\
\hline Proteínas $(\%)$ & $20,2 \pm 7,7$ & $15,0 \pm 3,4$ & 0,034 \\
\hline Ômega 3 (\%) & $14,7 \pm 10,2$ & $13,4 \pm 4,7$ & 0,670 \\
\hline Ômega 6 (\%) & $1,8 \pm 1,4$ & $1,7 \pm 1,3$ & 0,768 \\
\hline Gordura Monoinsaturada $(\%)$ & $30,2 \pm 6,1$ & $31,3 \pm 6,5$ & 0,650 \\
\hline Gordura Poliinsaturada $(\%)$ & $18,4 \pm 9,6$ & $16,8 \pm 5,9$ & 0,614 \\
\hline Gordura Saturada $(\%)$ & $31,7 \pm 8,0$ & $37,7 \pm 9,4$ & 0,092 \\
\hline Gordura Trans $(\%)$ & $2,6 \pm 2,3$ & $3,7 \pm 3,0$ & 0,310 \\
\hline
\end{tabular}

Variáveis apresentadas como média‡DP ou mediana e mínimo e máximo (em parêntese). * Menor consumo de ULTRA: consumo <541,2kcal. *Maior consumo de ULTRA: consumo >541,2kcal. IMC: Índice de Massa Corporal. CC: cincunferência da cintura. PAS: pressão arterial sistólica. PAD: pressão arterial diastólica. Hb glicada: hemoglobina glicada. HOMA-IR: Índice Homeostasis Model Assessment. ${ }^{* *}$ Teste $\mathrm{t}$ de Student ou MannWhitney. Diferença estatística quando $p<0,0$ 
Tabela 4 - Comparação dos parâmetros clínicos e nutricionais entre os grupos de maior e menor consumo de alimentos in natura ou minimamente processados.

\begin{tabular}{|c|c|c|c|}
\hline Variáveis & $\begin{array}{l}\text { Menor consumo } \\
\text { IN NAT + MP* } \\
(n=12)\end{array}$ & $\begin{array}{c}\text { Maior consumo } \\
\text { IN NAT + MP* } \\
(n=14)\end{array}$ & p-Valor** \\
\hline Idade & $23,3 \pm 2,8$ & $23,2 \pm 2,9$ & 0,916 \\
\hline IMC & $42,9 \pm 4,5$ & $43,9 \pm 6,6$ & 0,654 \\
\hline CC & $130,5 \pm 11,4$ & $135,3 \pm 16,4$ & 0,408 \\
\hline PAS (mmHg) & $139,2 \pm 11,3$ & $140,8 \pm 13,0$ & 0,770 \\
\hline PAD (mmHg) & $88,9 \pm 6,1$ & $91,7 \pm 13,4$ & 0,571 \\
\hline Glicemia (mg/dL) & $90,8 \pm 15,3$ & $87,8 \pm 6,7$ & 0,574 \\
\hline Insulina (UI/mL) & $19,5(8,5-32,6)$ & $16,5(9,3-54,1)$ & 0,796 \\
\hline Hb glicada (\%) & $5,6(5,2-6,5)$ & $5,3(4,7-9,1)$ & 0,143 \\
\hline HOMA - IR & $4,3(1,8-10,1)$ & $3,6(1,8-11,0)$ & 0,733 \\
\hline Caloria total (kcal) & $1566,8 \pm 678,3$ & $2233,2 \pm 1056,5)$ & 0,073 \\
\hline Carboidratos (\%) & $45,1 \pm 10,1$ & $46,1 \pm 12,2$ & 0,833 \\
\hline Lipídeos (\%) & $39,6 \pm 8,4$ & $34,2 \pm 8,3$ & 0,118 \\
\hline Proteínas (\%) & $15,3 \pm 3,9$ & $19,6 \pm 7,5$ & 0,084 \\
\hline Ômega 3 (\%) & $13,0 \pm 7,3$ & $15,0 \pm 8,4$ & 0,531 \\
\hline Ômega 6 (\%) & $1,8 \pm 1,4$ & $1,7 \pm 1,3$ & 0,822 \\
\hline Gordura Monoinsaturada (\%) & $31,1 \pm 7,3$ & $30,4 \pm 5,4$ & 0,770 \\
\hline Gordura Poliinsaturada (\%) & $15,6 \pm 5,7$ & $19,3 \pm 9,1$ & 0,237 \\
\hline Gordura Saturada (\%) & $35,9 \pm 6,4$ & $33,7 \pm 11,0$ & 0,538 \\
\hline Gordura Trans (\%) & $3,2 \pm 2,5$ & $3,2 \pm 3,0$ & 0,972 \\
\hline \multicolumn{4}{|c|}{$\begin{array}{l}\text { Variáveis apresentadas como média } \pm D P \text { ou mediana e mínimo e máximo (em parêntese). }{ }^{*} \text { Menor consumo } \\
\text { de in natura e minimamente processados: consumo }<644,59 \mathrm{kcal} \text {. }{ }^{*} \text { Maior consumo de in natura e } \\
\text { minimamente processados : consumo }>644,59 \mathrm{kcal} \text {. IMC: Índice de Massa Corporal. CC: circunferência da } \\
\text { cintura. PAS: pressão arterial sistólica. PAD: pressão arterial diastólica. Hb glicada: hemoglobina glicada. } \\
\text { HOMA-IR: Índice Homeostasis Model Assessment. }{ }^{* *} \text { Teste t de Student ou Mann-Whitney. Diferença } \\
\text { estatística quando }<0,05\end{array}$} \\
\hline
\end{tabular}

Em relação ao consumo de alimentos in natura e minimamente processados, verifica-se que $46,2 \%$ ( $n=12)$ dos obesos apresentam consumo menor que o valor calórico mediano, sendo categorizados no grupo de menor consumo. Comparando o grupo de indivíduos que apresentaram maior consumo de alimentos in natura ou minimamente processados com os de menor consumo, não foi evidenciada diferença estatística para nenhum parâmetro avaliado (Tabela 4).

\section{DISCUSSÃO DOS RESULTADOS}

Estudos atuais têm demonstrado o papel do estilo de vida, com destaque para a alimentação, na etiopatogenia da obesidade e da DHGNA $(6,22,23,24)$. No presente estudo, avaliamos o perfil de 
consumo alimentar dos participantes em termos da quantidade de nutrientes consumidos, mas também sob a ótica do grau de processamento industrial dos alimentos. Além disso, avaliamos se o perfil clínico e nutricional é diferente entre os indivíduos que consomem mais ou menos produtos ultraprocessados ou alimentos mais naturais (in natura ou minimamente processados). Para nosso conhecimento, este é o primeiro estudo que faz essa avaliação em indivíduos obesos com DHGNA.

A ocorrência de DHGNA é fortemente ligada à obesidade, resistência à insulina, HAS e outros componentes da SM, sendo considerada inclusive, uma manifestação hepática desta síndrome. Em particular, os indivíduos que apresentam uma das características da SM estão em risco aumentado para o desenvolvimento de DHGNA em comparação com os que não a possui ${ }^{(4,9)}$.

De fato, no presente estudo evidencia-se que o grupo de indivíduos obesos avaliados apresenta um perfil de risco favorável ao desenvolvimento de DHGNA, uma vez que apresentam uma ou mais anormalidades metabólicas característica da SM. Embora somente cerca de $40 \%$ dos indivíduos apresentam o diagnóstico de SM, todos têm aumento da CC e a maior parte (71\%) apresenta RI, fatores fortemente associados ao acúmulo de gordura no tecido hepático $(9,22$,$) .$

Segundo Oseini e Sanyal ${ }^{(25)}$ o acúmulo de gordura no fígado pode se dar pelo aumento do consumo de gordura, ou por desregulação da microbiota intestinal, sendo que ambas as formas permitirão que mais lipídios cheguem ao fígado oriundos do intestino. Também descreve como sendo possível que a doença se desenvolva devido ao influxo aumentado de ácidos graxos livres não esterificados advindos do tecido adiposo branco para o fígado. Já como terceira alternativa sugere que ocorra pelo aumento da lipogênese hepática a partir do excesso de carboidratos da dieta e/ou pela hiperinsulinemia gerada devido à RI. Este último mecanismo, deve ser destacado, uma vez que a RI é uma condição comum tanto na obesidade como na DHGNA, podendo ser um importante fator envolvido nas alterações metabólicas e clínicas observadas nos indivíduos avaliados neste estudo.

Vários mecanismos estão implicados na RI em obesos, e podem consequentemente, estar envolvido também na DHGNA. A obesidade e o excesso de nutrientes principalmente das gorduras saturadas, contribuem para o aumento de ácidos graxos livres e ativação de vias inflamatórias, com consequente aumento dos níveis de citocinas inflamatórias, como o TNF $\alpha$ (fator de necrose tumoral alfa) e IL-6 (interleucina 6), que por sua vez alteram várias etapas da via de sinalização da insulina, bem como a translocação de GLUT4 para a membrana celular, prejudicando assim, a captação de glicose e favorecendo o desenvolvimento de $\mathrm{RI}^{(25)}$.

Embora, não haja consenso em relação à contribuição dos macronutrientes na DHGNA, não sendo determinada a quantidade ideal para prevenir tal morbidade, tem sido relatado que a alta ingestão de 
carboidrato e de gordura, principalmente a saturada, associa-se com maior predisposição à RI, e pode promover o desenvolvimento da $\operatorname{DHGNA}^{(9)}$. No presente estudo foi evidenciado um consumo relativamente alto ( $37 \%$ do valor calórico total) de gordura, sendo grande parte advinda de fontes alimentares rica em gordura saturada. Em relação aos carboidratos, o consumo foi de $45,7 \%$, o que não é considerado alto consumo. Entretanto, é importante avaliar a qualidade do carboidrato consumido.

No presente estudo foi evidenciado que os produtos alimentícios ultraprocessados contribuem de forma semelhante aos alimentos in natura ou minimamente processados para a ingestão calórica dos obesos avaliados. Ressalta-se que esses produtos alimentícios prontos para o consumo possuem baixa qualidade nutricional, e de forma geral, têm grandes quantidades de carboidrato simples e gordura saturada, assim como baixo teor de fibra(18).

Apesar de não haver uma diretriz precisa de ingestão de ultraprocessados considerada segura, a recomendação atual é de que o consumo desses produtos industrializados seja a menor possível, pois o seu consumo excessivo tem sido associado a várias doenças crônicas, como obesidade, diabetes mellitus, HAS ${ }^{(18,26) .}$ Observou-se que mais de um terço das calorias consumidas foram provenientes de produtos alimentícios ultraprocessados, o que pode ser considerado relativamente alto para esta população, constituída de indivíduos com obesidade.

Quando analisada a diferença entre parâmetros clínicos e nutricionais segundo o gênero, observa-se que os homens apresentaram maior consumo calórico total e maior consumo calórico advindo de produtos alimentícios ultraprocessados. Desta forma, a maior ingestão desses produtos provavelmente é um fator que contribui para alta ingestão calórica nos homens, já que esses produtos em geral, têm maior densidade calórica.

Semelhante a esse dado foi observado no estudo de Nardocci et al. ${ }^{(27)}$, que os indivíduos do sexo masculino apresentaram maior consumo de ultraprocessados, o que consequentemente contribuiu para que a ingestão calórica fosse superior nos homens quando comparado com as mulheres. No estudo de Lee Anne et al. ${ }^{(28)}$ o mesmo sugere que o consumo de ultraprocessados ser inferior entre as mulheres quando comparadas aos homens, se deve a uma cultura em que as tradições culinárias são passadas geralmente para as mesmas em conjunto com o fato de em grande parte dos domicílios são as mulheres as responsáveis pelo preparo das refeições caseiras. Em concordância, Nardocci et al. (27) associa as refeições caseiras com alimentos mais saudáveis e com menor nível de processamento. O padrão de consumo alimentar observado nos homens avaliados no presente estudo pode de certa forma, colaborar para os maiores níveis de glicemia de jejum e maior prevalência de SM quando 
comparado com as mulheres. Os ultraprocessados são produtos que possuem altos níveis de gordura saturada, glicose, frutose e sal, fatores que aumentam a palatabilidade destes, o que contribui para o consumo excessivo de energia, e destes componentes dietéticos, que sabidamente favorecem o desenvolvimento da obesidade e da Rl, bem como das comorbidades associadas a estas, como a

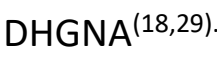

Neste estudo foi incluído no grupo de maior consumo de ultraprocessados, os indivíduos que apresentaram consumo calórico acima do valor mediano, sendo observado que metade dos indivíduos avaliados ( $n=13$ ) se incluía nesta categoria. Como era de se esperar, foi observado que estes ingerem significativamente mais calorias e menos proteína que os indivíduos categorizados com menor consumo de ultraprocessado. Para os demais parâmetros nutricionais e para os clínicos, não foi evidenciada diferença entre os indivíduos que apresentaram maior ou menor consumo de ultraprocessados.

Quando considerado o consumo de in natura ou minimamente processados, verificamos que quase metade dos indivíduos foram categorizados com menor consumo, não sendo evidenciada diferença estatísticas entre os grupos de maior e menor consumo.

Cabe mencionar, que nem todos os pacientes quiseram realizar os exames bioquímicos, de forma, que esse fator pode ter contribuído para não ter sido encontrada diferença estatística entre parâmetros clínicos e o consumo alimentar, comprometendo alguns resultados esperados.

Setyowati, Andarwulan e Giriwono(29) evidenciaram que os indivíduos que apresentaram menor consumo calórico também eram os que consumiam menor quantidade de ultraprocessados e também apresentavam maior percentual de contribuição calórica advindo de proteínas, ou seja, esses indivíduos consumiam em maior quantidade alimentos em outros níveis de processamento (in natura/minimente processados ou processados) que não possuíam a carga calórica excessiva apresentada pelos ultraprocessados, e provavelmente eram mais equilibrados em relação à proporção entre carboidratos, lipídeos e proteínas.

É importante ressaltar, que apesar de não ter sido encontrada diferença estatística entre os grupos de maior e menor consumo de ultraprocessados ou entre os de maior e menor consumo de in natura/minimamente processados, acredita-se que os indivíduos categorizados entre os de maior consumo de ultraprocessados e os considerados de menor consumo de in natura/minimamente processados, provavelmente são os que estão em maior risco de desenvolver excesso de peso corporal e as comorbidades associadas, como a DHGNA. Desta forma, é necessário para a melhora do quadro desses indivíduos, a implementação o mais precocemente possível, de mudanças no estilo de vida 
destes, com atenção para a alimentação, que como foi demonstrada pelo presente estudo, apresenta inadequações tanto quantitativas como qualitativas.

O tratamento para esses indivíduos, devido à obesidade e a presença da esteatose hepática não alcoólica, tem como base a perda de peso corporal, prática de atividade física e reeducação alimentar. Medidas que devem ser mantidas por longo prazo para se alcançar resultados satisfatórios, focando sempre na recuperação da saúde metabólica desses indivíduos ${ }^{(5)}$.

Segundo a American Association for the Study of Liver Diseases (AASLD) uma perda de peso satisfatória está em torno de 3 a 5\% do peso, e quando ótima em torno de 10\%, sendo esse resultado positivo para melhora dos processos inflamatórios decorrentes da liberação excessiva de espécies reativas de oxigênio que ocorrem devido à obesidade e a esteatose hepática não alcóolica ${ }^{(31)}$. Sendo assim, é recomendada a modificação dos hábitos alimentares, focando em uma dieta hipocalórica, rica em ácidos graxos monoinssaturados (MUFAS), ômega-3, e em alimentos com menor nível de processamento industrial, buscando introduzir o que seria uma dieta com características mais mediterrâneas ${ }^{(6,9)}$.

Ainda como uma medida preventiva no tratamento da DHGNA e que estará de acordo com a melhora no perfil alimentar do individuo é a sugestão de Cantero et al. ${ }^{(30)}$ que citam que uma dieta rica em fibras, com maior quantidade de alimentos integrais, verduras e frutas, ou seja, rica em alimentos in natura, possa prevenir a ocorrência e/ou evolução da DHGNA. Como já abordado, neste estudo o consumo de alimentos in natura/minimamente processados foi semelhante ao de ultraprocessados, o que pode ser considerado inadequado, uma vez que o ideal seria um consumo maior que o de ultraprocessados. Embora, não tenha sido avaliada a ingestão de fibras, é provável que o consumo esteja baixo, em função deste padrão alimentar apresentado.

As limitações deste estudo incluem o fato de ser um estudo transversal que não permite a avaliação de relações temporais; a amostra ser não probabilística tendo um número amostral limitado à demanda do serviço e a falta de dados bioquímicos de alguns pacientes que não quiseram realizar o exame. Esses fatores dificultam uma análise estatística robusta e que permita fazer associações. Além disso, o uso de um R24h de dia típico para avaliar o consumo alimentar habitual apresenta limitações relativas à obtenção de dados precisos, tais como a memória dos participantes, a dificuldade de estimar o porcionamento dos alimentos, além da limitação do software utilizado que não possuem todos os alimentos. Esses fatores podem contribuir para subestimar o consumo dos participantes. 
Com o objetivo de amenizar tais fatos, foi realizado treinamento para aplicação do R24, sendo este aplicado a todos os pacientes pelo mesmo pesquisador, bem como foi utilizado álbum fotográfico para auxiliar os participantes na estimativa das porções.

Ressalta-se que a maioria dos estudos avalia os nutrientes de forma isolada, ao invés de avaliar padrões alimentares; entretanto, os indivíduos não consomem nutrientes isolados, e sim, refeições constituídas por uma variedade de alimentos com combinações complexas de nutrientes e bioativos. Desta forma, o presente estudo reafirma a necessidade de avaliação global da alimentação do indivíduo, inclusive focando no grau de processamento dos alimentos.

\section{CONCLUSÃO}

Os indivíduos avaliados apresentaram um padrão alimentar que pode ser considerado de risco para o desenvolvimento de obesidade e de DHGNA, uma vez que os produtos alimentícios ultraprocessados contribuíram com mais de um terço para a ingestão calórica, e metade dos obesos foram categorizados no grupo de maior consumo desses produtos, possuindo maior ingestão calórica e menor ingestão proteica, sendo os homens, com mais inadequação nos perfis de consumo alimentar e clínico. 


\section{6-BIBLIOGRAFIA:}

1. Dias PC, Henriques P, dos Anjos LA, Burlandy L. Obesidade e políticas públicas : concepções e estratégias adotadas pelo governo brasileiro. Cad de Saúde Pública, Niterói, jan., 2017, 33 (7):112.

2. Nibi FA, Osti C. Cuidados Intensivos no Pós-Operatório Imediato de Cirurgia Bariátrica. Revista Uningá, Maringá, , jan., 2014, 39: 149-158.

3. Horn RC, Gelatti GT, Mori NC, Tissiani Ac, Mayer MS, Pereira EA et al. Obesity, bariatric surgery and oxidative stress. Rev Assoc Med Bras, Cruz Alta, , jan., 2017, 63 (3):229-235.

4. Moore JB. Conference on 'Over- and undernutrition: challenges and approaches': Symposium 1: Overnutrition: consequences and solutions Non-alcoholic fatty liver disease: the hepatic consequence of obesity and the metabolic syndrome. Proc Nutr Soc, Guilford, jun., 2010, 69: 211-220.

5. Reis TO, Ferolla SM, Lima MLP, Fausto MA, Albricker ACL, de Almeida Armiliato GN et al. Nonalcoholic fatty liver disease: a cohort study focusing on treatment response to nutritional counseling. MedicalExpress ,São Paulo, jan., 2015, 2(2): 1-6.

6. Mahadya SE, Georgea J. Exercise and diet in the management of nonalcoholic fatty liver disease. Metab. Clin. Exp, (S.I.), 65 : 1172-1182, JAN., 2016. Doi: 10.1016/j.metabol.2015.10.03

7. Marchesini G, Day CP, Dufour JF, Canbay A, Nobili V, Ratziu V et al. Normas de Orientação Clínica da EASL, EASD e EASO sobre a abordagem da doença hepática não alcoólica. Journal of Hepatology, Geneva, jan., 2016 64: 1388-1402.

8. Fan JG, Cao HX. . Role of diet and nutritional management in non-alcoholic fatty liver disease. JGH, Shanghai, mar., 2013, 28 (4): 81-87.

9. Asrih M, Jornayvaz FR. Diets and nonalcoholic fatty liver disease: The good and the bad. Eur E J Clin Nutr Metab, 2014, 33:186e190.

10. Lisboa QC, Costa SMF, Couto CA. Current management of non-alcoholic fatty liver disease. Rev Assoc Med Bras, Belo Horizonte, jan., 2016, 62(9): 872-878.

11. WHO. Physical status: the use and interpretation of anthropometry. Geneva, Switzerland:WHO; 1995. (WHO Technical Report Series 854).

12. Saadeh S, Younossi ZM, Remer EM, Gramalich T, Ong JP, Hurley M et al. The Utility of Radiological Imaging in Nonalcoholic Fatty Liver Disease. Cell Mol Gastroenterol Hepatol, (S.I.), set., 2002, 123(3): 745-750.

13. American Gastroenterological Association (2002) American Gastroenterological Association medical position statement: nonalcoholic fatty liver disease. Gastroenterology 123:1702-1704.

14. Brasil. Orientações básicas para a coleta, processamento, análise de dados e informação em serviços de saúde: norma técnica do Sistema de Vigilância Alimentar e Nutricional - SISVAN, Brasília, Ministério da Saúde, 2011. 
15. World Health Organization. Obesity: preventing and managing the global epidemic. Geneva: World Health Organization; 1998. (WHO Technical Report Series 894).

16. Monteiro JP, Pfrimer K, Tremeschin MH, Molina MC, ChiarelloP. Nutrição e Metabolismo : CONSUMO ALIMENTAR - Visualizando Porções,1ํed. Rio de Janeiro, 2007.

17. MOUBARAC, J.C.; PARRA, D.C.; CANNON, G.; MONTEIRO, C.A. Food classification systems based on food processing: significance and implications for policies and actions: a systematic literature review and assessment. Curr Obes Rep., 2014, 3 (2): 256-72.

18. Louzada MLC, Martins APB, Canella DS, Baraldi LG, Levy RB, Claro RM et al. Impacto de alimentos ultraprocessados sobre o teor de micronutrientes da dieta no Brasil. Rev Saude Publica, São Paulo, abr., 2015, 49(45):1-8.

19. Malachias MVB, Souza WKSB, Plavnik FL, Rodrigues CIS, Brandão AA, Neves MFT et al. 7ạ Diretriz Brasileira de Hipertensão Arterial, Arq Bras Cardiol, 70 ed. Rio de Janeiro, SBC, 2016, 107:11 p.

20. Giuliano ICB, Caramelli B, Pellanda L, Duncan B, Mattos S, Fonseca FH. I Diretriz de prevenção da aterosclerose na infância e na adolescência. Arq. Bras Cardiol, Rio de Janeiro, dez., 2005, 85 (Suppl 4): 3-36.

21. INTERNATIONAL DIABETES FEDERATION - IDF. The IDF consensus worldwide definition of the metabolic syndrome. IDF, 2006, 16 p.

22. Paris T, George ES, Roberts SK, Tierney AC. The effects of diet and lifestyle interventions on insulin resistance in patients with nonalcoholic fattyliver disease: a systematic reiew. Eur J Gastroenterol Hepatol, ago., 2017, 29 (8):867-878.

23. Zou T, Zhang C, Zhou YF, Han YJ, Xiong JJ, Wu XX et al.Lifestyle interventions for patients with nonalcoholic fatty liver disease : a network meta-analysis. . Eur J Gastroenterol Hepatol, jul., 2018, 30(7): 747-755.

24. Anania C, Perla FM, Olivro F, Pacifico L, Chiesa C. Mediterranean diet and nonalcoholic fatty liver disease. World J Gastroenterol, 21 mai., 2018, 24(19): 2083-2094.

25. Oseini A, Arun J. Therapies In Non- Alcoholic Steatohepatitis. Liver Int. Jan., 2017, 37(Suppl 1): 97-103.

26. BRASIL. Ministério da Saúde. Guia alimentar para a população brasileira. 2. ed. Brasília: Ministério da Saúde, 2014.

27. Nardocci M, Leclerc BS, Louzada ML, Monteiro CA, Batal M. Consumption of ultra-processed foods and obesity in Canada. Can J Public Health, 20 set., 2018, 11 p.

28. Lee Anne F, Bisakha S, Kilgore ML, Locher JL. The influence of gender, age, education and household size on meal preparation and food shopping responsabilities. Public Health Nutr. 2014 September ; 17(9): 2061-2070. 
29. Setyowati D, Andarwulan N, Giriwono PE. Processed and ultraprocessed food consumption pattern in the Jakarta Individual Food Consumption Survey 2014. Asia Pac J Clin Nutr. 2018, 27(4):840-847.

30. Cantero I, Abete I, Monreal JI, Martinez JA. Fruit Fiber Consumption Specifically Improves Liver Health Status in Obese Subjects under Energy Restriction. Nutrients. JUN., 2017, 9 (667): 1-12. 


\section{Capítulo 8}

doi $10.37423 / 211205120$

\section{ATENDIMENTO FISIOTERAPÊUTICO EM PACIENTE LESADO MEDULAR: RELATO DE EXPERIÊNCIA}


Introdução: Entende-se por lesão medular toda injúria às estruturas contidas no canal medular, podendo levar a alterações motoras, sensitivas, autonômicas e psicoafetivas. Trata-se de uma síndrome neurológica incapacitante que pode resultar em danos graves e distúrbios neurovegetativos abaixo do nível da lesão, com consequências em diversos órgãos e sistemas. Esta pode ser classificada como tetraplegia ou como paraplegia, dependendo do nível da lesão.

Objetivo: Relatar a experiência de atendimento a um paciente com diagnóstico clínico de lesão medular na Clínica Escola de Fisioterapia da Universidade Federal de Goiás (UFG) - Regional Jataí.

Metodologia: Foi realizado atendimento a um paciente do sexo masculino, 32 anos, com diagnóstico clínico de lesão medular nível C4-C5. Após avaliação e traçado os objetivos e condutas foi estabelecido realizar mobilizações, alongamentos, fortalecimento, treino respiratório e de mudança de decúbito, orientações referentes a atividades de vida diária. As sessões ocorriam 2 vezes por semana por 50 minutos, totalizando 7 atendimentos.

Resultados: Foi observado ganho de ADM e força da musculatura do complexo do ombro, tronco e pescoço, o que resultou em facilitação da movimentação ativa da musculatura íntegra. Auxílio nas mudanças de decúbito e houve analgesia da dor relatada em ombro direito. Apesar dos ganhos o quadro de lesão medular é irreversível, impossibilitando ao paciente um bom prognóstico e sendo necessário acompanhamento fisioterapêutico contínuo.

Conclusão: Em suma os atendimentos fisioterapêuticos foram benéficos, havendo assim a necessidade de continuidade do acompanhamento a fim de permanecerem os ganhos funcionais até o dado momento.

Palavras-Chave: Lesão medular; cinesioterapia; fisioterapia. 


\section{Capítulo 9}

doi $10.37423 / 211205121$

\section{REDES DE ATENÇÃO À SAÚDE, PANORAMA E DESAFIOS NA PERSPECTIVA DE GESTORES, PROFISSIONAIS E USUÁRIOS}


Resumo: Objetivou-se analisar a percepção de gestores, profissionais e usuários sobre as Redes de Atenção à Saúde em Lages/SC. Fundamentou-se na perspectiva da hermenêutica-dialética do decálogo Minayo 1, com abordagem quali-qualitativa, Os participantes, 12 gestores sendo da UBS e rede com roteiro semiestruturado; quanto aos profissionais foram 06 grupos focais e usuários da UBS e rede totalizando 70 entrevistados. Análise dos dados foi descritiva de frequência simples, por agrupamento, delimitadas em categorias e subcategorias. Revelaram-se fragilidades na estrutura e funcionamento das redes, como dificuldade no acesso, deficiência na articulação e comunicação entre os diferentes pontos da rede. Os resultados indicam deficiência na compreensão dos profissionais acerca da RAS e na organização do sistema de serviços de saúde; no que tange os usuários evidenciouse a excessiva utilização da UBS nas condições agudas. Conclui-se não existir uma RASs efetiva no município, ainda está incipiente, impossibilitando a integralidade na perspectiva do cuidado e articulação entre os atores envolvidos, para que sejam superados os obstáculos através de estratégias que assegurem a efetivação das RASs.

Palavras-Chave: Saúde; Redes de Atenção a Saúde; Atenção Primária a Saúde. 


\section{INTRODUÇÃO}

No processo histórico da estruturação atual do modelo assistencial brasileiro, a Constituição Federal de 1988 é um marco importante para o setor de saúde porque se definiu como setor de relevância pública, ficando o estado, a partir desta definição, obrigado a garantir, independente de solicitação, as condições necessárias ao atendimento à saúde da população.

A conquista da saúde como direito legítimo de cidadania é um fundamento básico da Saúde como estratégia de mudança, significa repensar as práticas e os conhecimentos de todas as pessoas envolvidas no processo de produção social da saúde.

A partir disto surge o Modelo de Saúde da Família implantado em 1994 que busca viabilizar o Sistema Único de Saúde (SUS) e seus princípios, e deve portanto, estar distinto dos demais programas tradicionais do setor saúde, pois, estes se configuram na maioria das vezes, em ações paralelas contrárias a lógica do sistema de saúde. O entendimento do que significa a Estratégia de Saúde da Família (ESF) só é possível em contraposição ao modelo atual, buscando como objeto de atenção o indivíduo enquanto membro de uma família e um cidadão da comunidade (BRASIL, 2006).

Nesse contexto surge a Atenção Primária à Saúde (APS) que se caracteriza por uma atenção ambulatorial não especializada ofertada através de unidades de saúde de um sistema, que se caracteriza pelo desenvolvimento diversificado de "atividades clínicas de baixa densidade tecnológica, ou seja, atividades de saúde pública, onde se pode destacar que a APS está colocada ao centro dos sistemas" (MENDES, 2011, p. 84)

Desta forma, a APS se torna importante para a organização da RAS, onde se configura como sendo a principal estratégia para a coordenação do cuidado em saúde. Nas RAS, a concepção de hierarquia é substituída e o sistema se organiza sob a forma de uma rede horizontal de atenção à saúde.

As RAS surgem formalmente, através da Portaria no 4.279 de 30 de dezembro de 2010, que a define como "arranjos organizativos de ações e serviços de saúde, de diferentes densidades tecnológicas que, integradas por meio de sistemas de apoio técnico, logístico e de gestão, buscam garantir a integridade do cuidado" (BRASIL, 2010, n.p.).

As RAS são conjunto de serviços de saúde, vinculados entre si por uma missão única, objetivos comuns, que permite ofertar uma "atenção primária prestada em tempo certo, lugar certo, custo certo, com qualidade, de forma humanizada, com responsabilidades sanitárias e econômicas por esta população", conforme indica Mendes (2010, p. 2300). 
Diante disto, pretendeu-se respostas à pergunta: Qual a percepção de gestores, profissionais e usuários sobre as Redes de Atenção à Saúde de um município de médio porte do estado de Santa Catarina?

As Redes de Atenção à Saúde (RAS) são apontadas como nova possibilidade no Sistema Único de Saúde (BRASIL, 2010), a partir da identificação da insuficiência do modelo de saúde vigente que não tem conseguido alcançar respostas resolutivas aos desafios sanitários: persistência de práticas de cunho curativas, centrados no médico, com fragmentação de ações e serviços, baixa eficiência na aplicação dos recursos, precarização e carência de profissionais alinhados com a política pública e configuração inadequada de modelos de atenção, dentre outros. Este trabalho parte da premissa da necessidade de pesquisas acerca da estruturação das RAS em contextos locais específicos, devido ao seu caráter inovador enquanto nova proposta de organização de serviços visando alcançar melhores práticas clínicas com mecanismos organizacionais mais eficientes

\section{BREVE REVISÃO DE LITERATURA}

A seguir, são apresentados os aportes teóricos principais que guiaram a pesquisa,

\section{O MODELO DE ATENÇÃO À SAÚDE NO BRASIL}

Com a promulgação da Constituição Federal de 1988, a saúde passou a ser um direito social, de base legal, um novo modelo de atenção à saúde no país, o Sistema Único de Saúde - SUS.

O movimento da Reforma Sanitária lutou para a concretização do Sistema Único de Saúde - SUS, bem como provou sua força ao inscrever em dispositivos legais um olhar ampliado sobre o conceito de saúde, tendo como conquistas a Lei de $\mathrm{n}$ - 8.080, que por sua vez culmina com o surgimento da Lei de no 8.142 que prevê a participação comunitária no SUS, que juntas formam a Lei Orgânica da Saúde (LOS).

Apesar dos avanços legais, as transformações que estas leis sugerem não se efetivaram na prática. Visto que a luta em prol da efetivação do SUS, não é um movimento individualizado, mas da sociedade como um todo.

A criação do SUS e as Normas Operacionais Básicas (NOB) no 01/93 e 01/96 estabelece os sistemas de saúde como forma de implementar os princípios definidos pela constituição através da descentralização, regionalização e integração com as redes assistenciais como diretrizes fundamentais, exigindo-se dos profissionais de saúde novas práticas na gestão. Desta forma, percebe- 
se a necessidade de se ter profissionais com um novo perfil para atuar no sistema, a partir da perspectiva multiprofissional e interdisciplinar.

Conforme destaca Silva (2011, p. 2755) "é importante lembrar que o SUS deve se organizar em redes, conforme determina a Constituição e, portanto, esse tema esteve presente, de forma explícita ou implícita, na agenda da reforma sanitária desde o seu início".

Ainda de acordo com Silva (2011, p. 2755) a publicação da Norma Operacional da Assistência à Saúde (NOAS/2001) "teve como um dos seus principais objetivos suprir essa lacuna, dando proeminência à necessidade de formação de redes integradas".

\section{ATENÇÃO PRIMÁRIA À SAÚDE}

De acordo com Lavras (2011, p. 868) a utilização do termo Atenção Primária à Saúde (APS)

[...] expressa comumente o entendimento de uma atenção ambulatorial não especializada ofertada através de unidades de saúde de um sistema, que se caracteriza pelo desenvolvimento de conjunto bastante diversificado de atividades clínicas de baixa densidade tecnológica, o que inclui, em muitos países, como no Brasil, as atividades de saúde pública.

Esses espaços se caracterizam como porta de entrada do sistema único de saúde, espaços estes onde deve ser realizado o primeiro contato com os usuários para identificação das necessidades trazidas pelos usuários do território de abrangência. Percebe-se que é comum as pessoas associarem as UBS a atendimentos realizados apenas para as populações em situações de vulnerabilidades sociais, não identificando o SUS como uma política pública de acesso universal e igualitário, que trabalha na perspectiva do coletivo.

As chamadas "doenças sociais" caminham quase como pano de fundo, desencadeando outros processos. "A vida doméstica e comunitária não é isolada, mas inserida na dinâmica política e econômica da sociedade como um todo" (VASCONCELOS, 1999, p. 12).

O Programa Saúde da Família (PSF) foi criado em 1994, como proposta do governo federal para prestar assistência em áreas de maior risco social, principalmente nas periferias, onde as situações de saúde pública são mais agravantes. Esta política de saúde toma dimensão em um cenário onde as pessoas estavam desacreditadas do SUS. Surge com objetivo de reorganizar a atenção básica a partir da implantação de Equipes de Saúde da Família (ESF) nos municípios de todo o Brasil. 
Pela primeira vez na história da saúde brasileira, o enfoque da atenção à saúde não mais se concentra somente no indivíduo, mas também na família e na comunidade que passa existir como unidade e com foco em ações de saúde pública, conforme afirmam Vianna e Dal Poz (1998).

Nesse aspecto que se apresenta como reorganizadora do modelo assistencial por meio de intervenções de saúde pautadas em parcerias, intersetorial capazes de potencializar as ações e o atendimento às demandas da comunidade, com vistas a resolutividade nos serviços, e, principalmente, trabalhando no aspecto preventivo junto às famílias através de ações educativas.

Este programa é considerado uma estratégia denominada de Estratégia de Saúde da Família (ESF) surge como forma de estruturar o sistema de saúde. Este modelo é organizado através de equipes multiprofissionais a qual têm o compromisso de trabalhar dentro dos princípios fundamentais do SUS, acompanhando as famílias cadastradas no território e com objetivo de trabalhar com de promoção e prevenção a saúde.

Porém, anos depois da implantação deste programa, existem obstáculos direcionados pela "ideologia flexneriana que impedem que se dê a devida continuidade no processo de expansão em que se encontra agora" (MENDES, 2002, p. 8). Superar este problema não é somente de ordem tecnicista, mas de uma mudança de concepção no sistema dos serviços de saúde (MENDES, 2002).

Mendes (2002, p. 6) afirma que os obstáculos encontrados na implantação da ESF decorrem nos "espaços político, ideológico e cognitivo-tecnológico". Os obstáculos "políticos" se caracterizam pela correlação de forças entre profissionais, gestores e o próprio sistema. Os de ordem "ideológica" se referem a mudança cultural, rompimento de paradigmas sobre a saúde e a ESF, trabalhando na lógica da produção social da saúde. E por fim, os obstáculos "cognitivo-tecnológicos" estão relacionados a necessidade da ESF obter novos conhecimentos e novas tecnologias que não é do pleno domínio dos gestores da saúde, mas sim de todos os profissionais e usuários, onde neste momento, entendemos também a necessidade do controle social se fazer presente não só em reuniões pontuais, mas estar presente nos territórios da ESF.

Portanto, o que se pode perceber é que tanto a ESF como a APS possuem obstáculos a serem superados como: a falta de compreensão sobre o real papel da ESF, adesão dos usuários nas atividades de grupo, a excessiva utilização da ESF na atenção às condições agudas, dificuldade de trabalhar na perspectiva do cuidado, infraestrutura inadequada das unidades básicas de saúde e com demandas muito além de sua capacidade física e técnica, falta de medicamentos essenciais, perfil dos 
profissionais de saúde inadequados para saúde pública, em quantidade e qualidade à ESF, entre outros.

\section{REDES DE ATENÇÃO À SAÚDE}

Silva (2011, p. 2756) define o conceito de "cadeia de valor" na atenção à saúde, tirando o foco das "condições agudas e dirigindo-o para as condições crônicas", dando ênfase a necessidade de ações preventivas e de promoção a saúde, individual e coletiva.

Para Mendes (2010, p. 2301) discutir a temática das RASs é fazer uma crítica à "fragmentação do SUS e ao desalinhamento do sistema". Para superação destes problemas, é necessário que "coordenem o sistema, reduzam as redundâncias, alinhem os objetivos com os incentivos financeiros, promovam a integração clínica e coordenem os mecanismos de governança”. O Conselho Nacional de Secretários de Saúde - CONASS (2006) coloca como um dos desafios do SUS "promover o alinhamento da situação de saúde com o modelo de atenção à saúde do SUS, por meio da implantação das RASs".

De acordo com Lavras (2011, p. 872) as redes de atenção à saúde são entendidas como:

[...] arranjos organizativos de unidades funcionais de saúde, pontos de atenção e apoio diagnóstico e terapêutico, onde são desenvolvidos procedimentos de diferentes densidades tecnológicas que, integrados através de sistemas de apoio e de gestão, buscam garantir a integralidade do cuidado.

A Rede de Atenção à Saúde é reafirmada como estratégia de reestruturação do sistema de saúde, tanto no que se refere a sua organização, quanto na qualidade e impacto da atenção, e representa o acúmulo e o aperfeiçoamento da política de saúde com aprofundamento de ações efetivas para a consolidação do SUS como política voltada para a garantia de direitos constitucionais de cidadania.

Nesse sentido, as Redes com IES, PET, PROSAÚDE são elementos importantes no processo de implementação e atuação via educação permanente nos processos formativos e de educação continuada.

\section{INTERSETORIALIDADE E INTERDISCIPLINARIDADE: DESAFIOS NA RAS}

A prática da intersetorialidade ainda se refere ao trabalho entre vários setores, além da fragmentação. No entanto, é importante que os diversos setores e da sociedade civil criem estratégias que favoreçam o trabalho em comum. 
Nesse sentido, a concepção de intersetorialidade pode ser denominada por uma concepção de condução dos problemas públicos, onde a administração pública tem sido apontada como um dos principais problemas para a não efetividade das políticas.

Segundo Inojosa (2001) e Junqueira (2004), em sua origem, o termo não incluía a participação da sociedade civil, nos dias atuais elas estão interligadas, avançando para se pensar o trabalho no cunho da intersetorialidade não mais como intersetores, ou seja, vários entes e atores se reunindo por um objetivo comum.

O desafio da intersetorialidade exige a concepção de uma nova forma de planejar, organizar, executar as ações, alterando a forma de articulação dos segmentos, que muitas vezes possuem percepções e interesses diferentes. Tal movimento requer a valorização e incremento dos saberes técnicos que garantem a qualidade do atendimento à população. Entretanto, é preciso conduzir esses diversos saberes a uma atuação articulada, assim, o desafio da intersetorialidade transcende o setor da saúde, permeando todos os segmentos, inclusive a formação dos profissionais da saúde.

Entender o conceito de interdisciplinaridade e suas contribuições para o trabalho em saúde é um dos desafios que se apresentam aos profissionais em saúde no contexto atual, e em razão disto, trago esta categoria para pautar a pesquisa, utilizando diferentes autores para fundamentar o mesmo.

Saupe, et al. (2005), demonstram, através de pesquisa, que a interdisciplinaridade se constrói a partir de uma realidade concreta, no âmbito da prática cotidiana e das demandas advindas dos usuários, sendo um dos caminhos que possibilita a aproximação de uma prática de atenção integral em saúde preconizada pela ESF e pela RASs.

O trabalho interdisciplinar pode levar os profissionais à reflexão sobre suas atitudes e ações necessárias aos trabalhadores em saúde para a efetivação de um fazer que vise a comunicação entre as diferentes áreas do conhecimento, que propicia um uma visão holística. Para Japiassu (1976, p. 74) "a interdisciplinaridade se caracteriza pela intensidade das trocas entre os especialistas e pelo grau de interação real entre as disciplinas".

Segundo Japiassu (1976, p. 75) a interdisciplinaridade é caracterizada pela "intensidade das trocas entre os profissionais". Já a multidisciplinaridade se caracteriza por uma "ação simultânea de uma gama de disciplinas em torno de uma temática comum", sendo essa atuação, no entanto, ainda muito fragmentada, não explorando a relação entre os conhecimentos disciplinares, não havendo nenhum tipo de cooperação entre as disciplinas como acontece na interdisciplinaridade, buscando uma 
religação entre as disciplinas, rompendo fronteiras, assegurando as características de cada uma e estabelecendo troca.

Como referem Saupe et al. (2005, p. 5), "não se é interdisciplinar o tempo todo, em alguns momentos se faz necessário o saber específico de uma disciplina", mas os profissionais necessitam estar atentos para reconhecerem situações interdisciplinares que exijam cooperação de outros membros da equipe. Portanto, é necessário que os profissionais "ultrapassem suas arrogâncias pessoais e a necessidade de exercer poder sobre outros", pois desta forma pode ser perdido o foco dos atendimentos em saúde que é o usuário (SAUPE et al., 2005, p. 5).

\section{PERCURSO METODOLÓGICO}

Os pressupostos teóricos nos quais se fundamenta a pesquisa têm sustentação na perspectiva teórica da hermenêutica - dialética (MINAYO, 2010).

Quanto a sua natureza, é um estudo de abordagem quali qualitativa, uma pesquisa de campo e exploratória.

Os sujeitos da pesquisa foram os gestores e profissionais das ESF, o estudo possui uma amostra de 30\% do total de 21 Unidades Básica de Saúde (UBS), ou seja, 06 UBS. Para alcançar essa amostra, foram sorteados $30 \%$ das UBS onde ocorreu a coleta dos dados através das entrevistas com os gestores, num total de 06 entrevistados, bem como 06 a 10 profissionais que fazem parte desta mesma UBS escolhidos de forma aleatória por manifestação espontânea dos mesmos para participação do grupo focal, totalizando 06 grupos.

Os profissionais que participaram do grupo focal foram da área de Medicina, Enfermagem, Odontólogo, Técnico de Enfermagem e Agente Comunitário de Saúde (ACS) e Técnico de Higiene Dental (THD).

Quanto aos gestores da rede foram entrevistados 06 (seis) sendo destes: Diretores, Gerentes e Coordenadores de Programas de Saúde, dentre eles profissionais da área de Medicina, Enfermagem, Serviço social e Psicologia.

Os usuários foram escolhidos de forma aleatória por manifestação espontânea dos mesmos no dia em que se realizou a coleta de dados nas USF e nos programas que compõem a rede de atendimento, sendo estes de 05 a 10 usuários de cada local, utilizando o critério de saturação, perfazendo um total de 70 usuários. 
O instrumento de coleta de dados utilizado na pesquisa aos gestores foi à entrevista semiestruturada e um grupo focal foi utilizado com os profissionais da ESF.

Os grupos foram compostos de 5 a 10 participantes com duração de aproximadamente uma hora à uma hora e meia, variando o tempo de acordo com o andamento da atividade.

O instrumento utilizado para coleta de dados na pesquisa aos usuários foi a entrevista estruturada, com perguntas fechadas, que possuem como respostas mais de uma das questões elencadas no instrumento.

Para o desenvolvimento da investigação foram observados os aspectos éticos conforme a Resolução 466/12 do Conselho Nacional de Pesquisa e aprovado pelo Comitê de Ética em Pesquisa, sob parecer nㅇ 091-2013.

A fim de assegurar o anonimato dos entrevistados optou-se por identificá-los com a letra "G" acompanhada pelo número da entrevista ficando da seguinte forma: Gestores da AB "GAB1 a GAB6; Gestores da Rede "GR1 a GR6" e Grupo Focal "GF1 a GF6".

As informações foram delimitadas em categorias e subcategorias e manuseadas de forma que, a partir das falas dos entrevistados, emergissem interpretações qualitativas.

\section{RESULTADOS E DISCUSSÃO}

Os resultados aqui apresentados referem-se às entrevistas aplicadas aos gestores, profissionais e usuários. Para fins deste artigo iremos efetuar uma análise avaliativa simples da rede de atenção à saúde, discutindo as principais categorias de análise quanto ao processo de estruturação das RAS e os demais níveis de atenção e sistema e serviços integrantes das RASs.

A pesquisa evidenciou a deficiência na compreensão dos profissionais acerca das RAS como uma estratégia de organização do sistema de serviços de saúde; a fragilidade institucional do SUS com falta de continuidade da atenção em saúde e infraestrutura inadequada das unidades básicas de saúde e dos demais serviços que compõem a rede; por parte dos usuários ficou evidenciado a excessiva utilização da UBS na atenção às condições agudas dificulta o processo de consolidação das RAS. 


\section{PROCESSO DE ESTRUTURAÇÃO RAS E ARTICULAÇÃO DA APS E DEMAIS NÍVEIS DE ATENÇÃO À}

\section{SAÚDE}

No que se refere ao processo de estruturação das RASs a pesquisa evidenciou que $(41,66 \%)$ dos entrevistados desconhece qualquer tipo de estruturação, no entanto as demais (8,33\%) como rede cegonha, urgência e emergência e psicossocial que de fato estão se organizando por conta do Programa de Educação pelo Trabalho para a Saúde (PET - Redes de Atenção à Saúde - do Ministério da Saúde) parceria entre a Uniplac e a Secretaria Municipal de Saúde de Lages, os gestores e profissionais não tem conhecimento se quer da sua existência.

Quanto ao que foi identificado como incipiente os dados nos mostram que $(58,33 \%)$ dos entrevistados não sabem sobre o que se trata as RASs, não identificando desta forma o que se apresenta incipiente na RAS, a seguir com (50\%) referem-se a referência e contra referência como sendo um dos nós críticos da RAS, seguido (33,33\%) da falta de comunicação e do entendimento que se está iniciando o processo. Fica claro que a falta de comunicação é um entrave nos sistemas de saúde, onde as pessoas ficam reféns de informações, sem conhecer se quer o que existe no próprio município, ou mesmo no próprio serviço de saúde a qual estão vinculados. Nos chama atenção o fato de que a grande maioria dos entrevistados desconhecem a RAS e diz não conhecer nenhuma estruturação da mesma.

Para tanto, a Rede de Atenção à Saúde representa uma malha que interconecta e integra os estabelecimentos e serviços de saúde de determinado território, organizando-os sistematicamente para que os "diferentes níveis e densidades tecnológicas de atenção estejam articulados" e adequados para o atendimento integral ao usuário e para a promoção da saúde, segundo Silva e Magalhães (2013 p.85).

No entanto, é imprescindível reafirmar a expectativa já definida de "empoderar" a Atenção Primária como "elemento estratégico e estrutural" na construção dessas redes. Entende-se por "empoderar" a real valorização da 'Base' como "ordenador do conjunto de serviços que se completam de forma interrelacionáveis", como afirmam Carvalho e Medeiros (2013 p. 156).

Na opinião dos entrevistados se acontece articulação entre APS e os demais níveis de atenção foi apresentado (50\%) a dificuldade de comunicação, e (50\%) a não existência de referência e contra referência entre ambos, seguido por (41,66\%) diz não acontecer esta articulação. 
Conforme relato GR1 “ainda está muito cru essa questão entre as redes, acredito que ainda precise ser amadurecido, ser conversado, dialogado para que isso funcione", enquanto para o GF1 "muitas vezes não sabem na realidade o que são cada um dos níveis de atenção".

Os dados acima, nos reportam mais uma vez que a grande dificuldade de articulação da rede está na comunicação e na dificuldade de se estabelecer a referência e contra referência, confirmando que não acontece a articulação e quando acontece em poucos momentos é falha, precisando ser melhorada nestes aspectos.

De acordo com Silva (2013, p. 241) o "gerenciamento das redes de atenção à saúde no SUS" é constituído pelos "processos que legitimam a rede", ou seja, as unidades assistenciais, os serviços, com as funções a serem desempenhadas por cada ponto, com competências, fluxos, monitoramento, avaliação e efetividade do sistema.

A complexa articulação entre os diferentes componentes da rede nos remete a Mendes (2011, p. 148) dizendo que a "cooperação entre os participantes da rede não é automática" acontece através de "negociações e acordos mediante processos gerenciais adequados".

Quando se investigou as facilidades para a estruturação das RASs os entrevistados apontaram, $(91,66 \%)$ não saberem e $(16,66 \%)$ não responderam. Quanto as dificuldades na percepção dos entrevistados, as respostas mais frequentes foram, (50\%) burocracia, comunicação e rotatividade profissional; seguido de $(41,66 \%)$ comprometimento profissional. Os desafios apresentados pelos entrevistados se apresentam como: (50\%) comunicação e referência e contra referência, seguido com $(41,66 \%)$ da gestão.

De acordo com os dados pesquisados pode-se verificar que conforme relato dos entrevistados a maioria destes não sabem e não responderam as facilidades para estruturação das RASs, o que vem de encontro quando perguntado sobre as dificuldades a maioria dos entrevistados se referem a comunicação, burocracia e rotatividade profissional ficaram entre os itens que mais apareceram como resposta, seguido dos também da comunicação, referência e contra referência e gestão como os quesitos que mais foram citados como desafios na estruturação da RAS.

Esta constatação sobre a dificuldade de comunicação quanto a referência e contra referência entre a rede os serviços e os vários níveis de atenção das RAS é reforçada na avaliação dos entrevistados como deficiente. 
Os serviços de referência, após prestar o cuidado, devem encaminhar ao serviço de origem do usuário, as informações necessárias para a continuidade do cuidado, o que é denominado de contra referência. Observa-se nos relatos dos entrevistados que isto não acontece como deveria de acordo com GF1 "os pacientes são mandados de um lado para o outro, até mesmo por nós, porque não temos as informações necessárias para passar ao paciente, eles sabem mais do que nós, isso é uma vergonha". Para dar conta desse fluxo acertado, são necessários definição e o conhecimento de cada ponto de atenção, como clareza dos fluxos e do papel ordenador e facilitador do "aparato regulatório público" (Magalhães; Pinto, 2014, p.16). Desta forma, as estruturas regulatórias passam a ter um papel de defesa dos direitos e necessidades reais dos usuários e de monitoramento do funcionamento da rede. Para tanto, a Rede de Atenção à Saúde representa uma malha que interconecta e integra os estabelecimentos e serviços de saúde de determinado território, organizando-os sistematicamente para que os "diferentes níveis e densidades tecnológicas de atenção estejam articulados" e adequados para o atendimento integral ao usuário e para a promoção da saúde, segundo Brêtas et al.

Na opinião dos entrevistados se acontece articulação entre APS e os demais níveis de atenção foi apresentado (50\%) a dificuldade de comunicação, e (50\%) a não existência de referência e contra referência entre ambos, seguido por $(41,66 \%)$ não acontecer esta articulação.

Os dados anteriores, nos reportam mais uma vez que a grande dificuldade de articulação da rede está na comunicação e na dificuldade de se estabelecer a referência e contra referência, confirmando que não acontece a articulação e quando acontece em poucos momentos é falha, precisando ser melhorada nestes aspectos.

De acordo com Silva o "gerenciamento das redes de atenção à saúde no SUS" é constituído pelos "processos que legitimam a rede", ou seja, as unidades assistenciais, os serviços, com as funções a serem desempenhadas por cada ponto, com competências, fluxos, monitoramento, avaliação e efetividade do sistema.

A complexa articulação entre os diferentes componentes da rede nos remete a Mendes 4 dizendo que a "cooperação entre os participantes da rede não é automática" acontece através de "negociações e acordos mediante processos gerenciais adequados". 


\section{CARACTERÍSTICAS SISTEMA INTEGRADO DE SAÚDE}

Ao serem questionados sobre quais as características de um sistema integrado de saúde, os entrevistados apontaram que $(41,66 \%)$ a resolutividade e a $(41,66 \%)$, comunicação são os aspectos que mais apareceram nas respostas, posteriormente $(33,33 \%)$ referência e contra referência, e com (25\%) a qualidade do atendimento, informatização e acesso da população a todos os serviços.

Como pode-se perceber as características identificadas pelos entrevistados como sendo de um sistema integrado de saúde na sua maioria aparecem a resolutividade acompanhada da comunicação e da referência e contra referência, reforçando os dados da questão acima, sendo extremamente importante se estabelecer meios de comunicação eficientes e eficazes pelo sistema de saúde para que se possa atingir o próximo item elencado pelos entrevistados que é o acesso da população a todos os serviços, ou seja, a qualidade do atendimento aos usuários do sistema de saúde.

Outro aspecto a ser observado na organização das redes é o processo de comunicação que orienta o "fluxo entre os pontos da rede, que garantem uma organização racional de fluxos e contra fluxos de informações, sendo estes o sistema regulador e os prontuários", segundo Mendes 4.

Diante da enorme quantidade de problemas que normalmente surgem no cotidiano da gestão, há uma necessidade de se "regular o tempo e o foco da atenção", caso não se deseje que a "organização perca o rumo frente a demanda diária de problemas". As pressões que o "dirigente sofre em sua gestão cotidiana contradizem o planejamento, a regulação racional do foco de atenção e o uso inteligente do tempo", conforme disse Magalhães.

Ainda de acordo com a Portaria 4279/2010 do Ministério da Saúde do BRASIL 2, a estrutura da Rede de Atenção à Saúde é a maneira de superar a fragmentação da atenção e da gestão, visando assegurar ao usuário o conjunto de ações e serviços de que necessita, com eficiência e eficácia, bem como a garantia de acesso universal, integral e equânime.

\section{PERFIL USUÁRIO DA ESF E REDE DE ATENDIMENTO}

Tendo em vista os dados da pesquisa, estes nos remetem a percepção de que $80 \%$ dos entrevistados são do sexo feminino, o que nos remete a compreensão de que o serviço de saúde possui uma procura muito maior pelas mulheres, pelo fato destas cuidarem mais de sua saúde e de seus familiares.

Comprovado pela análise seguinte que se refere a ocupação dos entrevistados sendo que aproximadamente $50 \%$ são do lar, seguidos de aposentados com aproximadamente $19 \%$ e $17 \%$ como 
diarista, ou seja, trabalho informal, o grau de instrução dos usuários com ensino fundamental é de aproximadamente $69 \%$ e com ensino médio incompleto de $16 \%$, demostrando desta forma a baixa escolaridade dos mesmos.

Os dados nos mostram que cerca de 64\% dos usuários utilizam a UBS de 10 a 20 anos, seguidos de $65 \%$ dos entrevistados utilizam o SUS de 10 a 20 anos, reafirmando os dados acima que nos mostram que a procura pelos serviços de saúde, mais especificamente do SUS e UBS se referem ao perfil de usuários com baixa escolaridade e com maior disponibilidade de procura pelos serviços de saúde da UBS de forma mais corriqueira que as de costume.

\section{MOTIVOS E PROCURA PELOS SERVIÇOS DE SAÚDE}

A pesquisa se propôs a investigar sobre os motivos que os usuários procuram a UBS, sendo a maior procura por conta da doença com cerca de 93\%, seguido de exames com 90\% da procura e receita de medicação e informações com aproximadamente $80 \%$.

Desta maneira percebe-se que a procura pela UBS ocorre muito dentro de uma perspectiva de cunho curativo, medicamentoso, hospitalocêntrico, voltado para a doença e não para a saúde.

Quando se investigou sobre a procura por outros serviços de saúde aos entrevistados foi evidenciado a grande procura de $95 \%$ pelo Pronto Atendimento, em seguida os laboratórios com 88\%, clínicas 77\%, farmácia e emergência com cerca de $74 \%$, indo de encontro aos demais dados apresentados na pesquisa, que identifica a procura por conta da doença.

Para tanto, pode-se perceber que apesar de todo o direcionamento da política de saúde estar voltada

para uma perspectiva de cunho preventivo, ainda é muito forte e também cultural a demanda espontânea pelos serviços de cunho curativo e medicamentoso, com ênfase na necessidade de medicamentos, exames e médicos especialistas, conforme indica o dado seguinte com $62 \%$ dos entrevistados pagam consultas médicas.

De acordo com Magalhães (2014) este cenário se dá por conta da insuficiência de resposta da Atenção Básica, seja por "seus processos de trabalho, ainda hegemônicos, seja pelo pequeno arsenal tecnológico ou pela tradição de horários de funcionamento em dias úteis e período diurno".

Nesse sentido a fragmentação do sistema faz com que o foco seja a doença ou a prevenção individual, ocasionando a divisão da doença em partes que não se comunicam, segundo Pérez e Garcia (2001, 2002), Campos (2003) e Mattos (2004). A visão da atenção aos pacientes deve ocorrer em diversos 
pontos de atenção, capazes de atender diferentes necessidades, onde o conjunto permite o alcance do cuidado integral. De acordo com Mattos (2006) supõe a organização para a busca da integração do cuidado em todo o sistema, através de uma rede mais estruturada de forma a maximizar as possibilidades de atendimento.

\section{QUALIDADE DOS SERVIÇOS DE SAÚDE}

Em termos de qualidade dos serviços de saúde, os dados nos revelam que 50\% dos entrevistados avalia como mais o menos a qualidade e $25 \%$ identifica como sendo boa.

Ante os dados apontados acima, pode-se perceber que os usuários avaliam que é necessário haver melhorias na qualidade dos serviços prestados aos usuários destes serviços.

Ao se investigar a facilidade de acesso dos usuários aos serviços de saúde, 32\% dos entrevistados avaliam como mais ou menos o serviço, $23 \%$ avalia como sendo bom e $16 \%$ sendo ruim.

Pode-se analisar que diante dos dados apresentados os usuários que obtiveram suas respostas entre mais ou menos, ruim e péssima somam aproximadamente $60 \%$, percebendo-se a grande dificuldade de acessar aos serviços existentes. Demostrando desta forma, a necessidade urgente de rever a organização do sistema como um todo.

A “inadequação da utilização dos serviços é decorrente da ausência de uma maior integração dos serviços organizados em RAS". Fica evidente quando constatamos as dificuldades que a segmentação entre os serviços e a fragmentação do cuidado acarretam para os usuários. Além disso, não conseguem ter a "garantia da continuidade do cuidado quando precisam utilizar os serviços em outros níveis de complexidade", tais como os de um especialista ou de um hospital, persistindo desta forma a "segmentação/fragmentação no contexto atual do SUS", conforme indica Carvalho e Medeiros (2013).

Para Giovanella e Mendonça (2012) "estudos mostram que os sistemas de saúde orientados por APS resolutiva estão associados a melhores resultados e maior eficiência". Ou seja, a organização dos serviços contribui em geral para maior eficiência do sistema.

\section{SERVIÇOS INTEGRANTES DA RAS}

Os serviços integrantes da RAS segundo os entrevistados $85 \%$ se referem as UBS, $74 \%$ ao Pronto Atendimento, $72 \%$ a ESF e $54 \%$ ao Ambulatório de Especialidades. 
Quanto ao que foi identificado como os serviços integrantes da RAS, evidenciou-se através dos entrevistados na sua maioria fazem menção a atenção primária, $67 \%$ atenção secundária e $80 \%$ se referem a atenção terciária. Os dados nos mostram um número expressivo de usuários que entende atenção secundária e terciária como não integrantes da rede.

A estrutura operacional da rede de uma rede de atenção à saúde é constituída por diferentes pontos, onde se ofertam serviços de saúde, e pelas ligações que os comunicam, como afirma Mendes (2011). A rede para ser integral precisa ser regulada publicamente em todos os seus aspectos e possibilidades.

\section{CONSIDERAÇÕES FINAIS}

Na perspectiva de analisar o processo de estruturação das Redes de Atenção à Saúde, esta pesquisa se constituiu por meio de uma análise quali e quantitativa a partir da percepção dos gestores, profissionais e usuários sobre o funcionamento das redes em que atuam. Com isto tentou-se obter uma visão dupla dos atores envolvidos diretamente no processo.

Emergiu sobre a RASs a percepção de um processo em construção, um novo modelo de atenção à saúde, baseado no cuidado e que apresente melhoria de qualidade de vida dos usuários. Neste sentido, entendemos que existe uma nova concepção de saúde, pautada no cuidado, na humanização, no respeito, no empoderamento e no protagonismo dos sujeitos.

Conforme observado nesta pesquisa a fragilidade na estrutura e funcionamento das redes de atenção à saúde no município de Lages, indicam que o SUS ainda é um sistema fragmentado e com dificuldades no acesso, deficiências tecnológicas, articulação e comunicação entre os pontos da rede, reafirmando os resultados da pesquisa quanto a incipiência do desenvolvimento das redes de atenção, dificultando desta forma o alcance da integralidade do cuidado.

Evidenciou-se a partir dos entrevistados, que as ações de regulação, controle e avaliação do SUS são incipientes e que há uma necessidade de melhor estruturá-las.

Há uma distância muito grande entre a estrutura e funcionamento de nossas organizações em geral e de saúde em particular em suas várias instâncias e o que a sociedade espera delas.

Se faz necessário desenvolver soluções para os problemas que estão latentes na sociedade, dentre eles todos os que foram elencados ao longo da pesquisa, são indicativo para se elaborar e dar respostas ao que a sociedade espera e necessita. 
Na perspectiva dos entrevistados a rede é formada por diferentes serviços e de diferentes densidades tecnológicas que se integram, incluindo serviços básicos de saúde, hospitais e urgências.

Além disso, a pesquisa mostrou que apesar de todos os esforços do MS no que tange a efetivação das RASs, ainda se percebe a visão apenas na integralidade, perdendo de vista o contexto da capacidade de organizar os serviços em linhas de cuidado.

Desta maneira, a partir do entendimento de gestores, profissionais da saúde e usuários foi possível conhecer como está a implantação, estruturação e organização das RASs, além de identificar as facilidades e dificuldades para a estruturação das RASs no município a partir da compreensão dos entrevistados acerca da sistemática de funcionamento da Atenção Básica e se estas atendem às reais necessidades da população nas RASs ficando evidenciado que isto acontece de forma parcial.

As redes de atenção à saúde carregam a esperança de tornar o SUS efetivo na prática, organizando a atenção e possibilitando o alcance da integralidade.

Existem dificuldades a serem enfrentadas para a consolidação das redes, dentre elas, destaca-se os recursos humanos insuficientes e pouco qualificados, qualificação dos gestores, problemas de comunicação e governança, ou seja, estas questões são recorrentes e históricas, porém exigem mudanças profundas, para não colocar em risco as conquistas dos SUS.

Dessa maneira, embora diante das legislações que respaldam a implantação, estruturação e efetivação das RASs nos municípios e do atual cenário da saúde no Brasil, nota-se ainda resistência para mudanças, contudo, estas mudanças não ocorrem de fora para dentro e sim de dentro para fora, precisam ser sensibilizados da real necessidade, eficiência e eficácia da mesma.

Portanto, esta pesquisa é fundamental no sentido de contribuir para que sejam identificadas as fragilidades do sistema e possam pensar em alternativas que venham de encontro a real necessidade do que os entrevistados apontam, suprindo as lacunas para construção e consolidação das RAS, bem como fomentar a discussão acerca das formas de incrementar e/ou ampliar a resolutividade de um fluxo mais ordenado entre os diferentes serviços, incentivando e proporcionando espaços de reflexão dos profissionais e gestores. 


\section{REFERÊNCIAS}

BRASIL. Ministério da Saúde. Portaria GM/MS n. 4.279, de 30 de dezembro de 2010. Estabelece diretrizes para a organização da Rede de Atenção à Saúde no âmbito do Sistema Único de Saúde (SUS). Brasília: Ministério da Saúde, 2010.

BRASIL. Ministério da Saúde. Portaria n. 648. Aprova a Política Nacional de Atenção Básica, estabelecendo a revisão de diretrizes e normas para a organização da Atenção Básica para o Programa Saúde da Família (PSF) e o Programa Agentes Comunitários de Saúde (PACS). Diário Oficial da União, 28 mar. 2006.

BRÊTAS, Nilo J; MAGALHÃES, Helvécio M; SILVA, Silvio F. Planejamento regional integrado no SUS. In: In: Silva S.F. Redes de atenção à saúde. Campinas: Saberes Editora, 2013. p. 159-198.

CAMPOS, C.E.A. O desafio da integralidade segundo as perspectivas da vigilância da saúde e da saúde da família. Ciência e Saúde Coletiva, v.8, n.2. 2003

CARVALHO, Gilson; MEDEIROS, Joellyngton. Redes assistenciais no SUS-financiamento e alocações. In: Silva S.F. Redes de atenção à saúde: desafio e regionalização no SUS. 2a ed Campinas: Saberes Editora, 2013. p. 118-119,

GIOVANELLA, L; MENDONÇA, M. H. M. Atenção Primária à Saúde. In: Políticas e Sistemas de Saúde no Brasil. 2. Ed. rev. e amp. Rio de Janeiro. Editora FIOCRUZ, 2012. p. 510.

MAGALHÃES JUNIOR, Helvécio Miranda Atenção Básica enquanto ordenadora da rede e coordenadora do cuidado: ainda uma utopia?.Divulgação em saúde para debate [on-line], v.51. p. 14-29, 2014.

MAGALHÃES JUNIOR, Helvécio Miranda. Redes de Atenção à Saúde: rumo à integralidade.Divulgação em saúde para debate [on-line], v. 52, p. 15-37, 2014.

MATTOS, R. A. Os sentidos da integralidade: algumas reflexões acerca de valores que merecem ser defendidos. In: Pinheiro R; Mattos R.A., orgs. Os sentidos da integralidade na atenção e no cuidado à saúde. 4a ed. Rio de Janeiro: Uerj/IMS, Abrasco; 2006. p. 39-64.

MATTOS, R.A. A integralidade na prática (ou sobre a prática da integralidade). Cad. Saúde Pública, v.20, n.5, p.1411-1416. Out. 2004.

MENDES, Eugênio V. As redes de atenção à saúde. Brasília: Organização Pan-Americana da Saúde. 2011. 549p.

MINAYO, Maria Cecília de Souza. Análise qualitativa: teoria, passos e fidedignidade. Ciências \& Saúde Coletiva, 17(3): 621-626, 2012.

PÉREZ, Lazaro JJ; GARCIA, Alegria J. La medida de los resultados clínicos. Cuad Med. Soc; v.80, p. 5-16. 2001. 
SILVA, Silvio F; MAGALHÃES, Helvécio M.J. Redes de atenção à saúde: importância e conceitos. In: Silva, S. F. Redes de atenção à saúde: desafio e regionalização no SUS. 2a ed. Campinas, SP: Ed. Saberes. 2013. p. 75-88.

SILVA, Silvio F. Redes de atenção à saúde no SUS: proposta de operacionalização. In: Silva, S. F. Redes de atenção à saúde: desafio e regionalização no SUS. 2a ed. Campinas: Saberes Editora, 2013. p. 201249. 


\section{Capítulo 10}

doi $10.37423 / 211205124$

HISTÓRICO DA FORMAÇÃO DO NUTRICIONISTA, COM ÊNFASE NA NUTRIÇÃO SOCIAL: UMA REVISÃO NARRATIVA

Cristina Garcia Lopes Alves

Monique Louise Cassimiro Inácio

Eliane Garcia Rezende

Michel Cardoso De Angelis Pereira

Luís Fernando Farah de Tófoli
Universidade Federal de Alfenas

Universidade Federal de Ouro Preto

Universidade Federal de Alfenas

Universidade/Federal de Lavras

Universidade Estadual de Campinas 


\section{INTRODUÇÃO}

No espectro mundial, o aparecimento do campo de formação profissional da Nutrição, seja em políticas sociais ou enquanto ciência e/ou profissão, é um fenômeno relativamente recente, característico dos primórdios do século XX. Entre 1918 e 1945 foram criados os primeiros cursos de Nutrição no mundo, localizados na Europa e no continente americano. Na América latina, eles se originaram em 1926 a partir da iniciativa do médico Pedro Escudeiro, na Argentina. No Brasil, isso ocorreu em 1939, mas a graduação nesse campo do conhecimento teve início em 1964, com a definição do currículo mínimo e modificação do tempo de duração do curso, que no início era de um ano e era tido como curso técnico (VASCONCELOS e CALADO, 2011; CANESQUI; GARCIA, 2005).

A formação em Nutrição, assim como a maioria das profissões da área da saúde surgidas nessa época, era baseada no "paradigma flexneriano", isto é, era fundamentada no modelo biomédico com destaque para o cuidado hospitalocêntrico, biologista e com foco no indivíduo enquanto ser fragmentado, sem considerar sua complexidade (PORTRONIERI, SILVA, ELIAS, 2009). Por essa razão, a matriz curricular dos cursos era fortemente biológica, com aulas predominantemente teóricas com enfoque para a concentração de conhecimentos "especializados", uma vez que, como supracitado, o indivíduo era estudando de modo seccionado (VASCONCELOS; BATISTA FILHO, 2011).

Sob a ótica de não atender às necessidades da realidade brasileira daquela época e não acompanhar o desenvolvimento técnico e científico, em 1970 o currículo mínimo do curso de Nutrição foi revisto (COSTA, 2002); no entanto, somente em 2001, com a criação das Diretrizes Curriculares Nacionais (DCN), foram identificadas modificações consistentes na matriz curricular do curso. A partir deste momento, tem ocorrido a inclusão de disciplinas relacionadas tanto à compreensão dos princípios e diretrizes do Sistema Único de Saúde (SUS) quanto ao desenvolvimento de competências e habilidades específicas para a atuação nessa área. Porém, apenas a inclusão dessas disciplinas não garante o efetivo desenvolvimento das competências e habilidades. Esta discussão surge, então, como uma possibilidade de reflexão sobre a formação, a partir da orientação das DCN (ALVES, 2018).

A formação acadêmica do Nutricionista é um tema que vem sendo discutido mesmo antes da constituição do SUS, buscando-se articular as ações de alimentação e nutrição junto às políticas públicas, e responder às necessidades para a atenção nutricional, tanto em nível individual quanto coletivo. Os conteúdos e práticas relacionados à formação do Nutricionista para o SUS são considerados dentro do campo da Nutrição Social, a qual se expande para as ações de alimentação e 
nutrição em outras áreas sob a gestão pública, como a alimentação escolar, as políticas de educação e de assistência social, e na área de segurança alimentar e nutricional (SAN) (LISBOA; FONSECA, 2020). De acordo com Cruz e Neto (2014), a Nutrição Social compreende uma extensa área "de estudos e realizações, nos quais se desvelam estratégias de trabalhar o campo da Alimentação e Nutrição em interface com o cotidiano da vida e os determinantes sociais de saúde nas coletividades". Além disso, se configura por meio da ênfase ao modo como os aspectos sociais, culturais, religiosos, econômicos e políticos relativos à alimentação podem influenciar a nutrição humana. No entanto, Recine et al. (2012) e Boog (2008) destacam que as vivências de inclusão de profissionais nutricionistas neste contexto passaram a revelar um descompasso da formação tradicional diante dos desafios impostos pelas situações sociais, especialmente em condições de privação social, tais como: vulnerabilidade socioeconômica, inequidade de saúde, insegurança alimentar e outros.

Compreender o histórico da formação do Nutricionista é fundamental, pois é a partir disso que identificamos os avanços no que concerne à estruturação dessa profissão, bem como os aspectos a serem aperfeiçoados. Considerando que nos últimos anos diversos acontecimentos têm demandado transformações na atuação profissional e na formação universitária dos nutricionistas, esse estudo tem como objetivo analisar a construção e constituição do campo de conhecimentos e práticas da Nutrição Social descrevendo a trajetória da formação acadêmica do Nutricionista para atuação na atenção primária.

\section{A TRAJETÓRIA DA PROFISSÃO NO BRASIL}

Os primeiros cursos de Nutrição surgiram entre as duas guerras mundiais, tanto na Europa quanto no continente americano, quando também foram criados os institutos e centros de pesquisa em Nutrição. Na América Latina, a primeira inciativa foi feita pelo médico argentino Pedro Escudero, criador do Instituto Nacional de Nutrição em 1926, da Escola Nacional de Dietistas em 1933, e do curso de médicos "dietólogos" da Universidade de Buenos Aires (VASCONCELOS, 2002). Conforme o mesmo autor, o curso de Nutrição no Brasil surgiu dentro de um projeto de modernização da economia brasileira conduzido pelo chamado Estado Nacional Populista, entre os anos de 1930 e 1940, configurando a transição para uma sociedade capitalista urbano-industrial no país.

Nesse momento da história, o trabalhador estava como principal alvo dos programas governamentais do país. Assim, o então dietista foi introduzido com o propósito de mudar as condições alimentares dessa porção populacional para que houvesse a manutenção da força de trabalho (BEZERRA, 2018). 
Nessa perspectiva, foi criado o Serviço de Alimentação e Previdência Social (SAPS). O SAPS funcionou por mais de 25 anos e alcançou quase a totalidade dos estados brasileiros. Este serviço funcionou em torno de quatro atividades centrais, a saber: assistência alimentar, educação alimentar, pesquisa científica no campo da nutrição e a formação de técnicos em alimentação. Ademais, criou cursos de formação específica, como o de visitadoras de alimentação, nutricionistas e nutrólogos (BEZERRA, 2018).

Em 1939 foram criados os primeiros cursos técnicos de Nutrição e Dietética com duração de um ano, localizados em São Paulo e Rio de Janeiro (ABN, 1991 citado por LOTTERMAN e JARDIM, 2015; VASCONCELOS e CALADO, 2011). A profissão de nutricionista nesse período da história era vista como exclusivamente feminina, passando também a ser entendida como "jovem e promissora" pelo surgimento da preocupação com o problema alimentar e nutricional da população brasileira, e pela emergência da medicina comunitária, que empregava o trabalho de outras categorias profissionais como complementares ao ato médico. Nesse contexto, a educação alimentar era vista como a ferramenta necessária para "libertar a sociedade humana da doença e da fome" (Santos, 1988, citado por COSTA, 2002)

Mais adiante, nas décadas de 1950 e 1960, em função da expansão dos cursos superiores no país, houve um aumento na formação de nutricionistas, principalmente nas instituições privadas de ensino superior (VASCONCELOS; CALADO, 2011). O reconhecimento da formação em Nutrição como curso superior ocorreu em 1962, e a regulamentação da profissão ocorreu em 1967, com a promulgação da Lei № 5276. Muito antes disso, o então deputado Dr. Josué de Castro havia apresentado na Câmara Federal, em 1959, um projeto de lei que dispunha sobre o ensino superior de Nutrição, regulava o exercício da profissão de dietista (nutricionista) e dava outras providências (ASBRAN, 2014a). A regulamentação da profissão só foi acontecer em 1991, através da Lei № 8.234, de 17 de setembro de 1991 (BRASIL, 1991). Essa lei estabelece, em seu artigo 3으, as atividades privativas do Nutricionista.

A abertura de novos cursos de Nutrição se deu especialmente a partir de 1976, após a instituição do II Programa Nacional de Alimentação e Nutrição (II PRONAN), que teve como uma das principais diretrizes instigar o desenvolvimento e a capacitação de recursos humanos em Nutrição (YPIRANGA e GIL, 1989). Até 1981, já havia 30 cursos de Nutrição no Brasil (VASCONCELOS, 1999a; YPIRANGA e GIL, 1989). Essa grande expansão também foi relacionada à necessidade de mão de obra devido à participação do nutricionista no mercado de trabalho pelo Programa de Alimentação do Trabalhador (PAT), criado em 1976 (BOSI, 1988; VASCONCELOS, 1999b). Em 1983 ocorreu a modificação do nome 
do "Curso de Nutricionistas" para "Curso de Nutrição" pela Resolução número 08, de 20 de maio, do CFE/MEC. Também é nesse período que ocorre a criação dos primeiros cursos de pós-graduação em Nutrição no país (ABN, 1991).

Vasconcelos (1999b) destacou a importância, para o processo de consolidação do campo de atuação do nutricionista, da inserção desse profissional nos programas e nas políticas públicas, não apenas com o PAT, mas também com a Política Nacional de Atenção Básica (PNAB), aprovada pela Portaria № 648 de março de 2006 (BRASIL, 2006a; BRASIL, 2012a), e o Programa de Alimentação Escolar (PNAE), já existente desde 1955. A partir de 2006, foi tornada obrigatória a presença do nutricionista como Responsável Técnico pelo PNAE (BRASIL, 2006b). Quanto à PNAB, embora o nutricionista não faça parte das equipes de saúde estabelecidas pela legislação, a implantação dos Núcleos de Apoio à Saúde da Família (NASF), pela Portaria № 154 de janeiro de 2008, ampliou a possibilidade de inserção do nutricionista na Atenção Primária a Saúde (APS), com aumento de vagas para o profissional no sistema de saúde.

A ocupação dos espaços de atuação pelo nutricionista, conforme exemplificado acima, pode ser discutida também a partir de outra abordagem, amparada na evolução do conhecimento que respaldou a construção da prática. Sobre esse tema, merece destaque o desenvolvimento conceitual da Educação Nutricional, atualmente referida como Educação Alimentar e Nutricional (EAN). A EAN se constituiu como importante estratégia de ação em Saúde Pública, e faz parte das ações do nutricionista em todos os campos de atuação (BEZERRA, 2018). Contudo, nem sempre esse campo de conhecimento foi valorizado. O caminho para se conseguir algum reconhecimento foi árduo e ainda não chegou ao fim. Por muitos anos a EAN foi vinculada a interesses governamentais e econômicos (PEREIRA, 2020).

Ampliando essa discussão, Boog (2008) também afirma que as novas competências requeridas para o Nutricionista como educador exigem um redirecionamento dos cursos para isso, pois o caráter muito biológico da formação ainda constitui o denominador comum. Embora não seja objetivo deste estudo aprofundar a discussão conceitual sobre a EAN, reconhecemos que a evolução do conhecimento na área trouxe impacto na constituição da prática profissional, ampliando a percepção da complexidade dos problemas alimentares e, consequentemente, afetou a busca pela ocupação de novos espaços de atuação.

Outros eventos podem ser destacados como tendo influência na constituição do campo de atuação deste profissional, como a fixação do segundo currículo mínimo, pelo Conselho Federal de Educação 
(CFE), definindo uma carga horária total de 2880 horas e a duração de 4 anos para o curso de Nutrição, e a realização dos I e II Diagnósticos dos Cursos de Nutrição. Também merecem destaques a criação do Conselho Federal e dos Conselhos Regionais de Nutricionistas, em 1979, além da constituição da Federação Brasileira das Associações de Nutricionistas (FEBRAN), em 1972, entidade de caráter técnico-científico e cultural que passou a assumir as funções da antiga ABN (Associação Brasileira de Nutrição), de 1949. É nessa época também que se inicia o processo de criação das associações profissionais (ou pré-sindicais), que dariam origem aos sindicatos de Nutricionistas no país (VASCONCELOS, 1999a).

Durante a década de 1970, modificações do currículo mínimo do curso de Nutrição foram propostas, considerando que ele não contemplava as questões técnicas, científicas, e nem atendia às necessidades da realidade brasileira (COSTA, 2002). Em decorrência desse processo, houve uma fragmentação nas suas três principais áreas de formação: Nutrição Social, Nutrição Clínica e Alimentação Institucional (LOTTERMAN e JARDIM, 2015).

Os diversos campos de atuação do Nutricionista foram estabelecidos pela Resolução №380 do Conselho Federal de Nutricionistas (CFN), de 2005, que dispõe sobre a definição das áreas de atuação deste profissional. Essa resolução inclui novas áreas para sua atuação.

Pelo que foi visto, a criação de novos cursos de Nutrição impulsionou o mercado de trabalho, expandindo a profissão dos hospitais e Serviços de Alimentação da Previdência Social (SAPS) para efetivamente assumir as escolas, os restaurantes de trabalhadores, docência, indústria, marketing, nutrição em esportes, saúde suplementar, núcleos de assistência à saúde da família (ASBRAN, 2014a).

Paralelamente à expansão dos cursos, modificações foram propostas para o currículo dos cursos de Nutrição, com novas discussões sobre o papel do profissional. Conforme Barreto (1991), o foco da discussão sobre a formação permaneceu na parte teórica e prática para as Ciências da Nutrição, ou seja, a formação mais tecnicista. Com o advento do Movimento da Reforma Sanitária no país, e com as demandas geradas pela implementação do SUS em 1990, os debates sobre a formação inadequada dos profissionais de saúde foram ampliados, assim como a necessidade de modificações nas orientações curriculares (SOARES e AGUIAR, 2010).

A expansão da profissão permitiu ao Nutricionista ocupar diversos espaços de atuação, tanto na esfera pública quanto na privada, o que naturalmente leva à incorporação de novos saberes e práticas. Hoje, a sua prática envolve ações diversas, não apenas voltadas para a doença, como para a promoção da saúde, como pode ser observado na sua atuação nas áreas de esporte e também em comunidades. As 
leis e políticas que regem o setor vêm organizando estas práticas desde os anos 40, no contexto da emergência de novos padrões de desenvolvimento econômico e industrial (CFN, 2006).

Em consulta à plataforma eletrônica do Conselho Federal de Nutricionistas (CFN), podemos observar o grande crescimento do número de profissionais no país nos últimos 20 anos. O número total de profissionais cadastrados no CFN no ano de 2000 era de 28983, considerando todas as regiões brasileiras. No ano de 2010 já eram 71337, passando para 108758 profissionais cadastrados ao final do ano de 2015. Em 2021, esse número saltou para 161.952, ou seja, um valor quase 6 vezes maior de nutricionistas em um período de 20 anos (CFN, 2021).

Em relação aos cursos de graduação em Nutrição, uma consulta à plataforma eletrônica do Ministério da Educação (e-MEC) revelou a existência de 990 cursos de bacharelado em Nutrição, sendo 93 cursos à distância credenciados no país no ano de 2021, todos na esfera privada. Do total dos cursos, apenas 77 estão em instituições públicas (com ensino gratuito), o que representa apenas 7,7\% dos cursos presenciais. A grande maioria dos cursos de graduação em Nutrição no país está na esfera privada (total de 913), incluindo os cursos à distância. Embora seja previsto nas Diretrizes Curriculares Nacionais (DCN) (BRASIL, 2001a) a possibilidade de cursos de Nutrição ser oferecidos também como Licenciatura, nenhum curso deste tipo foi localizado no e-MEC com cadastro ativo (BRASIL, 2021).

No que concerne o ensino à distância, em 2019 o Ministério da Educação (MEC) publicou a Portaria no 2117 em que libera as Universidades Federais e particulares a oferecerem cursos de graduação da área de saúde (exceto Medicina), com até $40 \%$ da carga horária por meio do ensino a distância (BRASIL, 2019). O CFN, assim como o Fórum dos Conselhos Federais da Área de Saúde (FCFAS) se posicionaram contrários a essa decisão. Segundo esses órgãos, o cuidado em saúde exige prática, o que não se consegue à distância. A falta de laboratórios, humanização do ensino, treinamento de habilidades para se adquirir competências, a fragilidade na formação do profissional são pontos importantes quando se pensa nesse tipo de modalidade para a área de saúde.

Há pouco mais de 30 anos atrás já eram identificadas críticas à redução significativa da carga horária destinada à prática, pois levava o corpo discente a uma formação cada vez mais teórica (BOSI, 1988).

\section{A CONSTITUIÇÃO E EMERGÊNCIA DO CAMPO DA NUTRIÇÃO SOCIAL}

De acordo com Vasconcelos (2002), no momento de constituição dos primeiros cursos de Nutrição, o principal desafio colocado para o Nutricionista era a superação do perfil epidemiológico nutricional presente naquele contexto, caracterizado por doenças carenciais associadas às condições de 
"subdesenvolvimento", de pobreza, de fome, de desigualdades regionais. O mesmo autor afirma que, para os dias atuais, somam-se a esse perfil as doenças nutricionais degenerativas e as condições da vida moderna, o que acarreta em novos dilemas e desafios para o profissional.

Em contraponto, Bosi (1988) afirma que os primeiros cursos se destinavam à formação de profissionais voltados para a prática individual, com ênfase na prática curativa, conhecida como "dietoterapia"; por outro lado, atividades de assistência alimentar ao trabalhador também eram enfatizadas, o que estaria de acordo com a fase populista da política vigente nas décadas de 1930/1940, considerando-se que a força de trabalho era um dos sustentáculos do modelo industrial que se implantava no país.

Costa (2002) lembra que no período que se estende da década de 1930 até a década de 1950, a atenção médica se fortalece, tornando-se o hospital o espaço privilegiado para esse tipo de atenção. Também é desse período o desenvolvimento da medicina estatal e da incorporação da assistência médica como contribuição do Estado para o cuidado individual. Com isto, Costa (2002) afirma que a profissão do Nutricionista surge em um momento de divisão técnica do trabalho no setor saúde, até então centrado na figura do médico, o que faz com que sua prática nasça ligada à prática médica exercida na área clínica, dentro dos hospitais, sem participação direta em ações de promoção e prevenção de doenças. Segundo Bosi (1988), as primeiras propostas de currículo, assim como as reformas curriculares, enfatizavam os aspectos biológicos e individuais em detrimento do social, situação que foi alvo de grande discussão no desenvolvimento dos cursos de Nutrição.

Sobre esse tema, Vasconcelos (2002), citando Coimbra et al. (1982) e L'Abbate (1988), aponta duas correntes do saber médico que influenciaram a constituição do campo da Nutrição nos primeiros anos da década de 1930. De um lado, uma corrente que é denominada como perspectiva biológica, onde a preocupação estava essencialmente nos aspectos clínico-fisiológicos relacionados ao consumo e à utilização biológica dos nutrientes, preocupação essa influenciada por concepções das Escolas de Nutrição e Dietética norte-americanas e de centros europeus. Os médicos integrantes do núcleo inicial da perspectiva biológica da Nutrição desenvolviam uma atuação voltada para o individual, o doente, a clínica, a fisiologia e o laboratório. De outro lado, havia a corrente denominada como sendo de "perspectiva social", com seus adeptos demonstrando uma preocupação com aspectos relacionados à produção, à distribuição e ao consumo de alimentos pela população brasileira. Os médicos integrantes do núcleo inicial da perspectiva social da Nutrição eram influenciados, principalmente, pelas concepções do pioneiro da Nutrição na América Latina, Pedro Escudero, e sua atuação era voltada para o coletivo, a população, a sociedade, a economia e a disponibilidade de alimentos. 
Conforme o mesmo autor, foi essa segunda vertente que, a partir de 1940, deu origem à Alimentação Institucional (área da Alimentação Coletiva) e, nos anos 1950 e 1960 originou a Nutrição em Saúde Pública, voltada ao desenvolvimento de ações de caráter coletivo. De acordo com Ypiranga e Gil (1989), a área denominada Nutrição em Saúde Pública tinha o objetivo de contribuir para garantir que a produção e distribuição de alimentos fossem adequadas e acessíveis a todos os indivíduos da sociedade, visão que reforça a discussão feita por Valente (1989) e Boog (1997) quando à EAN nesse período.

Como resultado desse processo, importantes produções científicas surgiram na área, podendo-se destacar a pesquisa "As Condições de Vida das Classes Operárias no Recife", de Josué de Castro, considerada como o primeiro inquérito dietético-nutricional feito no país, e cujos resultados serviram de base para outras pesquisas similares, resultando no estudo que serviu de base para a regulamentação da lei do salário mínimo e da formulação da chamada "ração essencial mínima" de 1938 (VASCONCELOS, 2002).

Portanto, conforme Vasconcelos (2002), a consolidação do campo da Nutrição no Brasil se deu pela confluência dessas duas vertentes, a biológica e a social, ao longo da década de 1930. Em função disso, os primeiros nutrólogos desenvolveram estudos sobre consumo e hábitos alimentares e sobre o estado nutricional da população brasileira, o que buscava dar legitimidade e especificidade a esse novo campo científico, além de evidenciar uma aproximação com o chamado Estado Populista, "contribuindo para a formulação das primeiras medidas e instrumentos da Política Social de Alimentação e Nutrição, os quais começavam a ser implantados no país". Em resumo, o processo de formação do Nutricionista até esse momento enfatizou a capacitação de um profissional para atuar tanto em Nutrição Clínica quanto em Alimentação Institucional (ou Alimentação Coletiva).

Em uma análise crítica, Lima (2000) aponta que no mesmo período, entre 1934 e 1939, já se esboçava o entendimento, por parte dos intelectuais do país, que o problema alimentar era uma questão de Estado, evidenciando a dimensão política do conhecimento sobre alimentação e nutrição. Porém, o problema ainda era visto sob a ótica do higienismo, e a ciência da Nutrição, em formação nesse período, adquiria uma feição mais instrumental, na perspectiva da aplicação imediata e pragmática dos dados fisiológicos e da natureza social, visando a determinação da alimentação racional nas várias regiões brasileiras, a ser implementada pelo Estado.

Outros autores situam a emergência do campo da Nutrição em Saúde Pública dentro de um contexto maior, a partir do momento em que alguns organismos e associações internacionais são constituídos 
especialmente no interior de agências como a Organização das Nações Unidas (ONU), tais como a (United Nations International Children"s Emergency Fund (UNICEF), Food and Agriculture Organization (FAO), Organização Mundial de Saúde (OMS) e Organização Panamericana de Saúde (OPAS); tais organizações surgiram no contexto do pós-guerra, criadas com o intuito de administrar conflitos de uma nova ordem mundial, a chamada "guerra fria" (COIMBRA et al.,1982; L"ABBATE, 1988 citado por VASCONCELOS, 2002).

No Brasil, a fundação do curso de Nutricionistas na Faculdade de Medicina de Recife, em 1957 tem sido associada ao primeiro marco da institucionalização do campo da Nutrição em Saúde Pública, uma vez que esse curso é considerado o primeiro voltado para a formação de profissionais para atuarem nesse campo. Vasconcelos (1999b) reconhece a emergência da Nutrição em Saúde Pública, também chamada de Nutrição em Medicina Preventiva, Nutrição Social, Nutrição Comunitária ou, mais recentemente, Nutrição em Saúde Coletiva, como fruto do processo histórico de especialização e divisão do trabalho/saber ocorrido no interior da ciência da Nutrição, entre os anos de 1930-1940.

A delimitação do campo da Nutrição em Saúde Coletiva na formação acadêmica do Nutricionista sempre foi um tema discutido dentro das instituições de ensino e nos órgãos de classe. Neste estudo, adotamos como equivalentes os termos Nutrição em Saúde Coletiva, Nutrição em Saúde Pública ou Nutrição Social, mesmo reconhecendo a possibilidade de interpretações diferenciadas entre esses termos. Na busca de uma definição, Taddei et al. (2011a; 2016b) define a Nutrição em Saúde Pública como sendo a área em que, "a partir de conhecimentos fundamentados em sólidas evidências científicas, gerados em pesquisas com metodologias quantitativas e qualitativas, que utilizam técnicas clínicas, epidemiológicas e etnográficas, buscam soluções para desvios nutricionais presentes de forma dinâmica em populações humanas".

Sobre o campo da Saúde Coletiva, sua definição é complexa e remonta, no Brasil, ao movimento da Reforma Sanitária, e reflete a concepção ampliada de saúde em suas inúmeras interfaces (NUNES, 2006). Paim e Almeida Filho (1998) propõem a compreensão da Saúde Coletiva como um campo científico em que "se produzem saberes e conhecimentos acerca do objeto saúde e onde operam distintas disciplinas que o contemplam sob vários ângulos"; também como um âmbito de práticas, em que "se realizam ações em diferentes organizações e instituições por diversos agentes (especializados ou não) dentro e fora do espaço convencionalmente reconhecido como setor saúde". Os mesmos autores colocam como elementos significativos do campo "a superação do biologismo dominante, da 
naturalização da vida social, da sua submissão à clínica e da sua dependência ao modelo médico hegemônico" (PAIM e ALMEIDA FILHO, 1998)

Buscando definir o escopo do que tem sido denominando Alimentação e Nutrição em Saúde Coletiva, Bosi e Prado (2011), na discussão da confluência dos dois campos, Alimentação e Nutrição e Saúde Coletiva, mostram as aproximações entre vários núcleos de saberes nessa constituição. Inicialmente, uma aproximação com o arcabouço teórico-metodológico da Epidemiologia, cujo aporte propiciou o desenvolvimento de habilidades para o diagnóstico nutricional, a identificação dos problemas nutricionais e dos grupos populacionais submetidos à privação ou escassez de alimentos. Os desdobramentos dessa articulação com a Epidemiologia iriam configurar, mais tarde, a Epidemiologia Nutricional, com o seu arcabouço teórico advindo também da Epidemiologia Social; além disso, também levou ao campo da Política, com abertura de novas frentes. Conforme estas autoras, outra aproximação da Alimentação e Nutrição foi em relação às Ciências Humanas e Sociais, o que implicou em uma reorientação significativa dos rumos do que até então se conhecia como sendo campo da "Nutrição" (grifo das autoras), trazendo questões relativas à cultura e à subjetividade. Essas aproximações, segundo elas, não se deram sem tensões, mas contribuíram para uma revisão dos conteúdos inerentes ao campo da Nutrição.

\section{REFORMAS CURRICULARES, AVALIAÇÕES DE CURSO, E A REPERCUSSÃO NO CAMPO DA}

\section{NUTRIÇÃO SOCIAL.}

No que tange a relação entre as disciplinas do campo da Saúde Coletiva, Bosi (1988) identificou uma oposição às disciplinas das demais áreas de atuação, em especial a área da Nutrição Clínica, por meio da análise de documentos de conferências e outros eventos relacionados ao curso de Nutrição. Analisando as contribuições das Conferências sobre a Formação de Nutricionistas da América Latina (I e II CEPANDAL, a primeira realizada em Bogotá, na Colômbia, em 1973, e a segunda em Washington, EUA, em 1974), a mesma autora afirma que, como desdobramentos, essas conferências tiveram o efeito de conferir maior peso aos conteúdos que atribuem identidade ao profissional, ou seja, se referem às disciplinas específicas da sua formação e, ao mesmo tempo, nas áreas que permitiram articular esses conhecimentos biológicos aos sociais, distribuídas, equitativamente, na mesma proporção.

A partir das recomendações da CEPANDAL, foram determinados cinco campos gerais do ensino em Nutrição: Ciências Básicas, Ciências Sociais e Econômicas, Ciências Pedagógicas, Ciências da Saúde 
Pública, e Ciências da Alimentação e Nutrição (COSTA, 1999). Ressalta-se que a II CEPANDAL buscou atender a uma solicitação da Organização Panamericana de Saúde (OPAS) para que se formasse uma Comissão de Estudos, em nível internacional, para elaborar recomendações sobre alguns aspectos na formação do Nutricionista, incluindo conteúdos e cargas horárias mínimas por disciplinas (BOSI, 1988).

Segundo a mesma autora, diagnósticos dos cursos de Nutrição evidenciaram deficiências em conteúdos relacionados à área denominada "social". O I Diagnóstico Nacional dos Cursos de Nutrição, de 1975 , demonstrou que $78 \%$ dos cursos apresentavam déficit de carga horária na área de saúde pública, considerando como parâmetro a recomendação da CEPANDAL

No que tange ao II Diagnóstico, de 1981, o CFN destaca o hiato entre o aspecto biológico e o social, o descompasso entre a teoria e a prática, e o fato de ser um curso demasiadamente teórico e inflexível, não atendendo às exigências particulares de cada região, instituição ou curso, bem como às necessidades sociais produzidas pelas desigualdades e peculiaridades do nosso país. Também foi considerado que o curso não incentiva a incorporação de novas tecnologias e conhecimento, desconsiderando a aprendizagem ativa (CFN, 2015). O currículo dos cursos de Nutrição até aquele momento privilegiava a vertente biológica, alienando o corpo discente, sobretudo dos conhecimentos que Ihes permitiriam aprofundar sua reflexão no sentido da compreensão dos determinantes dos problemas nutricionais (BOSI, 1988).

Esse caráter excessivamente biológico da formação, entretanto, vinha sendo denunciado entre os próprios docentes por meio de documentos de análise e revisão da formação profissional, apontando a insatisfação com um currículo que operava em sentido distinto das necessidades da população, como no texto das conclusões do Seminário Nacional de Avaliação do Ensino de Nutrição, promovido pelo MEC em 1982 (BOSI, 1988). Segundo esta autora, a menor carga horária destinada à área Social trazia como resultado um fortalecimento de alguns núcleos considerados como áreas prioritárias para a formação acadêmica, ou seja, aqueles com maior carga horária; consequentemente, o número de docentes se tornava escasso no Núcleo Social profissionalizante, tendo esses docentes que assumir várias funções didático-administrativas, sobrando pouco tempo para se dedicarem à pesquisa e ao debate na área, assim como para a oferta de cursos de pós-graduação.

Estudo conduzido entre alunos de cursos de Nutrição em diversas universidades públicas e privadas da cidade do Rio de Janeiro confirmou haver maior importância conferida pelos alunos às disciplinas biológicas em detrimento das disciplinas chamadas "sociais", o que pode levar a uma reflexão sobre a forma desarticulada com que as disciplinas vêm sendo ministradas (PORTRONIERI et al., 2009). Embora 
o estudo mereça discussão mais aprofundada quanto ao método de avaliação empregado, as autoras deste estudo apontam a necessidade de haver diálogo entre estas disciplinas e possibilitar aos alunos a visão holística dos problemas nutricionais.

Tem sido reconhecido que a formação dos profissionais de saúde tem sido pautada no uso de metodologias conservadoras (ou tradicionais), sofrendo influências do mecanicismo de inspiração cartesiano-newtoniana, de cunho fragmentado e reducionista; como consequência, compartimentaliza-se o conhecimento em busca da eficiência técnica, conforme Mitre et al. (2008). Segundo os autores citados, abordagens pedagógicas progressivas de ensino-aprendizagem vêm sendo construídas e implicam formar profissionais como sujeitos sociais com competências éticas, políticas e técnicas e dotados de conhecimento, raciocínio, crítica, responsabilidade e sensibilidade para as questões da vida e da sociedade, capacitando-os para intervirem em contextos de incertezas e complexidades (MITRE et al., 2008).

Embora não seja objeto deste estudo discutir as práticas pedagógicas, concordamos com a afirmação de Ribeiro (2001), de que o profissional de saúde tradicional já não atende mais às exigências de um paradigma emergente, inovador e que enxerga o indivíduo como ser humano acima de tudo, um sujeito inserido num contexto que interfere em seu pensar e em seu agir e que, portanto, deve ser considerado. Tal afirmação leva à reflexão de que a formação do profissional Nutricionista, portanto, requer o repensar sua prática dentro de uma perspectiva holística, capaz de incorporar saberes e práticas coerentes com as novas demandas sociais.

A complexidade da questão alimentar no Brasil e no mundo, com constituição de novos padrões de consumo, exigem uma reflexão contínua sobre as ações de alimentação e nutrição a serem desenvolvidas. Como exemplo, uma avaliação sistemática sobre a qualidade da alimentação de homens e mulheres em 187 países mostrou, além de uma grande variação no consumo alimentar em relação à idade, sexo e renda, ainda identificou que o aumento no padrão inadequado de alimentação tem ultrapassado o aumento no padrão alimentar saudável na maioria das regiões do mundo. Considerando a carga de doenças associadas a uma dieta de má qualidade, esses dados apontam para a necessidade de melhor elucidar os determinantes sociais, políticos e da indústria alimentar relacionados a essas diferenças e tendências, e para a implementação de políticas para lidar com essas desigualdades e melhorar a qualidade da alimentação em nível mundial (IMAMURA et al., 2015). O estudo citado pode também respaldar a necessidade da atuação do profissional junto às políticas e 
programas de saúde, enfatizando o papel da EAN frente aos problemas alimentares e nutricionais apontados.

Ressalta-se a importância da atuação do Nutricionista no que concerne a garantia do Direito Humano à Alimentação Adequada (DHAA) e Segurança Alimentar e Nutricional (SAN). No que diz respeito a sua formação para a atuação nessa área, há a necessidade de inclusão de conteúdos que subsidiem sua atuação enquanto profissional. Em estudo conduzido por Lisboa e Fonseca (2020), o qual buscou destacar como a SAN aparece nos currículos de nutrição, foi constatado que apesar da maioria estar de acordo com as orientações das DCN no que tange o perfil esperado para o egresso, a temática é abordada por um pequeno número de disciplinas, o que identifica baixa representatividade dos conteúdos de SAN em relação aos demais conteúdos.

\section{RESUMO DOS PRINCIPAIS EVENTOS RELACIONADOS À FORMAÇÃO DO NUTRICIONISTA, COM FOCO NA CONSTITUIÇÃO DA NUTRIÇÃO SOCIAL.}

Apresentamos, a seguir, os principais eventos ocorridos antes da implantação do SUS, e que tiveram importância na formação acadêmica deste profissional, considerando o campo da Nutrição Social. Todos os quadros tiveram como base a literatura consultada e apresentada nesse capítulo.

Quadro 1. Década de 1930, 1940, 1950, 1960-A implantação dos primeiros cursos, as primeiras associações de classe e a regulamentação da profissão.

\begin{tabular}{|c|c|}
\hline $\begin{array}{l}1^{\circ} \text { curso de nível médio para formação de nutricionistas/dietistas na Faculdade } \\
\text { de Saúde Pública/Instituto de Higiene da Universidade de São Paulo, com um } \\
\text { ano de duração. }\end{array}$ & 1939 \\
\hline $\begin{array}{l}\text { Criação do Serviço de Alimentação da Previdência Social (SAPS), que tornou } \\
\text { um dos principais centros de formação de recursos humanos em Nutrição, com } \\
\text { formação de técnicos de Nutrição, Nutricionistas, nutrólogos, economistas } \\
\text { domésticas. }\end{array}$ & 1940 \\
\hline $\begin{array}{l}\text { Abertura de cursos técnicos de Nutrição, com um ano de duração, no SAPS } \\
\text { (antigo curso do IAPI) e na Escola Técnica de Assistência Social Cecy } \\
\text { Dodsworth (atual curso de graduação da UERJ). }\end{array}$ & $\begin{array}{l}1940- \\
1944\end{array}$ \\
\hline $\begin{array}{l}\text { Fundação da Sociedade Brasileira de Nutrição (SBN), entidade de caráter } \\
\text { técnico-científico e cultural que defendia os interesses da classe profissional, } \\
\text { especialmente os médicos nutrólogos. }\end{array}$ & 1940 \\
\hline $\begin{array}{l}\text { Reforma Capanema: definição do ensino secundário e técnico-industrial. O } \\
\text { curso de Nutricionistas/dietistas passa a ter duração de dois anos a partir de } \\
1944 .\end{array}$ & 1942 \\
\hline $\begin{array}{l}\text { Criação dos Arquivos Brasileiros de Nutrição, primeira revista científica } \\
\text { brasileira na área. }\end{array}$ & 1944 \\
\hline $\begin{array}{l}\text { Inserção dos estágios à grade curricular do curso de formação de } \\
\text { Nutricionistas, e o curso passou a ter três anos de duração. }\end{array}$ & 1945 \\
\hline
\end{tabular}




\begin{tabular}{|c|c|}
\hline $\begin{array}{l}\text { Criação do curso de dietistas da Universidade do Brasil (atual curso de } \\
\text { graduação da UFRJ). }\end{array}$ & 1948 \\
\hline $\begin{array}{l}1^{a} \text { Conferência Latino-Americana da FAO (Montevidéu, Uruguai). } \\
\text { Recomendação para o desenvolvimento de atividades específicas no campo } \\
\text { da Nutrição em Saúde Pública. }\end{array}$ & 1948 \\
\hline $\begin{array}{l}\text { Criação da Associação Brasileira de Nutrição (ABN). Primeira entidade } \\
\text { brasileira criada para representar e defender os interesses da profissão, além } \\
\text { de desenvolver estudos e pesquisas na área. }\end{array}$ & 1949 \\
\hline $\begin{array}{l}\text { Criação de novos cursos para formação de Nutricionistas, com destaque para } \\
\text { o curso da Faculdade de Medicina da Universidade do Recife (primeiro com } \\
\text { foco em Saúde Pública, tem sido associado à institucionalização do campo da } \\
\text { Nutrição em Saúde Pública no Brasil). }\end{array}$ & $\begin{array}{l}1950- \\
1960\end{array}$ \\
\hline $\begin{array}{l}\text { Criação do Programa de Merenda Escolar, mais tarde se tornando o Programa } \\
\text { de Alimentação Escolar. }\end{array}$ & 1955 \\
\hline $\begin{array}{l}1^{\circ} \text { Congresso Brasileiro de Nutrição (CONBRAN), realizado pela ABN com } \\
\text { o objetivo de que as associações estaduais a ela se filiassem, sob a forma de } \\
\text { seções. }\end{array}$ & 1958 \\
\hline $\begin{array}{l}\text { Reconhecimento do curso de Nutricionistas como curso superior pelo } \\
\text { Conselho Federal de Educação (Parecer } \mathrm{n}^{\circ} 265,19 \text { de outubro de 1962). } \\
\text { Estabelecimento do primeiro currículo mínimo, divisão do currículo do curso } \\
\text { em ciclo básico e ciclo profissional; curso passa a ter } 3 \text { anos letivos e } 1 \text { ano de } \\
\text { estágios. }\end{array}$ & 1962 \\
\hline $\begin{array}{l}1^{\text {a }} \text { Conferência de Adestramento de Nutricionistas - Dietistas de Saúde } \\
\text { Pública (Caracas, Venezuela), que teve o objetivo de delimitar as } \\
\text { responsabilidades e qualificações do Nutricionista-dietista nos programas dos } \\
\text { serviços de saúde; criação da I Comissão de Estudos sobre Programas } \\
\text { Acadêmicos em Nutrição e Dietética da América Latina (CEPANDAL). } \\
\text { Foram definidos } 5 \text { campos gerais para o ensino da Nutrição: Ciências Básicas, } \\
\text { Ciências Sociais e Econômicas, Ciências Pedagógicas, Ciências da Saúde } \\
\text { Pública, Ciências da Alimentação e Nutrição; - utilização do termo } \\
\text { "nutricionista" para o profissional de nível superior. }\end{array}$ & 1966 \\
\hline $\begin{array}{l}\text { Regulamentação da profissão pela Lei } 5276 \text { de } 24 \text { de abril de } 1967 \text {, que dispõe } \\
\text { sobre a profissão do Nutricionista e regulamenta o seu exercício (esse } \\
\text { instrumento legal vigorou até 1991, quando foi revogada por nova legislação). } \\
\text { Foram definidas atividades privativas do nutricionista. }\end{array}$ & 1967 \\
\hline
\end{tabular}

Os novos cursos criados, nas décadas de 1950 a 1960, ajudaram a definir o perfil profissional, o que se fortaleceu com o reconhecimento da profissão. A partir da década de 1970, a discussão da formação acadêmica começou a tomar mais vulto, com a realização de eventos sobre o tema, incluindo a discussão sobre a área da Nutrição Social. Na discussão sobre a formação profissional, já se percebe a influência do mercado de trabalho, com aumento expressivo de vagas em algumas áreas, paralelamente à expansão dos novos cursos. Nesse período, ocorre a criação de entidades representativas da classe profissional. A década de 1980 foi marcada por um processo de luta pela redemocratização do país, com a importante discussão, na área da saúde, de uma nova política de 
saúde que promovesse o acesso universal, destacando-se o papel do Movimento da Reforma Sanitária, que vai impulsionar a implantação do SUS. Na área da Nutrição, várias avaliações de curso foram promovidas, com participação das entidades de classe e do movimento estudantil.

Quadro 2. Décadas de 1970 e 1980 - A expansão dos cursos, as discussões sobre a formação acadêmica, e as avaliações de curso.

\begin{tabular}{|c|c|}
\hline $\begin{array}{l}\text { Criação de novos cursos de Nutrição em função da Reforma Universitária de } \\
1968 .\end{array}$ & 1970 \\
\hline $\begin{array}{l}\text { Criação do Instituto Nacional de Alimentação e Nutrição (INAN), autarquia } \\
\text { ligada ao Ministério da Saúde. }\end{array}$ & 1972 \\
\hline $\begin{array}{l}\text { Criação da Federação Brasileira das Associações de Nutricionistas } \\
\text { (FEBRAN), entidade de caráter técnico-científico e cultural (substituindo as } \\
\text { funções da ABN), congregando as associações estaduais de Nutricionistas. } \\
\text { Início do processo de criação das associações profissionais (ou pré-sindicais). }\end{array}$ & 1972 \\
\hline $\begin{array}{l}\text { VI Congresso Brasileiro de Nutricionistas/ I Reunião sobre a formação do } \\
\text { Nutricionista. Sugerida a primeira revisão do currículo mínimo. }\end{array}$ & 1972 \\
\hline $\begin{array}{l}\text { Criação da Federação Brasileira das Associações de Nutricionistas } \\
\text { (FEBRAN): assume o papel da ABN, congregando as associações estaduais } \\
\text { de Nutricionistas. }\end{array}$ & 1972 \\
\hline $\begin{array}{l}\text { II Conferência de Adestramento de Nutricionistas - Dietistas de Saúde Pública } \\
\text { Objetivos: rever funções deste profissional, analisar programas dos cursos, } \\
\text { estabelecer critérios para o nível e a qualidade do curso Implicações: } \\
\text { reconhecimento do Nutricionista-dietista como integrante de uma equipe em } \\
\text { diferentes níveis de setores públicos e privados, segundo as necessidades e } \\
\text { prioridades de cada país: saúde, educação, agricultura, indústria e comércio, } \\
\text { economia e administração. }\end{array}$ & 1973 \\
\hline $\begin{array}{l}\text { I Reunião da CEPANDAL Implicações: recomendações ao currículo mínimo; } \\
\text { incorporação da área de estudo chamada Multidisciplinar }\end{array}$ & 1973 \\
\hline $\begin{array}{l}\text { I Programa Nacional de Alimentação e Nutrição (I PRONAN) em parceria } \\
\text { com o INAN: integração de vários subprogramas, como distribuição de } \\
\text { alimentos, comercialização de alimentos a baixo custo, atenção a grupos de } \\
\text { risco. }\end{array}$ & $\begin{array}{l}1973 / \\
74\end{array}$ \\
\hline $\begin{array}{l}\text { Resolução N } \text { N }^{\circ} 36 \text { do Conselho Federal de Educação: fixação do segundo } \\
\text { currículo mínimo. O curso passa a ter carga horária mínima de } 2880 \text { horas } \\
\text { (currículo mínimo), com duração média de } 4 \text { anos, com carga horária mínima } \\
\text { de } 300 \text { horas para os estágios supervisionados. }\end{array}$ & 1974 \\
\hline $\begin{array}{l}\text { II Reunião da CEPANDAL que implicou na Política de Formação e } \\
\text { Capacitação de Pessoal em Nutrição; participação da Nutricionista-dietista na } \\
\text { equipe de saúde. }\end{array}$ & 1974 \\
\hline $\begin{array}{l}\text { I Diagnóstico dos cursos de Nutrição feito pelo INAN, com resultados } \\
\text { apresentados no I Seminário Nacional de Avaliação dos Cursos de Nutrição } \\
\text { no Brasil. Foram observadas dificuldades em unir as disciplinas biológicas } \\
\text { com as sociais; discussão sobre os projetos pedagógicos. Foi feita uma } \\
\text { proposta de ensino integrado e recomendação de ampliação dos cursos de } \\
\text { Nutrição. }\end{array}$ & 1975 \\
\hline
\end{tabular}


Criação do Programa de Alimentação do Trabalhador (PAT). Houve o aumento da demanda de Nutricionistas no mercado de trabalho para atuação na produção de refeições coletivas.

II Programa Nacional de Alimentação e Nutrição (PRONAN) em parceria com o INAN. Houve o estímulo à formação e capacitação de recursos humanos em Nutrição Repercussões: ampliação significativa no número de cursos de graduação em Nutrição no país.

Implantação dos conselhos regionais e do Conselho Federal de Nutricionistas (CFN). Os Nutricionistas brasileiros passam a ter um órgão específico para fiscalizar o exercício da profissão, além de lutar pelos interesses da classe.

II Diagnóstico dos cursos de Nutrição feito pelo MEC /INAN/FEBRAN, com resultados apresentados no I Seminário Nacional de Avaliação do Ensino de Nutrição, de 1982. Os principais achados foram o distanciamento entre a formação acadêmica e a prática profissional; baixa proporção de determinadas disciplinas, incluindo a Saúde Pública. Dentre as recomendações estavam, a ênfase no caráter generalista da formação; integração teoria-prática; necessidade de se desenvolver a percepção crítica do aluno; articulação entre os conhecimentos da área biológica, econômica, social e política.

I Seminário Nacional de Avaliação do Ensino de Nutrição que teve como objetivo a análise dos aspectos conceituais, estruturais e metodológicos dos cursos; preocupação com a formação de um profissional de acordo com as necessidades do país. Resultou na constatação de um crescente distanciamento entre a formação acadêmica e a prática profissional (descompasso entre teoria e prática), assim como um "hiato entre o biológico e o social". E repercutiu em recomendações visando à reorganização curricular, enfatizando o caráter generalista da formação, a integração teoria-prática, o desenvolvimento da percepção crítica por parte do aluno, necessidade de articular conhecimentos biológicos, econômicos, políticos e sociais dentro das disciplinas e do curso como um todo.

Resolução $n^{\circ} 8$ do CFE/MEC. Culminou na modificação do nome do Curso de Nutricionistas para Curso de Nutrição.

I Encontro Nacional de Entidades de Nutricionistas (I ENEN). Debate sobre o perfil profissional e o mercado de trabalho. A partir disso foi definido o perfil do Nutricionista como "profissional generalista, de saúde, de nível superior, com formação em Nutrição e Dietética, que desenvolve uma visão crítica da realidade e comprometimento com as transformações da sociedade".

II Seminário Nacional de Avaliação do Ensino de Nutrição Repercussão. Foi definido o perfil do Nutricionista como um profissional de saúde com formação ou caráter generalista e com uma percepção crítica da realidade (consciência social, econômica, cultural e política) dentro de áreas próprias de atuação.

II Encontro Nacional de Entidades de Nutricionistas (II ENEN). Teve o objetivo de dar continuidade do debate sobre o perfil profissional e o mercado de trabalho. Foi definido o perfil do Nutricionista como "profissional generalista, de saúde, de nível superior, com formação em Nutrição e Dietética, que desenvolve uma visão crítica da realidade e comprometimento com as transformações da sociedade". 
A implantação do SUS em 1990 trouxe implicações sobre a formação dos profissionais de saúde, a partir da proposta de um novo modelo de atenção, sob a perspectiva da integralidade. Nesse período ocorreu uma grande expansão na oferta de vagas para o curso de Nutrição em todo o país, e uma redefinição das atividades privativas da área. É importante destacar também a criação da Política Nacional de Alimentação e Nutrição (PNAN), importante espaço para definição de ações de alimentação e nutrição em articulação com o modelo de saúde pretendido (ALVES, 2018).

Quadro 3. Décadas de 1990 e 2000 - A constituição do Sistema Único de Saúde, a expansão dos cursos de graduação e a PNAN.

\begin{tabular}{|l|l|}
\hline Constituição do Sistema Único de Saúde (SUS) pelas Leis 8080 e 8142. & 1990 \\
Ampliação do debate sobre a formação inadequada dos profissionais de saúde & \\
e a necessidade de adequações curriculares. & \\
\hline $\begin{array}{l}\text { Criação da Associação Brasileira de Nutrição (ASBRAN) em substituição à } \\
\text { Federação Brasileira de Nutrição (FEBRAN). }\end{array}$ & 1990 \\
\hline $\begin{array}{l}\text { Grande expansão da oferta de vagas em cursos superiores no Brasil, com } \\
\text { ampliação do número de cursos de Nutrição tanto nas instituições de ensino } \\
\text { públicas quanto privadas. }\end{array}$ & $\begin{array}{l}\text { parti } \\
\text { r de }\end{array}$ \\
\hline $\begin{array}{l}\text { Revogação da lei de 1967 e nova regulamentação da profissão pela Lei no 8234. } \\
\text { Culminou na redefinição de atividades privativas do Nutricionista, com } \\
\text { inclusão das atividades de ensino. }\end{array}$ \\
\hline $\begin{array}{l}\text { IV CEPANDAL. Discussão sobre a identidade profissional do profissional de } \\
\text { Nutrição; busca de aprimoramento da formação acadêmica e projeção } \\
\text { profissional; proposição de um Plano de Desenvolvimento Integral, com foco } \\
\text { na formação didático-pedagógica. }\end{array}$ \\
\hline $\begin{array}{l}\text { Descentralização do Programa de Alimentação Escolar (PNAE) pela Lei no } \\
\text { 8.913, que também estabeleceu o Nutricionista como o responsável pela } \\
\text { elaboração dos cardápios da alimentação escolar. }\end{array}$ \\
\hline $\begin{array}{l}\text { Reformulação da Lei de Diretrizes e Bases (LDB) com formulação das } \\
\text { Diretrizes Curriculares Nacionais (DCN) e discussão das competências } \\
\text { necessárias para os profissionais de saúde; foco no SUS. }\end{array}$ \\
\hline $\begin{array}{l}\text { I Seminário de Ensino: Novos Rumos para o Ensino da Nutrição } \\
\text { (CFN/ASBRAN e Comissão de Especialistas de Ensino da Nutrição). Teve } \\
\text { como objetivos principais a formulação de diretrizes e avaliação da qualidade } \\
\text { do ensino. }\end{array}$ \\
\hline $\begin{array}{l}\text { Aprovação da Política Nacional de Alimentação e Nutrição (PNAN)/ Ministério } \\
\text { da Saúde Implicação: o Ministério da Saúde passou a assumir a execução de } \\
\text { uma política que tem como propósito "a garantia da qualidade dos alimentos } \\
\text { colocados para consumo no País, a promoção de práticas alimentares saudáveis } \\
\text { e a prevenção e o controle dos distúrbios nutricionais, bem como o estímulo às } \\
\text { ações intersetoriais que propiciem o acesso universal aos alimentos". }\end{array}$ \\
\\
\\
\hline
\end{tabular}

A partir de 2001, as novas diretrizes para o curso de Nutrição reconheceram a necessidade da incorporação de conteúdos e práticas condizentes com o sistema de saúde e o modelo de atenção nos 
currículos de Nutrição em todo o país; também orientam para projetos pedagógicos com foco no desenvolvimento de competências e habilidades. A Atenção Básica se fortalece com o Programa Saúde da Família (PSF), abrindo novas possibilidades de atuação para os profissionais de saúde, o que se amplia com a implantação dos NASF, especialmente para a área da Nutrição.

Quadro 3 - Década de 2001 a 2011 - As Diretrizes Curriculares Nacionais e a definição das ações na Atenção Básica à Saúde

\begin{tabular}{|l|l|}
\hline Sancionadas as Diretrizes Curriculares Nacionais do Curso de Nutrição em & 2001 \\
substituição ao currículo mínimo. Definição do perfil acadêmico e profissional & \\
com competências e habilidades gerais e específicas. & \\
\hline $\begin{array}{l}\text { Portaria no 2.246/GM/MS: institui e divulga orientações básicas para a } \\
\text { implementação das Ações de Vigilância Alimentar e Nutricional, no âmbito }\end{array}$ & 2004 \\
das ações básicas de saúde do Sistema Único de Saúde - SUS, em todo o \\
território nacional.
\end{tabular}




\begin{tabular}{|c|c|}
\hline $\begin{array}{l}\text { Resolução n4 do Conselho Nacional de Educação (CNE). Estabelece carga } \\
\text { horária mínima de } 3200 \text { horas para o curso de Nutrição. }\end{array}$ & 2009 \\
\hline $\begin{array}{l}\text { Elaboração da "Matriz de Ações de Alimentação e Nutrição na Atenção Básica } \\
\text { de Saúde" pela Coordenação Geral de Alimentação e Nutrição (CGPAN) do } \\
\text { Departamento de Atenção Básica da Secretaria de Atenção Básica à Saúde do } \\
\text { Ministério da Saúde. Além do reconhecimento das estratégias de ação em } \\
\text { saúde coletiva, a matriz elenca as ações prioritárias nesta área, algumas delas } \\
\text { relacionadas ao conhecimento técnico específico da formação do } \\
\text { Nutricionista, quais sejam, as relações entre o homem e o alimento. }\end{array}$ & 2009 \\
\hline $\begin{array}{l}\text { Implantação do Programa Saúde na Escola pelo Ministério da Saúde, visando } \\
\text { articular e integrar as ações da educação e da saúde. Implicou em novas } \\
\text { possibilidades para o desenvolvimento de ações de promoção da alimentação } \\
\text { saudável, articuladas intersetorialmente, em nível de atenção primária. }\end{array}$ & 2009 \\
\hline $\begin{array}{l}\text { Portaria no } 4.279 / \mathrm{GM} / \mathrm{MS} \text { : estabelece diretrizes para a organização da Rede de } \\
\text { Atenção à Saúde no âmbito do Sistema Único de Saúde. }\end{array}$ & 2010 \\
\hline $\begin{array}{l}\text { Nova edição da Política Nacional de Alimentação e Nutrição (PNAN). } \\
\text { Enfatiza a atenção nutricional no SUS com foco na vigilância, promoção, } \\
\text { prevenção e cuidado integral de agravos relacionados à alimentação e } \\
\text { nutrição, atividades essas integradas às demais ações de saúde nas redes de } \\
\text { atenção, tendo a atenção básica como ordenadora das ações. }\end{array}$ & 2011 \\
\hline Publicação da segunda edição a Política Nacional de Atenção Básica (PNAB) & 2012 \\
\hline $\begin{array}{l}\text { Divulgação do Marco de Referência em Educação Alimentar e Nutricional } \\
\text { para Políticas Públicas. }\end{array}$ & 2012 \\
\hline $\begin{array}{l}\text { Guia Alimentar para a População Brasileira. NOVA Classificação dos } \\
\text { alimentos }\end{array}$ & 2014 \\
\hline $\begin{array}{l}\text { Divulgação da segunda edição do documento "O papel do Nutricionista na } \\
\text { atenção primária à saúde". CFN. }\end{array}$ & 2015 \\
\hline $\begin{array}{l}\text { Lei no13.666 dispõe sobre a inclusão da disciplina de educação alimentar e } \\
\text { nutricional na educação básica brasileira. }\end{array}$ & 2018 \\
\hline
\end{tabular}

Após o período acima citado, houve continuidade da discussão sobre a formação acadêmica a partir de eventos da área, incluindo estudos e avaliações sobre o curso. Sobre esse tema, podemos destacar o Consenso sobre habilidades e competências do Nutricionista no âmbito da saúde coletiva (RECINE e MORTOZA, 2013).

O II Encontro Nacional de Formação Profissional, promovido pelo CFN em 2015, apontou a necessidade de uma formação pedagógica e continuada dos docentes, assim como para a implementação de práticas pedagógicas inovadoras que desenvolvam a criticidade e a interdisciplinaridade (CFN, 2016). Outro ponto destacado no II Encontro de Formação Profissional foi a importância da indissociabilidade do ensino-pesquisa e extensão, tema já inserido nos debates sobre o ensino superior. Destaque também foi dado à necessidade da adequação dos projetos pedagógicos dos cursos ao contexto social (CFN, 2016). 
Chama a atenção, no documento final desse evento, o destaque dado à necessidade de uma formação política por docentes e discentes do curso, de forma a possibilitar uma efetiva participação frente aos órgãos de classe e representações sociais; para isso, torna-se imprescindível que haja valorização da formação humanística, contemplando o anseio da sociedade (CFN, 2016).

Também sobre a constituição da área social e a sua relevância diante do quadro de políticas públicas implantadas no país nos últimos anos, vale ressaltar a expansão das políticas e ações na área de Segurança Alimentar e Nutricional (SAN), especialmente após a criação do Sistema Nacional de Segurança Alimentar e Nutricional (SISAN), em 2006, e que tem sido um importante espaço para a definição do papel do profissional de Nutrição na elaboração e revisão das políticas da área (ALVES, 2018). Ademais, houve um elevado aumento de publicações de documentos governamentais com o objetivo de auxiliar a prática do Nutricionista na Nutrição Social, como o Marco de Referência em Educação Alimentar e Nutricional para Políticas Públicas (2012), o Guia Alimentar para a População Brasileira (2014) e o Instrutivo: metodologia de trabalho em grupos para ações de alimentação e nutrição na atenção básica (2016).

A importância do Nutricionista na área social foi se construindo de maneira notória com o passar do tempo. Nos anos 2000, ocorreu a inclusão deste profissional em diversas políticas, programas e estratégias, como na ESF por meio do NASF, pela PNAB e na alimentação escolar através do PNAE. E isso aconteceu devido às importantes mudanças identificadas no cenário epidemiológico brasileiro nas últimas décadas. $\mathrm{O}$ aumento no consumo de alimentos calóricos, ultraprocessados e com baixo valor nutricional se constituiu como um fator importante para o desenvolvimento de DCNT em indivíduos e populações (PNS, 2019). Nessa perspectiva, a inserção do Nutricionista junto à comunidade, como vetor de promoção da saúde e consequentemente de prevenção de doenças se fez de grande relevância e agregou novas atribuições a este profissional, no que tange à saúde coletiva.

Considerando esse cenário, houve a necessidade de adequação das atribuições do Nutricionista, haja vista o aumento da abrangência de seus cuidados na saúde coletiva (Quadro 4). A primeira Resolução publicada pelo CFN que dispõe sobre as áreas de atuação desse profissional, foi divulgada em 8 de Março de 1998. Nela, não há definição de saúde coletiva, há apenas a indicação das atribuições do Nutricionista, que eram majoritariamente "educação, orientação e assistência nutricional a coletividades, para a atenção primaria em saúde", com atribuições específicas para programas institucionais, atenção primária em saúde e vigilância sanitária. 
Sete anos depois, em 2005, foi publicada a Resolução no 380 que revogava o documento anterior incluindo novas áreas de atuação para o Nutricionista, como a de "marketing na área de alimentação e nutrição" e apresentava novas definições. Nesse documento, a saúde coletiva foi definida como "atividades de alimentação e nutrição realizadas em políticas e programas institucionais, de atenção básica e de vigilância sanitária" e possuía como atribuição principal "prestar assistência e educação nutricional a coletividades ou indivíduos sadios, ou enfermos, em instituições públicas ou privadas e em consultório de nutrição e dietética, através de ações, programas, pesquisas e eventos, direta ou indiretamente relacionados à alimentação e nutrição, visando à prevenção de doenças, promoção, manutenção e recuperação da saúde" (CFN, 2005).

Quadro 4 - Síntese das Resoluções que definem a saúde coletiva e áreas de atuação do nutricionista dentro desse campo do conhecimento de acordo com o CFN.

\begin{tabular}{|c|c|c|}
\hline Resolução & $\begin{array}{l}\text { Conceito de } \\
\text { saúde coletiva }\end{array}$ & $\begin{array}{l}\text { Áreas de atuação do } \\
\text { Nutricionista dentro da saúde } \\
\text { coletiva }\end{array}$ \\
\hline $\begin{array}{l}\text { Resolução CFN no } 200, \\
\text { de } 08 \text { de março de } 1998 . \\
\text { Dispõe sobre o } \\
\text { cumprimento das } \\
\text { normas de definição de } \\
\text { atribuições principal e } \\
\text { específicas dos } \\
\text { Nutricionistas, conforme } \\
\text { área de atuação. }\end{array}$ & - & $\begin{array}{l}\text { Programas institucionais; } \\
\text { Unidades primárias em saúde; } \\
\text { Vigilância sanitária. }\end{array}$ \\
\hline $\begin{array}{l}\text { Resolução CFN no } 380 \text {, } \\
\text { de } 28 \text { de dezembro de } \\
2005 . \\
\text { Dispõe sobre a definição } \\
\text { das áreas de atuação do } \\
\text { Nutricionista e suas } \\
\text { atribuições, estabelece } \\
\text { parâmetros numéricos de } \\
\text { referência, por área de } \\
\text { atuação, e dá outras } \\
\text { providências. }\end{array}$ & $\begin{array}{l}\text { Atividades de } \\
\text { alimentação e } \\
\text { nutrição } \\
\text { realizadas em } \\
\text { políticas e } \\
\text { programas } \\
\text { institucionais, de } \\
\text { atenção básica e } \\
\text { de vigilância } \\
\text { sanitária }\end{array}$ & $\begin{array}{l}\text { Políticas e programas } \\
\text { institucionais; } \\
\text { Atenção básica em saúde; } \\
\text { Vigilância em saúde. }\end{array}$ \\
\hline $\begin{array}{l}\text { Resolução CFN no } 600, \\
\text { de } 25 \text { de fevereiro de } \\
2018 \text {. Dispõe sobre a } \\
\text { definição das áreas de } \\
\text { atuação do Nutricionista } \\
\text { e suas atribuições, indica } \\
\text { parâmetros numéricos } \\
\text { mínimos de referência, } \\
\text { por área de atuação, }\end{array}$ & - & $\begin{array}{l}\text { Políticas e programas } \\
\text { institucionais: } \\
\text { - } \quad \text { Gestão das políticas e } \\
\text { programas; } \\
\text { - } \\
\text { Política Nacional de } \\
\text { Segurança Alimentar e } \\
\text { Nutricional (PNSAN); }\end{array}$ \\
\hline
\end{tabular}




\begin{tabular}{|c|c|}
\hline $\begin{array}{l}\text { para a efetividade dos } \\
\text { serviços prestados à } \\
\text { sociedade e dá outras } \\
\text { providências }\end{array}$ & $\begin{array}{l}\text { - Rede socioassistencial; } \\
\text { Alimentação e nutrição no } \\
\text { ambiente escolar; } \\
\text { • } \quad \text { Programa de Alimentação } \\
\text { do Trabalhador (PAT). } \\
\text { Atenção básica em saúde: } \\
\text { • Gestão das ações de } \\
\text { alimentação; } \\
\text { - Nutrição e cuidado } \\
\text { Vutricional. } \\
\text { Vigilância em saúde: } \\
\text { - Gestão da vigilância em } \\
\text { - } \text { Saúde; } \\
\text { - Vigilância sanitária; } \\
\text { - Vigilância epidemiológica; } \\
\text { Fiscalização do exercício } \\
\text { profissional. }\end{array}$ \\
\hline
\end{tabular}

Em 2018, com a publicação da Resolução no 600, houve a exclusão do glossário e a inclusão de novas subáreas e segmentos de atuação do Nutricionista na área social. Além disso, ocorreu uma modificação nas competências deste profissional na área de saúde coletiva, sendo a principal delas "organizar, coordenar, supervisionar e avaliar os serviços de nutrição; prestar assistência dietoterápica e promover a educação alimentar e nutricional a coletividades ou indivíduos, sadios ou enfermos, em instituições públicas ou privadas, e em consultório de nutrição e dietética; atuar no controle de qualidade de gêneros e produtos alimentícios; participar de inspeções sanitárias" (CFN, 2018).

Ainda em 2018, foi publicada a Lei no13.666, que dispõe sobre a inclusão da disciplina de educação alimentar e nutricional na educação básica brasileira. No tocante ao crescimento da obesidade infantil no Brasil, essa lei destaca a necessidade de discussões sobre alimentação adequada e saudável, além da valorização da culinária como prática emancipatória e da promoção da autonomia.

Com a pandemia de COVID-19 instaurada em 2020, de 211,7 milhões de brasileiros, 116,8 passaram a estar em Insegurança Alimentar (IA) grave, moderada ou leve. Destes, 43,4 milhões convivem com IA moderada ou grave, ou seja, não possuem alimentos em quantidades suficientes para atender suas necessidades. Enquanto isso, 19 milhões enfrentam a fome (VIGISAN, 2021). Nessa perspectiva, ações de promoção da SAN, DHAA e prevenção da IA se mostram, mais do que nunca, de suma importância para se combater a fome, o que mais uma vez enfatiza a relevância de uma formação profissional 
condizente com a complexidade do processo saúde-doença e as demandas da população nos seus aspectos biopsicossociais.

\section{CONSIDERAÇÕES FINAIS}

Para fins dos objetivos desse estudo, não buscamos elencar todas as políticas implantadas que possam ter repercussão no campo da Nutrição Social, mas procuramos dar destaque àquelas que podem permitir, por seu alcance, uma reflexão sobre a formação profissional do Nutricionista, com foco na inserção das ações de alimentação e nutrição dentro do sistema de saúde.

A partir da trajetória de formação desse profissional até o momento atual, e diante da realidade epidemiológica do país, somado a configuração do sistema de saúde, com seus princípios, diretrizes e políticas implantadas, consideramos que o Nutricionista é o profissional capaz de responder pelas ações e pelas políticas de alimentação e nutrição dentro do SUS. A relevância deste profissional ocorre em todas as etapas do Sistema de Saúde, desde o diagnóstico da situação alimentar, passando pelo planejamento e pela execução, até a avaliação e revisão das ações desenvolvidas, o que implica no desenvolvimento de determinadas competências e habilidades pertinentes à área.

Finalizando, consideramos também que apenas a incorporação de novos conteúdos e aplicação de novas metodologias de ensino, não irão garantir uma formação adequada para o Nutricionista, sem uma revisão da potencialidade desse profissional como protagonista de ações de saúde, com a ocupação de espaços estratégicos para enfrentamento dos problemas alimentares e nutricionais. Embora tenhamos feito a opção por uma dimensão específica da atuação profissional como objeto deste estudo, defendemos uma visão ampliada da questão alimentar condizente com uma prática reflexiva, que considere a perspectiva da integralidade, a humanização do cuidado, o enfoque interdisciplinar e a articulação entre os diversos setores da sociedade, na busca de resolutividade para o problema alimentar de indivíduos e comunidades.

Este artigo está presente na tese da autora, sob referência: Alves, C.G. competências para a atenção primária à saúde - uma proposta para a atuação do nutricionista. [Tese]. Campinas: Universidade Estadual de Campinas; 2018. 


\section{REFERÊNCIAS BIBLIOGRÁFICAS}

Alves, C.G. competências para a atenção primária à saúde - uma proposta para a atuação do nutricionista. [Tese]. Campinas: Universidade Estadual de Campinas; 2018.

Associação Brasileira de Nutrição (ASBRAN). ASBRAN completa 65 anos e faz festa no Dia do Nutricionista. 2014a. [Acesso 02 Ago 2017]. Disponível em:

http://www.asbran.org.br/noticias.php?dsid=1178

Brasil. Lei № 8.234, de 17 de setembro de 1991. Regulamenta a profissão de Nutricionista e determina outras providências. Brasília, DF; 1991.

Brasil. Ministério da Educação. Conselho Nacional de Educação. Diretrizes Curriculares Nacionais dos Cursos de Graduação em Enfermagem, Medicina e Nutrição. Brasília, DF: 2001c.

Brasil. Ministério da Saúde. Secretaria de Atenção à Saúde. Departamento de Atenção Básica. Política nacional de atenção básica / Ministério da Saúde, Secretaria de Atenção à Saúde, Departamento de Atenção à Saúde. - Brasília: Ministério da Saúde; 2006a. 60 p. - (Série A. Normas e Manuais Técnicos) (Série Pactos pela Saúde 2006, v. 4).

Brasil. Ministério da Saúde. Secretaria de Atenção à Saúde. Departamento de Atenção Básica. Política Nacional de Atenção Básica / Ministério da Saúde. Secretaria de Atenção à Saúde. Departamento de Atenção Básica. - Brasília: Ministério da Saúde; 2012a. 110 p. (Série E. Legislação em Saúde).

Brasil. Ministério da Educação (MEC). Instituições de Educação Superior e Cursos Cadastrados. Plataforma e-MEC, Curso: Nutrição. Ministério da Educação; 2021. [Acesso 01 Set 2021]. Disponível em: http//https://emec.mec.gov.br//.

Bezerra, J.A.B., Educação Alimentar e Nutricional: Articulação de saberes. 2018, Fortaleza.

Bosi MLM. A Face Oculta da Nutrição: Ciência e Ideologia. Rio de Janeiro: Espaço e Tempo; 1988. 220 p.

Bosi MLM, Prado SD. Alimentação e Nutrição em Saúde Coletiva: constituição, contornos e estatuto científico. Cien Saude Colet [online]. 2011, 16(1): 7-17.

Canesqui, A. M; Garcia, R. W. D. Ciências Sociais e Humanas nos Cursos de Nutrição in Antropologia e Nutrição: um diálogo possível. Ed Fiocruz, Rio de Janeiro, 2005.

Coimbra M, Meira JFP, Starling MBL. Comer e aprender: uma história da alimentação escolar no Brasil. Belo Horizonte: MEC/INAE; 1982. 685p.

Conselho Federal de Nutricionistas (CFN). Resolução CFN N 380/2005 - Dispõe sobre a definição das áreas de atuação do nutricionista e suas atribuições, estabelece parâmetros numéricos de referência, por área de atuação, e dá outras providências. Brasília, DF; 2005.

Conselho Federal de Nutricionistas (CFN). Inserção profissional dos nutricionistas no Brasil. Brasília: CFN; 2006. [Acesso 01 Fev 2015]. Disponível em: http://www.cfn.org.br/novosite/pdf/pesquisa.pdf. 
Conselho Federal de Nutricionistas (CFN). Relatório do II Encontro Nacional de Formação Profissional. Brasília, DF, 2016.

Conselho Federal de Nutricionistas (CFN). Estatísticas. Quadro Estatístico do 4o Trimestre de 2015 (10/10/2015 A 31/12/2015). Brasília: CFN; 2017d. [Acesso 29 Ago 2017]. Disponível em: http://www.cfn.org.br/index.php/estatistica/.

Conselho Federal de Nutricionistas (CFN). Nutricionista: 50 anos de história. 2017a. [Acesso 08 Jul 2021]. Disponível em:

http://www.cfn.org.br/wp content/uploads/2017/08/RevistaDigital_Edicao_1.4_2.pdf.

Conselho Federal de Nutricionistas (CFN). Estatísticas 2021 [Acesso 10 Jul 2021]. Disponível em: https://www.cfn.org.br/index.php/estatistica/

Costa NSC. Revisitando os estudos e eventos sobre a formação do nutricionista no Brasil. Rev. Nutr. 1999, 12(1): 5-19.

Costa NSC. A formação do nutricionista: educação e contradição. 2ª reimpr. Goiânia: Ed. da UFG; 2002.

Gil MF. Recursos Humanos em Nutrição no Brasil - Nutricionistas. Cad. Saúde Pública; 1986. 2(4): 56169.

Imamura F, Micha R, Khatibzadeh S, Fahimi S, Shi P, Powles J et al. Dietary quality among men and women in 187 countries in 1990 and 2010: a systematic assessment. Lancet Glob Health, 2015, 3 (3): 113 - 77. DOI: http://dx.doi.org/10.1016/S2214-109X (14)70381-X.

L"Abbate S. As Políticas de Alimentação e Nutrição no Brasil. I. Período de 1940 a 1964. Rev. Nutr. 1988, 1(2): 87-138.

Lima VV. Competência: distintas abordagens e implicações na formação de profissionais de saúde. Interface - Comunic., Saúde, Educ., 2005, 9 (17): 369-79.

Lotterman K, Jardim PCBV. Formação do nutricionista no Brasil. In: Costa NMSC, Pereira ERS. (Org.). Ensino na Saúde: transformando práticas profissionais. Goiânia: Gráfica da UFG, V.1; 2015.

Mitre SM, Siqueira-Batista R, Girardi-de-Mendonça JM, Morais-Pinto NM, Meirelles CAB.; Pinto-Porto $C$ et al. Metodologias ativas de ensino-aprendizagem na formação profissional em saúde: debates atuais. Ciên. Saúde Colet. 2008,13(Suppl 2):2133-44.

Paim JS, Almeida Filho N. Saúde Coletiva: uma "nova saúde pública" ou campo aberto a novos paradigmas? Rev. Saúde Públ. 1998, v.32, n.4, p. 299-316

Pereira, R.C; Inácio, M.L.C, Pereira, M. C. A. Educação alimentar e nutricional: das bases teóricas às experiências práticas. Editora UFLA. Lavras, 2020.

Pesquisa nacional de saúde (PNS) : 2019 : informações sobre domicílios, acesso e utilização dos serviços de saúde : Brasil, grandes regiões e unidades da federação / IBGE, Coordenação de Trabalho e Rendimento. - Rio de Janeiro : IBGE, 2020. 85p 
Portronieri FRD, Elias RC, Fonseca ABC. A importância das disciplinas sociais na formação em Nutrição na percepção dos alunos. Relatório do Encontro Nacional de Pesquisa em Educação em Ciências - VII ENPEC, Florianópolis; 2009. [Acesso 27 Jan 2015]. Disponível em: http://www.mendeley.com/research/importncia-das-disciplinas-sociais-na-formao-em-nutrio-napercepo-dos-alunos-1/.

Nunes ED. Saúde coletiva: uma história recente de um passado remoto, In: Campos GWS. et al. (orgs.). Tratado de saúde coletiva. São Paulo: Hucitec; Rio de Janeiro: Fiocruz; 2006. p. 295-315.

Recine E, Mortoza AS. Consenso sobre habilidades e competências do nutricionista no âmbito da saúde coletiva. Brasília: Observatório de Políticas de Segurança e Nutrição (OPSAN/UNB); 2013. 64 p.

Ribeiro ACM. Os novos paradigmas e a formação do profissional da Nutrição. Rev. Diálogo Educ. 2001, 2(4): 113-28.

Santos SMC. Nutricionista e sociedade brasileira: elementos para a abordagem histórico-social da profissão. [Dissertação]. Salvador: Universidade Federal da Bahia; 1988.

Soares NT, Aguiar AC. Diretrizes curriculares nacionais para os cursos de nutrição: avanços, lacunas, ambiguidades e perspectivas. Rev. Nutr. 2010, 23(5): 895-905.

Taddei JAAC, Lang RMF, Longo-Silva G, Toloni MHA. (Ed.). Nutrição em Saúde Pública. Rio de Janeiro: Editora Rubio; 2011a.

Taddei JAAC, Lang RMF, Longo-Silva G, Toloni MHA. (Ed.). Nutrição em Saúde Pública. Rio de Janeiro: Editora Rubio; 2016b.

Valente FLS. Em busca de uma educação nutricional crítica. In: Valente FLS (org.). Fome e desnutrição: determinantes sociais. São Paulo: Cortez, 1989.

Vasconcelos FAG. Os Arquivos Brasileiros de Nutrição: uma revisão sobre produção científica em nutrição no Brasil: 1944 a 1968. Cad. Saúde Pública, 1999a, 15(2): 303-16

Vasconcelos FAG. O nutricionista no Brasil: uma análise histórica. Rev Nutr 2002, 15(2): 127-138.

Vasconcelos, F. A. G.; Batista Filho, M. História do campo da alimentação e nutrição em saúde coletiva no Brasil. Ciência \& Saúde Coletiva, Rio de Janeiro, v. 16, n. 1, p. 81-90, jan. 2011.

Vasconcelos FAG, Calado CLA. Profissão nutricionista: 70 anos de história no Brasil. Rev. Nutr. 2011, 24(4): 605-617.

Vigisan: Inquérito Nacional sobre Insegurança Alimentar no Contexto da Pandemia da Covid-19 no Brasil. Rede Brasileira de Pesquisa em Soberania e Segurança Alimentar e Nutricional (Rede PENSAN). 2021.

Ypiranga L, Gil, MF Formação profissional do nutricionista: por que mudar? In: Cunha DTO, Ypiranga L, Gil MF (Org.). Il Seminário Nacional sobre o Ensino de Nutrição. Goiânia: FEBRAN; 1989 


\section{Capítulo 11}

doi $10.37423 / 211205125$

\section{ATIVIDADE ANTIOXIDANTE, COMPOSIÇÃO CENTESIMAL E MINERAL DE COGUMELOS PLEUROTUS OSTREATUS}




\section{INTRODUÇÃO}

As espécies reativas de oxigênio (ROS) estão relacionadas a vias bioquímicas importantes, como sinalização celular e defesa contra patógenos (Bhatt et al., 2021; Martins-Marques et al., 2021). Metabolitos parcialmente reduzidos e altamente reativos podem ser formados durante reações de transferência de elétrons. Esses metabólitos incluem o ânion superóxido $\left(\mathrm{O}_{2}^{-}\right)$e o peróxido de hidrogênio $\left(\mathrm{H}_{2} \mathrm{O}_{2}\right)$, formados por reduções de $\mathrm{O}_{2}$ em um e dois elétrons, respectivamente (Mailloux, 2020). Na presença de íons de metal de transição, o radical hidroxila $(\mathrm{OH} \cdot)$, ainda mais reativo, pode ser formado. Para que as ROS executem seus papéis fisiológicos, deve haver um equilíbrio apropriado entre agentes oxidantes e antioxidantes. Esse equilíbrio pode ser perturbado e deslocado para o aumento da produção de ROS quando os níveis de agentes antioxidantes diminuem. Como consequência, a superprodução de ROS danifica macromoléculas, induzindo apoptose e necrose tecidual (Bhatt et al., 2020; Mailloux, 2020).

O estresse oxidativo provocado por processos patofisiológicos e/ou fatores ambientais adversos está associado a doenças cardíacas, neurodegenerativas, diabetes mellitus e câncer (Bhatt et al., 2021; Mailloux, 2020; Molyneux Philip, 2004; Pisoschi et al., 2021; Prasad et al., 2021). Na tentativa de manter a homeostase, os antioxidantes impedem a oxidação de proteínas e DNA nas células, fornecendo elétrons às ROS de forma espontânea ou catalisada por enzima (Avery, 2011; Lushchak, 2014). Certos antioxidantes podem atuar eliminando os ROS produzidos ou revertendo o dano induzido por ROS em macromoléculas alvo (Birben et al., 2012). Os antioxidantes podem estar presentes endogenamente ou obtidos através da dieta (Hasanuzzaman et al., 2020; Kurutas, 2016).

Por muitos anos, os cogumelos culinários eram percebidos como iguarias e seu uso nos países ocidentais era restrito. Entretanto, os cogumelos têm se destacado como alimentos nutritivos que apresentam efeitos protetores contra disfunções fisiológicas (Phan et al., 2017; Roupas et al., 2012). Diferentes compostos bioativos foram identificados em cogumelos, incluindo flavonoides, terpenos, lectinas, compostos fenólicos, esteróis e alcaloides (Khan et al., 2013; Villares et al., 2012). Entre o abundante número de cogumelos comestíveis, o gênero Pleurotus é uma fonte promissora de novos "micoquímicos". A espécie Pleurotus ostreatus tem se destacado pela abundância de nutrientes importantes como vitaminas e selênio, antioxidantes naturais importantes no sistema biológico (Alam et al., 2008; Jayakumar et al., 2009). 
Até agora, as pesquisas se concentraram no valor dietético dos cogumelos comestíveis; contudo, há poucas informações sobre suas propriedades antioxidantes. Portanto, o objetivo deste trabalho foi avaliar a atividade antioxidante in vitro de Pleurotus ostreatus enriquecidos com ferro, zinco e lítio bem como a composição centesimal e mineral deste cogumelo comestível quando cultivado em casca de café.

\section{MATERIAL E MÉTODOS}

\subsection{CULTIVO DE PLEUROTUS OSTREATUS ENRIQUECIDO COM METAIS}

Os cogumelos foram cultivados no Departamento de Microbiologia da Universidade Federal de Viçosa, Viçosa, Minas Gerais, Brasil. O crescimento dos cogumelos ocorreu em casca de café previamente fervida durante $2 \mathrm{~h}$ e centrifugada a $1800 \mathrm{~g}$ durante $5 \mathrm{~min}$. Aproximadamente $1 \mathrm{~kg}$ de casca de café foi colocado em sacos de polipropileno e autoclavados por $2 \mathrm{~h}$. Aos cogumelos enriquecidos com ferro foram adicionados $25 \mathrm{~mL}$ de sulfato ferroso $0,8 \mathrm{mg} \mathrm{kg}^{-1}$. O tratamento enriquecido com zinco recebeu $25 \mathrm{~mL}$ de carbonato de zinco $2,13 \mathrm{mg} \mathrm{kg}^{-1}$ e os cogumelos que cresceram em meio enriquecido com lítio recebeu $25 \mathrm{~mL}$ de cloreto de lítio $0,25 \mathrm{~g} \mathrm{~kg}^{-1}$. Os isolados de $P$. ostreatus (Plo 02) foram inoculados em cabine de fluxo laminar. O período de incubação foi de 15 dias a 25 oC e o tempo de frutificação foi 40 dias a 20 ㄷ, com umidade do ar em $80 \%$. Cogumelos sem tratamento também foram cultivados como controle.

Todos foram secos em estufa a 50 으 durante $17 \mathrm{~h}$ para serem triturados. Os extratos dos cogumelos foram macerados e $10 \mathrm{~g}$ de cada amostra foi imerso em $100 \mathrm{~mL}$ de álcool metílico durante $30 \mathrm{~min}$ em agitação. Os extratos foram filtrados e submetidos à secagem em evaporador rotativo a 40 ㅇ C até a completa evaporação do solvente.

\subsection{ANÁLISE DE COMPOSTOS ANTIOXIDANTES}

O teste antioxidante do $\mathrm{DPPH}^{\bullet}$ foi realizado conforme a metodologia descrita por Sousa et al. (2007) com algumas modificações. A $1 \mathrm{~mL}$ de solução $0,06 \mathrm{mM}$ de DPPH foram adicionados $2,5 \mathrm{~mL}$ de soluções dos extratos metanólicos. Assim, foram utilizadas as seguintes concentrações 14,3; 42,9; 85,7; 128,6; 171,$4 ; 214,3 ; 257,1$ e $300 \mu \mathrm{g} \mathrm{mL}^{-1}$. Trinta minutos após a adição de DPPH, a leitura de absorvância foi realizada em triplicata no espectrofotômetro (Hitachi U-5100) a $517 \mathrm{~nm}$. A determinação da $I_{50}$ foi obtida por regressão exponencial dos pontos plotados para cada extrato, chegando-se assim à 
concentração necessária para reduzir em $50 \%$ a concentração inicial do radical $\mathrm{DPPH}^{\circ}$. O composto orgânico BHT foi utilizado como referência, devido à alta capacidade antioxidante.

A porcentagem de $\mathrm{DPPH}^{\bullet}$ remanescente foi calculada a partir da equação: \% de captura do radical $\mathrm{DPPH}^{\bullet}=\left[\left(\mathrm{A}_{0}-\mathrm{A}_{s}\right) / \mathrm{A}_{0}\right] \times 100$, sendo $A_{0}$ a absorbância do controle (contendo todos os reagentes exceto a amostra testada), e $A_{s}$ a absorbância da amostra.

\subsection{CULTIVO DE PLEUROTUS OSTREATUS PARA AS ANÁLISES DE COMPOSIÇÃO QUÍMICA}

O isolado de Pleurotus ostreatus foi recuperado da coleção de fungos armazenado em tubo contendo o meio de cultura Ágar Batata Dextrose (BDA) a 4 으 em geladeira. Um disco de BDA de 8 mm de diâmetro contendo micélio foi transferido das bordas das colônias das culturas estoques, para o centro de placas de Petri de $90 \mathrm{~mm}$ de diâmetro, contendo BDA a fim de reativar as culturas. As placas foram incubadas por 12 dias a $25 \stackrel{\circ}{\circ}$.

As culturas foram utilizadas para produção de inóculo em substrato à base de grãos de arroz em casca para o crescimento do fungo. Após o pré-cozimento do arroz em casca por $30 \mathrm{~min}$, foi realizado preparo da semente. $\mathrm{O}$ arroz em casca foi acondicionado em frascos de vidro (60 g por frasco), juntamente com gesso e calcário, denominado semente. Os frascos foram autoclavados a 121 ㅇ $\mathrm{Cpor}$ $90 \mathrm{~min}$. Os potes de sementes foram inoculados com o micélio do fungo cultivado em BDA. O substrato utilizado foi casca de café, fervido por $2 \mathrm{~h}$, centrifugado por 5 min a $1800 \mathrm{~g}$.

Amostras de 1,0 kg foram colocadas em sacos de polipropileno e autoclavadas uma vez por $90 \mathrm{~min}$ a $121{ }^{\circ} \mathrm{C}$. Para a produção final do inoculante, a casca de café foi acondicionada em sacos de polipropileno (1 kg por saco) e autoclavados como descrito anteriormente. Após o resfriamento, cada saco foi inoculado com $30 \mathrm{~g}$ da semente. O período de incubação foi de 30 dias em temperatura de 25 \pm 3 ㅇ e em câmaras BOD. As colheitas ocorreram durante 45 dias. Amostras de cogumelos foram secas a $50{ }^{\circ} \mathrm{C}$ por $16 \mathrm{~h}$, pesadas e maceradas em Tissuelyser para obtenção de uma farinha de cogumelos desidratados utilizada nas análises de composição química.

\subsection{ANÁLISE DA COMPOSIÇÃO CENTESIMAL E MINERAL DE PLEUROTUS OSTREATUS}

Os métodos da Association of Official Analytical Chemists - AOAC (AOAC, 2005) foram utilizados para determinação da composição química do cogumelo. O teor de umidade foi realizado por meio de secagem em estufa a $105 \stackrel{\circ}{\circ}$ até peso constante. A determinação de proteínas foi realizada pelo método micro Kjeldahl para a quantificação de nitrogênio total, utilizando 6,25 como fator de 
conversão. O conteúdo de lipídeos foi analisado por meio de extrator de Soxhlet, utilizando éter etílico como solvente por $8 \mathrm{~h}$ sob refluxo. A quantificação de cinzas foi determinada pela calcinação em mufla e o resultado expresso pela diferença de massa.

A análise de fibra dietética total (FDT) foi realizada de acordo com Prosky et al. (1988) por meio do método enzimático gravimétrico, utilizando a hidrólise enzimática, $\alpha$-amilase termoresistente, protease e amiloglicosidase (Sigma-Aldrich ${ }^{\circledR}$, St. Louis, MO, USA). O teor de carboidratos foi obtido pela diferença entre o total da amostra (100\%) e os teores de proteína, cinzas, umidade, lipídeos e fibra alimentar total. O conteúdo de minerais (ferro, cálcio, zinco, potássio, sódio, fósforo, magnésio, cromo, cobre e manganês) foi analisado por meio de espectrometria de emissão de plasma (Perkin Elmer - Optima 3300 DV, Norwalk, USA).

\section{RESULTADOS E DISCUSSÃO}

\subsection{ATIVIDADE ANTIOXIDANTE IN VITRO DE PLEUROTUS OSTREATUS}

Apesar de a atividade sequestrante dos radicais DPPH em corpos de frutificação de $P$. ostreatus já ter sido documentada em trabalhos anteriores, a atividade antioxidante de $P$. ostreatus enriquecidos com ferro, zinco e lítio é um avanço a fim de se obter um alimento com propriedades medicinais e nutritivas significativamente relevantes.

A tabela 1 mostra o efeito das concentrações de cada extrato e o composto de referência BHT requerido para sequestrar o radical DPPH ao longo de um intervalo de concentração de 1,43 - $300 \mu \mathrm{g}$ $\mathrm{mL}^{-1}$, com os valores percentuais.

Tabela 1 - Atividade sequestrante (\%) do radical DPPH de extratos metanólicos de Pleurotus ostreatus enriquecidos em diferentes concentrações, com respectivo IC $\mathrm{C}_{50}$

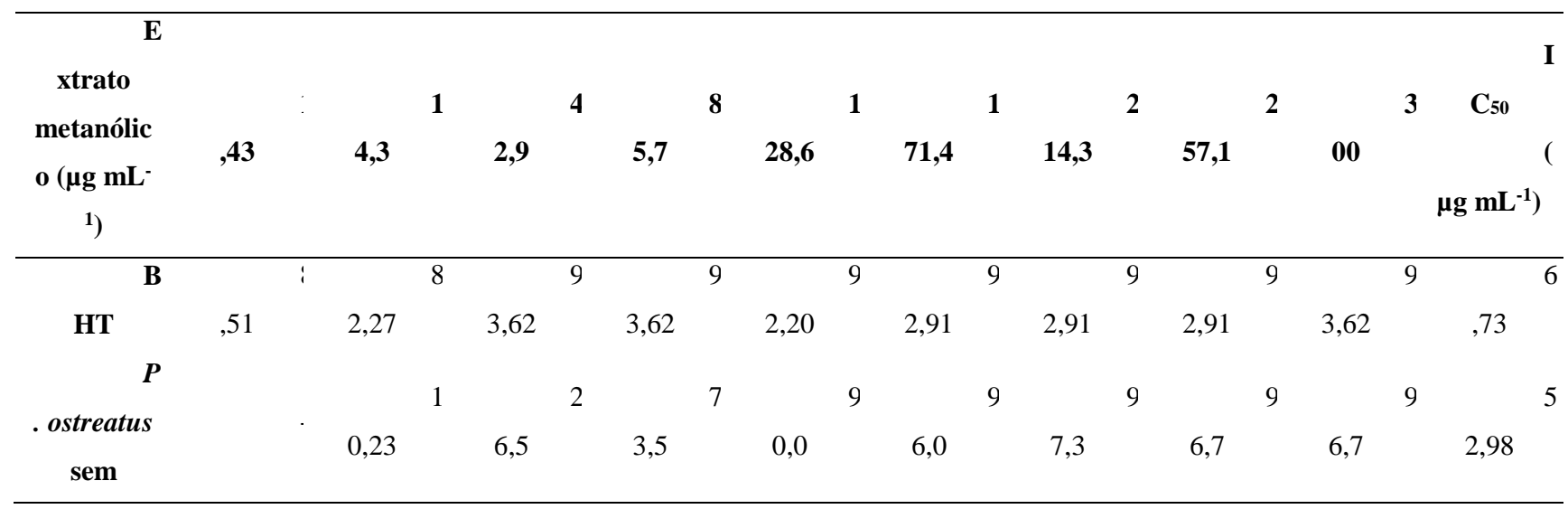




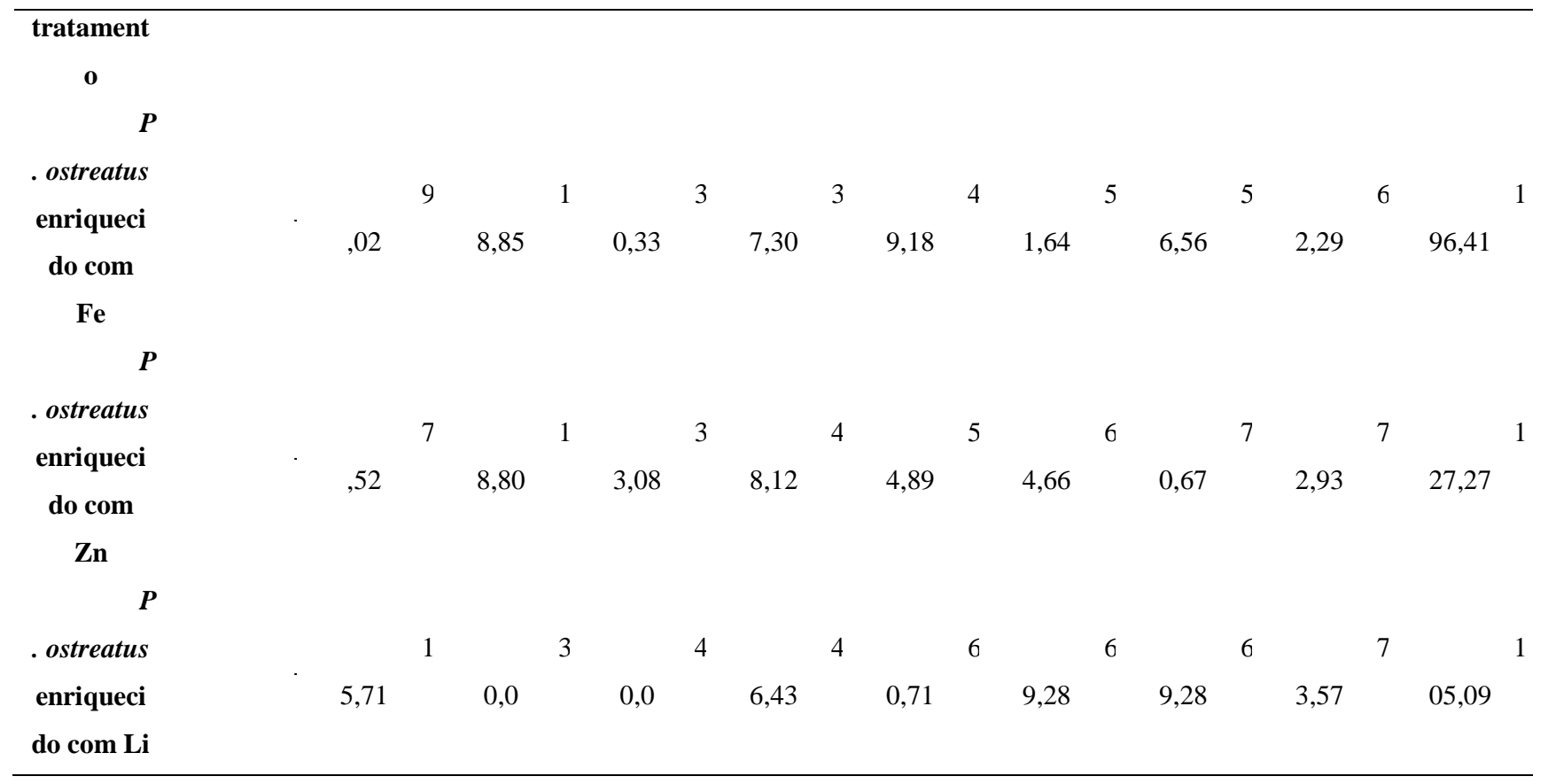

$\mathrm{IC}_{50}=$ quantidade em massa de extrato necessária para reduzir em $50 \%$ a concentração inicial do radical DPPH.

A avaliação antioxidante por DPPH mostrou um IC50 de 6,73 $\mu \mathrm{g} \mathrm{mL}^{-1}$ para o padrão de referência BHT. Este valor foi aproximadamente 8 vezes menor do que o $\mathrm{IC}_{50}$ do controle $\left(\mathrm{IC}_{50} 52,98 \mu \mathrm{g} \mathrm{mL}{ }^{-1}\right)$. Os valores de $\mathrm{IC}_{50}$ para os cogumelos enriquecidos com Fe, $\mathrm{Zn}$ e Li foram 196,41 $\mu \mathrm{g} \mathrm{mL}^{-1} ; 127,27 \mu \mathrm{gL}^{-1}$ e $105,09 \mu \mathrm{g} \mathrm{mL}{ }^{-1}$, respectivamente.

As diferenças de atividade antioxidante encontradas para as amostras testadas podem estar relacionadas à ação quelante dos metais $\mathrm{Fe}, \mathrm{Zn}$ e $\mathrm{Li}$, que podem ter complexado com compostos fenólicos, presentes em cogumelos do gênero Pleurotus.

Kim et al. (2009) verificaram que a atividade sequestradora de radicais DPPH de $P$. ostreatus em extratos metanólicos foi de 44 e $51 \%$ em 1 e 30 min, respectivamente. Houve também 57,7\% de sequestro do radical DPPH em uma concentração de $8 \mathrm{mg} \mathrm{mL}^{-1}$ de $P$. ostreatus. Os cogumelos $P$. ostreatus se mostraram potentes compostos bioativos naturais e uma boa fonte de antioxidantes. Atualmente há uma demanda crescente para a utilização de agentes antioxidantes naturais, uma vez que os antioxidantes sintéticos demasiadamente utilizados como o butilhidroxianisol (BHA) e butilhidroxitolueno (BHT) têm se mostrado tóxicos e carcinogênicos (Botterweck et al., 2000; Chen et al., 1992; Ito et al., 1985), além da crescente resistência de microrganismos por antibióticos sintéticos (Oyetayo, 2009). 


\subsection{COMPOSIÇÃO CENTESIMAL E MINERAL DE PLEUROTUS OSTREATUS}

O cogumelo $P$. ostreatus apresentou valores elevados de proteínas e fibras dietéticas totais, além de baixo teor de lipídios quando cultivado no substrato casca de café, como mostrado na tabela 2.

Tabela 2 - Composição centesimal do cogumelo Pleurotus ostreatus desidratado

\begin{tabular}{cc}
\hline $\begin{array}{c}\text { Componentes } \\
\left(\mathbf{g ~} \mathbf{~ 1 0 0 g}^{-1}\right)\end{array}$ & Média \pm Desvio padrão \\
\hline Proteína & $32,63 \pm 3,1$ \\
$\begin{array}{c}\text { Lipídeos } \\
\text { totais } \\
\quad \text { Fibra } \\
\text { dietética total } \\
\text { Fibra solúvel } \\
\quad \text { Fibra }\end{array}$ & $1,07 \pm 0,05$ \\
insolúvel \\
Cinzas \\
Umidade \\
$\begin{array}{c}\text { Carboidratos } \\
\text { totais }\end{array}$ & $35,49 \pm 1,7$ \\
\hline
\end{tabular}

O teor de proteína de $32,63 \%$ encontrado no cogumelo $P$. ostreatus desidratado cultivado em casca de café corrobora com o encontrado por Petrovska (2001), que verificou um teor médio de proteína de 32,6\% na matéria seca de 47 espécies de cogumelos comestíveis da Macedônia. O valor de fibra dietética total e de cinzas encontrado estão de acordo com os apresentados por Furlani \& Godoy (2007), que encontraram valores entre 22,3 e 51,25\% para fibra dietética total e entre 5,61 e 8,77\% para cinzas em cogumelos Pleurotus spp. Porém, o teor de lipídio do presente trabalho $(1,07 \%)$ foi menor que o encontrado pelos mesmos autores $(2,46-5,12 \%)$.

A composição de minerais presente no cogumelo $P$. ostreatus cultivado em casca de café está apresentada na tabela 3. O potássio foi o mineral mais abundante no cogumelo (13625 $\mathrm{mg} \mathrm{kg}^{-1}$ ), seguido de fósforo (3820 mg kg-1) e do enxofre (2640 mg kg-1). Entre os minerais presentes no cogumelo cultivado no substrato analisado, os valores de potássio e fósforo estão em menores quantidades quando comparados aos cogumelos estudados por Sales-Campos et al. (2009), que encontraram de 36830 a $42180 \mathrm{mg} \mathrm{kg}^{-1}$ de potássio e 6,95 a 10,600 $\mathrm{mg} \mathrm{kg}^{-1}$ de fósforo. 
Tabela 3 - Composição mineral do cogumelo Pleurotus ostreatus desidratado

\begin{tabular}{ccc}
\hline \multirow{2}{*}{ Minerais } & \multicolumn{2}{c}{ Concentração de minerais no cogumelo $\left(\mathbf{m g ~ k g}^{-1}\right)$} \\
\cline { 2 - 3 } K & Mínimo & Máximo \\
$\mathbf{P}$ & 10045 & 13625 \\
$\mathbf{S}$ & 3380 & 3820 \\
$\mathbf{M g}$ & 2290 & 2640 \\
$\mathbf{C a}$ & 900 & 985 \\
$\mathbf{F e}$ & 278,1 & 307,9 \\
$\mathbf{Z n}$ & 144,4 & 156,5 \\
$\mathbf{C u}$ & 53,15 & 60,13 \\
$\mathbf{P b}$ & 11,3 & 15,3 \\
$\mathbf{N i}$ & 0 & 0 \\
$\mathbf{C d}$ & 0 & 0 \\
\hline
\end{tabular}

Os valores de cálcio, ferro, zinco, cobre e magnésio do cogumelo cultivado no resíduo de café estão de acordo com os relatados por Kalač (2009), que encontrou valores entre 100 e $500 \mathrm{mg} \mathrm{kg}^{-1} \mathrm{de}_{\text {cálcio, }}$ 30 e $150 \mathrm{mg} \mathrm{kg}^{-1}$ de ferro, 30 e $150 \mathrm{mg} \mathrm{kg}^{-1}$ de zinco, 10 e $70 \mathrm{mg} \mathrm{kg}^{-1}$ de cobre e entre 800 e $1800 \mathrm{mg}$ $\mathrm{kg}^{-1}$ de magnésio. Chumbo, cádmio e níquel são metais pesados e sua ausência na análise dos cogumelos é importante, já que podem ser prejudiciais à saúde humana quando ingeridos.

\section{CONCLUSÃO}

Pelo método antioxidante $\mathrm{DPPH}^{\bullet}$, o extrato do cogumelo $P$. ostreatus sem tratamento apresentou a maior atividade antioxidante quando comparado com os extratos dos cogumelos enriquecidos com ferro, zinco e lítio. Os cogumelos enriquecidos mostraram ação quelante dos compostos fenólicos, reduzindo sua ação antioxidante. Assim, este trabalho contribui na busca de novas fontes naturais de antioxidantes a serem empregados em substituição aos compostos sintéticos utilizados pelas indústrias de alimentos. Além disso, a utilização do resíduo de café é uma alternativa viável para a produção do cogumelo, que é um alimento com alto teor de proteínas e fibras alimentares, além do baixo teor de lipídeos e fonte considerável dos minerais $\mathrm{K}, \mathrm{P}, \mathrm{Ca}$ e $\mathrm{Fe}$, essenciais à saúde humana. 


\section{REFERÊNCIAS}

Alam, N., Amin, R., Khan, A., Ara, I., Shim, M. J., Lee, M. W., \& Lee, T. S. (2008). Nutritional Analysis of Cultivated Mushrooms in Bangladesh - Pleurotus ostreatus, Pleurotus sajor-caju, Pleurotus florida and Calocybe indica. Mycobiology, 36(4), 228. https://doi.org/10.4489/myco.2008.36.4.228

AOAC. (2005). Official Methods of Analysis of AOAC International. In Association of Official Analysis Chemists International. AOAC International.

Avery, S. V. (2011). Molecular targets of oxidative stress. Biochemical Journal, 434(2), 201-210. https://doi.org/10.1042/BJ20101695

Bhatt, S., Nagappa, A. N., \& Patil, C. R. (2020). Role of oxidative stress in depression. Drug Discovery Today, 25(7), 1270-1276. https://doi.org/10.1016/j.drudis.2020.05.001

Bhatt, S., Puli, L., \& Patil, C. R. (2021). Role of reactive oxygen species in the progression of Alzheimer's disease. Drug Discovery Today, 26(3), 794-803. https://doi.org/10.1016/j.drudis.2020.12.004

Birben, E., Sahiner, U. M., Sackesen, C., Erzurum, S., \& Kalayci, O. (2012). Oxidative stress and antioxidant defense. World Allergy Organization Journal, 5(1), 9-19. https://doi.org/10.1097/WOX.0b013e3182439613

Botterweck, A. A. M., Verhagen, H., Goldbohm, R. A., Kleinjans, J., \& Van Den Brandt, P. A. (2000). Intake of butylated hydroxyanisole and butylated hydroxytoluene and stomach cancer risk: results from analyses in the Netherlands Cohort Study. Food and Chemical Toxicology, 38(7), 599-605. https://doi.org/10.1016/S0278-6915(00)00042-9

Chen, C., Pearson, A. M., \& Gray, J. I. (1992). Effects of synthetic antioxidants (BHA, BHT and PG) on the mutagenicity of IQ-like compounds. Food Chemistry, 43(3), 177-183. https://doi.org/10.1016/0308-8146(92)90170-7

Furlani, R. P. Z., \& Godoy, H. T. (2007). Nutritional value of edible mushrooms. Ciencia e Tecnologia de Alimentos, 27(1), 154-157. https://doi.org/10.1590/s0101-20612007000100027

Hasanuzzaman, M., Bhuyan, M. H. M. B., Zulfiqar, F., Raza, A., Mohsin, S. M., Al Mahmud, J., Fujita, M., \& Fotopoulos, V. (2020). Reactive oxygen species and antioxidant defense in plants under abiotic stress: Revisiting the crucial role of a universal defense regulator. Antioxidants, 9(8), 1-52. https://doi.org/10.3390/antiox9080681

Ito, N., Fukushima, S., \& Tsuda, H. (1985). Carcinogenicity and modification of the carcinogenic response by bha, bht, and other antioxidants. Critical Reviews in Toxicology, 15(2), 109-150. https://doi.org/10.3109/10408448509029322

Jayakumar, T., Thomas, P. A., \& Geraldine, P. (2009). In-vitro antioxidant activities of an ethanolic extract of the oyster mushroom, Pleurotus ostreatus. Innovative Food Science and Emerging Technologies, 10(2), 228-234. https://doi.org/10.1016/j.ifset.2008.07.002

Kalač, P. (2009). Chemical composition and nutritional value of European species of wild growing mushrooms: A review. Food Chemistry, 113(1), 9-16. https://doi.org/10.1016/J.FOODCHEM.2008.07.077 
Khan, M. A., Tania, M., Liu, R., \& Rahman, M. M. (2013). Hericium erinaceus: An edible mushroom with medicinal values. Journal of Complementary and Integrative Medicine, 10(1), 253-258. https://doi.org/10.1515/jcim-2013-0001

Kim, M. Y., Chung, III M., Lee, S. J., Ahn, J. K., Kim, E. H., Kim, M. J., Kim, S. L., Moon, H. I., Ro, H. M., Kang, E. Y., Seo, S. H., \& Song, H. K. (2009). Comparison of free amino acid, carbohydrates concentrations in Korean edible and medicinal mushrooms. Food Chemistry, 113(2), 386-393. https://doi.org/10.1016/j.foodchem.2008.07.045

Kurutas, E. B. (2016). The importance of antioxidants which play the role in cellular response against oxidative/nitrosative stress: Current state. Nutrition Journal, 15(1). https://doi.org/10.1186/s12937016-0186-5

Lushchak, V. I. (2014). Free radicals, reactive oxygen species, oxidative stress and its classification. Chemico-Biological Interactions, 224, 164-175. https://doi.org/10.1016/j.cbi.2014.10.016

Mailloux, R. J. (2020). An update on mitochondrial reactive oxygen species production. Antioxidants, 9(6), 472. https://doi.org/10.3390/antiox9060472

Martins-Marques, T., Rodriguez-Sinovas, A., \& Girao, H. (2021). Cellular crosstalk in cardioprotection: Where and when do reactive oxygen species play a role? Free Radical Biology and Medicine, 169, 397409. https://doi.org/10.1016/j.freeradbiomed.2021.03.044

Molyneux Philip. (2004). The Use Of The Stable Free Radical Diphenylpicryl-hydrazyl (DPPH) For Estimating Anti-oxidant Activity. Songklanakarin Journal of Science and Technology, 26(May), 1-10. https://www.researchgate.net/file.PostFileLoader.html?id=503cd237e4f0761a4b000020\&assetKey= AS\%3A273786924929035\%401442287297816

Oyetayo, V. O. (2009). Atividade sequestradora de radicais livres e propriedades antimicrobianas de extratos de cogumelos selvagens. Brazilian Journal of Microbiology, 40(2), 380-386. https://doi.org/10.1590/S1517-83822009000200031

Petrovska, B. B. (2001). Protein fraction in edible Macedonian mushrooms. European Food Research and Technology, 212(4), 469-472. https://doi.org/10.1007/s002170000285

Phan, C. W., David, P., \& Sabaratnam, V. (2017). Edible and Medicinal Mushrooms: Emerging Brain Food for the Mitigation of Neurodegenerative Diseases. Journal of Medicinal Food, 20(1), 1-10. https://doi.org/10.1089/jmf.2016.3740

Pisoschi, A. M., Pop, A., Iordache, F., Stanca, L., Predoi, G., \& Serban, A. I. (2021). Oxidative stress mitigation by antioxidants - An overview on their chemistry and influences on health status. European Journal of Medicinal Chemistry, 209, 112891. https://doi.org/10.1016/j.ejmech.2020.112891

Prasad, A., Mahmood, A., Gupta, R., Bisoyi, P., Saleem, N., Naga Prasad, S. V., \& Goswami, S. K. (2021). In cardiac muscle cells, both adrenergic agonists and antagonists induce reactive oxygen species from NOX2 but mutually attenuate each other's effects. European Journal of Pharmacology, 908, 174350. https://doi.org/10.1016/j.ejphar.2021.174350 
Prosky, L., Asp, N. G., Schweizer, T. F., DeVries, J. W., \& Furda, I. (1988). Determination of insoluble, soluble, and total dietary fiber in foods and food products: interlaboratory study. Journal - Association of Official Analytical Chemists, 71(5), 1017-1023. https://doi.org/10.1093/jaoac/71.5.1017

Roupas, P., Keogh, J., Noakes, M., Margetts, C., \& Taylor, P. (2012). The role of edible mushrooms in health: Evaluation of the evidence. Journal of Functional Foods, 4(4), 687-709. https://doi.org/10.1016/j.jff.2012.05.003

Sales-Campos, C., Oliveira, L. A. de, Araujo, L. M., Varejão, M. de J. C., \& Andrade, M. C. N. de. (2009). Composição mineral de uma linhagem de Pleurotus ostreatus cultivada em resíduos madeireiros e agroindustriais da região amazônica. Ciência e Tecnologia de Alimentos, 29(4), 868-872. https://doi.org/10.1590/s0101-20612009000400026

Sousa, C. M. D. M., Silva, H. R. E., Vieira, G. M., Ayres, M. C. C., Da Costa, C. L. S., Araújo, D. S., Cavalcante, L. C. D., Barros, E. D. S., Araújo, P. B. D. M., Brandão, M. S., \& Chaves, M. H. (2007). Fenóis totais e atividade antioxidante de cinco plantas medicinais. Quimica Nova, 30(2), 351-355. https://doi.org/10.1590/S0100-40422007000200021

Villares, A., Mateo-Vivaracho, L., \& Guillamón, E. (2012). Structural features and healthy properties of polysaccharides occurring in mushrooms. Agriculture (Switzerland), 2(4), 452-471. https://doi.org/10.3390/agriculture2040452 


\section{Capítulo 12}

doi $10.37423 / 211205133$

O VISAGISMO E A SUA APLICABILIDADE NA ODONTOLOGIA 
Como a boca é uma das partes do corpo que mais expressa informações acerca de um indivíduo, ela carrega conotações sensuais, autoconfiantes, de saúde e disposição. Então, entende-se com o Visagismo a arte de gerar uma imagem própria particularizada e atraente a partir uma avaliação do paciente como um todo a fim de elaborar o plano de tratamento abrangendo a intenção do indivíduo, a reabilitação, a estética, a mudança de personalidade e de vida. O objetivo desse trabalho é mostrar a importância do Visagismo na Odontologia Estética e Reabilitadora. A revisão bibliográfica incluiu artigos indexados na base de dados LILACS, e foi utilizada uma literatura de 2011. Utilizou-se os seguintes descritores: Estética Dentária; Reabilitação Bucal; Personalidade. Em primeiro plano, para se trabalhar com o conceito de Visagismo, é necessário estabelecer a intenção do cliente para orientar na elaboração do trabalho protético. Em seguida, é feita uma composição psicodentofacial (Coachman et al), onde o dentista trabalhará com a expressão das linhas e formas a fim de dar vivacidade ao trabalho. Os elementos do sorriso mais importantes são: plano incisal, eixos dentais, posicionamento dos dentes, forma dos dentes, exposição dos dentes, proporção dos dentes e linhas complementares. O plano incisal confere a posição das bordas incisais dos incisivos centrais, laterais e caninos na arcada superior e (quando esse plano se apresenta reto) associa-se a características masculinas e idade avançada; já quando esse plano se apresenta curvo e projetado, correlaciona-se a caracteres femininos e joviais. Os eixos dentais retratam o posicionamento dos elementos na arcada em comparação a linha média central - e, na maior parte das vezes, o eixo dos dentes anteriores superiores estão convergindo para incisal (Paolucci et al). Em relação ao posicionamento dental do arco, é possível verificar o modo com expressam possíveis características comunicativas do paciente. A forma dos dentes, em seguida, é estabelecida de acordo com as intenções que o indivíduo deseja transmitir (onde o formato retangular confere força, objetividade; o triangular, criatividade e alegria; o oval, delicadeza e suavidade). Logo depois, a exposição dental é o quanto de dente que aparece no momento que os lábios estão em repouso; quanto mais aparece estrutura dental, mais jovem é o sorriso. A relação proporcional entre os dentes é um fator importante a ser considerado, onde a simetria bilateral expressa frieza, estabilidade e calma. Por último, é necessário considerar as linhas complementares, onde as linhas de união e zênites gengivais podem variar desde o cônico-invertido (expressando tristeza, melancolia) até convexa-ascendente (caracterizando extroversão e impulsividade. Desse modo, o Visagismo Odontológico é considerado um complemento significativo do processo de planejamento, pois é possível proporcionar ganhos estéticos e construção de um sorriso que expresse o melhor da personalidade do paciente. 


\section{Capítulo 13}

doi) $10.37423 / 211205137$

PERFIL EPIDEMIOLÓGICO DOS PACIENTES INTERNADOS COM HANSENÍASE EM UM HOSPITAL DE REFERÊNCIAS DE DOENÇAS INFECCIOSAS DE FORTALEZA-CE DE 2009 A 2019

William Arruda Tavares

Geraldo de Azevedo Souza

Humberto Maciel Gondim Gonçalves Filho

Severino Ferreira Alexandre
Centro Universitário Christus

Centro Universitário Christus

Centro Universitário Christus

Hospital São José de Doenças Infecciosas 
Resumo: Introdução: A hanseníase é uma doença infectocontagiosa que acomete a população há milhares de anos, suas principais manifestações são dermatológicas, com hipocromia e diminuição da sensibilidade juntamente com estigmas sociais e preconceito. A Organização Mundial de Saúde (OMS), com intuito de eliminar a hanseníase, criou, por vezes, metas a serem conquistadas, entretanto alguns países ainda não obtiveram sucesso, a maioria dos países são subdesenvolvidos ou em desenvolvimento com recursos limitados na área da saúde. Considerando o exposto se fez necessária a realização do estudo para conhecer, avaliar e analisar o perfil clínico e epidemiológico dos pacientes portadores de hanseníase. Objetivos: Traçar o perfil sociodemográficos, as formas mais comuns da doença e suas complicações nos pacientes internados no hospital de referência de doenças infectocontagiosas do estado do Ceará no período de 2009 a 2019. Metodologia: Estudo transversal, retrospectivo, quantitativo, analítico e descritivo. Os dados foram obtidos por análise de 184 prontuários médicos do arquivo do hospital em estudo. Resultados e Discussão: Maior acometimento de hanseníase do sexo masculino (62\%), de idade média entre 41 e 50 anos, com baixa escolaridade, de etnia parda $(72,8 \%)$, solteiros $(45,7 \%)$, residentes na capital $(61,4 \%)$ e em bairros com baixos Índices de Desenvolvimento Humano $(<0,5)$. A forma clínica mais evidente foi a multibacilar $(88 \%)$ e a complicação foi a reação hansênica tipo $2(78,3)$, a maioria dos pacientes apresentavam no início do tratamento grau $2(66,8 \%)$ de incapacidade com uma redução de 33,7\% ao final do tratamento. Conclusão: Os pacientes são, na maioria, jovens, com baixo níveis de escolaridade, solteiros, do sexo masculino, economicamente ativos e com grau de incapacidade tipo 2.

Palavras-chave: Hanseníase; Epidemiologia; Mycobacterium Leprae; Pacientes internados; Doenças transmissíveis 


\section{INTRODUÇÃO}

A hanseníase é uma patologia infectocontagiosa de caráter crônico causada pelo Mycobacterium leprae, que possui predileção para a pele e nervos periférico.

Essa doença deixa estigmas físicos e/ou emocionais nos indivíduos, estando ligada à baixa renda familiar, desnutrição, escolaridade e condições de saúde precárias. (MELÃO, 2011) (MOURA, 2016)

Os primeiros relatos da existência da hanseníase foram há cerca de três a quatro mil anos, nos países da Índia, China e Japão. No Brasil, os primeiros casos descritos na literatura datam do ano de 1600, relacionados a chegada dos colonizadores europeus que trouxeram o mal de Hansen para as Américas. (FERREIRA, 2019)

Em 1873, o médico norueguês Armauer Hansen, identificou a bactéria causadora da hanseníase, elucidando que a doença não era originada de castigos divinos ou hereditária, entretanto o preconceito e os estigmas continuaram atrelados a moléstia. (CAVALIERE, 2020)

O Brasil representa o primeiro lugar na incidência e o segundo na prevalência mundial, sendo responsável por mais de $90 \%$ dos casos registrados nas Américas e no contexto mundial se destaca a Índia. A transmissão ocorre através da propagação dos bacilos por meio de gotículas provenientes das vias aéreas superiores de doentes com a forma multibacilar e, em menor casos, através do contato direto com as lesões em atividade. (MELÃO, 2011) (SOUZA, 1997)

No tocante a classificação operacional dos casos de hanseníase, torna-se imprescindível, pois, diante desta, se define a abordagem e o esquema terapêutico específico para cada subtipo, denominado de poliquimioterapia, supervisionado pelo profissional de saúde. Tal classificação baseia-se no número de lesões cutâneas apresentadas, portanto, paucibacilares (PB) são os pacientes que apresentarem até cinco lesões de pele, e multibacilar (MB) os indivíduos que possuam mais de cinco lesões de pele. (VELÔSO, 2018)

No ano de 1991, foi estabelecido pela Organização Mundial de Saúde (OMS) a primeira meta de eliminar a hanseníase até o ano de 2000, ou seja, obter prevalência menor que 1 para 10000 habitantes. Infelizmente, devido a falha dessa dessa e outras diversas metas, em 2016, a OMS realizou uma nova proposta, a Estratégia Global para Hanseníase 2016 - 2020, onde foram definidas as metas: eliminação da incapacidade de grau 2 (IG2) em pacientes pediátricos acometidos com hanseníase; 
redução dos novos casos de hanseníase com IG2 a menos de um caso por milhão de habitantes; nenhum país terá leis que permitem a descriminação por hanseníase. (WHO, 2016) (RIBEIRO, 2018) Considerando o exposto acima, fez-se necessário realizar o estudo para conhecer, avaliar e analisar o perfil clínico e epidemiológico dos pacientes com diagnóstico de hanseníase no período de 2009 a 2019 de um hospital de referência de doenças infectocontagiosas de Fortaleza - CE, objetivando uma melhor prática médica na assistência aos pacientes com hanseníase de maneira longitudinal e na prevenção de agravos que levam a incapacitação dos pacientes com hanseníase.

O objetivo deste trabalho consiste em analisar características clínicas e epidemiológicas dos pacientes internados e diagnosticados, no estado do Ceará, com hanseníase em um centro de referência durante o período de 2009 - 2019.

\section{METODOLOGIA}

\subsection{TIPO DE ESTUDO}

Trata-se de um estudo transversal, retrospectivo, quantitativo, analítico e descritivo.

\subsection{LOCAL E PERÍODO DE ESTUDO}

Estudo realizado por meio da análise de dados dos prontuários médicos dos pacientes internados tratados no hospital de referência de doenças infectocontagiosas de Fortaleza - CE, no período de 2009 a 2019.

\subsection{AMOSTRA DO ESTUDO}

Selecionados 184 prontuários médicos dos pacientes atendidos no hospital de referência de doenças infectocontagiosas de Fortaleza - CE. Destes, 124 são pacientes do sexo masculino e 60 do sexo feminino.

\subsection{COLETA DE DADOS}

Dados coletados dos prontuários médicos foram agrupados em um formulário para coleta das informações quantitativas por tópicos conforme descritos:

1. CARACTERÍSTICAS SOCIODEMOGRÁFICAS: idade, sexo, estado civil, escolaridade, ocupação; local de residência.

2. ATENDIMENTO MÉDICO: ano de atendimento; dias de internação. 
3. ASPECTOS CLÍNICOS: classificação clínica (OMS); grau de incapacidade no início do tratamento; grau de incapacidade após o tratamento; reação hansênica; óbito.

\subsection{CRITÉRIOS DE INCLUSÃO E EXCLUSÃO}

Incluídos pacientes diagnosticados com hanseníase atendidos no período de 2009 a 2019, no hospital de referência. Excluídos os pacientes diagnosticados antes de janeiro de 2009 ou depois de dezembro 2019 e prontuários não compatíveis com o diagnóstico de hanseníase.

\subsection{ANÁLISE DE DADOS}

Dados quantitativos foram analisados por meio do software estatístico Microsoft Excel ${ }^{\circledR}$ 16.0. Os resultados expressos na forma de quadros, tabelas e gráficos de acordo com suas características.

\subsection{PROCEDIMENTOS ÉTICOS}

Submetido ao Comitê de Ética do Centro Universitário Unichristus e considerando os princípios éticos que regem a resolução 466/12 do Conselho

Nacional de Saúde - CNS/Ministério da Saúde - MS, garantindo o anonimato de todos os pacientes, dos prontuários analisados, podendo os resultados da pesquisa serem apresentados em congressos e artigos científicos.

\section{RESULTADOS E DISCUSSÃO}

Foram analisados 184 prontuários de pacientes com diagnóstico de hanseníase. A idade média foi de 40,6 anos, o mais novo 7 anos e o mais velho 88 anos. A faixa etária predominante foi de 41 a 50 anos (22,2\%), seguida de 21 a 30 anos (20,1\%) e 51 a 60 anos (14,6\%) (Gráfico 1).

QUEIRÓS, 2016 demostrou que no período de 2007 a 2011 a idade média foi de 45,2 anos. SOUZA, 2012 constatou que nos anos de 2007 e 2008 na cidade de Fortaleza a faixa etária com maior número de pacientes foi de 20 a 29 anos (20,0\%), seguido de 30 a 39 anos (18,2\%) e de 50 a 59 anos (18,2\%).

O sexo mais prevalente foi o masculino com 67,4\% e o feminino 32,6\% (Gráfico 2), dados semelhantes são apresentados por MONTEIRO, 2017, que em seu estudo apresentou uma prevalência maior no sexo masculino $(54,7 \%)$. 


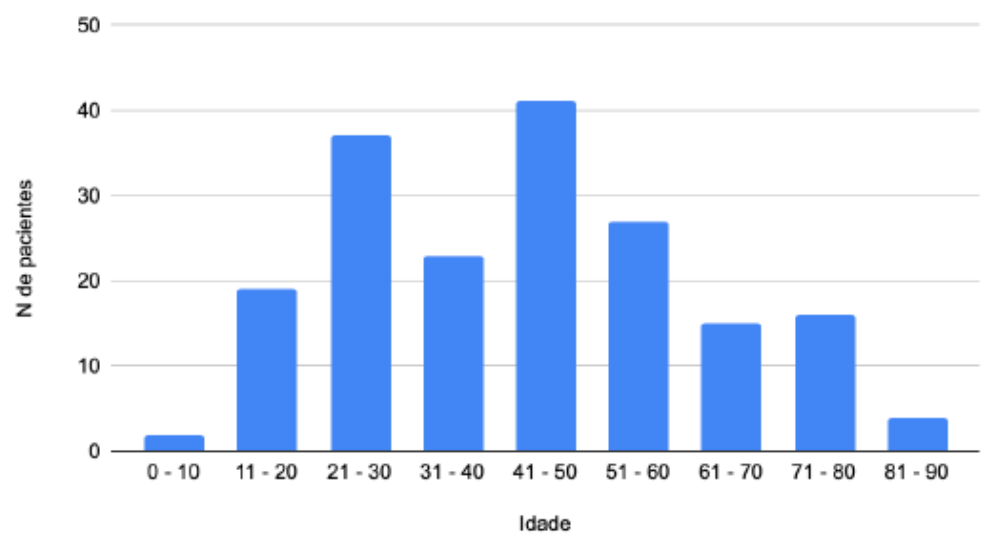

Gráfico 1: Número de pacientes / idade com hanseníase de 2009 a 2019

Fonte: Arquivos médicos.

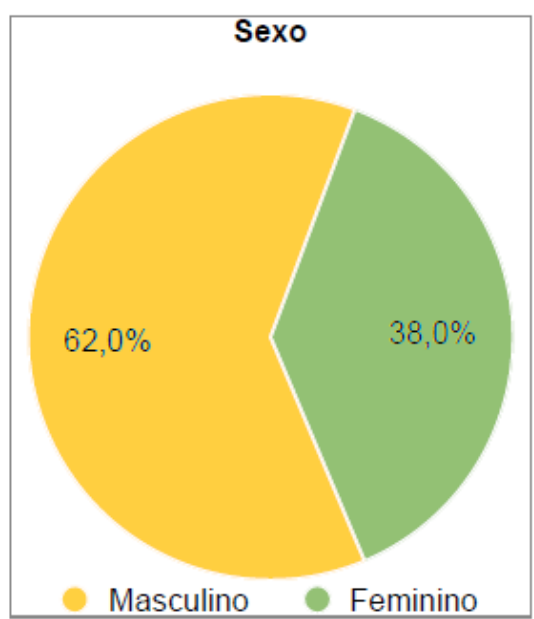

Gráfico 2: Sexo dos pacientes internados com hanseníase de 2009 a 2019.

Fonte: Arquivos médicos.

A maioria dos pacientes eram de etnia parda (72,8\%), seguido de 9,2\% amarelos, 7,1\% brancos,1,6\% negros e 9,2\% não constava no prontuário médico (Gráfico 3).

Chama atenção a etnia amarela em nosso estudo com proporção maior em comparação ao Boletim Epidemiológico de Hanseníase 2018, onde 58,9\% eram pardos, 26,8\% brancos, 12,8\% negros e 0,9\% amarelos. Vale ressaltar o grande números de prontuários que a etnia não era informada. A hanseníase, em geral, tem prevalência em lugares onde há maior concentração de pobreza, tendo uma relação próxima com más condições de habitação, baixa renda e escolaridade. (ABRAÇADO, 2015) Muitos estudos epidemiológicos demonstra a relação entre baixa escolaridade e hanseníase, principalmente com quadros clínicos mais graves, por existir dificuldade no acesso aos serviços de saúde (ABRAÇADO, 2015; SILVA 2007; RIBEIRO, 2018).

Sexo Masculino Feminino ALVES, 2017 analisou o perfil de escolaridade de pacientes em um centro de reabilitação para doentes com hanseníase, encontrando um perfil de baixa escolaridade: Analfabetos (6\%) e ensino fundamental incompleto (54,4\%). No estudo, os indivíduos analfabetos, analfabetos funcionais e com primeiro grau incompleto compuseram $74,2 \%$ da amostra. Chama atenção os prontuários em que a escolaridade não foi informada (47,3\%). (Gráfico 4). 


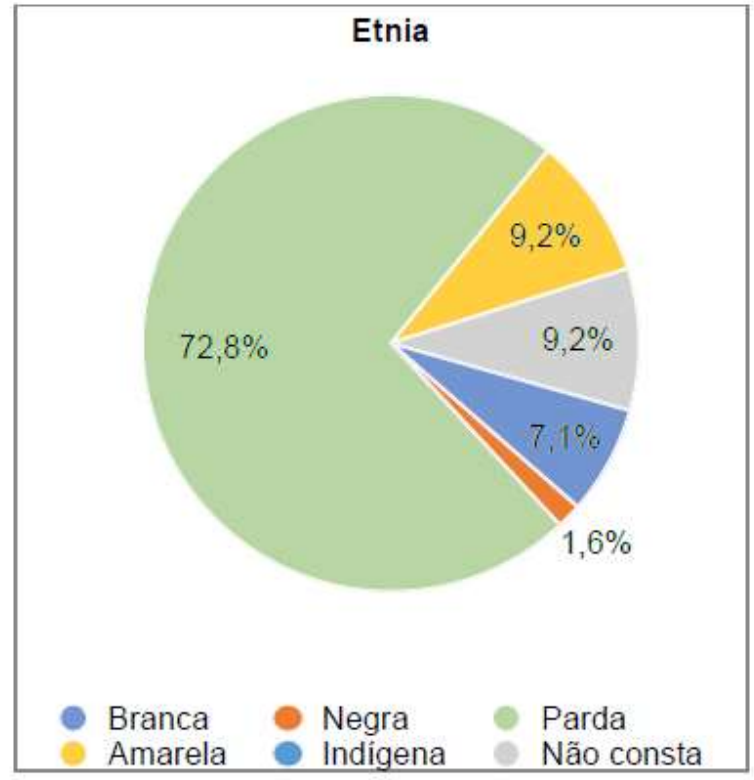

Gráfico 3: Etnia dos pacientes internados de 2009 a 2019 .

Fonte: Arquivos médicos.

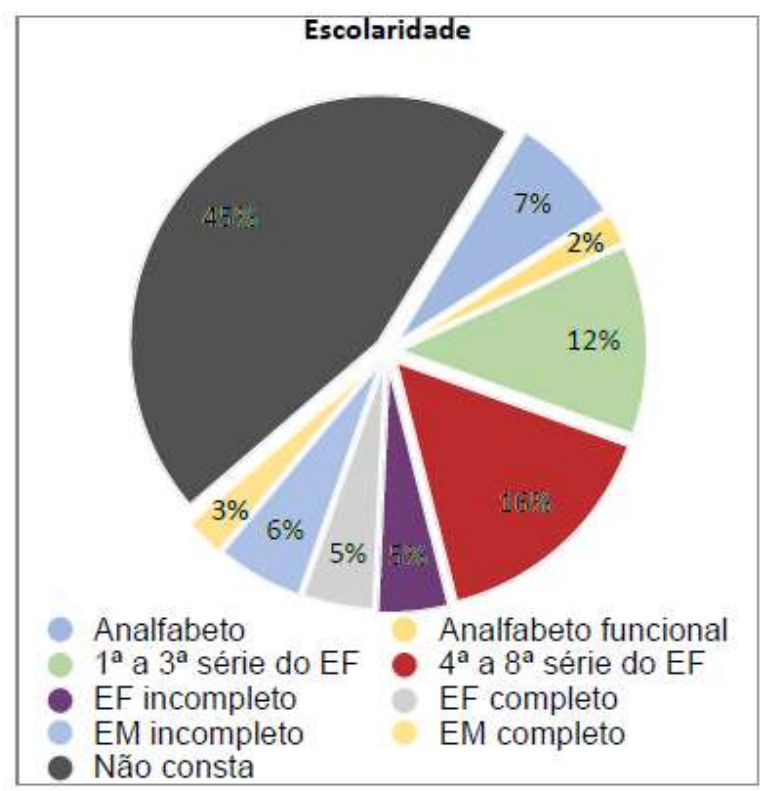

Gráfico 4: Escolaridade dos pacientes internados de 2009 a 2019

Fonte: Arquivos médicos.

Dos pacientes internados no hospital de referência de doenças infecciosas no período de 2009 a 2019, houve uma prevalência na população de solteiros de $45,7 \%$, casados $26,6 \%$, união estável $12 \%$, viúvos 4,9\% e separados ou divorciados (4,9\%) (Gráfico 5).

Dados semelhantes foram encontrados no estudo feito por DA COSTA LOBATO, 2016, mostrando a maior prevalência dos solteiros $(42,8 \%)$ também sendo seguida pela dos casados $(30,07 \%)$, confirmando os dados do presente estudo.

Em relação ao local de residência, 61,4\% residem em Fortaleza - CE e 38,6\% no interior do estado (Gráfico 6). Essa diferença é observada por contar com a rede hospitalar de referência e contrareferência. Outro fator que corrobora é a falta de assistência especializada no interior, fragilizando a assistência a esses pacientes.

QUEIRÓS, 2016 apresentou dados semelhantes em relação a prevalência dos Etnia Branca Negra Parda Amarela Indígena Não consta Escolaridade Analfabeto Analfabeto funcional 1a a 3a série do EF 4aa a 8aㅡ série do EF EF incompleto EF completo EM incompleto EM completo Não consta pacientes que moravam em fortaleza, mostrando uma diferença ainda maior sobre o local de residência dos pacientes que moravam na capital $(82,3 \%)$. 


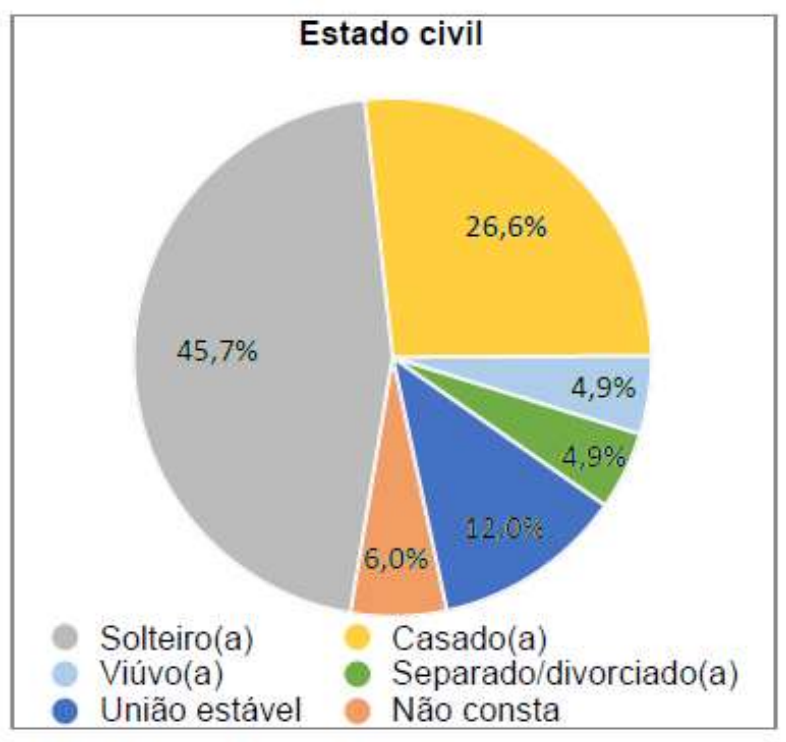

Gráfico 5: Estado civil dos pacientes internados com hanseníase de 2009 a 2019

Fonte: Arquivos médicos.

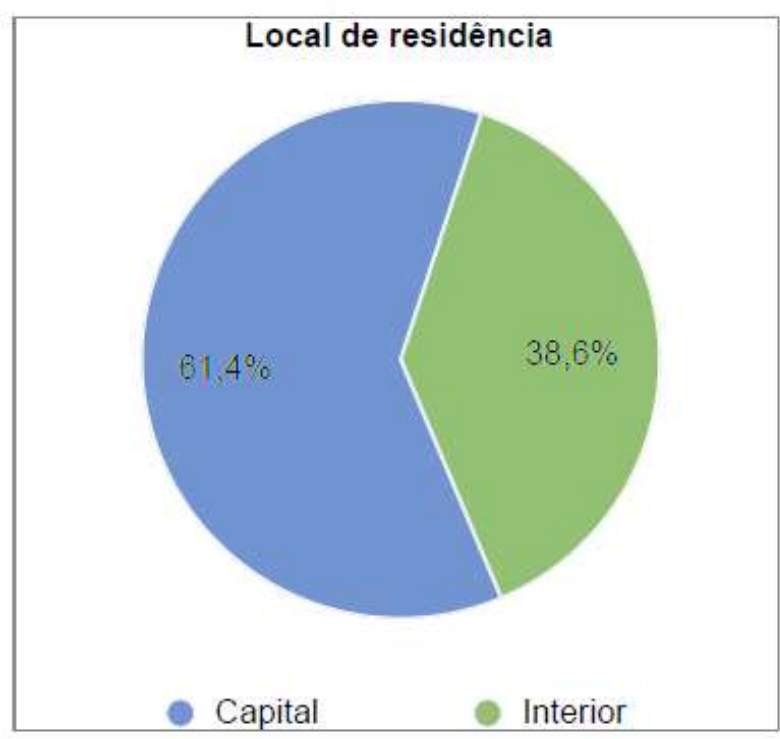

Gráfico 6: Local de residência dos pacientes internados com hanseníase de 2009 a 2019 Fonte: Arquivos médicos.

Dos pacientes que residiam no interior do estado, 38,3\% situavam-se nas região metropolitana de Fortaleza - CE. As cidades de Caucaia - CE (16,4\%), Parambu - CE (9,5\%) e Canindé - CE $(5,4 \%)$ são as que mais se destacam. Fortaleza é dividida em seis secretarias regionais (SER).

Os achados do estudo evidenciam que a SER V apresenta maior concentração dos casos (31,2\%), seguido da SER III (24,8\%) e da SER VI (20,2\%) (Gráfico 7). Estas regionais possuem baixo Índice de Desenvolvimento Humano (IDH). A SER V possui IDH 0,22, a SER III IDH 0,37 e a SER VI IDH 0,30 (Gráfico 8) (SDE, 2010). Um Índice de Desenvolvimento Humano é considerado baixo quando menor que 0,5.

O IDH do Brasil é de 0,73, do Ceará é 0,68 e Fortaleza - CE 0,74 (PNUD, 2010). No estudo, os bairros com maior concentração são o Bom Jardim (9,3\%) com IDH 0,19, o Canindezinho (4,6\%) com IDH 0,13 e o Quintino Cunha $(4,6 \%)$ com IDH 0,22, evidenciando a relação inversamente proporcional do número de casos com os baixos IDHs (Gráfico 8). Dentre o período de 2012 a 2016, os achados seguem o padrão de queda conforme evidenciado pelo ministério da saúde.

Entretanto, a partir de 2018, há um aumento na quantidade de pacientes internados (Gráfico 9) que não é demonstrado Local de residência Capital Interior Estado civil Solteiro(a) Casado(a) Viúvo(a) Separado/divorciado(a) União estável Não consta por estudos na população em geral. Isso pode ter ocorrido por conta deste estudo analisar, predominantemente, uma população vulnerável. Tal fato abre uma discussão sobre a efetividade das políticas públicas no combate à hanseníase no Ceará, e também se essas ações provêm benefícios para a população contida estudo. 


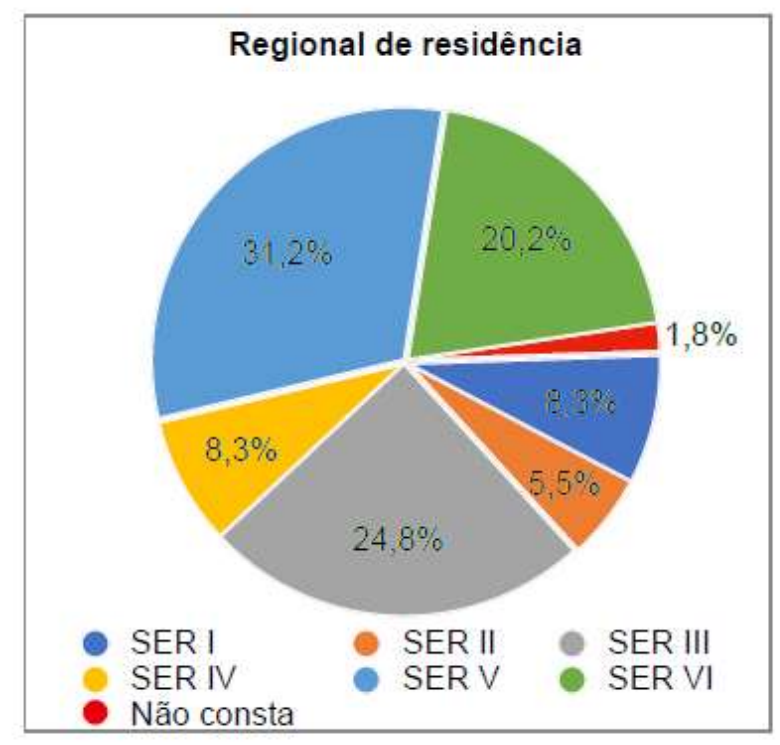

Gräfico 7: Regional de residência dos pacientes internados com hanseníase de 2009 a 2019. Fonte: Arquivos médicos.
IDH das Secretarias Regionais de Fortaleza

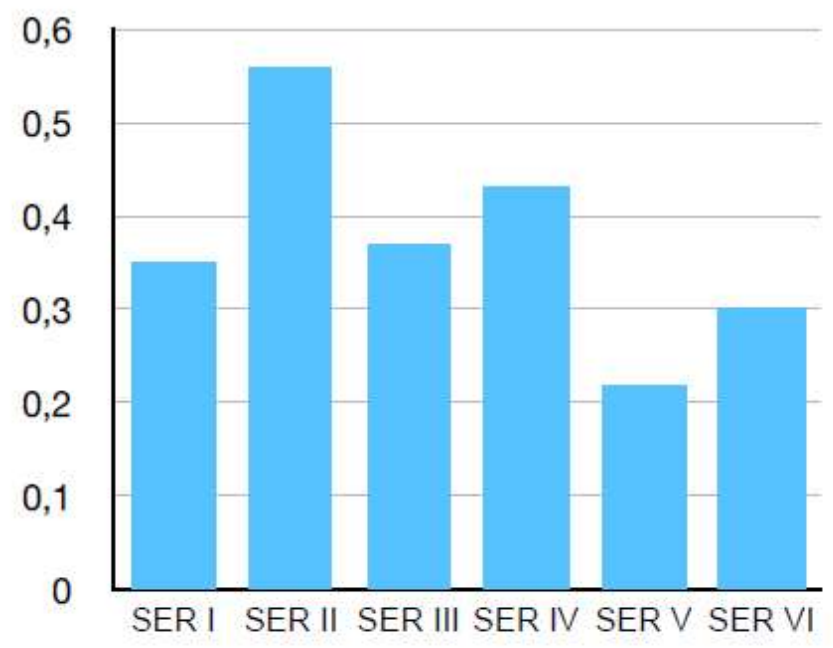

Gráfico 8: IDH das regionais de Fortaleza - CE Fonte: Arquivos médicos.

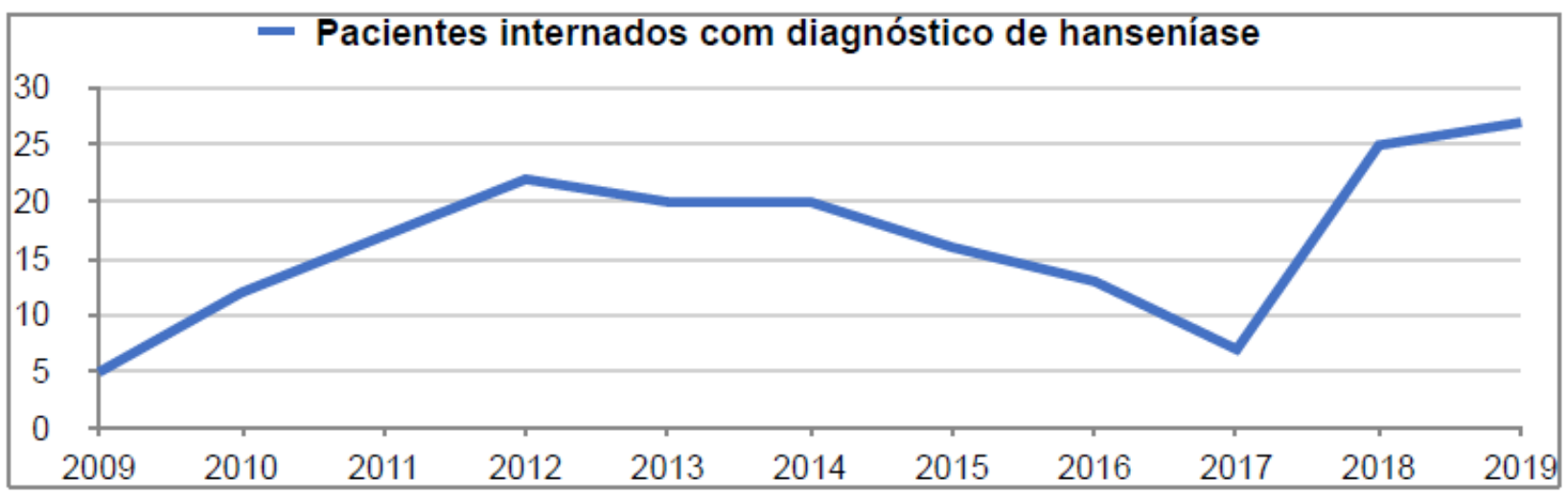

Gráfico 9: Pacientes internados com hanseníase no período de 2009 a 2019. Fonte: Arquivos médicos.

Em relação ao tempo de internamento dos pacientes, o maior período de internamento foi de 152 dias e o menor de 2 dias, apresentando uma média de 14 dias de internamento.

No estudo, a forma multibacilar foi de $88 \%$, os paucibacilares de 5,4\%, e 6,5\% não foram classificados de acordo com o número de lesões (Gráfico 10). Esses 0 0,1 0,2 0,3 0,4 0,5 0,6 SER I SER II SER III SER IV SER V SER VI IDH das Secretarias Regionais de Fortaleza Regional de residência SER I SER II SER III SER IV SER V SER VI Não consta 051015202530200920102011201220132014201520162017 20182019 Pacientes internados com diagnóstico de hanseníase números confirmam os dados apresentados no estudo de QUEIROZ, 2015, o qual evidenciou uma prevalência de $91,8 \%$ de pacientes 
com a forma multibacilar. Em relação ao aparecimento de reação hansênica, foi identificado em 166 pacientes (90,2\%). Destes 144 (78,3\%) foram internados com reação do tipo 2 , 14 (7,6\%) com reação tipo 1 e 3 (1,6\%) com quadro de fenômeno de lúcio (Gráfico 11).

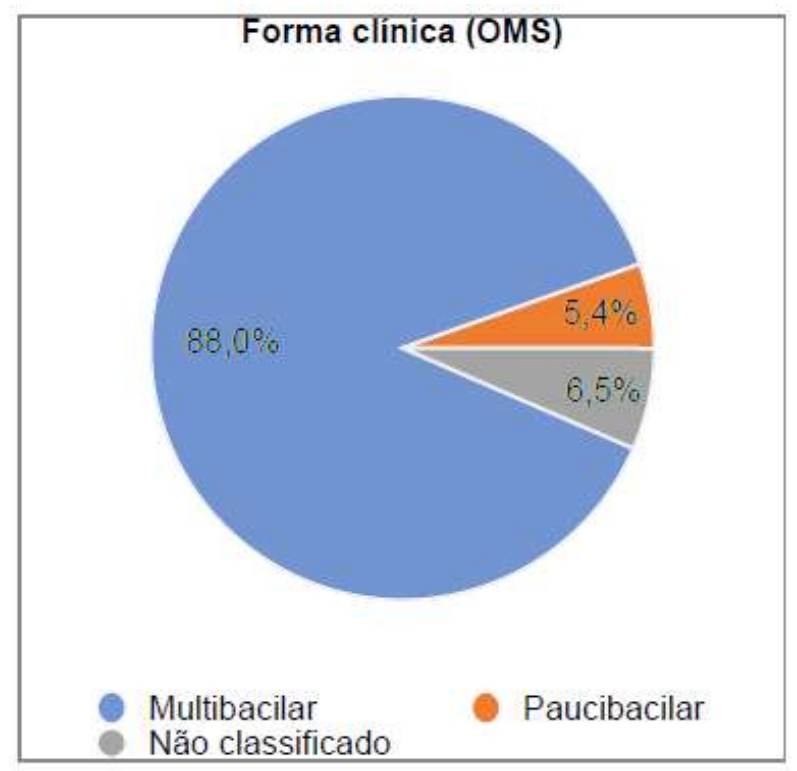

Gráfico 10: Forma clínica (OMS) dos pacientes internados com hanseníase de 2009 a 2019. Fonte: Arquivos médicos.

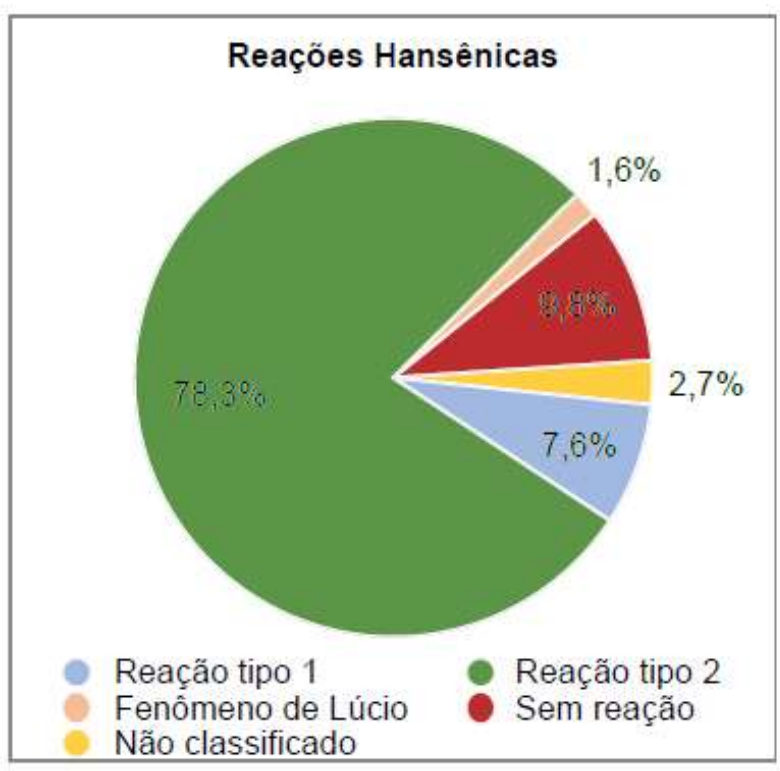

Gráfico 11: Reações hansênicas dos pacientes. internados com hanseníase de 2009 a 2019 Fonte: Arquivos médicos.

As reações hansênicas podem ocorrer antes, durante ou após a instituição do tratamento específico para hanseníase, e seus dois subtipos podem ser divididos em: tipo 1, no qual há uma reação mediada por células (hipersensibilidade tipo 4) e na tipo 2, onde ocorre uma reação medida por imunocomplexos (hipersensibilidade tipo 3) (GELBER, 2017).

TEXEIRA, 2010 analisou indivíduos paucibacilares e multibacilares atendidos em um centro de referência e encontrou que, dentre os pacientes em estado reacional, 75,1\% apresentaram estado reacional tipo 1 e 15,4\% estado reacional tipo 2, sendo essa proporção semelhante à constatada em outros estudos da literatura (SILVA, 2007; ABRAÇADO, 2015).

O estudo SILVA, 2007 obteve em seus achados o predomínio da reação tipo 1 (61\%) dentre os pacientes multibacilares. O presente estudo revelou um maior número de pacientes com reação tipo $2(78,3 \%)$, diferindo dos outros estudos encontrados na literatura, e isso se deve, possivelmente, à maior gravidade dos pacientes incluídos no estudo.

Os pacientes com quadro de eritema nodoso têm Forma clínica (OMS) Multibacilar Paucibacilar Não classificado Reações Hansênicas Reação tipo 1 Reação tipo 2 Fenômeno de Lúcio Sem reação Não classificado maior risco de evoluir com complicações graves, necessitando de internação hospitalar 
(KAHAWITA, 2008). Os graus de incapacidade física foram avaliados no momento da internação e da alta hospitalar.

Da amostra, 158 pacientes $(85,8 \%)$ apresentaram algum tipo de incapacidade física decorrente da hanseníase, sendo 123 pacientes (66,8\%) com incapacidade grau 2 e 35 (19\%) com incapacidade Grau 1. Não apresentaram nenhum tipo de incapacidade relacionada com a hanseníase 19 pacientes (10,3\%). Não foram classificados em relação ao grau de incapacitação 7 pacientes (3,8\%) (Gráfico 12).

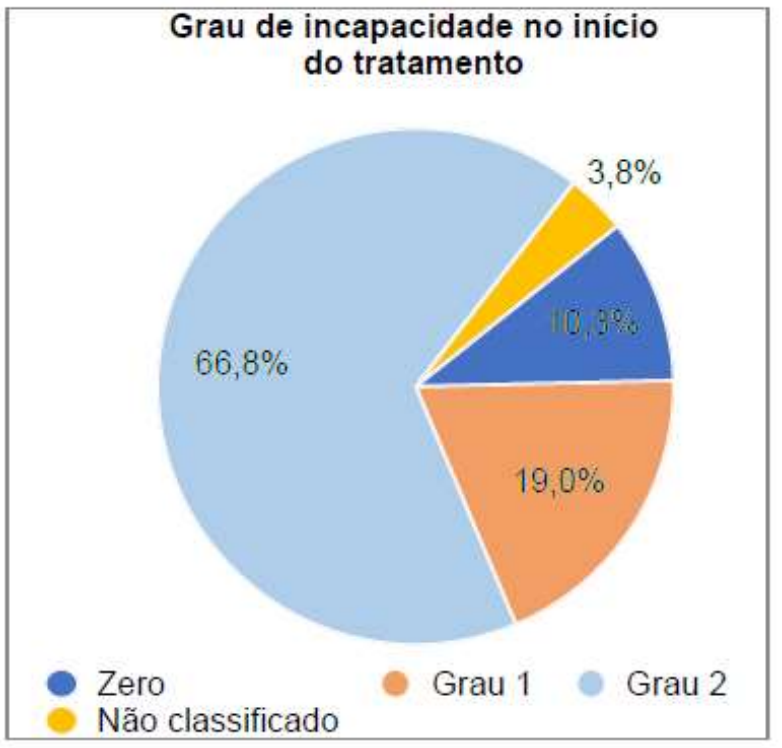

Gráfico 12: Grau de incapacidade no início do tratamento dos pacientes internados de 2009 a 2019 Fonte: Arquivos médicos.

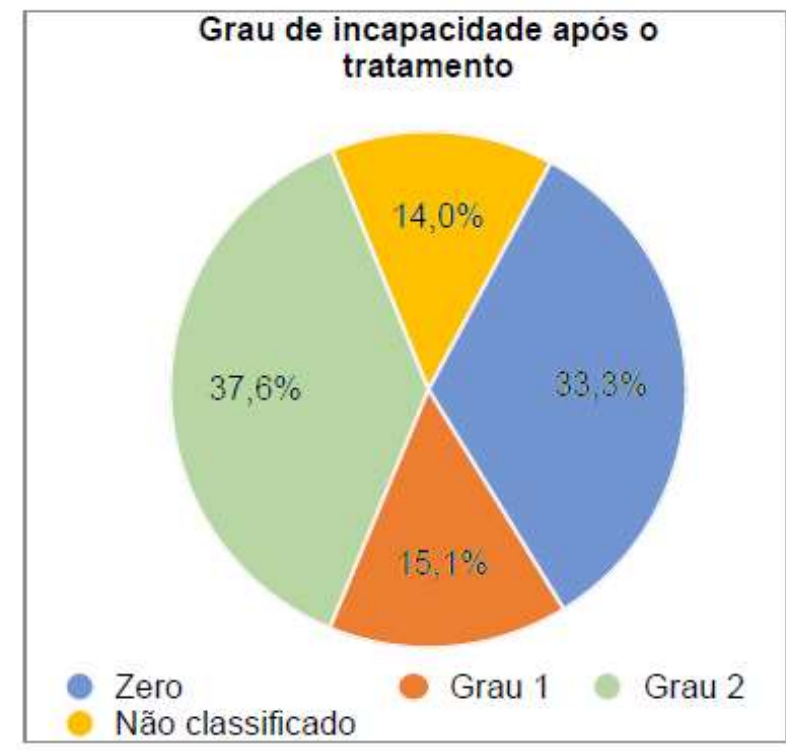

Gráfico 13: Grau de incapacidade após o tratamento dos pacientes internados de 2009 a 2019.

Fonte: Arquivos médicos.

Após a alta hospitalar, 98 pacientes $(53,2 \%)$ ainda apresentavam algum grau de incapacidade, sendo 70 pacientes (38\%) com grau 2, e 28 pacientes $(15,2 \%)$ com grau 1. Os pacientes com grau zero de incapacidade passaram de 19 (10,3\%) para 62 (33,7\%), podendo representar uma melhoria na qualidade de vida desses pacientes (Gráfico 13). No Brasil, dentre 2009 e 2018, a maioria dos pacientes apresentou grau 0 de incapacidade física, seguido do grau 1 e grau 2.

Quanto ao Grau 2 de incapacidade, dentre os pacientes diagnosticados com hanseníase, 7,2\% em 2009 e 8,5\% em 2018 possuíam grau 2 de incapacidade física (MINISTÉRIO DA SAÚDE, 2020).

Em outros estudos da literatura, o Grau de incapacidade no momento do atendimento varia significativamente, pois o contexto do quadro clínico do paciente varia Grau de incapacidade no início do tratamento Zero Grau 1 Grau 2 Não classificado Grau de incapacidade após o tratamento Zero 
Grau 1 Grau 2 Não classificado dependendo de alguns fatores, como localidade onde a pesquisa foi realizada e nível de complexidade do atendimento.

Outros estudos epidemiológicos demonstraram uma menor proporção de pacientes com grau 2 de incapacidade física quando comparados com este estudo (Quadro 1). Esta diferença ocorreu, provavelmente, pelo estado mais avançado de doença encontrado na mostra. Em contrapartida, DE FARIA 2015 e MOURA 2016 analisaram pacientes desde o diagnóstico.

\begin{tabular}{|l|l|l|}
\hline Presente Estudo & DE FARIA, 2015 & MOURA, 2016 \\
\hline Grau 0: $10,3 \%$ & Grau 0: $60 \%$ & Grau 0:66,7\% \\
\hline Grau 1: $19 \%$ & Grau 1: $32 \%$ & Grau 1: $21,5 \%$ \\
\hline Grau 2: $66,8 \%$ & Grau 2: $8 \%$ & Grau 2: $11,7 \%$ \\
\hline Não consta: $3,8 \%$ & Não consta: $0 \%$ & Não consta: $0 \%$ \\
\hline
\end{tabular}

Quadro 1: Comparação do grau de incapacidade do estudo vs DE FARIA, 2015 e MOURA, 2016.

Fonte: Arquivos médicos.

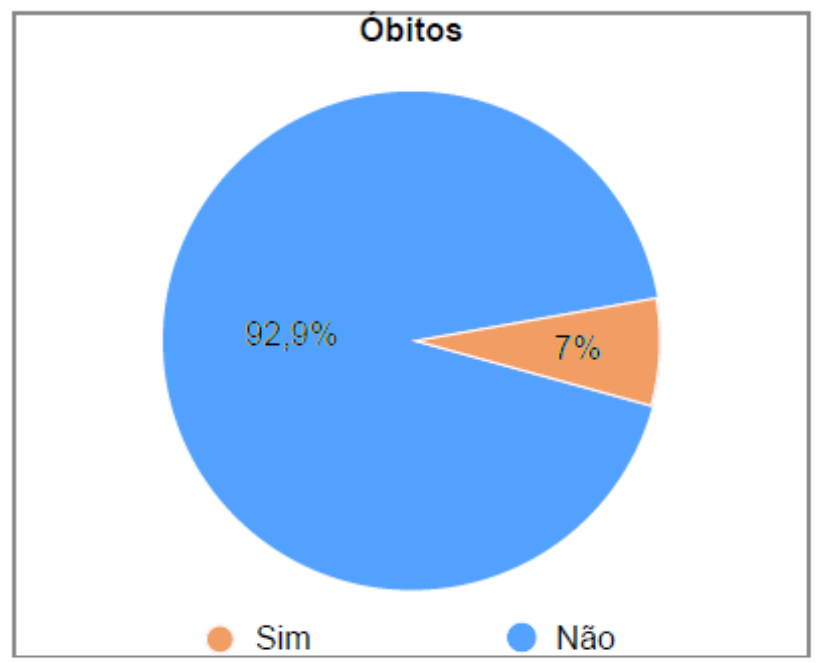

Gráfico 14: Óbitos dos pacientes internados com hanseníase de 2009 a 2019.

Fonte: Arquivos médicos.

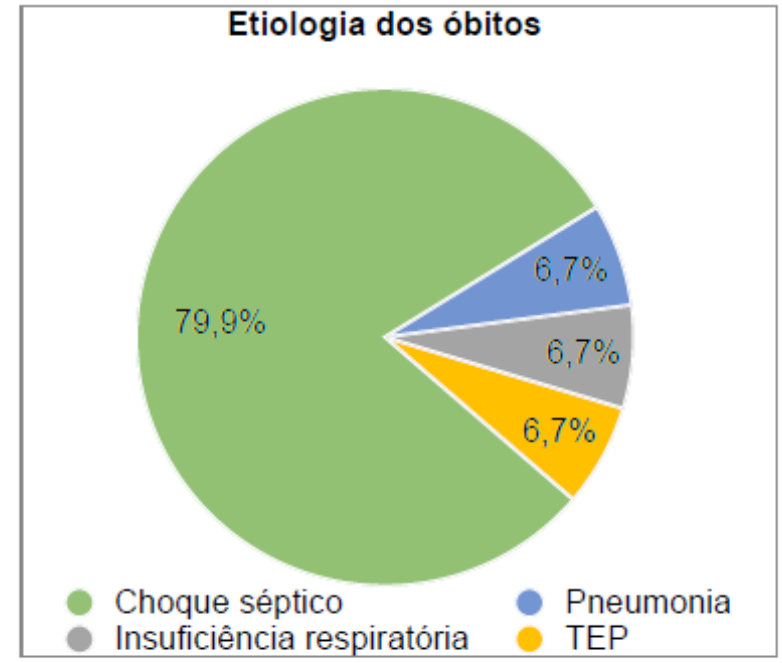

Gráfico 15: Etiologia dos óbitos dos pacientes internados com hanseníase de 2009 a 2019. Fonte: Arquivos médicos.

Faleceram por complicações decorrentes da hanseníase 7,1\% dos pacientes (Gráfico 14). 0 aumento do número de óbitos obtidos na pesquisa em comparação ao valor exposto por BARBOSA, 2014 $(1,33 \%)$ era esperado, pois a amostra do presente estudo avaliava apenas pacientes internados e que, portanto, apresentavam uma gravidade maior da doença quando comparados aos de BARBOSA, 2014, que avaliou pacientes com e sem necessidade de internamento. 
Entre os pacientes que evoluíram para óbito, a principal causa encontrada no estudo foi o choque séptico (80\%), sendo ainda encontradas causas, como pneumonia, insuficiência respiratória e tromboembolismo pulmonar (TEP), cada uma dessas com 6,7\% das causas de óbito (Gráfico 15). A idade média desses pacientes que faleceram foi de 57,33 anos. Dados semelhantes foram observados por ROCHA, 2015, o qual apresentou uma idade média de 56,6 anos em seu estudo.

\section{CONCLUSÃO}

Portanto, a hanseníase continua sendo uma doença muito prevalente em Fortaleza - CE. Pode-se observar que, mesmo com a redução do número do casos de hanseníase nos últimos anos, houve um aumento de casos graves da doença entre os anos de 2018 a 2019. Tal fato pode estar relacionado a diversos fatores, como baixo nível de escolaridade, fatores econômicos e áreas densamente povoadas com baixos IDHs.

Chama atenção que os principais pacientes são, na maioria, jovens, solteiros, do sexo masculino, economicamente ativos, acometidos com uma patologia que pode ter danos permanentes ou transitórios, que interferem, muitas vezes, em seus status psicológicos, por se considerarem incapacitados e não estarem inseridos no mercado de trabalho, devido ao estigma social que a doença acarreta e/ou às sequelas deixadas por este agravo.

Deve-se considerar que populações vulneráveis ou em estado de extrema pobreza, na sua maioria, não possuem acesso às informações de forma clara e objetiva, deixando de procurar assistência médica em estágios iniciais da doença, quer seja por desconhecimento, por medo, por descaso, por dificuldade de acesso à assistência à saúde ou por manutenção do tratamento, ocasionando agravos ou danos permanentes.

Diante disso, faz-se necessário alertar cada vez mais a população sobre os perigos que a doença pode acarretar e a eficiência do tratamento precoce e completo. Ademais, deve-se reforçar a importância da busca ativa dos pacientes e a qualificação dos profissionais da saúde para a identificação do diagnóstico, visando diminuir o número de casos, de incapacitações e/ou de complicações dos pacientes acometidos com hanseníase. 


\section{REFERÊNCIAS}

1. ABRAÇADO, Maria de Fátima Silveira; DA CUNHA, Maria Heliana Chaves Monteiro; XAVIER, Marília Brasil. Adesão ao tratamento de hanseníase em pacientes com episódios reacionais hansênicos em uma unidade de referência. Revista Pan-Amazônica de Saúde, v. 6, n. 2, p. 6-6, 2015.

2. ALVES, Anna Cláudia Rodrigues; LEMOS, Giulia Stella; DE PAIVA, Priscila Delgado Rodrigues. Perfil socioeconômico dos pacientes atendidos pelo Centro de Referência em Reabilitação da Hanseníase da Zona da Mata Mineira. HU Revista, v. 43, n. 2, p. 99-104, 2017.

3. BARBOSA, Débora RM; ALMEIDA, Manoel G.; DOS SANTOS, Ariane G. Características epidemiológicas e espaciais da hanseníase no Estado do Maranhão, Brasil, 2001-2012. Medicina (Ribeirao Preto. Online), v. 47, n. 4, p. 347-356, 2014.

4. BATISTA, Elisa Siqueira et al. Perfil sócio-demográfico e clínico-epidemiológico dos pacientes diagnosticados com hanseníase em Campos dos Goytacazes, RJ. Rev Bras Clin Med, v. 9, n. 2, p. 1016, 2011.

5. BRASIL. Ministério da Saúde. Secretaria de Vigilância em Saúde. Boletim epidemiológico: hanseníase. Brasília: Editora Ms/cgdi, 2020. GELBER, Robert H.. Hanseníase. In: KASPER, Dennis L. et al. Medicina Interna de Harrison. 19. ed. Porto Alegre: Artmed, 2017. Cap. 203. p. 1633-1640.

6. CAVALIERE, Irene. Hanseníase na história. Disponível em:

http:// www.invivo.fiocruz.br/cgi/cgilua.exe/sys/start.htm?infoid=1182\&sid=7. Acessado em: 17 de jun. 2020.

7. CUNHA, Ana Zoé Schilling da. Hanseníase: aspectos da evolução do diagnóstico, tratamento e controle. Ciência \& Saúde Coletiva, v. 7, p. 235-242, 2002.

8. DA COSTA LOBATO, Diana; DE OLIVEIRA NEVES, Dilma Costa; XAVIER, Marília Brasil. Avaliação das ações da vigilância de contatos domiciliares de pacientes com hanseníase no Município de IgarapéAçu, Estado do Pará, Brasil. Revista Pan-Amazônica de Saúde, v. 7, n. 1, p. 9-9, 2016.

9. DE FARIA, Claudia Regina Sgobbi et al. Grau de incapacidade física de portadores de hanseníase: estudo de coorte retrospectivo. Arquivos de Ciências da Saúde, v. 22, n. 4, p. 58-62, 2015. 10.FERREIRA, Isaías Nery. Um breve histórico da hanseníase. HUMANIDADES E TECNOLOGIA (FINOM), v. 1, n. 16, p. 436-454, 2019.

11. FREITAS, Lúcia Rolim Santana de; DUARTE, Elisabeth Carmen; GARCIA, Leila Posenato. Análise da situação epidemiológica da hanseníase em uma área endêmica no Brasil: distribuição espacial dos períodos 2001-2003 e 2010- 2012. Revista Brasileira de Epidemiologia, v. 20, p. 702-713, 2017.

12.GOMES, Cícero Cláudio Dias et al. PP005-Perfil clínico-epidemiológico dos pacientes diagnosticados com hanseníase em um centro de referência na região nordeste do Brasil Clinical and epidemiological profile of patients diagnosed with leprosy in a reference center in the northeast of Brazil. An Bras Dermatol, v. 80, n. Supl 3, p. S283-8, 2005.

13.KAHAWITA, Indira P.; WALKER, Stephen L.; LOCKWOOD, Diana NJ. Leprosy type 1 reactions and erythema nodosum leprosum. Anais brasileiros de dermatologia, v. 83, n. 1, p. 75-82, 2008. 
14. MELÃO, Suelen et al. Perfil epidemiológico dos pacientes com hanseníase no extremo sul de Santa Catarina, no período de 2001 a 2007. Rev Soc Bras Med Trop, v. 44, n. 1, p. 79-84, 2011.

15.MESQUITA, Rafael et al. Avaliação neurofuncional em pacientes com Hanseníase. Revista Brasileira em Promoção da Saúde, v. 27, n. 2, p. 247-255, 2014.

16.MONTEIRO, Mísia Joyner de Sousa Dias et al. Perfil epidemiológico de casos de hanseníase em um estado do nordeste brasileiro. Revista de Atenção à Saúde, v. 15, n. 54, p. 21-28, 2017.

17.MOURA, A. D. H. et al. Perfil dos portadores de hanseníase de um centro de referência de um estado brasileiro. Rev. enferm. UERJ, v. 24, n. 6, p. e9625, 2016.

18.PNUD. Ranking IDHM Municípios 2010. Disponível em: https://www.br.undp.org/ content/brazil/pt/home/idh0/rankings/idhm-municipios-2010.html. Acesso em: 10 de jun. 2020.

19.QUEIRÓS, M. I. et al. Perfil clínico epidemiológico de pacientes com hanseníase atendidos em hospital universitário no Ceará entre 2007 e 2011. An Bras Dermatol [Internet], v. 91, n. 3, p. 311-7, 2016.

20.RIBEIRO, Mara Dayanne Alves; SILVA, Jefferson Carlos Araujo; OLIVEIRA, Sabrynna Brito. Estudo epidemiológico da hanseníase no Brasil: reflexão sobre as metas de eliminação. Revista Panamericana de Salud Pública, v. 42, p. e42, 2018.

21.ROCHA, Margarida Cristiana Napoleão et al. Óbitos registrados com causa básica hanseníase no Brasil: uso do relacionamento de bases de dados para melhoria da informação. Ciência \& Saúde Coletiva, v. 20, p. 1017-1026, 2015.

22.SDE. Desenvolvimento Humano, por Bairro de Fortaleza. Disponível em: https:// dados.fortaleza.ce.gov.br/catalogo/dataset/desenvolvimento-humano-por-bairrode-fortaleza.

Acesso em: 10 de jun. 2020.

23.SILVA, Slete Ferreira da; GRIEP, Rosane Hart. Reação hansênica em pacientes portadores de hanseníase em centros de saúde da Área de Planejamento 3.2. do Município do Rio de Janeiro. Hansenologia Internationalis (Online), v. 32, n. 2, p. 155-162, 2007.

24.SOUZA, Cacilda Silva. Hanseníase: formas clínicas e diagnóstico diferencial. Medicina (Ribeirao Preto. Online), v. 30, n. 3, p. 325-334, 1997.

25.SOUZA, Viviane Bezerra de et al. Perfil epidemiológico dos casos de hanseníase de um centro de saúde da família. Rev Bras Promoç Saúde, v. 26, n.1, p. 110-116, 2013.

26.TEIXEIRA, Márcia Almeida Galvão; SILVEIRA, Vera Magalhães da; FRANÇA, Emmanuel Rodrigues de. Características epidemiológicas e clínicas das reações hansênicas em indivíduos paucibacilares e multibacilares, atendidos em dois centros de referência para hanseníase, na Cidade de Recife, Estado de Pernambuco. Revista da Sociedade Brasileira de Medicina Tropical, v. 43, n. 3, p. 287-292, 2010.

27.VELÔSO, Dilbert Silva et al. Perfil clínico epidemiológico da hanseníase: uma revisão integrativa. Revista Eletrônica Acervo Saúde v. 10, n. 1, p. 1429-1437, 2018.

28.WORLD HEALTH ORGANIZATION et al. Estratégia Global para Hanseníase 2016-2020. Brasília: Organização Pan-Americana da Saúde [Internet], 2016. 


\section{Capítulo 14}

doi $10.37423 / 211205139$

\section{ANTIBIOFILM ACTIVITY OF GLYCOLIC PLANT EXTRACTS ON KLEBSIELLA PNEUMONIAECLINICAL ISOLATES}

Patrícia Michelle Nagai de Lima

\section{Lucas de Paula Ramos}

Thaís Cristine Pereira

Marcela dos Santos Oliveira

Maria Angélica de Sá Assis

Suelen Simões Amaral

\section{Leandro Wagner Figueira}

Carlos Eduardo Rocha Santos

João Manoel Theotônio dos Santos
Universidade Estadual Paulista Júlio de Mesquita Filho, Instituto de Ciência e

Tecnologia

Universidade Estadual Paulista Júlio de Mesquita Filho, Instituto de Ciência e

Tecnologia

Universidade Estadual Paulista Júlio de Mesquita Filho, Instituto de Ciência e Tecnologia

Universidade/Estadual Paulista Júlio de Mesquita Filho, Instituto de Ciência e

Tecnologia

Universidade Estadual Paulista Júlio de Mesquita Filho, Instituto de Ciência e

Tecnologia

Universidade Estadual Paulista Júlio de Mesquita Filho, Instituto de Ciência e

Tecnologia

Universidade Estadual Paulista Júlio de Mesquita Filho, Instituto de Ciência e

Tecnologia

Universidade Estadual Paulista Júlio de Mesquita Filho, Instituto de Ciência e

Tecnologia

Universidade Anhembi Morumbi 
Resumo: Objetivo: Avaliar a atividade antibiofilme dos extratos de Gymnema sylvestre, Hamamelis virginiana, Juglans regia, Persea americana, Pfaffia paniculata, Rosmarinus officinalis, Stryphnodendron barbatiman e Thymus vulgaris em 3 cepas clínicas e 1 ATCC (4352) de Klebsiella pneumoniae. Métodos: Primeiramente foi feita uma triagem com teste de microdiluição em caldo, protocolo M7-A9, conforme CLSI. Os extratos que apresentaram valores de Concentração Microbicida Mínima (CMM) foram selecionados para testes de biofilmes em placas de 96 poços. Os tratamentos utilizaram concentrações de 25 e $50 \mathrm{mg} / \mathrm{mL}$, após os biofilmes foram mensurados pelos testes de biomassa (Cristal violeta) e MTT, e analisados estatisticamente por ANOVA e teste de Tukey $(p<0,05)$. Resultados: Todos os extratos apresentaram CIM para todas as cepas de $K$. pneumoniae estudadas, com valores variando de 12,5-100 mg/mL. A biomassa das cepas ATCC e MDR (400381) de $K$. pneumoniae obteve reduções de 37,7 e $44,3 \%$ com os extratos de

P. paniculata e $R$. officinalis. O isolado 386546 obteve redução de $29,7 \%(p<0,05)$ sob ação de $R$. officinalis. Conclusão: Dentre os extratos estudados, os mais eficazes na ação anti-biofilme foram J. regia, P. paniculata e R. officinalis. Portanto, esses extratos poderiam atuar como agentes bactericidas contra K. pneumoniae MDR.

Palavras-chave: Klebsiella pneumoniae; Antibiofilme; Fitoterapia; Bactéria; Resistência; Microbiologia. 


\section{INTRODUCTION}

Klebsiella pneumoniae is a Gram-negative bacillus in the family of enterobacteria. It is an opportunistic pathogen, present in $70 \%$ of hospital infections, and causes mainly pulmonary and urinary tract infections (Bowers et al., 2016; Rahim et al., 2016). K. pneumoniae may be prevalent as an infectious agent in patients with urinary catheters and may develop bacterial biofilms in these devices (Djeribi, Bouchloukh, Jouenne, \& Menaa, 2012; Ramstedt et al., 2019). This virulence mechanism is fundamental in many bacterial infections, as it can resist the host's defense system and antimicrobial treatments (Djeribi et al., 2012; Vuotto, Longo, Balice, Donelli, \& Varaldo, 2014). In addition to the ability to form biofilms, the species has other virulence factors, such as polysaccharide capsules, siderophore, urease, the presence of fimbriae and resistance to antibiotics, in which they help in the maintenance and resistance of infections (Bowers et al., 2016; Clegg \& Murphy, 2016; Rahim et al., 2016).

Several classes of antimicrobials are commonly used to treat infections caused by K. pneumoniae, but excessive and inappropriate use can favor the increase in microbial resistance (Aslam et al., 2018; Goossens, 2009; Osman, Hassan, Orabi, \& Abdelhafez, 2014). In hospital settings, where the use of these drugs is frequent, multidrug-resistant (MDR) bacteria have been a problem (Aslam et al., 2018). K. pneumoniae has an easier time developing resistance when compared to other bacteria.

Resistance to most conventional antibiotics is due to the emergence of strains producing broadspectrum $\beta$-lactamase (ESBL) and carbapenemase producers (Cai et al., 2012). In view of this, the World Health Organization (WHO) declared in 2017 that K. pneumoniae is among the critical resistant bacteria that need research to develop new treatment alternatives (WHO, 2017). The consequences of antimicrobial resistance caused by K. pneumoniae are serious and can lead to increased morbidity, mortality or even longer hospital stays. The growth of MDR bacteria limits and makes therapeutic options more and more difficult, thus emerging the need to search for new drug alternatives (Li \& Webster, 2018; Pacios et al., 2020).

Among the therapies studied, for the control of resistant strains, phytotherapy gained notability. It is known that medicinal plants are rich in phytochemicals with diverse biological activities. Many studies have demonstrated the antimicrobial action of different plant extracts against bacteria and fungi (de Oliveira et al., 2017; De Zoysa, Rathnayake, Hewawasam, \& Wijayaratne, 2019; Elansary et al., 2018; Hadadi, Nematzadeh, \& Ghahari, 2020). However, there are still many gaps, whether due to plant species or even the use of extracts against MDR strains (Farooqui et al., 2015; Khalil, Fikry, \& Salama, 
2020). Considering the world scenario of microbial resistance and the wide variety of plant extracts with potential to be explored, the present study evaluated the antimicrobial action of Gymnema sylvestre (Gimena), Hamamelis vir-giniana L. (Hamamelis), Juglans regia L. (Walnut ), Persea americana (Avocado), Pfaffia paniculata (Brazilian Ginseng), Rosmarinus officinalis L. (Rosemary), Stryphnodendron barbatiman (Barbatiman) and Thymus vulgaris (Thyme) in planktonic forms and biofilms of Klebsiella pneumoniae MDR strains.

\section{METHODOLOGY}

\subsection{EXTRACTS}

Glycolic extracts of Gymnema sylvestre (Gimena), Hamamelis virginiana L. (Hamamelis), Juglans regia L. (Walnut), Persea americana (Avocado), Pfaffia paniculata (Brazilian Ginseng), Rosmarinus officinalis L. (Rosemary), Stryphnodendron barbatiman (Barbatiman) and Thymus vulgaris (Thyme) were purchased from Mapric (SP, Brazil) at a concentration of $200 \mathrm{mg} / \mathrm{mL}$ (20\%), eluted in propyleneglycol.

\subsection{K. PNEUMONIAE ATCC AND MULTIDRUG-RESISTANT STRAINS}

Antibacterial activity was tested on four K. pneumoniae strains, one ATCC 4352 strain (ATCC - American Type Culture Collection) and three MDR strains (367725, 386546, 400381) provided by Bioclin Laboratory, belonging to Policlin medical group - São José dos Campos, São Paulo, Brazil. The resistance of clinical isolates was identified using the autoSCAN 4 automated system (Beckman Coulter, Brea, CA, USA) (Delgado-Gardea et al., 2016). The resistance profile of clinical isolates is shown in Appendice - Table A1.

\subsection{GLYCOLIC EXTRACTS MIC AND MMC}

MIC (Minimum Inhibitory Concentration) and MMC (Minimum Microbicidal Concentration) values of the extracts were determined by Broth Microdilution Method, protocol M7-A9 (2012), according to CLSI. First, suspensions of K. pneumoniae strains were prepared in sterile saline solution $(\mathrm{NaCl} 0.9 \%)$ and turbidity was adjusted to $106 \mathrm{CFU} / \mathrm{mL}$ in a spectrophotometer (Micronal, São Paulo, Brazil). The test was performed in 96-well plates (TPP, Trasadingen, Switzerland), where each extract was serially diluted in 10 wells with $100 \mu \mathrm{L} /$ well of Muller Hilton Broth (Himedia, Mumbai, India), obtaining concentrations from 100 to $0.19 \mathrm{mg} / \mathrm{mL}$. Next, $100 \mu \mathrm{L}$ of standardized microorganism suspension was added to all the wells and the plate was incubated in at $37^{\circ} \mathrm{C}$ for $24 \mathrm{~h}$. After, MIC was determined in the last well of the microplate where no turbidity was observed. For MMC determination, aliquots 
were removed from the microplates and seeded on Brain Heart Infusion (BHI) agar (Himedia, Mumbai, India) and were determined in the lowest concentration where no growth of colonies was observed.

\subsection{ANTIMICROBIAL ACTION AGAINST MONOTYPIC BIOFILMS}

After the screening promoted by the broth microdilution test, only the extracts that obtained MMC into the interval tested were selected for monotypic biofilm tests: H. virginiana, J. regia, P. americana, P. paniculata, and R. officinalis.

Initially, the K. pneumoniae strains were cultured in BHI broth (Himedia, Mumbai, India) at $37^{\circ} \mathrm{C} / 24$ h. After incubation, the microorganism suspension was centrifuged at $2000 \mathrm{rpm} / 10 \mathrm{~min}$ (MPW-350, Warsaw, Poland) and washed twice with $0.9 \%$ saline solution for the removal of the microorganisms metabolites. The turbidity of the suspensions was adjusted in a spectrophotometer (Micronal) at a concentration of $107 \mathrm{CFU} / \mathrm{mL}$. The microorganism suspension was distributed into 96-well plates with $\mathrm{N}=10$ for each group, then $100 \mu \mathrm{L} /$ well of BHI broth (Himedia, Mumbai, India) was added and the plate was incubated at $37^{\circ} \mathrm{C}$ for $48 \mathrm{~h}$, under constant stirring ( $\left.75 \mathrm{rpm}\right)$.

\subsection{TREATMENT}

In the control group, $200 \mu \mathrm{L} /$ well of $0.9 \%$ saline was applied and in the experimental groups, 200 $\mu \mathrm{L} /$ well of each extract ( $\mathrm{H}$. virginiana, J. regia, P. americana, P. paniculata, and R. officinalis) at concentrations of 25 and $50 \mathrm{mg} / \mathrm{mL}$ were applied, with 10 replicates for each group. After 5 min of treatment, the extracts were removed and the wells were washed twice with $0.9 \%$ saline solution. In order to evaluate the action of the extracts on the biofilm, the following tests were performed: measurement of the biomass by violet crystal and evaluation of the metabolic activity of the microorganisms by MTT (3- (4,5- Dimethylthiazol-2-yl) -2,5-Diphenyltetrazolium bromide.

\subsection{MEASUREMENT OF BIOMASS BY THE CRYSTAL VIOLET TEST}

After the treatments, $200 \mu \mathrm{L} /$ well of methanol were added and after $20 \mathrm{~min}$, for biofilm fixation, it was removed and the plate was incubated at $37^{\circ} \mathrm{C}$ for $24 \mathrm{~h}$ for drying. After incubation, $200 \mu \mathrm{L} /$ well of violet crystal 1\% (V/V) were added for $5 \mathrm{~min}$ and then the dye was removed and the wells washed twice with acetic acid 33\% (Synth, Diadema, Brazil) and sterile saline solution $(0.9 \% \mathrm{NaCl})$. The plate was read at $570 \mathrm{~nm}$ by the microplate reader (Lonza Biotek ELX808LBS, Winooski, Vermont) and the optical densities were converted into biofilm biomass (Skogman et al., 2012; Marcos-Zambrano et al., 2014). 


\subsection{METABOLIC ACTIVITY EVALUATION}

Two hundred microliters of MTT (3- (4,5-Dimethylthiazol-2-yl) -2,5-Diphenyltetrazolium Bromide) solution were added to each well of the plate. The plate was incubated, protected from light, for $1 \mathrm{~h}$ at $37^{\circ} \mathrm{C}$. The solution was removed and $200 \mu \mathrm{L}$ of dimethylsulfoxide (DMSO) was added to the plate, which was incubated again, at $37^{\circ} \mathrm{C}$ for $10 \mathrm{~min}$ and then placed in the shaker under constant shaking for another $10 \mathrm{~min}$. After this process, the optical densities were read in a microplate reader at 570 $\mathrm{nm}$ and converted into a percentage of metabolic activity of the microbial cells.

\subsection{STATISTICAL ANALYSIS}

Data were statistically analyzed by ANOVA, complemented by the Tukey test, in order to verify the differences among the groups with $p<0.05$, with GraphPad Prism 5.0 software

\section{RESULTS}

All extracts showed MIC for all K. pneumoniae strains studied, at different concentrations (table 1). For K. pneumoniae ATCC 4352, H. virginiana obtained growth inhibition with $12.5 \mathrm{mg} / \mathrm{mL}$, P. americana and R. officinalis with $25 \mathrm{mg} / \mathrm{mL}$, P. paniculata with $50 \mathrm{mg} / \mathrm{mL}$ and S. barbatiman, G. sylvestre, J. regia, and T. vulgaris with $100 \mathrm{mg} / \mathrm{mL}$ (Table 1). For KPC 367725 strain, the MIC of G. sylvestre, J. regia, S. barbatiman and T. vulgaris extracts obtained was $100 \mathrm{mg} / \mathrm{mL}, \mathrm{H}$. virginiana, P. americana, and R. officinalis showed inhibition with $25 \mathrm{mg} / \mathrm{mL}$ and $P$. paniculata with $50 \mathrm{mg} / \mathrm{mL}$.

For KPC strain 386546, H. virginiana showed MIC with $12.5 \mathrm{mg} / \mathrm{mL}$, J. regia, P. americana, P. paniculata, and R. officinalis with $25 \mathrm{mg} / \mathrm{mL}$, S. barbatiman, and T. vulgaris with $50 \mathrm{mg} / \mathrm{mL}$ and G. sylvestre with $100 \mathrm{mg} / \mathrm{mL}$. KPC 400381 strain was inhibited by H. virginiana with $12.5 \mathrm{mg} / \mathrm{mL}$, J. regia, P. americana and R. officinalis with $25 \mathrm{mg} / \mathrm{mL}$, G. sylvestre, J. regia and S. barbatiman with $50 \mathrm{mg} / \mathrm{mL}$ and T. vulgaris with $100 \mathrm{mg} / \mathrm{mL}$.

Regarding the microbicidal activity, G. sylvestre, S. barbatiman, and T. vulgaris extracts did not present MMC values for any strain of $K$. pneumoniae and the J. regia showed only two microbicidal actions (ATCC 4352 and KPC 367725) of the four strains analyzed. On the other hand, H. virginiana, P. americana, P. paniculata, and R. officinalis extracts were able to eliminate all strains, in different concentrations (Table 1).

For the ATCC 4352 strain, H. virginiana and R. officinalis extracts obtained MMC with $50 \mathrm{mg} / \mathrm{mL}, P$. americana extract with $25 \mathrm{mg} / \mathrm{mL}$ and P. paniculata with $100 \mathrm{mg} / \mathrm{mL}$. For strain 367725, H. virginiana, 
$\mathrm{P}$ americana, and R. officinalis extracts presented $\mathrm{MMC}$ with $50 \mathrm{mg} / \mathrm{mL}$ and $\mathrm{P}$. paniculata extract with $100 \mathrm{mg} / \mathrm{mL}$. For strain 386546, H. virginiana obtained MMC with $12.5 \mathrm{mg} / \mathrm{mL}$, J. regia, P. americana and R. officinalis with $25 \mathrm{mg} / \mathrm{mL}$ and P. paniculata with $100 \mathrm{mg} / \mathrm{mL}$. For strain 400381, J. regia, P. americana, and R. officinalis extracts showed microbicidal activity with $25 \mathrm{mg} / \mathrm{mL}, \mathrm{H}$. virginiana with $50 \mathrm{mg} / \mathrm{mL}$ extract and P. paniculata with $100 \mathrm{mg} / \mathrm{mL}$.

With the screening promoted by the broth microdilution test, it was defined that extracts with MMC for all K. pneumoniae strains would be selected for biofilm tests. The concentrations of the extracts applied in monotypic biofilms also derived from the results of the broth microdilution test.

Table 1: Broth microdilution test performed with Klebsiella pneumoniae strains.

\begin{tabular}{|c|c|c|c|c|c|c|c|c|}
\hline \multirow[b]{2}{*}{ Glycolic extracts } & \multicolumn{2}{|c|}{ ATCC 4352} & \multicolumn{2}{|c|}{ KPC 367725} & \multicolumn{2}{|c|}{ KPC 386546} & \multicolumn{2}{|c|}{ KPC 400381} \\
\hline & MIC & MMC & MIC & MMC & MIC & MMC & MIC & MMC \\
\hline G. sylvestre (gimena) & 100 & Abs & 100 & abs & 100 & abs & 50 & abs \\
\hline $\begin{array}{l}\text { H. virginiana } L \text {. (witch } \\
\text { hazel) }\end{array}$ & 12,5 & 50 & 25 & 50 & 12,5 & 12,5 & 12,5 & 50 \\
\hline J. regia L. (walnut) & 100 & Abs & 100 & abs & 25 & 25 & 25 & 25 \\
\hline P. americana (avocado) & 25 & 25 & 25 & 50 & 25 & 25 & 25 & 25 \\
\hline $\begin{array}{l}\text { P. paniculata (brazilian } \\
\text { ginseng) }\end{array}$ & 50 & 100 & 50 & 100 & 25 & 100 & 50 & 100 \\
\hline $\begin{array}{l}\text { R. officinalis } L \text {. } \\
\text { (rosemary) }\end{array}$ & 25 & 50 & 25 & 50 & 25 & 25 & 25 & 25 \\
\hline $\begin{array}{l}\text { S. barbatiman } \\
\text { (barbatiman) }\end{array}$ & 100 & Abs & 100 & abs & 50 & abs & 50 & abs \\
\hline T. vulgaris (thyme) & 100 & Abs & 100 & abs & 50 & abs & 100 & abs \\
\hline
\end{tabular}

Legends: values express in mg/mL; Abs - Absent; MIC - Minimum Inhibitory Concentration; MMC - Minimum Microbicidal Concentration; absent - No values for MMC were found.

Source: Autors.

\subsection{BIOMASS REDUCTION}

For the ATCC strain, only the P. paniculata and R. officinalis extracts presented statistically significant reductions $(p<0.05)$ when compared to the control. For P. paniculata at 25 and $50 \mathrm{mg} / \mathrm{mL}$ there were 
reductions of $35.9 \%$ and $37.7 \%$, respectively, and for $\mathrm{R}$. officinalis at $25 \mathrm{mg} / \mathrm{mL}$ and $50 \mathrm{mg} / \mathrm{mL}$, the reductions were 38.8 and $44.3 \%$, respectively (Figure 1 ).

The five extracts tested in the clinical strain 400381 obtained statistically significant reductions $(p<0.05)$ compared to the growth of the control group. P. americana extract obtained reductions of $26.8(25 \mathrm{mg} / \mathrm{mL})$ and $28.8 \%(50 \mathrm{mg} / \mathrm{mL}), \mathrm{H}$. virginiana of $41.5(25 \mathrm{mg} / \mathrm{mL})$ and $45.1 \%(50 \mathrm{mg} / \mathrm{mL}), \mathrm{J}$. regia of $33.8(25 \mathrm{mg} / \mathrm{mL})$ and $39.7 \%(50 \mathrm{mg} / \mathrm{mL})$, P. paniculata of $42.7(25 \mathrm{mg} / \mathrm{mL})$ and $50 \%(50$ $\mathrm{mg} / \mathrm{mL})$. R. officinalis extract promoted the greatest reductions $(p<0.05), 50.4(25 \mathrm{mg} / \mathrm{mL}$ ) and $50.5 \%$ (50 mg/mL) (Figure 1).

For KPC strain 386546, only the extract of R. officinalis presented statistically significant reductions $(p<0.05)$ of the biomass, compared to the control group. These reductions were $29.8 \%$ for the concentration of $25 \mathrm{mg} / \mathrm{mL}$ and $29.7 \%$ for $50 \mathrm{~g} / \mathrm{mL}$. For the strain KPC 367725 , no extract showed a statistically significant reduction of the biomass $(p<0.05)$ (Figure 1 ).

Figure 1 - Biomass reduction after extracts action on Klebsiella pneumoniae strains.
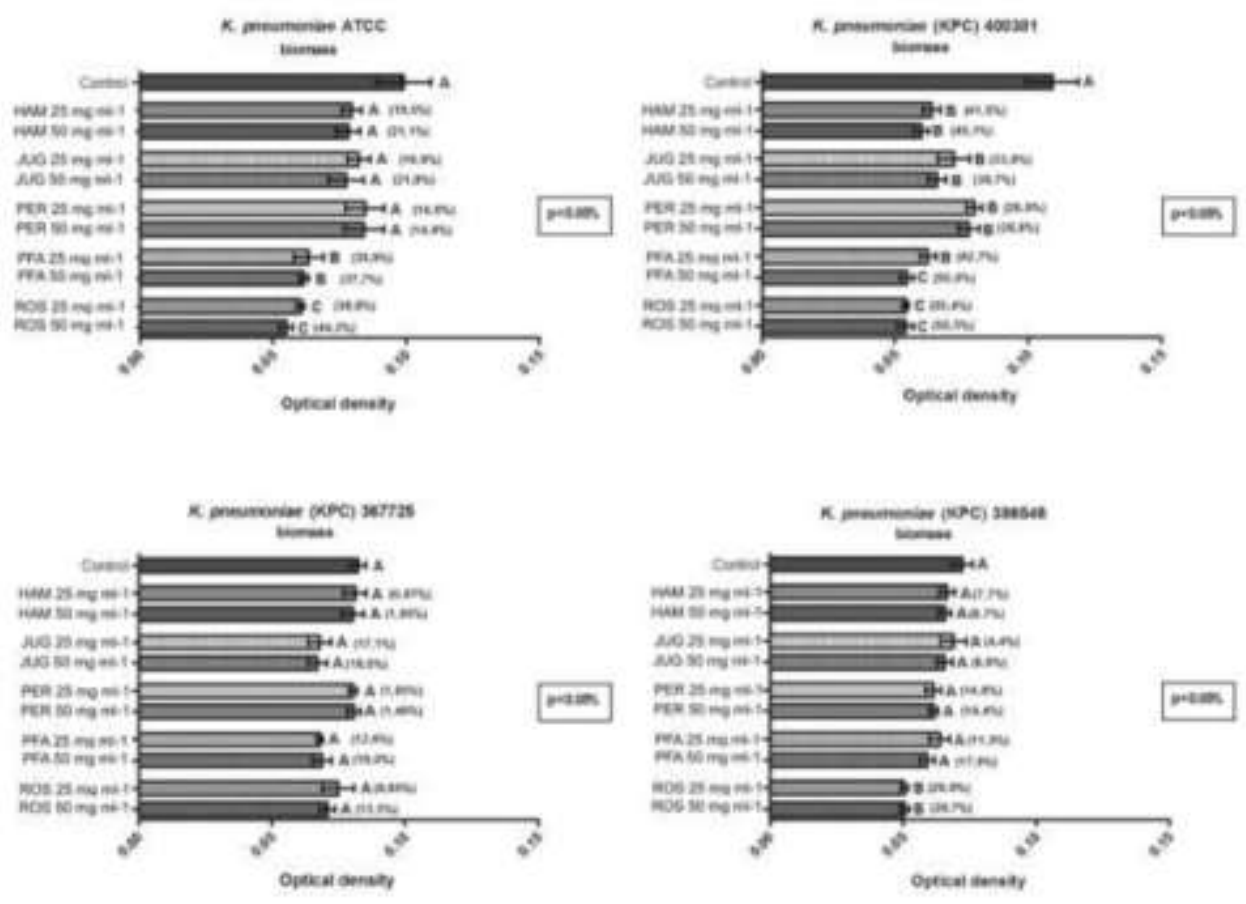

Legend: HAM- Glycolic extract of Hamamelis virginiana; JUG - Juglans regia glycolic extract; PER - Glycolic extract of Persea americana; PFA - Glycolic extract of Pfaffia paniculate; ROS - Glycolic extract of Rosmarinus officinalis. Different letters $(A, B$ and $C$ ) indicate statistical significant difference (ANOVA, Tukey, p<0.05). K.pneumoniae $\operatorname{ATCC}(p=0.0001) ; \operatorname{KPC} 400381$ ( $p=0.0001) ; \operatorname{KPC} 367725$ ( $p=0.0018) ; \operatorname{KPC} 386546$ ( $p=0.0001)$.

Source: Authors. 


\subsection{REDUCTION OF METABOLIC ACTIVITY OF STRAINS}

For K. pneumoniae ATCC strain, J. regia promoted the greatest reductions in the metabolic activity: $53.2 \%$ at $25 \mathrm{mg} / \mathrm{mL}$ and $41.3 \%$ at $50 \mathrm{mg} / \mathrm{mL}$, statistically different from other groups $(\mathrm{p}<0.05) . R$. officinalis and $P$. paniculata extracts also showed significant reductions when compared to the control ( $p<0.05$ ): 30.3 and $39.7 \%$ for $R$. officinalis and 27.7 and $33.5 \%$ for $P$. paniculata. Only $P$. americana extract at $25 \mathrm{mg} / \mathrm{mL}$ and $H$. virginiana extract at 25 and $50 \mathrm{mg} / \mathrm{mL}$ did not present statistical significant reduction $(p<0.05)$ in metabolic activity.

Regarding KPC 367725, all 5 extracts showed a significant reduction in metabolic activity. The extracts of R. officinalis (25 and $50 \mathrm{mg} / \mathrm{mL})$, P. paniculata $(25 \mathrm{mg} / \mathrm{mL})$ and $P$. americana $(50 \mathrm{mg} / \mathrm{mL})$ showed the greatest reductions. They were statistically similar to each other $(p<0.05)$ but different from the control group $(\mathrm{p}<0.05)$. For the KPC strain 386546, only extracts of J. regia $(25$ and $50 \mathrm{mg} / \mathrm{mL}), H$. virginiana $(50 \mathrm{mg} / \mathrm{mL})$ and $R$. officinalis $(50 \mathrm{mg} / \mathrm{mL})$ showed a statistically significant reduction in metabolic activity $(\mathrm{p}<0.05)$. For KPC 400381 strain, only extracts of $R$. officinalis and J. regia, both at $50 \mathrm{mg} / \mathrm{mL}$ presented a statistically significant reduction when compared to the control group $(\mathrm{p}<0.05)$ (Figure 2).

Figure 2 - Metabolic activity reduction after extracts action on strains of Klebsiella pneumoniae.
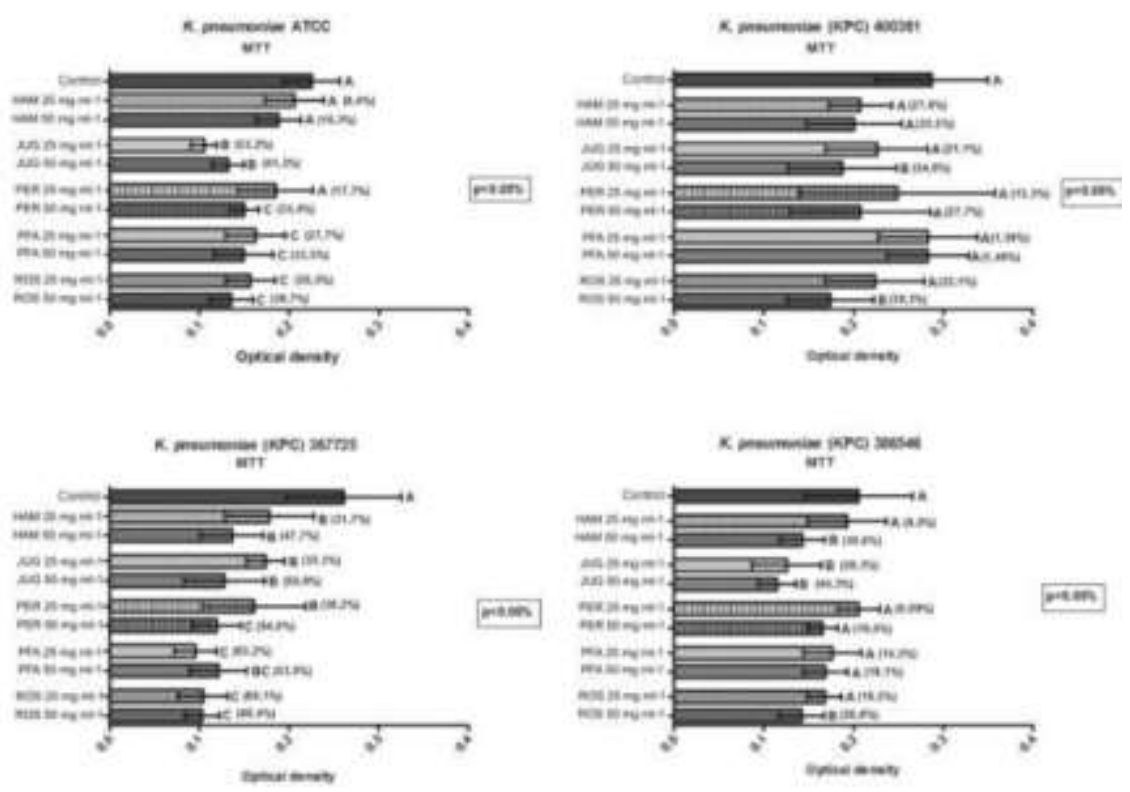

Legend: HAM- Glycolic extract of Hamamelis virginiana; JUG - Glycolic extract of Juglans regia; PER - Glycolic extract of Persea americana; PFA - Glycolic extract of Pfaffia paniculata; ROS - Glycolic extract of Rosmarinus officinalis. Different letters (A, B and C) indicate statistical significant difference (ANOVA, Tukey, $p<0.05$ ). K.pneumoniae ATCC ( $p=0.0001)$; KPC 400381 ( $p=0.0001)$; KPC 367725 ( $p=0.0001)$; KPC 386546 ( $p=0.0001)$.

Source: Authors. 


\section{DISCUSSSION}

Bacterial resistance to conventional antimicrobials increases progressively, representing a global threat (Roca et al., 2015). The emergence of MDR pathogens searches for new treatment alternatives essential (Li \& Webster, 2018; Pacios et al.,

2020). Therefore, phytotherapy has been studied for its antimicrobial action, as it produces several bioactive compounds with therapeutic properties and has shown promising results against MDR bacteria (Assis et al., 2018; Elisha, Botha, McGaw, \& Eloff, 2017; Gadisa et al., 2019). Based on the above, this study evaluated the antimicrobial activity of Gymnema sylvestre, Hamamelis virginiana, Juglans regia, Persea americana, Pfaffia paniculata, Rosmarinus officinalis, Stryphnodendron barbatiman and Thymus vulgaris against multidrug resistance strains Klebsiella pneumoniae.

In this study, G. sylvestre glycolic obtained MIC at $100 \mathrm{mg} / \mathrm{mL}$ in K. pneumoniae ATCC and two clinical strains, but no MMC value was found, indicating a low antimicrobial potential. Corroborating with our results, Selvi et al. (2007) used the agar diffusion test and found the low antimicrobial activity of G. sylvestre in K. pneumoniae (Selvi, Devi, Chinnaswamy, Giji, \& Sharmila, 2007). The ethanolic extract indicated moderate inhibition of the mentioned species and the aqueous extract showed no inhibition. The absence of antimicrobial activity of the aqueous extract of G. sylvestre against K. pneumoniae (MTCC 530) was also observed by Arora and Sood et al. (2017), in which they found that the strain was insensitive even when tested at a concentration of $30 \%$ of the extract (Arora \& Sood, 2017).

In relation to the Barbatiman extract (Stryphnodendron barbatiman, S. adstringens or S. obovatum), there are few reports in the literature that have evaluated its antimicrobial action. Ishida et al. (2009) reported the antifungal action of the extract on Cryptococcus neoformans (Ishida, Rozental, de Mello, \& Nakamura, 2009). The action of Barbatiman extract was also demonstrated against common microorganisms of the oral microbiota, in this study Pereira et al. (2011) observed that the mentioned extract can be an adjunctive method of prophylaxis and treatment of oral infectious conditions of the oral cavity (E.

M. Pereira et al., 2011). De Freitas et al. (2018) reported that tannins obtained from the stem bark of the species have the potential for topical treatment of vaginal candidiasis and suggest that it may be an alternative for the treatment of infections caused by Candida spp. resistant to antifungals (de Freitas et al., 2018). Studies in the literature involving Barbatiman extract and microorganisms are scarce, and so far no reports of their action on K. pneumoniae strains have been found. Thus, the 
present study is a pioneer in the identification of antimicrobial activity against the growth of this species, thus, our findings demonstrate MIC of $50-100 \mathrm{mg} / \mathrm{mL}$, showing that this extract can be a promising alternative against standard strains and K. pneumoniae MDR.

Fournomiti et al. (2015) assessed the antimicrobial action of Thymus vulgaris essential oil on clinical strains of K. pneumoniae and the results showed mean MIC values of $11.34 \mathrm{mg} / \mathrm{mL}$, being different from the results of the present study in which clinical strains of $\mathrm{K}$ pneumoniae were inhibited with 50 $\mathrm{mg} / \mathrm{mL}$ and the ATCC strain with $100 \mathrm{mg} / \mathrm{mL}$ (Fournomiti et al., 2015). However, in the present study, the glycolic extract was used, which has advantages in relation to the water solubility of the extract, when compared to essential oil. On the other hand, our results are consistent with the study by Van Vuuren et al. (2009), who evaluated the essential oil of T. vulgaris in strains of K. pneumoniae NTCC 9633 (National Collection of Type Cultures), with MIC in 40 mg/mL (van Vuuren, Suliman, \& Viljoen, 2009), similar to our findings.

In the present study, extracts of G. sylvestre, S. barbatiman, and T. vulgaris showed bacteriostatic action, with different MIC values, these results may open new paths for pioneering studies with herbal medicines, which aim to interact with different therapies using the capacity inhibitory effect of these extracts in combination with conventional antimicrobial drugs (Hong et al., 2016; Kuok et al., 2017; Olajuyigbe \& Afolayan, 2012, 2013; Silva et al., 2019).

The extracts of H. virginiana, J. regia, P. americana, P. paniculata, and R. officinalis showed better antimicrobial results, with microbicidal concentrations (MMC) for all tested strains. The broth microdilution test indicated $50 \mathrm{mg} / \mathrm{mL}$ MMC for glycolic extract of $\mathrm{H}$. virginiana in strains KPC 367725 , 400381 and ATCC 4352, with replications of biofilm ranging from $41 \%$ to $47 \%$. Despite being considered antiseptic; few studies have evaluated the antimicrobial action of $\mathrm{H}$. virginiana. Mouchrek et al. (2015) evaluated the anti-biofilm action of several commercial types of mouthwash and, among the tested substances, $\mathrm{H}$.

virginiana demonstrated a reduction in dental biofilm, however, only the clinical aspect of biofilms was evaluated, that is, there was no identification of microbial species that suffered reductions (Mouchrek Junior et al., 2015).

Pereira et al. (2008) found that two different aqueous extracts of J. regia showed antimicrobial action against clinical isolates of K. pneumoniae from urinary infections with MIC values of $100 \mathrm{mg} / \mathrm{mL}$ (J. Pereira et al., 2008), corroborating the results obtained in the present study for strains KPC 367725 
and ATCC 4352, except for the fact that, in our study, the glycolic extract was used. Rather et al. (2012) evaluated the action of J. regia essential oil in K. pneumoniae strains, using the agar diffusion technique and the verified antimicrobial action (Rather et al., 2012). Regarding the action of antibiofilm, De Paula Ramos et al. (2016) evaluated the potential of the glycolic extract of J. regia in the ATCC strain of K. pneumoniae (4352) and found that the biomass reduction was not statistically significant ( $p<0.05$ ) compared to the control group (Paula-Ramos et al., 2016), confirming the results of this study. The present study also demonstrates that the clinical strain 400381 was sensitive to the action of the extract of J. regia, with reductions of 33.8 and $39.7 \%$ of the biofilm, showing a strong potential for the use of antimicrobials in these resistant multi-drug strains, with promising results.

Few studies have evaluated the action of P. americana extract on strains of K. pneumoniae. Idris et al. (2009) found that extracts of P. americana based on petroleum ether, ethyl acetate, chloroform and methanol obtained similar MIC values against clinical strains of K. pneumoniae, with growth inhibition at a concentration of $30 \mathrm{mg} / \mathrm{mL}$ (Idris, S, GI, \& CE, 2009). In the present study, it was possible to observe the microbicidal activity of the extract of P. americana against all strains of K. pneumoniae.

Although studies on the anti-inflammatory role of P. paniculate are common (Costa et al., 2015; da Silva et al., 2015), studies on its antimicrobial activity are rare. In the present study, it was found that the glycolic extract of P. paniculata has an important antimicrobial action in resistant multidrug clinical strains of K. pneumoniae, corroborating with De Paula Ramos et al. (2016), who evaluated a clinical strain (Paula-Ramos et al., 2016). It can be seen that the sensitivity to the extract varies according to the strain, with MIC and MMC values ranging from 12.5 to $25 \mathrm{mg} / \mathrm{mL}$ (Paula-Ramos et al., 2016) and from 50 to $100 \mathrm{mg} / \mathrm{mL}$ in the present study. The results found in the biofilm tests follow the same direction as those found by De Paula Ramos (2016), who indicated reductions in biomass and metabolic activity of 55.7 and $72.3 \%$, respectively, with the use of the extract. P. paniculata at 200 $\mathrm{mg} / \mathrm{mL}$ in strain ATCC 4352 (Paula-Ramos et al., 2016). In the present study, lower concentrations of the extract were applied, 25 and $50 \mathrm{mg} / \mathrm{mL}$, with reductions of 35.9 and $37.7 \%$ for biomass and 42.7 and $50 \%$ for metabolic activity, respectively.

Prabuseenivasan et al. (2006) used the essential oil of R. officinalis and the indicated antimicrobial action of the herb. By testing the zone of inhibition, they found a $27.5 \mathrm{~mm}$ zone of inhibition for the growth of the ATCC 15380 strain of K. pneumoniae, indicating its high sensitivity. These authors also indicated that even using an ATCC strain of K. pneumoniae, few extracts obtained antimicrobial activity, only 9 of the 21 extracts tested showed positive results (Prabuseenivasan, Jayakumar, \& 
Ignacimuthu, 2006). The question of K. pneumoniae resistance can also be seen in the present study, since 3 of the 8 extracts tested did not have great antimicrobial potential. However, it is important to emphasize that 5 extracts showed a promising antimicrobial potential, even when applied to biofilms of strains resistant to conventional antibiotics. These results corroborate the development of new antimicrobial drugs, in addition to pointing out new directions for research involving the active principles of the extracts under study.

\section{CONCLUSION}

In conclusion, the glycolic extracts of $\mathrm{H}$. virginiana, J. regia, P. americana, P. paniculata and R. officinalis showed antimicrobial action, resulting in concentrations with microbicidal capacity and reductions in the K. pneumoniae MDR biofilms.

The extracts of G. sylvestre, S. barbatiman, and T. vulgaris, despite not presenting microbicidal concentrations, provided inhibitory concentrations in resistant strains of K. pneumoniae, which can be explored as adjuvant therapy with the use of antibiotics. In addition to the antimicrobial action on planktonic strains, the extracts also demonstrated anti-biofilm action. Among the extracts studied, those that were most effective in the anti-biofilm action were J. regia, P. paniculata and R. officinalis, promoting significant reductions in biomass and metabolic activity. In view of this, our findings revealed that these extracts investigated have antimicrobial and anti-biofilm activity, and may be a promising therapeutic alternative for K. pneumoniae MDR

\section{DECLARATIONS}

Ethical Statement: Clinical isolates of K. pneumoniae were obtained from a hospital in São José dos Campos, São Paulo, Brazil, where the samples are collected directly from the patient. We asked the hospital staff for permission to obtain access to laboratory strains, being cautious about all the ethical and legal precepts that govern this type of subject, where after hospital approval, we obtained access only the samples already collected and analyzed from micro-organisms that belong to the sample repertoire of the laboratory, not getting direct contact with the patient, due to this the approval of the ethics committee is not applied.

Funding: This work was supported by the:Fundação de Amparo à Pesquisa do Estado de São Paulo (FAPESP) [FAPESP scholarship: 15/08776-3] Conselho Nacional de Desenvolvimento Científico e Tecnológico (CNPq): 307396/2018-5 


\section{REFERENCES}

Arora, D. S., \& Sood, H. (2017). In vitro antimicrobial potential of extracts and phytoconstituents from Gymnema sylvestre R.Br. leaves and their biosafety evaluation. AMB Express, 7(1), 115. doi:10.1186/s13568-017-0416-z

Aslam, B., Wang, W., Arshad, M. I., Khurshid, M., Muzammil, S., Rasool, M. H., \& Baloch, Z. (2018). Antibiotic resistance: a rundown of a global crisis. Infect Drug Resist, 11, 1645-1658. doi:10.2147/IDR.S173867

Assis, F. V., Siqueira, F. L., Gonçalves, I. E., Lacerda, R. P., Nascimento, R. A., Araújo, S. G., \& Ferreira, J. M. S. (2018). Antibacterial activity of Lamiaceae plant extracts in clinical isolates of multidrug-resistant bacteria. An Acad Bras Cienc, 90(2), 1665-1670. doi:10.1590/0001-3765201820160870

Bowers, J. R., Lemmer, D., Sahl, J. W., Pearson, T., Driebe, E. M., Wojack, B., \& Keim, P. (2016). KlebSeq, a Diagnostic Tool for Surveillance, Detection, and Monitoring of Klebsiella pneumoniae. J Clin Microbiol, 54(10), 2582-2596. doi:10.1128/JCM.00927-16

Cai, J. C., Yang, W., Hu, Y. Y., Zhang, R., Zhou, H. W., \& Chen, G. X. (2012). Detection of KPC-2 and qnrS1 in clinical isolates of Morganella morganii from China. Diagn Microbiol Infect Dis, 73(2), 207-209. doi:10.1016/j.diagmicrobio.2012.03.013

Clegg, S., \& Murphy, C. N. (2016). Epidemiology and Virulence of Klebsiella pneumoniae. Microbiol Spectr, 4(1). doi:10.1128/microbiolspec.UTI-0005-2012

Costa, C. A., Tanimoto, A., Quaglio, A. E., Almeida, L. D., Severi, J. A., \& Di Stasi, L. C. (2015). Antiinflammatory effects of Brazilian ginseng (Pfaffia paniculata) on TNBS-induced intestinal inflammation: Experimental evidence. Int Immunopharmacol, 28(1), 459-469. doi:10.1016/j.intimp.2015.07.002

da Silva, T. C., Cogliati, B., Latorre, A. O., Akisue, G., Nagamine, M. K., Haraguchi, M., \& Dagli, M. L. (2015). Pfaffosidic Fraction from Hebanthe paniculata Induces Cell Cycle Arrest and Caspase-3-Induced Apoptosis in HepG2 Cells. Evid Based Complement Alternat Med, 2015, 835796. doi:10.1155/2015/835796

de Freitas, A. L. D., Kaplum, V., Rossi, D. C. P., da Silva, L. B. R., Melhem, M. S. C., Taborda, C. P., \& Ishida, K. (2018). Proanthocyanidin polymeric tannins from Stryphnodendron adstringens are effective against Candida spp. isolates and for vaginal candidiasis treatment. J Ethnopharmacol, 216, 184-190. doi:10.1016/j.jep.2018.01.008

de Oliveira, J. R., de Jesus, D., Figueira, L. W., de Oliveira, F. E., Pacheco Soares, C., Camargo, S. E., \& de Oliveira, L. D. (2017). Biological activities of Rosmarinus officinalis L. (rosemary) extract as analyzed in microorganisms and cells. Exp Biol Med (Maywood), 242(6), 625-634. doi:10.1177/1535370216688571

De Zoysa, M. H. N., Rathnayake, H., Hewawasam, R. P., \& Wijayaratne, W. M. D. G. (2019). Determination of. Int J Microbiol, 2019, 7431439. doi:10.1155/2019/7431439

Djeribi, R., Bouchloukh, W., Jouenne, T., \& Menaa, B. (2012). Characterization of bacterial biofilms formed on urinary catheters. Am J Infect Control, 40(9), 854-859. doi:10.1016/j.ajic.2011.10.009 
Elansary, H. O., Szopa, A., Kubica, P., Ekiert, H., Ali, H. M., Elshikh, M. S., \& El-Ansary, D. O. (2018). Bioactivities of Traditional Medicinal Plants in Alexandria. Evid Based Complement Alternat Med, 2018, 1463579. doi:10.1155/2018/1463579

Elisha, I. L., Botha, F. S., McGaw, L. J., \& Eloff, J. N. (2017). The antibacterial activity of extracts of nine plant species with good activity against Escherichia coli against five other bacteria and cytotoxicity of extracts. BMC Complement Altern Med, 17(1), 133. doi:10.1186/s12906-017-1645-z

Farooqui, A., Khan, A., Borghetto, I., Kazmi, S. U., Rubino, S., \& Paglietti, B. (2015). Synergistic antimicrobial activity of Camellia sinensis and Juglans regia against multidrug-resistant bacteria. PLoS One, 10(2), e0118431. doi:10.1371/journal.pone.0118431l

Fournomiti, M., Kimbaris, A., Mantzourani, I., Plessas, S., Theodoridou, I., Papaemmanouil, V., \& Alexopoulos, A. (2015). Antimicrobial activity of essential oils of cultivated oregano (Origanum vulgare), sage (Salvia officinalis), and thyme (Thymus vulgaris) against clinical isolates of Escherichia coli, Klebsiella oxytoca, and Klebsiella pneumoniae. Microb Ecol Health Dis, 26, 23289. doi:10.3402/mehd.v26.23289

Gadisa, E., Weldearegay, G., Desta, K., Tsegaye, G., Hailu, S., Jote, K., \& Takele, A. (2019). Combined antibacterial effect of essential oils from three most commonly used Ethiopian traditional medicinal plants on multidrug resistant bacteria. BMC Complement Altern Med, 19(1), 24. 10.1186/s12906-0192429-4

Goossens, H. (2009). Antibiotic consumption and link to resistance. Clin Microbiol Infect, 15 Suppl 3, 12-15. 10.1111/j.1469-0691.2009.02725.x

Hadadi, Z., Nematzadeh, G. A., \& Ghahari, S. (2020). A study on the antioxidant and antimicrobial activities in the chloroformic and methanolic extracts of 6 important medicinal plants collected from North of Iran. BMC Chem, 14(1), 33. 10.1186/s13065-020-00683-5

Hong, S. B., Rhee, M. H., Yun, B. S., Lim, Y. H., Song, H. G., \& Shin, K. S. (2016). Synergistic Anti-bacterial Effects of Phellinus baumii Ethyl Acetate Extracts and $\beta$-Lactam Antimicrobial Agents Against Methicillin-Resistant Staphylococcus aureus. Ann Lab Med, 36(2), 111-116. 10.3343/alm.2016.36.2.111

Idris, S, GI, N., \& CE, G. (2009). Preliminary phytochemical screening and antimicrobial activity of seed extracts of Persea americana (Avocado Pear). In (Vol. 2): Bayero Journal of Pure and Applied Sciences.

Ishida, K., Rozental, S., de Mello, J. C., \& Nakamura, C. V. (2009). Activity of tannins from Stryphnodendron adstringens on Cryptococcus neoformans: effects on growth, capsule size and pigmentation. Ann Clin Microbiol Antimicrob, 8, 29. 10.1186/1476-0711-8-29

Khalil, N., Fikry, S., \& Salama, O. (2020). Bactericidal activity of Myrrh extracts and two dosage forms against standard bacterial strains and multidrug-resistant clinical isolates with GC/MS profiling. AMB Express, 10(1), 21. 10.1186/s13568-020-0958-3

Kuok, C. F., Hoi, S. O., Hoi, C. F., Chan, C. H., Fong, I. H., Ngok, C. K., \& Fong, P. (2017). Synergistic antibacterial effects of herbal extracts and antibiotics on methicillin-resistant Staphylococcus aureus: A computational and experimental study. Exp Biol Med (Maywood), 242(7), 731-743. doi:10.1177/1535370216689828 
Li, B., \& Webster, T. J. (2018). Bacteria antibiotic resistance: New challenges and opportunities for implant-associated orthopedic infections. J Orthop Res, 36(1), 22-32. doi:10.1002/jor.23656

Mouchrek Junior, J. C., Nunes, L. H., Arruda, C. S., Rizzi, C. e. C., Mouchrek, A. Q., Tavarez, R. R., \& Maia Filho, E. M. (2015). Effectiveness of Oral Antiseptics on Tooth Biofilm: A Study in vivo. J Contemp Dent Pract, 16(8), 674-678. doi:10.5005/jp-journals-10024-1739

Olajuyigbe, O. O., \& Afolayan, A. J. (2012). Synergistic interactions of methanolic extract of Acacia mearnsii De Wild. with antibiotics against bacteria of clinical relevance. Int J Mol Sci, 13(7), 8915-8932. doi:10.3390/ijms13078915

Olajuyigbe, O. O., \& Afolayan, A. J. (2013). Evaluation of combination effects of ethanolic extract of Ziziphus mucronata Willd. subsp. mucronata Willd. and antibiotics against clinically important bacteria. ScientificWorldJournal, 2013, 769594. doi:10.1155/2013/769594

Osman, K. M., Hassan, H. M., Orabi, A., \& Abdelhafez, A. S. (2014). Phenotypic, antimicrobial susceptibility profile and virulence factors of Klebsiella pneumoniae isolated from buffalo and cow mastitic milk. Pathog Glob Health, 108(4), 191-199. doi:10.1179/2047773214Y.0000000141

Pacios, O., Blasco, L., Bleriot, I., Fernandez-Garcia, L., González Bardanca, M., Ambroa, A., \& Tomás, M. (2020). Strategies to Combat Multidrug-Resistant and Persistent Infectious Diseases. Antibiotics (Basel), 9(2). doi:10.3390/antibiotics9020065

Paula-Ramos, L., da Rocha Santos, C. E., Camargo Reis Mello, D., Nishiama Theodoro, L., De Oliveira, F. E., Back Brito, G. N., \& de Oliveira, L. D. (2016). Planktonic and Biofilm Reduction by Different Plant Extracts:. ScientificWorldJournal, 2016, 3521413. doi:10.1155/2016/3521413

Pereira, E. M., Gomes, R. T., Freire, N. R., Aguiar, E. G., Brandão, M., \& Santos, V. R. (2011). In vitro antimicrobial activity of Brazilian medicinal plant extracts against pathogenic microorganisms of interest to dentistry. Planta Med, 77(4), 401-404. doi:10.1055/s-0030-1250354

Pereira, J., Oliveira, I., Sousa, A., Ferreira, I., Bento, A., \& Estevinho, L. (2008). Bioactive properties and chemical composition of six walnut (Juglans regia L.) cultivars. Food and chemical toxicology : an international journal published for the British Industrial Biological Research Association, 46, 21032111. doi:10.1016/j.fct.2008.02.002

Prabuseenivasan, S., Jayakumar, M., \& Ignacimuthu, S. (2006). In vitro antibacterial activity of some plant essential oils. BMC Complement Altern Med, 6, 39. doi:10.1186/1472-6882-6-39

Rahim, K., Qasim, M., Rahman, H., Khan, T. A., Ahmad, I., Khan, N., \& Saleha, S. (2016). Antimicrobial resistance among aerobic biofilm producing bacteria isolated from chronic wounds in the tertiary care hospitals of Peshawar, Pakistan. J Wound Care, 25(8), 480-486. doi:10.12968/jowc.2016.25.8.480

Ramstedt, M., Ribeiro, I. A. C., Bujdakova, H., Mergulhão, F. J. M., Jordao, L., Thomsen, P., \& Sjollema, J. (2019). Evaluating Efficacy of Antimicrobial and Antifouling Materials for Urinary Tract Medical Devices: Challenges and Recommendations. Macromol Biosci, 19(5), e1800384. doi:10.1002/mabi.201800384 
Rather, M. A., Dar, B. A., Dar, M. Y., Wani, B. A., Shah, W. A., Bhat, B. A., \& Qurishi, M. A. (2012). Chemical composition, antioxidant and antibacterial activities of the leaf essential oil of Juglans regia L. and its constituents. Phytomedicine, 19(13), 1185-1190. doi:10.1016/j.phymed.2012.07.018

Roca, I., Akova, M., Baquero, F., Carlet, J., Cavaleri, M., Coenen, S., \& Vila, J. (2015). The global threat of antimicrobial resistance: science for intervention.

New Microbes New Infect, 6, 22-29. doi:10.1016/j.nmni.2015.02.007

Selvi, S., Devi, P. U., Chinnaswamy, P., Giji, T. M., \& Sharmila, S. P. (2007). Antibacterial efficacy and phytochemical observation of some Indian medicinal plants. Anc Sci Life, 26(3), 16-22.

Silva, D. M., Costa, P. A. D., Ribon, A. O. B., Purgato, G. A., Gaspar, D. M., \& Diaz, M. A. N. (2019). Plant Extracts Display Synergism with Different Classes of Antibiotics. An Acad Bras Cienc, 91(2), e20180117. doi:10.1590/0001-3765201920180117

van Vuuren, S. F., Suliman, S., \& Viljoen, A. M. (2009). The antimicrobial activity of four commercial essential oils in combination with conventional antimicrobials. Lett Appl Microbiol, 48(4), 440-446. doi:10.1111/j.1472-765X.2008.02548.x

Vuotto, C., Longo, F., Balice, M. P., Donelli, G., \& Varaldo, P. E. (2014). Antibiotic Resistance Related to Biofilm Formation in Klebsiella pneumoniae.

Pathogens, 3(3), 743-758. doi:10.3390/pathogens3030743

WHO. (2017). WHO publishes list of bacteria for which new antibiotics are urgently needed. In. World Health Organization. 


\section{Capítulo 15}

doi) $10.37423 / 211205144$

A EFETIVIDADE DAS PAUSAS PASSIVAS E ATIVAS NO AMBIENTE DE TRABALHO PARA O CONTROLE DAS QUEIXAS MUSCULOESQUELÉTICAS: UMA REVISÃO INTEGRATIVA 
Resumo: Revisão integrativa de literatura, em publicações científicas de 2011 a 2021, que objetivou avaliar a efetividade das pausas passivas e ativas no ambiente de trabalho para o controle das queixas musculoesquléticas nas regiões cervical e lombar através de uma revisão integrativa. Os dados foram coletados do portal da Biblioteca Virtual em Saúde/LILACS e da SciELO, utilizando os descritores: "queixas musculoesqueléticas ", "ambiente de trabalho"; “” estes, por sua vez, foram relacionados com o descritor " pausa". A busca originou 200 artigos, que, observados critérios de inclusão e exclusão, resultou em cinco artigos completos. A análise dos dados formou a categoria Pausas no ambiente de trabalho. Considerou-se os fatores associados relevantes foram: sociodemográficos, doenças associadas e assistência em saúde. A equipe de multiprofissional/saúde deve focar abordagens de cuidado mais interativas e humanizadas, direcionadas a incrementar a avaliação da dor.

Palavras-chaves: queixas musculoesqueléticas, ambiente de trabalho, pausa. 


\section{INTRODUÇÃO}

Os trabalhadores submetidos à rotina de trabalho sedentário em escritório sofrem com frequência de desconforto musculoesquelético e dor, especialmente em região de coluna e membros superiores ${ }^{1}$. Uma das possíveis consequências da rotina de trabalho em escritório é a prevalência pontual de lombalgia limitante de atividade ocupacional de $7.3 \%$, o que equivale a 540 milhões de pessoas afetadas com essas queixas em algum momento da vida ${ }^{2}$. A dor lombar ocorre em razão de diversos fatores de risco, inclusive os presentes no trabalho sendentário ${ }^{3}$, que incluem: fatores físicos (trabalho repetitivo, postura sentada prolongada, movimentos inadequados de pescoço e ombros), fatores organizacionais (integração, confiança, comunicação, diferenças, criatividade), e fatores psicossociais (estresse, alta demanda de trabalho, baixa atitude de decisão). Esses fatores associados à tensão muscular, insuficiente tempo para recuperação, e à fadiga geram sintomas que podem variar de desconforto e dor à redução da capacidade funcional e a incapacidade para o trabalho ${ }^{3,4}$. A dor cervical é um dos problemas musculoesqueléticos mais comuns, com prevalência de 30 a 50\%, sendo que em 1,7 a $11,5 \%$ dos casos resultam em restrição de atividade laboral ${ }^{5}$. Além do que, a dor no pescoço é responsável por muitos custos pessoais e sociais, constituindo a principal causa de incapacidade ocupacional, e dificuldade de retomar o trabalho.

As transformações das formas de trabalho, a partir da industrialização favoreceu o sedentarismo, devido aumento de atividades ocupacionais com menor gasto calórico o que contribuiu com o aumento das doenças crônicas não transmissíveis ${ }^{6}$. O trabalho sedentário, mais comumente atribuído a trabalhadores de escritório ${ }^{6-9}$, tem sido um grave problema de saúde pública ${ }^{8}$. Pois tem demonstrado estar associado a agravos a saúde como obesidade ${ }^{7}$, doenças cardiovasculares, câncer, diabetes, saúde mental ${ }^{9}$ e principalmente as doenças musculo esqueléticas por resultarem em dores, e limitação funcional ${ }^{6,9,10}$. Desta forma, para a construção de um ambiente de trabalho saudável, que favoreça a produtividade e diminua a incidência das diferentes formas de acidentes sofridos pelos trabalhadores, é necessário mais do que a mera elaboração dos Programas de Controle Médico de Saúde, e de Riscos Ambientais. Na realidade, é necessária uma adequação das atividades do trabalhador, que deve ocorrer através de análises, intervenções e programas ergonômicos.

A promoção da saúde e segurança dos trabalhadores estão previstas na legislação brasileira, por meio das Normas Regulamentadoras (NRs) do Ministério do Trabalho. A NR-17 ${ }^{11}$ que é uma norma de Ergonomia, fiscalizada as ações das empresas, envolvendo ajustes mobiliários, organização do trabalho, duração de ciclos, estrutura de horário e pausas para descanso que podem ser passivas e 
ativas. Salientamos que a adoção das intervenções ergonômicas contribui na prevenção das lesões musculoesqueléticas causadas pela rotina em diferentes empresas, incluindo tarefas de escritório ${ }^{12}$. Contudo, para a realização de uma análise e de uma intervenção ergonômica, é necessário analisar o posto de trabalho, olhar os elementos e circunstâncias que o compõem, tais como as posturas assumidas, tempo de execução das tarefas, organização do trabalho ${ }^{12,13}$. As pausas para descanso é uma intervenção organizacional no trabalho prevista na NR-17. E está entre as intervenções mais utilizadas no ambiente de trabalho para controle da fadiga, e a prevenção e controle dos distúrbios musculoesqueléticos em trabalhadores ${ }^{13}$. As pausas podem ocorrer com ou sem a prática de exercícios físicos e são eficazes para evitar um acúmulo de fadiga durante o trabalho ${ }^{14}$. Os exercícios físicos durante as pausas, por sua vez, podem contribuir para redução da prevalência de queixas musculoesqueléticos, mas a adesão a prática de exercícios físicos ainda é um desafio para muitos empregados ${ }^{15}$.

Com isso tivemos como objetivo avaliar a efetividade das pausas passivas e ativas no ambiente de trabalho para o controle das queixas musculoesquléticas nas regiões cervical e lombar através de uma revisão integrativa.

\section{METODOLOGIA}

Trata-se de uma revisão integrativa da literatura, a fim de deduzir generalizações sobre questões substantivas, a partir de um conjunto de estudos diretamente influenciados sobre essas questões. Tais revisões incluem exame das pesquisas para discutir hipóteses, sugestões para novas questões teóricas e identificação de uma pesquisa necessária. ${ }^{16}$

A revisão integrativa é um método de exame específico que resume literaturas empíricas ou teóricas para fornecer uma compreensão mais abrangente de um fenômeno particular. Assim, tem o potencial de apresentar o estado da ciência, contribuir para o desenvolvimento da teoria, e tem aplicabilidade direta à prática e à política. ${ }^{16}$

Para ser considerada uma pesquisa, a revisão de literatura deve seguir o mesmo rigor da pesquisa primária. Nesse sentido, para esta revisão, foram consideradas as fases de pesquisa16: identificação do problema e objetivo da pesquisa; pesquisa da literatura com foco sobre o tema a ser estudado; avaliação dos dados aplicando critérios de inclusão e exclusão; análise dos dados extraindo das fontes primárias as características da amostra e método, que, no caso, foi qualquer referência ao conceito de 
abandono/não adesão e os fatores a que esses estão relacionados. Como última fase, temos a apresentação da síntese, que retrata a construção dos conceitos e seus fatores relacionados.

A busca pela literatura ocorreu na Biblioteca Virtual em Saúde (BVS), nos meses de dezembro 2021 e janeiro 2022. As bases de dados de literatura científica e técnica consultadas foram: Literatura LatinoAmericana e de Caribe em Ciências da Saúde (LILACS) e Scientific Electronic Library On- line (SciELO). Foram selecionadas essas bases de dados considerando-se o interesse em conhecer a construção desse conhecimento na América Latina, onde a Prevalência de dor crônica em Universitários tem importante expressão epidemiológica. Os descritores foram selecionados a partir da terminologia em saúde consultada nos Descritores em Ciências da Saúde (DECS-BIREME); são eles: " queixas musculoesqueléticas", "ambiente de trabalho"; estes, por sua vez, foram relacionados com o descritor "pausa". Inicialmente, a busca considerou as publicações dos últimos cinco anos; porém, optou-se pelo período de 2011 a 2021, que deu maior amplitude ao estudo e resultou em 200 estudos: 50 da base de dados LILACS e 150 das referências na base da SciELO.

Após a leitura dos resumos, segundo pertinência e consistência do conteúdo, foram 300 observados os seguintes critérios de inclusão: estudos disponíveis na íntegra, em open acess, de 2011a 2021, publicações originais, nas línguas portuguesa, espanhola e inglesa, que adotaram uma abordagem quantitativa, considerando o objetivo do estudo e o protocolo de revisão elaborado previamente. Foram critérios de exclusão: artigos repetidos, artigos não acessíveis em texto completo, resenhas, anais de congresso, artigos de opinião, artigos de reflexão, editoriais, artigos que não abordaram diretamente o tema deste estudo e artigos publicados fora do período de análise. Ao todo, foram excluídos 100 artigos (30 da base de dados LILACS e 70 da base SciELO). Assim, após essa fase, iniciouse a análise de cinco estudos completos.

Foi elaborado um quadro para organização da análise dos artigos contendo os itens: tipo de publicação, ano, fonte, autores, título, tema, método e objetivo. No que se refere aos a Pausas no ambiente de trabalho, a análise se fez em termos qualitativos, sumarizando os dados para formar as categorias. Os resultados foram discutidos e sustentados com outras literaturas pertinentes.

\section{RESULTADOS}

A partir da análise dos textos selecionados, tem-se, quanto ao tipo de publicação, que os dois estudos, apresentados no Quadro 1, são resultados de pesquisas, e todos são nomeados pelos editores como originais. 
Com respeito ao ano de publicação, artigos foram publicados em 2021, um em 2019, um demonstrando que houve lacunas de publicações na sequência de anos pesquisados.

Quanto aos tipos de estudos, foram assim classificados: dois estudos revisão integrativa; As pesquisas adotaram a abordagem qualitativa conforme critério de inclusão.

Quadro 1 - Artigos selecionados sobre a efetividade das pausas passivas e ativas no ambiente de trabalho para o controle das queixas musculoesqueléticas nas regiões cervical e lombar segundo autores, ano de publicação, título, tipo e objetivo do estudo

\begin{tabular}{|c|c|c|c|c|}
\hline Autor & Ano & Título & $\begin{array}{l}\text { Tipo de } \\
\text { Estudo }\end{array}$ & Objetivo \\
\hline $\begin{array}{l}\text { Nezilda Ramos } \\
\text { da Silva Malcher } \\
\text { Antônio Augusto } \\
\text { da Cunha Palheta } \\
\text { Eliane Ferreira } \\
\text { Marinho }\end{array}$ & 2021 & $\begin{array}{l}\text { Queixas álgicas e } \\
\text { distúrbios } \\
\text { musculoesqueléticos } \\
\text { em profissionais da } \\
\text { enfermagem: uma } \\
\text { revisão integrativa }\end{array}$ & $\begin{array}{c}\text { Revisão } \\
\text { Integrativa }\end{array}$ & $\begin{array}{l}\text { Investigar as } \\
\text { principais queixas } \\
\text { álgicas } \\
\text { indicativas de } \\
\text { Distúrbio } \\
\text { Osteomuscular } \\
\text { Relacionado ao } \\
\text { trabalho (DORT) } \\
\text { entre } \\
\text { profissionais da } \\
\text { enfermagem }\end{array}$ \\
\hline $\begin{array}{l}\text { Tamires Costa } \\
\text { Silva }\end{array}$ & 2019 & $\begin{array}{l}\text { Investigar as } \\
\text { principais queixas } \\
\text { álgicas indicativas } \\
\text { de Distúrbio } \\
\text { Osteomuscular } \\
\text { Relacionado ao } \\
\text { trabalho (DORT) } \\
\text { entre profissionais } \\
\text { da enfermagem }\end{array}$ & $\begin{array}{l}\text { Revisão } \\
\text { Integrativa }\end{array}$ & $\begin{array}{l}\text { Realizar um } \\
\text { estudo de revisão } \\
\text { integrativa, } \\
\text { visando } \\
\text { apresentar a } \\
\text { relevância da } \\
\text { ginástica laboral } \\
\text { nas dores da } \\
\text { coluna vertebral } \\
\text { em decorrência a } \\
\text { longa jornada de } \\
\text { trabalho }\end{array}$ \\
\hline
\end{tabular}

\section{PAUSAS NO AMBIENTE DE TRABALHO}

"O conceito de Pausa é definido como a "interrupção temporária de uma ação,", ou seja, "interrupção de algo que está acontecendo", que depois voltará a acontecer ${ }^{17}$. As pausas para descanso fazem parte da rotina dos trabalhadores, pois nenhuma ação ou ato acontece sem que ocorra uma parada para descanso ${ }^{18}$. A finalidade das pausas é o restabelecimento do trabalhador, e a recuperação de sua condição fisiológica, sendo indispensável para manter a capacidade das funções do corpo ${ }^{19}$ 
Portanto, para um bom desempenho no trabalho existem os tipos de pausa previstos na consolidação das Leis do Trabalho (CLT, art. 71), que podem ser definidas como; interjornadas, intrajornada, micro pausas e macro pausas ${ }^{20,21}$ As pausas interjornadas, são intervalos de 15 minutos, recomendados para jornadas de trabalho entre 6 e 8 horas, destacamos que o art. 66 da CLT, prevê que o trabalhador descanse 11 horas, mesmo que tenha realizado horas extras ${ }^{22}$. Enquanto, as pausas intrajornada ocorrem em jornadas de trabalho superior a 6 horas, sendo recomendadas intervalos de no mínimo 1 hora e de no máximo duas horas, esses intervalos são para repouso e alimentação, realizados fora do posto de trabalho e não sendo computados como horas trabalhadas ${ }^{23}$.

Além das normativas sobre pausa, encontradas na CLT, as Normas Regulamentadoras (NR's) do Ministério do Trabalho também orientam intervalos de descanso e, para alguns tipos de trabalhos, estipulando tempos de pausas específicas, visando estabelecer melhores condições para os trabalhadores ${ }^{11}$. A NR17 regulamenta que todo trabalhador de escritório deve ter de 10 a 15 minutos de pausa a cada 50 minutos trabalhado, tendo como finalidade recuperar as condições fisiológicas dos trabalhadores, incluindo um maior número de intervalos intrajornada, que se ajustem as necessidades de cada trabalhador, e atividade de trabalho. Convêm destacar que a NR17 ${ }^{11}$ e a NR36 ${ }^{24}$, apresentam regulamentação de pausas diferenciadas para trabalhadores de frigoríficos e de escritório que realizada entrada de dados.

A regulação do tempo de pausa para as atividades de trabalho que não estão contidas nas NRs são organizadas a partir da análise ergonômica do trabalho. A compreensão das tarefas, a partir dessa análise permite que cada empresa adote as pausas de acordo com as necessidades dos trabalhadores, ou da forma que a empresa julgar necessária, devendo ser considerado ainda acordos sindicais ${ }^{20}$ Outros tipos de pausa de descanso também podem ser identificados durante a jornada de trabalho, como as micropausas. As micropausas são caracterizadas por curtos intervalos de interrupção que ocorrem durante as tarefas realizadas, mas propriamente dentro de um ciclo de trabalho ${ }^{18,25}$.

As micropausas, também ocorrem no caso de profissionais que trabalham diretamente com celulares, devido ao cansaço, fadiga, e necessidade de descansar, elas são importantes para a recuperação do estado físico do trabalhador, minimizando os riscos ocupacionais ${ }^{27,28}$. As pausas para descanso são aquelas paradas que o trabalhador faz, para relaxar, ou mesmo tomar um café, e conversar com colegas, elas podem proporcionar alívio de todas as fontes de tensão física imposta pelo trabalho ${ }^{28}$ Ainda sobre as pausas de descanso, podemos destacar a macropausas, que é caracterizada como o período de descanso utilizado para a realização dos exercícios ${ }^{11,28}$. Normalmente, a macropausas é 
utilizada por empresas que demonstram uma preocupação com o bem-estar físico e psicológico dos trabalhadores, dessa forma, utilizam estratégias como adoção de ginástica laboral, também caracterizada como pausa ativa. O intervalo para realização da macropausas é de 10 a 20 minutos durante a jornada de trabalho, regulamentado pela NR17 no anexo I sobre trabalhos de Teleatendimento ${ }^{11}$. Ressaltamos, que a macropausas é iniciativa das empresas, portanto, cabe a elas definir a frequência dessa pausa ativa na carga horaria semanal.

Analisando as vantagens e desvantagens do estabelecimento de pausas no trabalho, podemos afirmar que ausência de pausas na jornada do trabalhador, podem sobrecarregar o trabalhador, causando alterações físicas e psicológicas, levando até às lesões do trabalho, absenteísmo, piora na qualidade de vida e ao surgimento das doenças ocupacionais, que são consideradas atualmente um grave problema de saúde pública ${ }^{29,30,31}$. E como vantagem as inserções de pausas curtas de 5-10 min a cada hora trabalhada podem resultar em melhora física ${ }^{32}$ e mental, para o trabalhador, proporcionando bem-estar e reduzindo desconfortos musculoesqueléticos, juntamente com desempenho inalterado ou mesmo melhorado. ${ }^{33}$

\section{CONSIDERAÇÕES FINAIS}

A literatura pesquisada reforça que a efetividade das pausas passivas e ativas no ambiente de trabalho para o controle das queixas musculoesqueléticas nas regiões cervical e lombar através de uma revisão integrativa não foi satisfaria para população.

Assim, entre os fatores relacionados as pausas passivas e ativas funcionam como contribuintes para a não prática, salientam-se os relacionados à humanização nos serviços de prevenção. Estes nos levam a outras inquietações relacionadas ao tipo de relação que se estabelece entre trabalhadores, muitas vezes marcadas por relações de poder e hegemonia do saber em detrimento das vivências e experiências de quem é sujeito ativo desse processo.

É necessário o desenvolvimento de pesquisas e de novos modelos de pausas ativas e passivas que considere, em seus enfoques, a horizontalidade nas relações entre os trabalhadores, com diálogo e interação, estabelecendo cuidados que tragam melhores resultados para a compreensão dos instrumentos na Saúde do Trabalhador.

A pesquisa aponta a importância de processos de capacitação da equipe de saúde a fim de rever o paradigma de cuidado e educação adotados, desenvolvendo intervenções diferenciadas, direcionadas a incrementar pausa passiva e ativa no ambiente de Trabalho. 


\section{REFERÊNCIAS}

1. Wahlstrom J. Ergonomics, musculoskeletal disorders and computer work. Occup Med (Lond).55(3):168-76, 2005

2. Hartvigsen, J., Hancock, M.J., Kongsted, A., Louw, Q., Ferreira, M.L., Genevay, S., et al., What low back pain is and why we need to pay attention. The Lancet. 2018

3. Lima VA de, Aquilas, AL, Ferreira Junior M. Efeitos de um programa de exercícios físicos no local de trabalho sobre a percepção de dor musculoesquelética em trabalhadores de escritório. Rev Bras Med Trab. São Paulo • Vol. 7 • 2009

4. Hush JM , Maher CG, Refshauge KM. Risk factors for neck pain in office workers: a prospective study. BMC Musculoskeletal Disorders 2006, 7:81 doi:10.1186/1471-2474-7-81

5. Namvar,H, olyaei G , Moghadam, B A, Hosseinifar M. Effect of myofascial release technique on pain, disability, maximum isometric contraction of the extensor muscles, and pressure pain threshold in patients with chronic nonspecific neck pain: Double blinded randomizedclinical trial. International Journal of Medical Research \& Health Sciences, 2016, 5, 7S:500-506

6. Commissaris D, Huysmans M, Mathiassen S, Srinivasan D, Koppes L, Hendriksen I. Interventions to reduce sedentary behavior and increase physical activity during productive work: a systematic review. Scand J Work Environ Health. 2016;42:181-91.

7. Brown W, Miller Y, Miller R. Sitting time and work patterns as indicators of overweight and obesity in Australian adults. International Journal of Obesity. 2003;27:1340-6.

8. Craig CL, Lambert EV, Inoue S, Alkandari JR, Leetongin G, et al. The pandemic of physical inactivity: global action for public health. The Lancet. 2012;380:21-7.

9. Picavet HSJ, Pas LW, Oostrom SHv, Ploeg HPvd, Verschuren WMM, Proper KI. The Relation between Occupational Sitting and Mental, Cardiometabolic, and Musculoskeletal Health over a Period of 15 Years--The Doetinchem Cohort Study. Plos One. 2016;1:1-11.

10. Pitanga, FJ G; Lessa I, Prevalência e fatores associados ao sedentarismo no lazer em adultos. Cad. Saúde Pública, Rio de Janeiro, 21(3):870-877, mai-jun, 2005.

11. Brasil, Manual de aplicação da Norma Regulamentadora no 17. - 2 ed. - Brasília : MTE, SIT, 2002. 101 p. : il. Inclui bibliografia. A Portaria no 3.751, de 23.11.1990, estabelece os princípios da Ergonomia da NR - 17. 1. Ergonomia, Normas, Brasil. 2. Saúde ocupacional, Brasil. 3. Inspeção do trabalho, Brasil. I. Brasil. Ministério do Trabalho e Emprego (MTE). II. Brasil. Secretaria de Inspeção do Trabalho (SIT).

12. Kajiki S, Izumi H, Hayashida K, Kusumoto A, Nagata T, Mori K. A randomized controlled trial of the effect of participatory ergonomic low back pain training on workplace improvement.J Occup Health 2017 May 25;59(3):256-266

13. Sultan-Taïeb H1, Parent-Lamarche A, Gaillard A, Stock S, Nicolakakis N, Hong QN, Vezina M, Coulibaly $Y$, Vézina $N$, Berthelette $D$.Economic evaluations of ergonomic interventions preventing work-related musculoskeletal disorders: a systematic review of organizational-level interventions. BMC Public Health 2017 Dec 8;17(1):935. doi: 10.1186/s12889-017-4935-y 
14. Blasche G, Pasalic S, Bauböck VM, Haluza D, Schoberberger R. Effects of Rest-Break Intention on Rest-Break Frequency and Work-Related Fatigue. Mar;59(2):289-298. doi:

\subsection{7/0018720816671605. Epub 2016 Oct 20, 2017}

15. Andersen L L, Influence of Psychosocial Work Environment on Adherence to Workplace Exercise JOEM . Volume 53, Number 2, February 2011

16- Chirinos, Narda Estela Calsin e Meirelles, Betina Hörner Schlind wein Fatores associados ao abandono do tratamento da tuberculose: uma revisão integrativa. Texto \& Contexto - Enfermagem [online]. 2011, v. 20, n. 3 [Acessado 14 Dezembro 2021], pp. 599-606. Disponível em: <https://doi.org/10.1590/S0104-07072011000300023>. Epub 23 Dez 2011. ISSN 1980-265X. https://doi.org/10.1590/S0104-07072011000300023

17-Ferreira ABH. Dicionário da Língua Portuguesa. 5. ed. Rio de Janeiro: Positivo, 2010.

18. Grandjean E. Manual de ergonomia: adaptando o trabalho ao homem. 4. ed. Trad. João Pedro Stein. Porto Alegre: Artes Médicas, 2005

19. lida I. Ergonomia : projeto e produção. São Paulo: Edgard Blücher , 3o revisada, 2016.

20. Brasil. Decreto Lei no 5.452 de 01 de Maio de 1943. Aprova a Consolidação das Leis do Trabalho. Diário Oficial da União 09 out 1943.

21. Brasil .Ministério do Trabalho e Emprego - Art. 71 Consolidação das Leis do Trabalho - Decreto Lei $5452 / 43$.

22 Brasil .Ministério do Trabalho e Emprego - Art. 66 Consolidação das Leis do Trabalho - Decreto Lei $5452 / 43$.

23. Brasil,Ministério do Trabalho e Emprego (Brasil) Normal Regulamentadora 1. Portaria GM n.으 3.214, de 08 de junho de 1978. Diário Oficial da União 06/07/78.

24. Brasil,Ministério do Trabalho e Emprego (Brasil). Normal Regulamentadora 36. Portaria MTE n.으 555, de 18 de abril de 2013. Diário Oficial da União 06 jul 19 abr 2013.

25. McLean L, Tingley M, Scott RN. Rickards. Computer terminal work and the benefit of microbreakes. J Applied Ergonomics .2001;32: 225-237.

26. Hallbeck MS., Lowndes BR, Bingener J., Abdelrahman AM., Yu D., Bartley, Park AE.. The impact of intraoperative microbreaks with exercises on surgeons: A multi-center cohort study, Applied Ergonomics 60 334e e 341, 2017

27.Raci, T L. Alinsky, G, Num Om Ig. Nson, Swa, Steven, L Sauter S, Jo Seph J. Hurr Ell E La Wr En Ce M. Sch Leifer $A{ }^{\circledR}$ eld study of supplem entary rest breaks for data-entry operators., Ergonomics, Vol . 43, No. $5,622 \pm 638,2000$

28. Laporte $W$. The Influence of a gymnastic pause upon recovery following post office work,Ergonomics.9: 501 -506, 1966. 
29.Burbigd, JL.,. Glossary of terms used in Production Control.Inglaterra: Elsevier Science Publishers.1987

30..Silva Junior, SHA., Vasconcelos, AGG., Griep, RH, Rotenberg, L,. Confiabilidade teste-reteste do Índice de Capacidade para o Trabalho (ICT) em trabalhadores de enfermagem. Rev Bras Epidemiologia.16(1):202-209,2013.

31.Padula, RP, Comper, MLC, Moraes, AS, Sabbagh, C, Junior, PW, Perracini, M.R.,. The work ability index and functional capacity among older workers. Braz J Phys Therapy.17(4):382-391, 2013

32. Kakarot N, Mueller F \& Bassarak C Activity-rest schedules in physically demanding work and the variation of responses with age. Ergonomics 55, 282-294. 2012.

33.Dababneh AJ, Swanson N \& Shell RL Impact of added rest breaks on the productivity and well being of workers. Ergonomics 44, 164-174. 2001. 


\section{Capítulo 16}

doi $10.37423 / 211205176$

\section{O TRANSTORNO DE PERSONALIDADE NARCISISTA E AS RELAÇÕES AFETIVAS: UMA CONTRIBUIÇÃO DA PSICANÁLISE}


Resumo: $O$ transtorno de personalidade narcisista tem como principais características um padrão difuso de grandiosidade, perfeccionismo, necessidade de ser admirado e falta de empatia. Uma pessoa com esse transtorno demandará de um reconhecimento supervalorizado do outro, ela necessitará ser reconhecida por outras pessoas e acabará desvalorizando e desqualificando o que o outro fizer. Como método deste trabalho, trata-se de uma revisão integrativa da literatura, onde foram utilizadas como palavras chaves: "Transtorno de Personalidade Narcisista", "Introdução ao Narcisismo", "Narcisismo e Relações Afetivas". Para tal, foi extraído a partir da base de dados do Google Acadêmico e Scielo, tendo como critério de inclusão os artigos publicados em português e em inglês que retratassem a temática proposta acerca do transtorno de personalidade narcisista e suas relações afetivas, e como critérios de exclusão, artigos que não obedeceram aos critérios de inclusão. O objetivo geral do presente artigo é de fazer uma revisão integrativa da literatura dos últimos anos sobre pessoas com esse transtorno, para isso, foi-se necessária utilizar de uma abordagem qualitativa, com ênfase no estudo documental. Partindo então dos conceitos apresentados pelos principais autores da teoria psicanalítica, o trabalho analisará o perfil dessas pessoas, buscando compreender a visão psicanalítica freudiana a respeito e qual o conceito desenvolvido por Freud acerca do tema, suas teorias e contribuições finais. O resultado final deste trabalho foi constituído por sete artigos científicos selecionados a partir dos critérios de inclusão estabelecidos previamente, partindo do pressuposto de que os autores destacados utilizaram como base para o desenvolvimento e elaboração dos seus respectivos artigos, o texto de 1914 escrito por Sigmund Freud nomeado de: "Introdução ao Narcisismo". Espera-se que o artigo possa contribuir na compreensão sobre o transtorno através das informações que forem fornecidas.

Palavra-Chave: Narcisista. Transtorno. Personalidade. Narcisismo. 


\section{INTRODUÇÃO}

Originalmente o termo narcisismo foi usado para esclarecer o comportamento de certos indivíduos que se sentiam atraídos de forma excessiva pelo seu próprio corpo. A partir de 1914, por meio do artigo publicado por Sigmund Freud como resposta a Jung, é possível constatar que o narcisismo estaria presente no desenvolvimento de todos os seres humanos, mas poderia transforma-se em uma patologia por causa de vários fatores que estão relacionados diretamente ao exagero e aos potenciais prejuízos no meio social. Ademais, Freud constatou de que o narcisismo primário referia-se ao investimento da libido no próprio eu, e o narcisismo secundário se referia ao retorno do investimento da libido ao ego depois de ser dirigida aos objetos externos (KLAUTAU, 2018).

O transtorno de personalidade narcisista tem como principais características um padrão difuso de grandiosidade, perfeccionismo, necessidade de ser admirado e falta de empatia com o outro. Eles precisam sempre ser valorizados, e por muitas vezes, chegam a serem pretenciosos, condizente com uma preocupação ilimitada de se ter a admiração das demais pessoas, buscando ter privilégios em todos os contextos sociais. A pessoa com esse tipo de transtorno demanda de um reconhecimento supervalorizado do outro, ela necessita ser reconhecida por outras pessoas e acontece de acabar desvalorizando e desqualificando o que o outro faz. Geralmente esse transtorno se inicia na idade adulta e se estende ao longo da vida do sujeito (ARAÚJO, 2010).

Um ponto importante a ser levado em consideração diz respeito à autoestima dessas pessoas, que apesar de apresentarem comportamentos soberbos e autoconfiantes, existe uma fragilidade interna que muitas vezes não é manifestada. São pessoas muito sensíveis às criticas e/ou frustrações, e isso acontece com frequência em suas relações interpessoais. Os narcisistas começam a se relacionar visando apenas o beneficio próprio, esperando que o outro supra as suas necessidades, sendo sempre muito centrado apenas nas suas próprias questões e nos seus próprios desejos, sem se preocupar com o que de fato o outro está sentindo (CHRISTO, 2017).

O transtorno de personalidade narcisista é classificado como uma desordem mental altamente prejudicial, que causa perturbação na vida da pessoa em todos os seus âmbitos prejudicando a si mesmo e as suas relações afetivas. Neste sentido é possível afirmar que: "O narcisismo de outra pessoa exerce grande atração sobre aqueles que renunciaram a uma parte do seu próprio narcisismo" (FREUD, 1914;1974, p.106) “O que ele projeta diante de si mesmo como o seu ideal é o substituto do narcisismo perdido de sua infância na qual ele era seu próprio ideal" (FREUD, 1914; 2010). 
Convivendo em sociedade nos deparamos com diversas pessoas de personalidades diferentes, cada um com sua peculiaridade e excentricidade. Pessoas com transtorno de personalidade narcisista estão presentes diariamente em nossos ciclos sociais e a dificuldade de lidar com essas pessoas motivou a elaboração desse projeto. A proposta deste presente trabalho visa elucidar como identificá-las e em como desenvolver um melhor relacionamento com essas pessoas, seja no âmbito afetivo ou social, de forma que possamos colocar limites e evitar possíveis conflitos. O problema sobrevém devido à necessidade constante de aprovação que pessoas com o transtorno de personalidade narcisista possuem se tornando invasivas em suas relações interpessoais, de modo que ter um relacionamento saudável e estável com pessoas com esse transtorno parece impossível.

De acordo com Wallace e Baumeister ( 2002), o narcisismo clínico pode ser compreendido como um transtorno de personalidade, o narcisismo não patológico refere-se a uma característica de personalidade, apresentada por um número significativo de indivíduos considerados "normais" e associada a custos e benefícios. O desenvolvimento libidinal no narcisismo só adquire caráter patológico a partir de certo limiar, pois, inicialmente, o desenvolvimento da libido em direção ao narcisismo primário segue uma dinâmica semelhante, isto é, independente do fato de estes sujeitos desenvolverem ou não alguma patologia no futuro (ARAÚJO, 2010).

A construção do conceito de narcisismo subverteu a primeira teoria freudiana das pulsões na medida em que o eu, passou a ser um objeto de investimento libidinal. Por outro lado, já é possível encontrar alguns dos elementos essenciais para uma teoria do narcisismo. São eles: a ideia do eu como objeto de amor, o postulado de uma identificação como base do narcisismo e, ainda, a relação deste com as escolhas amorosas (MAXWELL, 2008).

O narcisismo é indicado como uma perturbação da personalidade que vem sendo caracterizada como um investimento exagerado em sua própria imagem à custa do self. Pessoas com esse transtorno não se preocupam em como se sentem, mas sim como os modos que se apresentam, eles conseguem negar seus sentimentos que contradizem a imagem que eles querem passar para as outras pessoas, sendo extremamente concentrados em seus próprios interesses, mas em contrapartida são carentes dos valores verdadeiros do self. Sem esses valores e sentimentos do self, eles levam suas vidas como algo sem um significado plausível (LOWEM, 2017; p.5).

Segundo Lowen (2017), o narcisismo pode ser considerado como uma perda de valores humanos onde há uma ausência de interesse pelo ambiente e pelo o outro. Devido a isso, pessoas com esse 
transtorno apresentam ausência de algumas qualidades que fazem de nós, seres humanos, empáticos. Apesar dos narcisistas demonstrarem uma falta de interesse com o outro e suas necessidades, eles também são insensíveis às próprias necessidades, tendo comportamentos autodestrutivos. Pessoas com o transtorno de personalidade narcisista amam sua imagem, mas não amam seu verdadeiro eu, sendo o narcisismo é uma condição patológica.

O objetivo principal deste artigo é fazer um levantamento da literatura sobre pessoas com transtorno de personalidade narcisista, explorando suas características e suas relações afetivas e sociais. Assim como, compreender a visão psicanalítica freudiana a respeito do transtorno de personalidade narcisista, o conceito desenvolvido por ele acerca do tema, suas teorias e contribuições, e como elas são usadas atualmente para lidar com esse transtorno. Como são estabelecidas as relações afetivas das pessoas que sofrem com transtorno de personalidade narcisista e de que modo às pessoas com esse transtorno se relacionam no âmbito social e afetivo.

\section{NARCISISMO PRIMÁRIO E NARCISISMO SECUNDÁRIO}

Na psicologia, o conceito de "Narcisismo" foi desenvolvido por Sigmund Freud, e ao contrário do que é pensado, Freud não o extrai do mito de Narciso, mas sim da obra de um psiquiatra chamado Paul Nacke, onde o mesmo se refere ao termo narcisismo como um comportamento pelo qual o indivíduo vê seu próprio corpo como um objeto sexual de desejo. Porém, é importante salientar a história de Narciso que é um personagem da mitologia grega, descrito como um jovem de uma beleza fora do comum, contemplado por homens e mulheres, no entanto, era retratado como arrogante e orgulhoso. Apesar de a história ter várias versões, a mais recorrente e popular cita que o jovem Narciso ao se observar no reflexo de um lago se apaixonou pela própria imagem e em uma tentativa desesperada de tocar o seu reflexo acabou morrendo afogado (VETTORAZZO, 2007).

De acordo com Vettorazzo (2007), o narcisismo, baseado na concepção de Freud, é caracterizado pela capacidade de amar e respeitar a si mesmo como um efeito do investimento amoroso do outro. $\mathrm{O}$ texto de 1914 nomeado de "Narcisismo: Uma Introdução" foi conduzido por Freud através de uma leitura quantitativa dos fatos clínicos e de suas respectivas experiências, da observação de alguns quadros perversos, além do homossexualismo e da vida sexual dos dois gêneros. A partir disso, Freud reconhece o narcisismo como uma etapa fundamental do processo de construção do eu, que se situa entre o autoerotismo e o amor objetal (NICEAS, 2017; p.15). 
Para Barbosa, Campos e Neme (2021), o narcisismo primário é um processo natural do desenvolvimento psíquico a partir da qual o Eu é desenvolvido. Diante disso, é destacado o narcisismo como um momento fundamental na constituição do Eu, possuindo o papel de formar ideais, função de auto conservação e de defesa. O narcisismo primário é situado logo após o autoerotismo e antes da fase de investimento em objetos. Com isso, é importante destacar a apresentação do narcisismo primário como sendo uma condição de possibilidade para emergência das relações objetais. Entretanto, é considerado que o narcisismo infantil não é completamente abandonado. Apenas é deslocado para os ideais do Eu, que irão passar a substituí-lo, garantindo assim que satisfações narcísicas aconteçam.

No artigo "Introdução ao Narcisismo (1914)", Freud dividiu o narcisismo em dois conceitos: o narcisismo primário e o narcisismo secundário. Que são referentes a uma forma de estruturação da personalidade e etapas do desenvolvimento do ser humano, uma personalidade narcisista se estrutura pela fixação do desenvolvimento mental em etapas infantis ou em uma regressão do individuo em enfrentar os desafios da vida adulta (FREUD [1914] 2010).

Neste mesmo texto, Freud definiu o Narcisismo Primário como: "uma fase necessária do desenvolvimento da Libido entre o Auto Erotismo e o Amor Objetal". Ao nascer, a criança acredita que tudo ao seu redor fazem parte dela mesma, principalmente a sua mãe, quando a criança passa a ter a percepção de si mesma e do outro, desperta o seu narcisismo primário. Segundo Freud, o narcisismo primário nada mais é do que uma transferência para a criança do narcisismo de seus pais. É exigido direto ou indiretamente que a criança recupere os privilégios que os pais foram obrigados a renunciar, fazendo-a que ocupe lugares que Ihes foram perdidos (FREUD [1914] 2010).

Todavia, o narcisismo começará a se desenvolver quando os cuidados emocionais primários forem excluídos da criança quando ela está desenvolvendo a sua personalidade. Com isso, muitos pais inconscientemente não permitem a autonomia da criança, assim ela é moldada a própria semelhança dos pais. É onde acontece a maior ferida narcísica, que seria a de não ter sido amado pelo o que se era verdadeiramente (FARIA, 2003).

Para Falcão (Freud, 1914; 2014), o desenvolvimento psicossexual do bebê não é diferenciado da pessoa que dele o cuida, sendo o funcionamento narcísico que o engloba, dando origem aos atributos que caracterizam o narcisismo primário. Através do investimento da libido que ocorrerá o desenvolvimento psicossexual, onde a libido do eu se transformará em libido do objeto e vice-versa, 
e a partir disso, a estruturas psíquicas serão formadas. É importante ressaltar que é na libido do eu que promoverá a base da satisfação e vivência narcísica, onde as sensações de desprazer e prazer vão ser promovidas. Sendo assim, o narcisismo primário como autoerotismo e o narcisismo secundário como diferenciação entre Eu e não-Eu.

Nesse sentido, "O narcisismo primário que supomos nas crianças e que contém uma das premissas de nossas teorias sobre a libido é mais difícil de apreender pela observação direta do que de comprovar através de uma inferência retrospectiva feita a partir de outro ponto" (FREUD [1914] 2010: 87). Enquanto "o narcisismo secundário será o resultado do retorno sobre o Eu dos investimentos que até então estavam depositados no objeto, mas também da modificação que este retorno promove no Eu, constituindo-se sobre a base do narcisismo primário" (FREUD, 1914; 2010a, p. 98).

Conforme Falcão (Freud, 1914; 2014), o desenvolvimento do eu acontecerá a partir do momento que houver o distanciamento do narcisismo primário em direção ao ideal do eu, por meio do deslocamento da libido. Sendo no narcisismo secundário que o eu, como reservatório libidinal, passará a se dirigir aos objetos externos. A partir disso, o amor por si mesmo que teve origem na infância onde o eu foi desfrutado pelo eu verdadeiro agora irá se dirigir ao eu ideal.

Em outras palavras, em algum momento de sua vida, este narcisismo primário é dirigido para o exterior, para um objeto, surgindo assim narcisismo secundário ou narcisismo do ego. Que corresponde à volta da libido retirada de objetos ao ego, que é caracterizada pela falta de interesse no mundo exterior, se voltando apenas para si próprio e por delírios de grandeza. A criança passa a desejar objetos externos que a satisfazem indo de encontro a eles e ao frustrar-se em seus objetivos a pulsão é recolhida novamente ao ego. Em decorrência disso, o indivíduo se torna desinteressado no outro, sendo quase incapaz de se expressar para o mundo externo fazendo-o com que isso dificulte que os outros se manifestem para ele. Freud especula que o narcisismo faz com que o indivíduo seja impulsionado por uma necessidade de autopreservação (VASCONCELLOS, 2019).

\section{NARCISISTAS NO ÂMBITO AFETIVO E SOCIAL}

Um campo de aplicação do conceito de narcisismo desenvolvido de forma bem interessante por Freud (1914) é o das escolhas amorosas: o sujeito poderia amar segundo o tipo narcísico ou por apoio. A pessoa amaria, de acordo com o tipo narcísico: O que ela própria é (isto é, ela mesma); O que ela própria foi; O que ela própria gostaria de ser; Alguém que foi uma vez parte dela mesma; $E$ em conformidade com o tipo por apoio; A mulher que alimenta; O homem que a protege, e a sucessão de 
substitutos que tomam o seu lugar. (CHRISTO, 2017). Todavia, os indivíduos com o transtorno de personalidade narcisista estão tão ocupados provando o seu valor e desaprovando tudo que o menos o valia que apenas não conseguem sentir todos os sentimentos positivos de estar ligado ao outro. Ou seja, eles não conseguem usufruir do resultado de seus esforços que são estimulados em si e nos outros (FARIA 2003).

Segundo Freud (1914), o desenvolvimento de uma relação amorosa narcisista surge a partir de dois modos, que seria amar o que se era no passado, visto que já não se é mais, ou amar o que se gostaria de ser por não possuir a sublimidade do objeto. Explorando a dinâmica do narcisismo individual, o líder ou ideia exerce seu domínio sobre cada sujeito em um grupo, fazendo com que se abdique a parte do narcisismo a favor da coletividade. Estar no grupo compensa esta renúncia, pois representa uma relação carregada de um forte componente narcísico, uma vez que as relações entre os sujeitos passam a se regular pela identificação ao poder de um destes elementos (CHRISTO, 2017).

Os narcisistas sentem que devem confiar em si próprios mais do que nos outros, para saciar suas necessidades. Estão persuadidos de que não podem confiar no amor ou na lealdade de ninguém. Acreditam ser autossuficientes, mas, no seu íntimo, ressentem-se de um sentimento de perda e de vazio. Os narcisistas preocupam-se em estabelecer sua competência, seu poder, sua beleza, seu status, seu prestígio e sua superioridade. Paralelamente a isso, os narcisistas desejam que os outros partilhem da alta estima que eles próprios tenham de si mesmos e que satisfaçam suas necessidades. O que espanta no comportamento dessas pessoas é a exploração dos outros. Os narcisistas vivem na ilusão de que eles devem ser servidos, de que seus desejos têm preferência sobre os dos outros (KET DE VRIES; MILLER, 1990).

Freud aponta os caminhos traçados para o narcisista em suas escolhas amorosas, segundo ele, pessoas com esse transtorno amam sua própria imagem no outro; o que ele foi; o que ele queria ser (NICEAS, 2017; p.17). Para Faria (2003), pessoas com o transtorno de personalidade narcisista, se relacionam com quem possa reafirmar sua grandiosidade e quando não consegue transforma-las em admiradores, o narcisista perde o interesse e a ligação com elas. A questão é que o narcisista apenas consegue ter e manter um elo, quando eles veem particularidades de si refletidos no outro, e se o outro desenvolver um pouco de autonomia para ter uma opinião independente do narcisista, ele perderá o interesse.

A personalidade narcisista e a personalidade dependente estão próximas, embora que em direções opostas, mas a mesma dinâmica opera cada um, por exemplo, em relação aos críticos, o narcisista não 
quer contato com quem os critica já o dependente tenta agradá-los. Pessoas com transtorno de personalidade narcisista vão se preocupar com a empatia de seus pais por eles, e pessoas com transtorno de personalidade dependente vão se preocupar com a sua empatia por seus pais devido ao imenso medo de abandono. O narcisista não vai se relacionar com quem não seja autônomo, a seus olhos essa pessoa deixará de existir. Porém, para o dependente, se por ventura a relação terminar a sua própria existência ficará ameaçada (FARIA, 2003).

Um relacionamento entre um narcisista e um dependente, ambos estão focados na mesma pessoa que é o narcisista, reforçando o comportamento do dependente. Em o mito de Narciso, Eco era uma ninfa da mitologia grega que admirava a beleza do jovem Narciso sem que ele a notasse, sendo a ninfa Eco retratada como o protótipo da personalidade dependente e Narciso retratado como o protótipo da personalidade narcisista. São duas personalidades que se completam principalmente pela sensibilidade excessiva a respeito da avaliação alheia, porém é o reverso um do outro (FARIA, 2003).

De acordo com a autora, para entender mais a respeito, é necessário parafrasear a respeito da personalidade dependente. O dependente estará focado na outra pessoa, fazendo pouco por si e muito pelo o outro, diferentemente do altruísmo, o dependente faz isso, pois se considera onipotente a pessoa com transtorno de personalidade dependente, ela necessitará manter uma falsa sensação de segurança em suas relações sociais e afetivas, para isso abrirá mão de suas necessidades com o intuito de satisfazer os outros.

Pessoas com transtorno de personalidade narcisista, são, por muitas vezes mais dispostos a chegar em um cargo de poder e é o narcisismo a força condutora que alimenta o desejo de obter uma posição de liderança, esses indivíduos impressionam os outros por sua forte personalidade, podendo agir facilmente como verdadeiros líderes. Ao estudar as relações de líderes e subordinados, Freud confirmou que o líder narcisista é a própria natureza dominadora, seguro de si e independente. No âmbito organizacional, o narcisista ocupará uma posição de liderança, alcançando cargos de poder, onde serão por muitas vezes arrogantes com quem estiver em uma posição inferior a deles (KET DE VRIES; MILLER, 1990).

Os narcisistas buscam confiar em si próprios mais do que nos outros, para conseguir saciar suas necessidades, acreditam que não podem confiar na lealdade de ninguém. São autossuficientes, mas, em seu íntimo, possui um sentimento de vazio e perda. E para mascarar suas inseguranças, os narcisistas buscam estabelecer sua competência, status e prestígio. Em contrapartida, necessitam de 
que os outros satisfaçam suas vontades, vivendo na ilusão de que eles devem ser servidos, de que seus desejos são mais importantes do que os desejos dos outros (KET DE VRIES; MILLER, 1990).

\section{MÉTODO}

Para obter os resultados e respostas acerca da problematização apresentada neste trabalho, foi utilizado o método de pesquisa documental partindo de uma revisão integrativa da literatura composta pelos principais autores, psiquiatras e psicólogos adeptos da abordagem psicanalítica, para isso, foi-se necessária utilizar de uma abordagem qualitativa, com ênfase no estudo documental. Segundo Carvalho, Silva e Souza (2010), a revisão integrativa é uma metodologia que proporciona a súmula de conhecimento e a integração da aplicação de resultados de estudos significativos na prática, apresentando as questões relevantes a serem consideradas para a utilização desse recurso metodológico.

Para Soares (2020), a pesquisa qualitativa é caracterizada pelo desenvolvimento de fatos e ideias, tendo como base o entendimento interpretativo a partir dos dados que foram encontrados, sendo de caráter exploratório e subjetivo, visando à observação direta, entrevistas e análise de documentos e textos. Sendo a pesquisa qualitativa um modelo que forma-se além do esperável, mensurável e informativo, assim o método qualitativo, vai do descobrimento à compreensão dos fatos.

Para Pope e Mays (2005), a pesquisa qualitativa é vinculada as vivências e aos significados que são atribuídos pelas pessoas e como elas os compreendem. Segundo os autores, além da pesquisa qualitativa ser útil como o primeiro estágio para uma pesquisa quantitativa, possui também a função de desempenhar sua validação e, além disso, oferece uma nova perspectiva a respeito dos mesmos fenômenos estudados.

Segundo Kitto, Chesters e Grbich (2008),existem alguns critérios operacionais que são fundamentais para classificar um trabalho como pesquisa qualitativa, são eles: O objetivo da pesquisa deve estar definido e sendo retratado de forma clara; Explicação de qual técnica foi utilizada para a elaboração da pesquisa; Possuir um rigor avaliativo para a escolha do tema, o método utilizado relacionando com os resultados da pesquisa; $O$ artigo deve ser escrito em linguagem cientifica; $A$ mensagem proposta pelo artigo deve ser retratada de maneira clara e concisa; Sendo necessário o uso de um embasamento teórico e metodológico para a elaboração do artigo em questão. 


\section{RESULTADOS E DISCUSSÃO}

No presente artigo desenvolvido, buscou-se fazer um levantamento da literatura, procurando compreender as teorias e contribuições da psicanalise acerca do transtorno de personalidade narcisista. Realizado e desenvolvido no período de 01 de abril até o dia 15 de novembro de 2021, tendo como duração total de sete meses. Durante sua execução foram realizadas leituras em revistas e artigos científicos compostos pelos principais autores, psiquiatras e psicólogos adeptos da abordagem psicanalítica.

Para tanto, realizou-se uma revisão integrativa da literatura a partir das bases de dados do Google Acadêmico e Scielo, através dos descritores "Transtorno de Personalidade Narcisista" "Introdução ao Narcisismo" "Narcisismo e Relações Afetivas", também foi utilizados livros acadêmicos para a realização deste trabalho. Tendo como critérios de inclusão, artigos que foram publicados em português, inglês e artigos na íntegra que pudessem retratar a temática proposta, tendo como critérios de exclusão os artigos que não obedeceram aos critérios de inclusão.

Este artigo apresenta um introdutório a respeito do que é o narcisismo conforme estudos de teóricos adeptos da abordagem psicanalítica Freudiana. Com base nisso, visou abordar a respeito do transtorno de personalidade narcisista e de que maneira suas relações afetivas são estabelecidas. Tal estudo se faz necessário devido a pouca produção cientifica sobre o assunto, apesar de ser um vasto campo para pesquisas tanto quantitativas quanto qualitativas, não se encontra um número considerável de estudos a respeito.

Este trabalho foi constituído por dezessete artigos científicos. A partir dos critérios de inclusão estabelecidos previamente foram selecionados seis artigos encontrados na base de dados do Google Acadêmico e Scielo. O quadro 1 representa as especificações de cada um desses artigos.

\begin{tabular}{|l|l|l|l|l|}
\hline Autores & Objetivo Geral & Resultados & Ano & $\begin{array}{l}\text { Revista/ } \\
\text { Artigo }\end{array}$ \\
\hline FALCÃO, L. & $\begin{array}{l}\text { Mostrar a importância do } \\
\text { caminho pulsional para a } \\
\text { diferenciação entre Eu e o } \\
\text { outro. }\end{array}$ & $\begin{array}{l}\text { Conclui que o } \\
\text { narcisismo secundário } \\
\text { não existe sem o } \\
\text { narcisismo primário e de } \\
\text { que sem narcisismo não } \\
\text { há o ser humano. }\end{array}$ & 2014 & $\begin{array}{l}\text { Revista } \\
\text { Brasileira } \\
\text { de } \\
\text { Psicanálise }\end{array}$ \\
\hline FARIA, L. & $\begin{array}{l}\text { Salienta-se a importância } \\
\text { do entendimento do } \\
\text { Narcisismo. Existindo }\end{array}$ & $\begin{array}{l}\text { Relata-se o mito de } \\
\text { Narciso e Eco, que } \\
\text { mostra uma clara }\end{array}$ & 2003 & $\begin{array}{l}\text { Faculdade } \\
\text { de Ciência } \\
\text { da Saúde - }\end{array}$ \\
\hline
\end{tabular}




\begin{tabular}{|c|c|c|c|c|}
\hline & $\begin{array}{l}\text { uma complementaridade } \\
\text { entre a personalidade } \\
\text { narcisista e a personalidade } \\
\text { co- } \\
\text { dependente. }\end{array}$ & $\begin{array}{l}\text { relação co-dependente } \\
\text { entre seus sujeitos. }\end{array}$ & & FACS \\
\hline FREUD, $\mathrm{S}$. & Introdução ao Narcisismo & $\begin{array}{l}\text { De que há narcisismo } \\
\text { primário e normal e } \\
\text { narcisismo secundário e } \\
\text { patológico. }\end{array}$ & 1914 & $\begin{array}{l}\text { Companhia } \\
\text { das Letras }\end{array}$ \\
\hline $\begin{array}{l}\text { MARTELLO, } \\
\text { A. }\end{array}$ & $\begin{array}{l}\text { O conceito de Narcisismo } \\
\text { segundo Freud. }\end{array}$ & $\begin{array}{l}\text { Discorrer a respeito do } \\
\text { livro de } 1914 \text { de } \\
\text { Sigmund Freud sobre } \\
\text { Narcisismo. }\end{array}$ & 2019 & ISEPOL \\
\hline MAXWELL. & $\begin{array}{l}\text { O conceito de narcisismo } \\
\text { em Freud e alguns de seus } \\
\text { destinos }\end{array}$ & $\begin{array}{l}\text { Discutir sobre os } \\
\text { conceitos de narcisismo } \\
\text { seguindo o percurso de } \\
\text { Freud. }\end{array}$ & 2008 & PUC-RIO \\
\hline NOBRE, T. L. & $\begin{array}{l}\text { Correlação entre o } \\
\text { narcisismo e a melancolia, } \\
\text { enfatizando, } \\
\text { principalmente, a gênesee } \\
\text { os sintomas desta patologia. }\end{array}$ & $\begin{array}{l}\text { A clínica da melancolia } \\
\text { apresenta como } \\
\text { possibilidade de suscitação } \\
\text { no analista um desejo } \\
\text { onipotente de"salvação" do } \\
\text { ego do paciente da } \\
\text { angústia gerada pela acídia } \\
\text { e pelos movimentos } \\
\text { característicos da pulsão } \\
\text { de morte. }\end{array}$ & 2014 & \\
\hline $\begin{array}{l}\text { VETTORAZZ } \\
\mathrm{O}, \mathrm{H} .\end{array}$ & $\begin{array}{l}\text { Especificar dentro do } \\
\text { referencial psicanalítico a } \\
\text { noção de narcisismo e } \\
\text { coloca-la em movimento a } \\
\text { partir de seu emprego tanto } \\
\text { na teoria como na prática } \\
\text { psicanalítica. }\end{array}$ & $\begin{array}{l}\text { A condição narcísica está, } \\
\text { para o autor, na base das } \\
\text { relações amorosas de } \\
\text { objeto, transmitido e } \\
\text { identificado sob a forma } \\
\text { dos ideais para o Eu. }\end{array}$ & 2007 & $\begin{array}{l}\text { Instituto } \\
\text { Sedes } \\
\text { Sapientiae }\end{array}$ \\
\hline
\end{tabular}

Fonte: as autoras

Partindo do pressuposto de que os autores destacados no quadro acima utilizaram como base para o desenvolvimento e elaboração dos seus respectivos artigos, o texto de 1914 escrito por Sigmund Freud nomeado de: "Introdução ao Narcisismo". Pode-se assim dizer que todos os autores citados são adeptos da abordagem psicanalítica freudiana e reconhecem a importância de Freud para o estudo inicial acerca do narcisismo em si e para o entendimento do transtorno de personalidade narcisista.

Para Maxwell (2008), um dos principais motivos que levou Freud a escrever o artigo de 1914 foi para responder à crítica que Jung havia lhe feito quanto à insistência em prevalecer o fator sexual para explicar o funcionamento psíquico, sendo neste trabalho que pela primeira vez, é estabelecido uma 
relação entre as pulsões sexuais através da noção de apoio. Com isso, para o autor, é a partir de então que Freud aprofunda esta perspectiva e introduz o narcisismo como um conceito.

Segundo o autor citado acima, é afirmado que Freud para desenvolver o conceito de narcisismo ele toma como referência suas observações sobre esquizofrenia e a saúde mental das crianças e de povos primitivos. Sendo a atitude narcisista em neuróticos uma resistência transferencial intensa. $\mathrm{Na}$ esquizofrenia acontece à retirada da libido do mundo externo para o eu, na neurose a libido que será retirada dos objetos será investido os objetos da fantasia.

Dando seguimento ao conceito de narcisismo segundo Freud, podemos citar Ándrea Martello (2019) que em seu artigo nomeado de "O conceito de Narcisismo", traz trechos do texto original escrito por Freud em 1910, onde o narcisismo é pensado como forma de esclarecer escolhas homossexuais, trazendo como consequências o fato de que o próprio ego é tomado para a escolha do objeto. Porém, um ano após a sua publicação, é encontrado a definição de narcisismo como sendo uma etapa para o desenvolvimento que confluiriam as pulsões sexuais, parciais e auto eróticas (MAXWELL, 2008).

Para Nobre (2014), Freud indica de que o narcisismo da criança manifesta-se a partir do narcisismo dos pais, com isso, os pais projetam seus próprios narcisismos no filho e o mesmo se identifica com eles. Sendo importante observar que Freud, neste momento, diferencia entre o que acontece com o ego ideal e o ideal do ego. O ego ideal surge a partir de um investimento narcísico e ao crescer se deparando com as críticas, terá que constituir uma nova forma mais próximo do conceito de ideal do ego. Deste modo, os momentos primitivos estariam ligados ao o ego ideal e o ego ideal comprova o acesso às questões da cultura e à organização da civilização.

De acordo com Vettorazzo (2007), o narcisismo na concepção de Freud, é caracterizado pela capacidade de amar e respeitar a si mesmo como efeito da investidura amorosa do outro. Para se amar é preciso conseguir estimar-se.

Visando este sentido o autor considera importante o quê a função narcisisante materna determina, onde acontece a renúncia da mãe para com o filho enquanto objeto de satisfação pulsional fornecendo as bases da renúncia pulsional.

Vettorazzo (2007), concluiu que sem narcisismo haverá desenvolvimento do superego, pois para amar e respeitar o outro, é preciso amar e respeitar a si próprio. Tal condição indica que o amor a si e ao objeto esteja marcado por preceitos éticos. Com relação a essa condição, o autor acredita ser importante, a escuta e a apreensão dos mandatos que regem o eu em suas oscilações entre o eu ideal 
e os ideais do eu. A condição narcísica estará como base das relações amorosas transmitidas e identificadas sob a forma dos ideais para o eu.

Falcão (2014), concluindo de que é na libido do eu que promoverá a base da satisfação e vivência narcísica, onde as sensações de desprazer e prazer vão ser promovidas. Sendo assim, o narcisismo primário como autoerotismo e o narcisismo secundário como diferenciação entre eu e não-eu. Pois o bebê não consegue diferenciar a si da pessoa que dele o cuida, pois o funcionamento narcísico abrange esse bebê. Seu desenvolvimento psicossexual acontecerá a partir do investimento da libido do eu em libido do objetivo. Conclui também que o narcisismo secundário não existe sem o narcisismo primário e de que sem narcisismo não há o ser humano.

Faria (2003), determinou de que o transtorno de personalidade dependente é, basicamente, depender da dependência do outro. Onde o narcisismo não é causa e nem precede a dependência. Dessa forma, pessoas com transtorno de personalidade dependente podem ser vistos como protótipo de como algumas pessoas são capazes de tolerar, e até mesmo procurar relacionamentos adoecidos com parceiros narcísicos. Para Faria (2003), segundo o DSM IV, o transtorno de personalidade narcisista começa na vida adulta onde há um sentimento grandioso da própria importância; preocupação com fantasias de ilimitado sucesso e poder; exigência de admiração excessiva; possui expectativas irracionais de receber um tratamento especialmente favorável e obediência automática às suas expectativas; são pessoas que tiram vantagens de outros para atingir seus próprios objetivos; há ausência de empatia; dificuldade de reconhecer as necessidades alheias; sentem e acreditam serem alvos da inveja alheia; possuem comportamentos e atitudes arrogantes.

\section{CONSIDERAÇÕES FINAIS}

Para realização deste trabalho, fez-se necessário retomar as ideias de Sigmund Freud e de outros médicos psiquiatras, psicólogos e pesquisadores que fossem adeptos da abordagem psicanalítica, com a finalidade de compreender a respeito da temática abordada. Foi imprescindível entender primeiramente o conceito de narcisismo, por conseguinte, ser capaz de identificar e distinguir o que é narcisismo primário e o que é narcisismo secundário para só então adentrar ao transtorno de personalidade narcisista e em como são estabelecidas suas relações afetivas.

Pode-se dizer que o narcisismo é um dos campos de pesquisas mais evidentes no atual momento, devido ao fato da nossa sociedade viver na "era do narcisismo", onde as condutas dos indivíduos estão sempre voltadas para si próprias. Em razão da popularização das redes sociais e das "selfies", são 
construídos "mundos" perfeitos no quais são montados e manipulados cuidadosamente os melhores momentos para serem captados e compartilhados entre si, como estímulos para a ausência de empatia e foco restrito ao próprio ego.

Porém, é importante observar que, apesar de ser um campo vasto para pesquisas ainda não há uma quantidade significativa de pesquisas quantitativas publicadas a respeito da temática. Quanto ao transtorno de personalidade narcisista, ainda não é apresentado um campo maduro para a realização de pesquisas qualitativas especificas, visto que não há uma quantidade significativa de estudos disponíveis na literatura onde deveriam ser investigadas suas relações afetivas. Porém a respeito do transtorno em si, é possível encontrar estudos na literatura que fazem um introdutório a respeito.

A atuação do psicólogo no atendimento a pacientes com transtorno de personalidade narcisista tem como objetivo principal em seu tratamento o de auxilia-los a estabelecer novos modelos de relacionamentos sociais saudáveis, visto que pacientes com esse transtorno buscam a terapia em razão de estarem com bloqueios em seus relacionamentos afetivos e sociais sendo dessa forma apresentado, para eles, uma ameaça direta a sua autoestima.

Tendo em vista os objetivos que foram apresentados inicialmente, por meio desse trabalho foi-se possível compreender a visão psicanalítica freudiana a respeito do transtorno de personalidade narcisista, também como o seu conceito que fora desenvolvido por Freud acerca do tema e em como suas teorias e contribuições para a psicologia são usadas atualmente para lidar com esse transtorno.

É importante que seja feito estudos futuros acerca do tema, para que fique cada vez mais solidificado o campo de pesquisas qualitativas e quantitativas acerca do tema. Podendo ser realizado cada vez mais relatos clínicos acerca dos processos terapêuticos para que sejam publicados e sirva de exemplo para população em geral.

Dessa forma, conclui-se que o presente trabalho trouxe maiores conhecimentos não apenas sobre o transtorno de personalidade narcisista, mas também sobre o narcisismo em si. Diante do exposto conclui-se que o objetivo do trabalho foi alcançado, pois foi realizado o levantamento da literatura a respeito da temática, juntamente com a visão psicanalítica sobre o tema. Espera-se que o trabalho apresentado possa auxiliar pesquisadores quantitativos a conduzirem suas pesquisas com maior precisão a respeito da metodologia e com melhores possibilidades de aceitação para publicações em revistas científicas. 


\section{REFERÊNCIAS}

ABCMED, Personalidade narcisista - como ela é?. 2017. Disponível em:

https://www.abc.med.br/p/psicologia-e-psiquiatria/1295373/personalidade-narcisista-como-elae.htm Acesso em: 31 mai. 2021. ARAÚJO, M. Considerações sobre o narcisismo. Belo Horizonte. 2010. Disponível em:

http://pepsic.bvsalud.org/scielo.php?script=sci_arttext\&pid =S0100-34372010000200011Acesso em: 31 mai. 2021.

BARBOSA, C. G; CAMPOS, E. B; NEME, C. M. Narcisismo e desamparo: algumas considerações sobre as relações interpessoais na atualidade. Psicol - USP. 2021. Disponível em:

https://doi.org/10.1590/0103-6564e190014 Acesso em: 27 Nov 2021

CARVALHO, R.; SILVA, M. D.; SOUZA, M. T. Revisão integrativa: o que é e como fazer. Einstein. 2010; 8(1 Pt 1):102-6 Disponível em:

https://www.scielo.br/j/eins/a/ZQTBkVJZqcWrTT34cXLjtBx/?format=pdf\&lang=pt Acesso em: 01 Nov. 2021

CHRISTO, F. Narcisismo e alguns de seus reflexos nas subjetividades. Belo Horizonte. 2017. Disponível em: https://repositorio.ufmg.br/bitstream/1843

/BUOS-APENBM/1/felipe_azevedo_mono_27_04_vf.pdf. 31 mai. 2021.

FALCÃO, L. Cem anos de Narcisismo: aquém da psicanálise e além de Freud. 2014. Disponível em: http://pepsic.bvsalud.org/pdf/rbp/v48n3/v48n3a05.pdf Acesso em: 01 out. 2021.

FARIA, L. S. A natureza das relações co-dependentes sob o enfoque bio-psico-social. Faculdade de Ciências da Saúde, 2003. Disponível em:

https://repositorio.uniceub.br/jspui/bitstream/123456789/2811/2/9813357.pdf Acesso em: 20 Nov 2021. FREUD, S. Introdução ao narcisismo. São Paulo: Companhia das Letras. (1914/2010). Acesso em: 25 mai. 2021. KETS DE VRIES, M; MILLER, D; "Narcisismo e liderança: uma perspectiva de relações de objetos" Disponível em: https://www.scielo.br/j/rae/a/7GJT9DGWwwSptCV6vhVXNsf/ Acesso em: 18 set. 2021.

KITTO, S. C., CHESTERS, J. E., \& GRBICH, C. Quality in qualitative research: criteria for authors and assessors in the submission and assessment of qualitative research articles. The Medical Journal of Australia. Medical Journal of Australia, 2008. Disponível em:

https://www.mja.com.au/journal/2008/188/4/quality-qualitative-research Acesso em: 05 Nov. 2021

KLAUTAU, P. Sobre o narcisismo como campo de pesquisa: variações da técnica psicanalítica e desdobramentos clínicos. Ágora (Rio J.). 2018. Disponível em:

https://www.scielo.br/j/agora/a/jHwYGTMGNckMK7FTrZPnZ7r/?lang=pt Acesso em: 05 Nov. 2021 LACAN, J. O estádio do espelho como formador da função do eu, in Escritos. Rio de Janeiro: Jorge 
Zahar. 1966/1998. LOWEN, A. Narcisismo: A negação do verdadeiro self - São Paulo: Summus Editorial, 2017.

MARTELLO, A. O conceito de narcisismo. Sobre o narcisismo: uma introdução (1914). Disponível em: http://www.isepol.com/pdf/SOBRE\%200\%20NARCISISMO.pdf Acesso em: 25 mai. 2021.

MARUCCO, N.C. Édipo, castração e fetiche: uma revisão da teoria psicanalítica da sexualidade. Rev. Bras. de Psicanálise, vol. XXX, 1996, pp. 547-553 Acesso em: 15 set. 2021.

MAXWELL. O conceito de narcisismo em Freud e alguns de seus destinos. PUC - Rio de Janeiro, 2008. Disponível em: <https://www.maxwell.vrac.puc-rio.br/11780/11780_3.PDF> Acesso em: 18 set. 2021. NICÉAS, C. Para ler Freud - Introdução ao Narcisismo: O amor de si. Civilização Brasileira; 1 edição. 2017.

NOBRE, T. A questão do narcisismo na melancolia. 2014. Disponível em: http://pepsic.bvsalud.org/pdf/rs/v15n1/02.pdf Acesso em: 18 set. 2021. POPE, C; MAYS, N. Pesquisa qualitativa na atenção à saúde. 2a edição. Porto Alegre: Artmed, 2005. 118 p. SILVEIRA S. L. Posição do estágio do espelho na teoria lacaniana do imaginário. Rev. Dep. Psicol. UFF 17(1). Junho 2005. Disponível em: https://doi.org/10.1590/S0104-80232005000100009 Acesso em: 05 Nov. 2021

SOARES, S. J. Pesquisa científica: uma abordagem sobre o método qualitativo. Revista Ciranda, [S. I.], 3(1), p. 1-13, 2020. Disponível em:

https://www.periodicos.unimontes.br/index.php/ciranda/article/view/314 Acesso em: 9 nov. 2021.

VETTORAZZO, H. O espelho, no mito de Narciso, em Machado de Assis e em Guimarães Rosa. São Paulo, 2007. Disponível em: http://pepsic.bvsalud.org/scielo.php?script=sci_arttext\&pid=S010131062007000200017 Acesso em: 20 Nov 2021

WALLACE, H. M; BAUMEISTER, R. F. The Performance of Narcissists Rises and Falls with Perceived Opportunity for Glory. Journal of Personality and Social Psychology, 2002. Disponível em: https://psycnet.apa.org/record/2002-12575-010 